\title{
The Role of
}

\section{the Insulin-like Growth Factor Binding Protein 5 (IGFBP5) \\ in Cardiogenesis and Cardiac Remodelling}

\author{
Doctoral Thesis
}

In partial fulfillment of the requirements for the degree

"Doctor rerum naturalium (Dr. rer. nat.)"

Division of Mathematics and Natural Sciences

in the Molecular Medicine Study Program

at the Georg-August University Goettingen

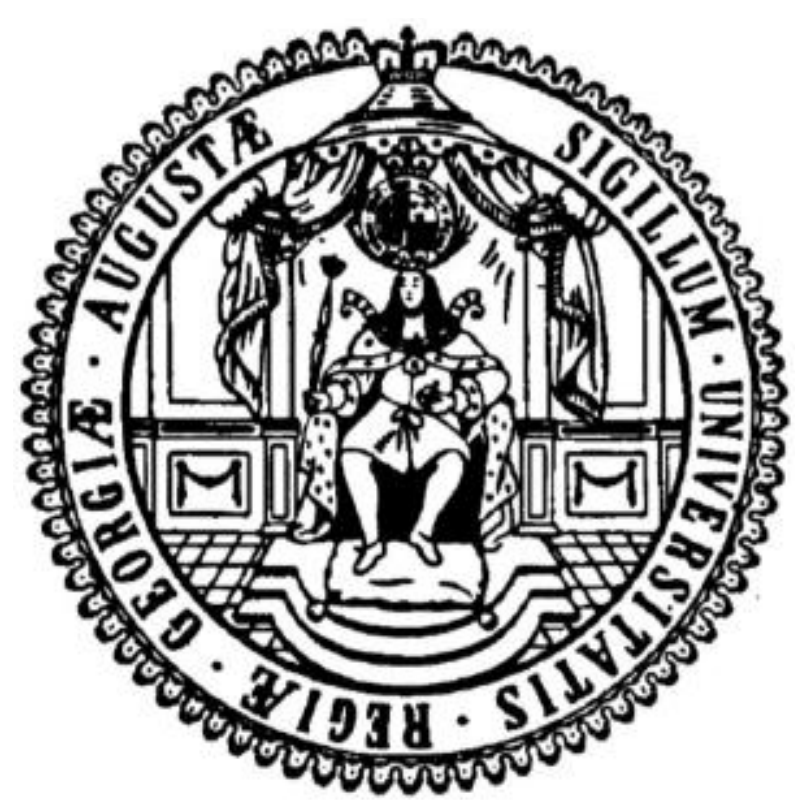

submitted by

\section{Monique Wölfer}

born in Bautzen, Germany 


\section{Members of the Thesis Committee}

PD Dr. rer. nat. Laura C. Zelarayan (Supervisor)

Email: $\quad$ laura.zelarayan@med.uni-goettingen.de

Phone: $\quad$ +49 (0) $55139-20730$

Postal Address: $\quad$ Institute of Pharmacology and Toxicology

University Medical Centre Goettingen

Georg-August University Goettingen

Robert-Koch-Str. 40

37075 Goettingen

PD Dr. rer. nat. Katrin Streckfuß-Bömeke (Second member of thesis committee)

Email: $\quad$ katrin.streckfuss@med.uni-goettingen.de

Phone: $\quad$ +49 (0) $55139-20559$

Postal Address: $\quad$ Clinic for Cardiology and Pneumology

University Medical Centre Goettingen

Georg-August University Goettingen

Robert-Koch-Str. 40

37075 Goettingen

Prof. Dr. rer. Nat. Holger Bastians (Third member of thesis committee)

Email: holger.bastians@uni-goettingen.de

Phone: $\quad$ +49 (0) $55139-33823$

Postal Address: $\quad$ Institute of Molecular Oncology

University Medical Centre Goettingen

Georg-August University Goettingen

Goettingen Center for Molecular Biosciences (GZMB)

Grisebachstraße 8

37077 Goettingen

Date of Disputation: $14^{\text {th }}$ August 2018 


\section{Affidavit}

Here I declare that my doctoral thesis entitled:

"The role of the insulin-like growth factor binding protein 5 (IGFBP5) in cardiogenesis and cardiac remodelling"

has been written independently with no other sources and aids than quoted.

Monique Wölfer

Goettingen, July 2018 


\section{Dedication}

This dissertation is dedicated to the memory of $\mathcal{D} r$. Wolfgang Rohner. Although he was my inspiration and encouraged me to pursue a career in science, he was unable to see my graduation.

This is for him. 


\section{Table of Contents}

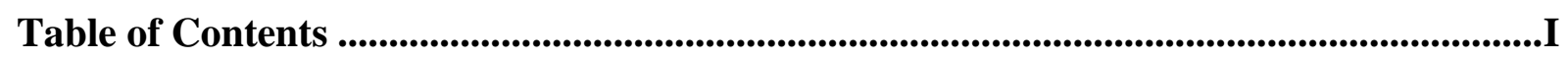

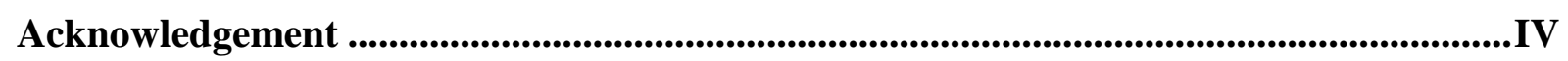

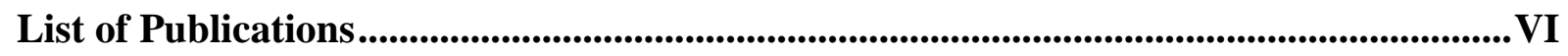

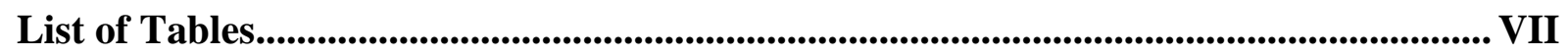

List of Figures ...........................................................................................................................................VIII

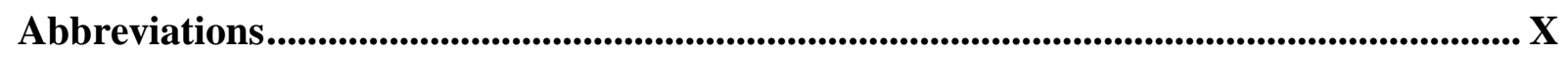

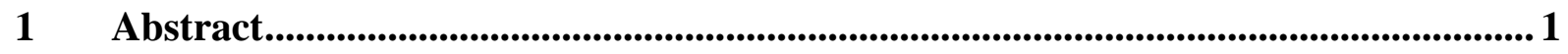

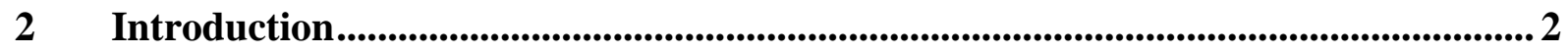

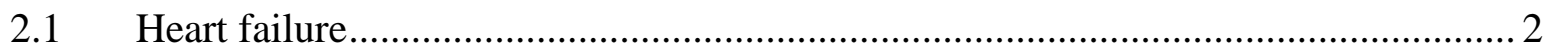

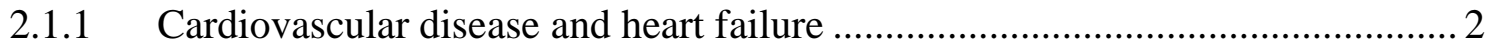

2.1.2 Cardiac remodelling and fetal gene re-activation ........................................... 2

2.1.3 Regenerative capacity of the heart................................................................ 3

2.1.4 Cardiogenic potential of cardiac progenitor cells ............................................. 4

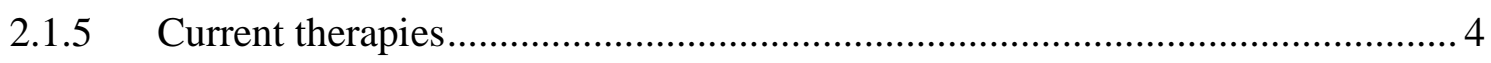

2.2 The insulin-like growth factor binding protein 5 .......................................... 5

2.2.1 Insulin-like growth factor binding proteins ................................................... 5

2.2.2 The insulin-like growth factor binding protein 5 ........................................... 6

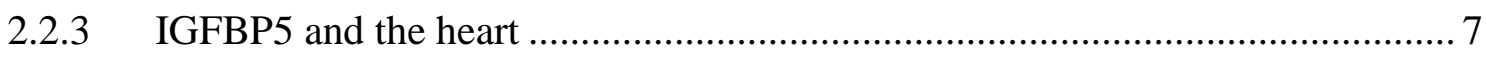

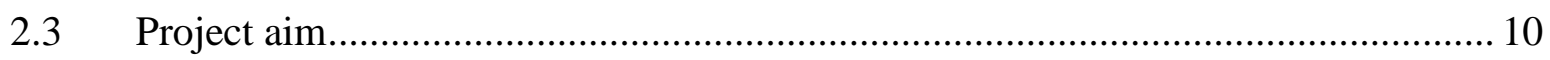

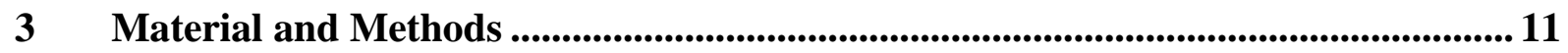

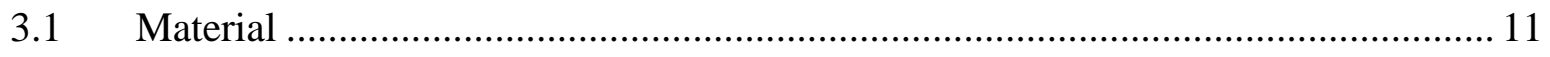

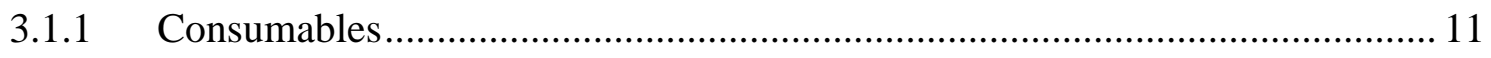

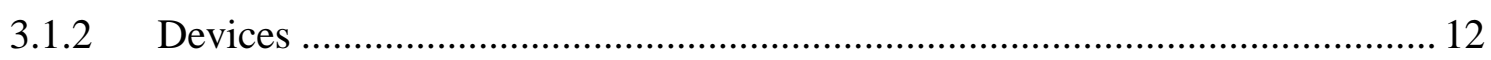

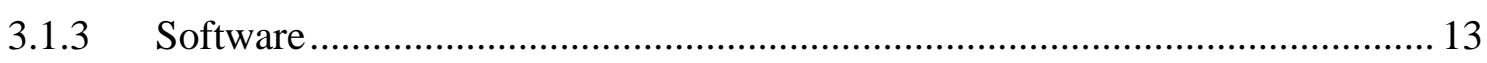

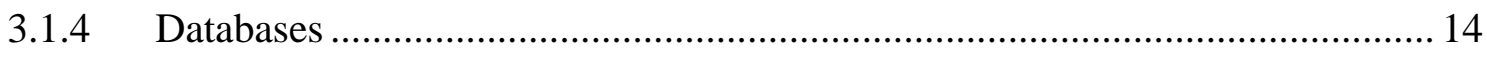

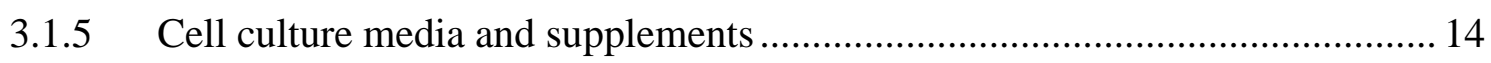

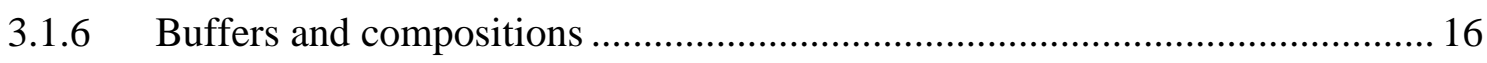

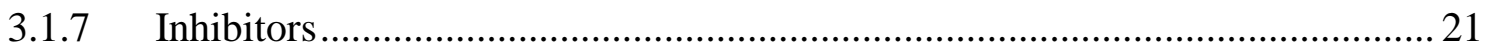

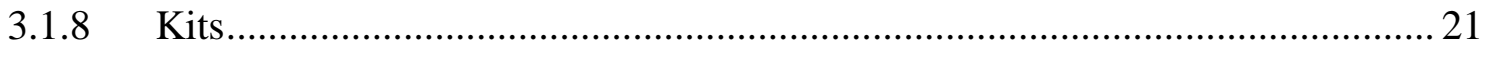

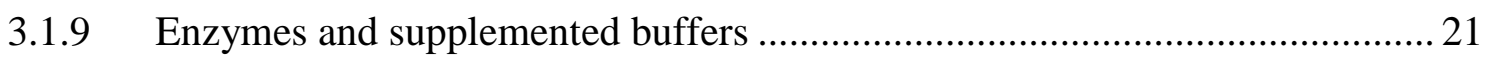

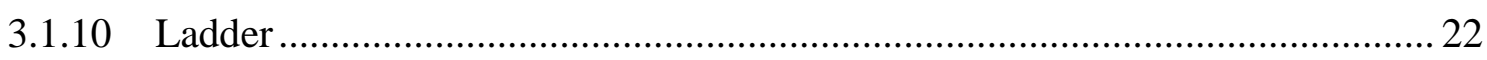

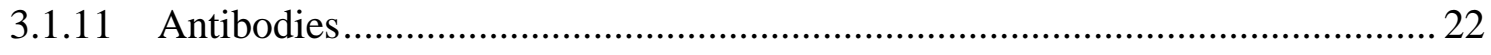

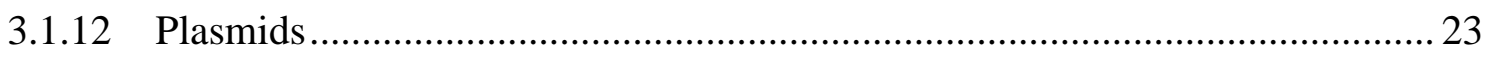

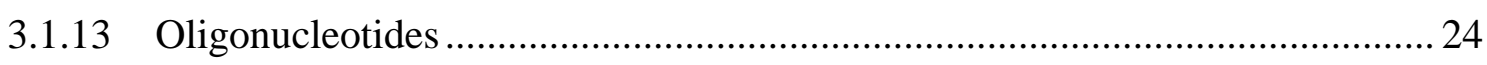

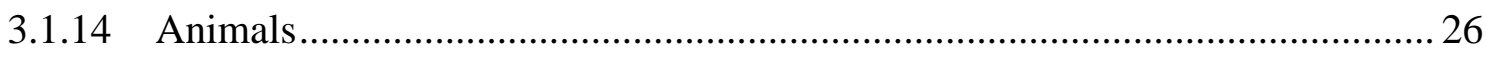

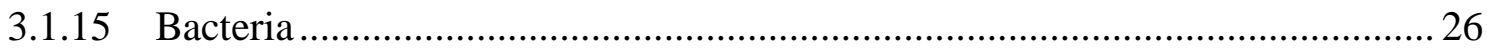




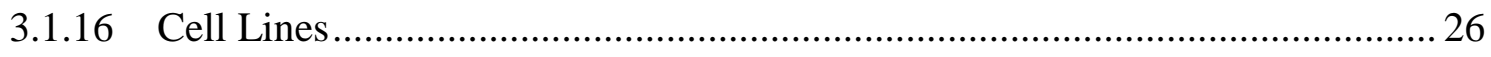

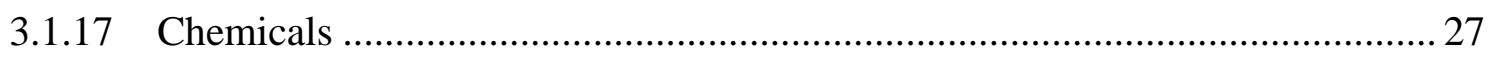

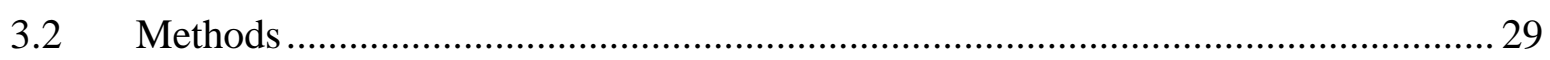

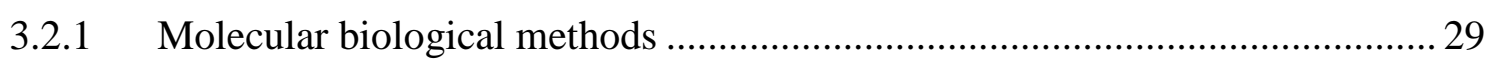

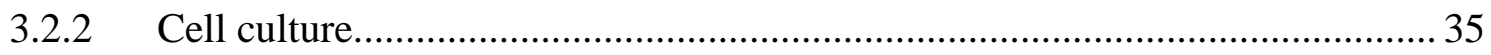

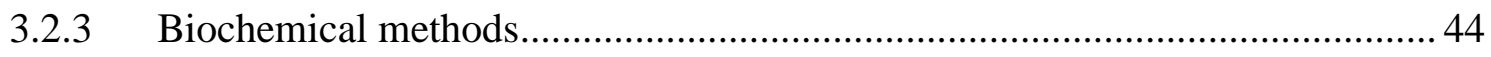

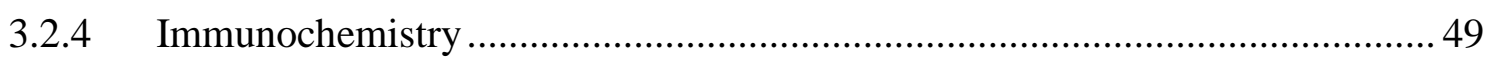

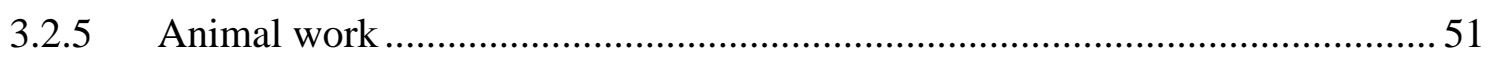

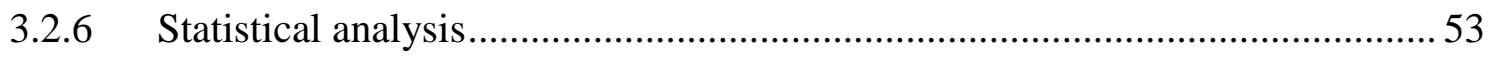

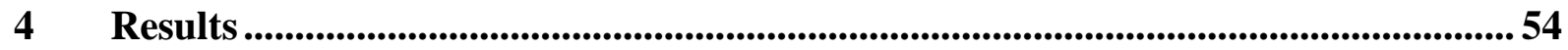

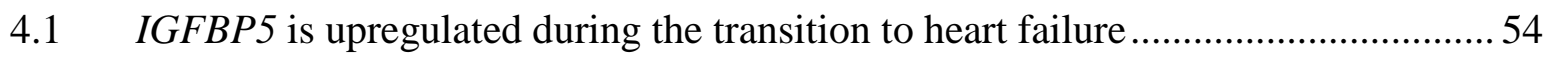

4.1.1 Igfbp5 is upregulated upon murine heart failure............................................ 54

4.1.2 Igfbp5 expression is normalized upon preserved cardiac function post-TAC.. 55

4.1.3 IGFBP5 is upregulated in human heart failure with a concomitant downregulation of IGFBP5 targeting microRNAs ....................................... 55

4.1.4 Intracellular protein levels of IGFBP5 are not altered in the diseased heart .... 56

4.2 Cardiac overexpression of Igfbp5 alters function and gene expression in the murine heart

4.3 IGFBP5 originates from cardiomyocytes of the diseased murine heart and can be detected in blood serum 66

4.4 IGFBP5 can be uptaken by cardiac fibroblasts and affects gene expression ........... 70

4.4.1 IGFBP5 can be uptaken by cardiac fibroblasts and activates its own expression 70

4.4.2 Molecular and physiologic effect of IGFBP5 on human cardiac fibroblasts ... 70

4.4.3 Myofibroblast activation and IGFBP5 upregulation are not directly associated

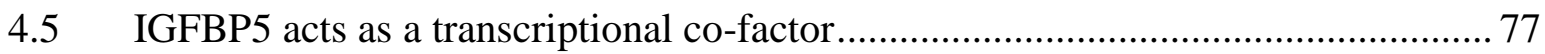

4.5.1 IGFBP5 binds to DNA and regulates promoter activity ................................. 77

4.5.2 NKX2.5 occupies and regulates same genomic regions as IGFBP5 ................ 78

4.6 IGFBP5 controls human cardiac cell commitment ............................................... 81

4.6.1 Generation and validation of an IGFBP5 knockout hES cell line using the CRISPR/Cas9 technology ..................................................................... 81

4.6.2 Characterization of directed cardiomyocyte differentiation in IGFBP5 knockout cells

4.7 Igfbp5 is downregulated upon norepinephrine and angiotensin II mediated

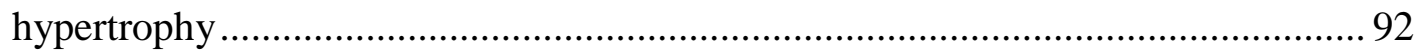

5 Discussion

5.1 IGFBP5, a conserved developmental gene, is re-activated during the transition to heart failure 
5.1.1 IGFBP5 is upregulated during the transition to heart failure in mice and in

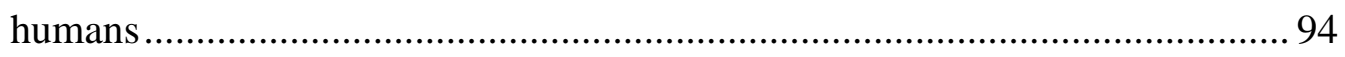

5.1.2 IGFBP5 is part of the fetal gene program................................................. 95

5.2 IGFBP5 stimulates atrophic and anti-fibrotic processes in vivo ............................ 96

5.2.1 IGFBP5 mediates atrophy in the normal heart via downregulation of ECM and

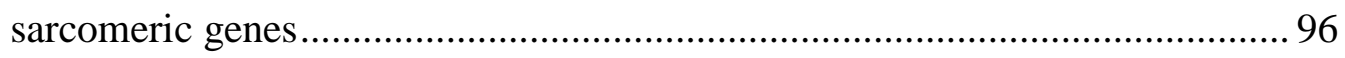

5.2.2 IGFBP5 increases fatty acid metabolism in the healthy heart ........................ 99

5.3 IGFBP5 is a novel cardiokine with paracrine and endocrine features ................... 101

5.3.1 IGFBP5 is a potential cardiokine which might serve as a biomarker............. 101

5.3.2 IGFBP5 can mediate cardiomyocyte-fibroblast crosstalk ............................. 102

5.4 Potential role of IGFBP5 in cardiac fibroblasts and the failing heart ................... 104

5.4.1 Identification of potential IGFBP5 targets in human cardiac fibroblasts ....... 104

5.4.2 Potential role of IGFBP5-induced genes in human cardiac fibroblasts.......... 106

5.4.3 Functional performance of fibroblasts with IGFBP5 overexpression ............ 107

5.4.4 Potential influence of IGFBP5 on fibrosis and premature fibroblast senescence 108

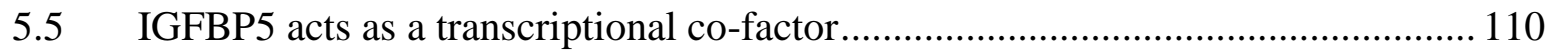

5.6 IGFBP5 plays a central role in the cardiac regulatory hierarchy mediating cardiac progenitor fate.

5.6.1 IGFBP5 controls stem cell commitment and arrests cardiomyocyte

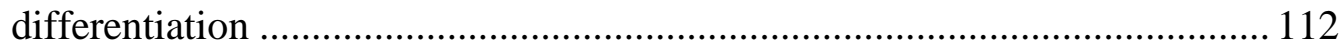

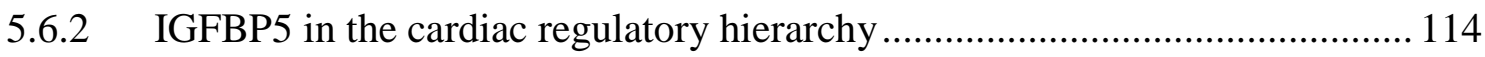

5.7 Downregulation of Igfbp5 correlates with cardiomyocyte maturation and might be

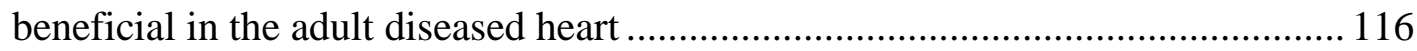

5.7.1 Neonatal cell maturation is accompanied by Igfbp5 downregulation ............ 116

5.7.2 Igfbp5 is downregulated during angiotensin II-induced hypertrophy in vivo. 117

6 Conclusion and outlook ........................................................................................... 119

7 Bibliography ..................................................................................................................... 122

8 Appendix...................................................................................................................................... 142

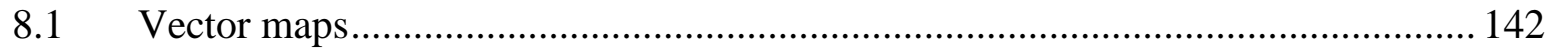

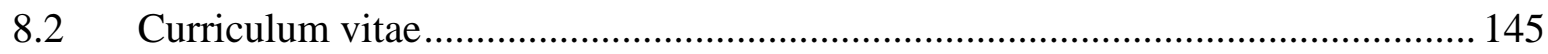




\section{Acknowledgement}

I would like to thank my supervisor PD Dr. Laura C. Zelarayán for giving me the opportunity to work on this fascinating project in her research group. I am grateful for her support, patience, and especially for her faith in me throughout the duration of my studies. I am indebted to her for being an exceptional mentor who moulded me into the independent scientist that I am today. My sincere gratitude to Prof. Dr. Wolfram-Hubertus Zimmermann for offering me a chance to be part of his institute at the University of Goettingen.

I would furthermore like to thank the members of my thesis committee, PD Dr. Katrin Streckfuß-Bömeke and Prof. Holger Bastians, as well as the members of my extended committee, Prof. Thomas Meyer, Prof. Rüdiger Behr and Prof. Hubertus Jarry.

My heartfelt gratitude to my current and former group members (AG Zelarayán) who I already miss: Dr. Elena Chebbock, Dr. Claudia Noack, Dr. Maria-Patapia Zafieriou, Franziska Rathjens, Dr. Cheila Lencastre, Eric Schoger, Tobias Weber and Denise Hartung. I appreciate the lovely atmosphere and all the support you provided. I would also like to thank my student and friend, Fereshteh Younesi for being such a great help.

I am grateful to Lavanya M. Iyer, Dr. Norman Liaw, Dr. Farah Raad, Tobias Weber, Dr. Sarah Khadjeh, the "Stem Cell Unit" (Martina Grohe/Dr. Lukas Cyganek), The Transcriptome and Genome Analysis Laboratory (TAL, Dr. Gabriela Salinas) and Prof. O. Mueller (UKSH, Kiel) for contributing their data and expertise to this project.

I would also like to thank Sarah Zafar, Marcel Zoremba and Roland Blume for supporting the animal studies that were conducted as a part of this project. I would particularly like to thank the whole "human lab team", Monika Hoch, Daria Reher, Andreas Schraut, Krasimira Sharkova and Iris Quentin for their excellent technical assistance and their guidance.

Thanks to Ursel Leonhardt, Rohland Blume, Ines Müller and Daniela Liebig-Wolter; I will miss my Mol-Lab parents, my aunt and my sister a lot!

I would like to thank Silvia Magerkurth and particularly Jutta Creydt (thank you so much for your personal support!) for administrative and organizational help. I am grateful to the DZHK for giving me the chance to participate and present my work at several esteemed congresses, meetings and retreats. Here, I especially appreciate the administrative and organizational help of Sylvia Vann, thanks a lot! 
My sincere thanks also go to Esa-Pekka Miettinen for advising me on my thesis layout and Sonia Joseph for her help with proof reading. I am also very grateful to Susanne Schlick for the very helpful administrative and personal support throughout writing of this thesis. I really appreciate that we managed "this" together!

I would like to express my gratitude to the "Margaret Maltby" Mentoring Program of the UMG, to Ulla Heilmeier and to my mentor Donna Arndt-Jovin. During my PhD I acquired various technical skills, but the Mentoring Program gave me the chance to gain a better appreciation of my own personality, social and communication skills and professional abilities. I am very grateful for that!

I would like to express a very special thank you to Svenja, Susanne, Normi, Farah, Marleen, Tina, Irina and Franzi for the pleasant and joyful time both within and outside the lab! Thank you for being not just colleagues, but also friends! It was simply great!

I would like to express my deepest gratitude to Lavanya M. Iyer once again for her precious support at all levels. Thank you for all the effort you put into analysing my data and especially thank you for the amazing scientific discussions and all the fun we had! I will never forget this! Amazing ideas mainly came together with coffee and you! Thanks a lot, I will never forget this awesome time!!!

I wish to thank all the members of the Institute of Pharmacology and Toxicology for being such friendly and helpful colleagues, and for creating an enjoyable atmosphere in the lab. Thanks to you it has always been a nice place to be, even during stressful times.

I will definitely miss that...

Finally, I would like to express my deepest affection for my beloved sister "Belli" and my boyfriend Sebastian. Thank you for always believing in me! Without your unconditional support none of this would have been possible. 


\section{List of Publications}

\begin{tabular}{|c|c|c|}
\hline Title & $\begin{array}{l}\text { Type of } \\
\text { publication }\end{array}$ & Date and location \\
\hline $\begin{array}{l}\text { SHISA3: A novel gene in cardiac endothelial } \\
\text { remodeling, combinatorially regulated by KLF15 and } \\
\text { Wnt signaling } \\
\text { C Noack, LM Iyer, NY Liaw, D Hartung, E Schoger, S } \\
\text { Khadjeh, E Wagner, M Woelfer, MP Zafiriou, G } \\
\text { Hasenfuss, WH Zimmermann, LC Zelarayan }\end{array}$ & $\begin{array}{l}\text { Research } \\
\text { article, in } \\
\text { submission }\end{array}$ & 2018 \\
\hline $\begin{array}{l}\text { A context-specific cardiac } \beta \text {-catenin and GATA4 } \\
\text { interaction influences TCF7L2 occupancy and remodels } \\
\text { chromatin driving disease progression in the adult heart } \\
\text { LM Iyer, S Nagarajan, M Woelfer, E Schoger, S Khadjeh, } \\
\text { MP Zafiriou, V Kari, J Herting, ST Pang, T Weber, FS } \\
\text { Rathjens, TH Fischer, K Toischer, G Hasenfuss, C Noack, } \\
\text { SA Johnsen and LC Zelarayan }\end{array}$ & $\begin{array}{l}\text { Research } \\
\text { article }\end{array}$ & $\begin{array}{l}\text { Nucleic Acids } \\
\text { Research, } 2018\end{array}$ \\
\hline $\begin{array}{l}\text { IGFBP5 - a potential developmental gene is regulated } \\
\text { upon heart failure transition }\end{array}$ & Poster & $\begin{array}{l}\text { AHA Scientific } \\
\text { Sessions, Anaheim, } \\
\text { CA, USA, } 2017\end{array}$ \\
\hline $\begin{array}{l}\text { IGFBP5 - a potential biomarker for heart failure } \\
\text { transition }\end{array}$ & Poster & $\begin{array}{l}\text { 5th DZHK Retreat and } \\
\text { 4th Young DZHK } \\
\text { Retreat, Warnemünde, } \\
2017\end{array}$ \\
\hline $\begin{array}{l}\text { IGFBP5 - a potential developmental gene is regulated } \\
\text { upon heart failure }\end{array}$ & Poster & $\begin{array}{l}\text { 34th ISHR-ES } \\
\text { Meeting, Hamburg } \\
2017\end{array}$ \\
\hline $\begin{array}{l}\text { IGFBP5 - a potential developmental gene is regulated } \\
\text { upon cardiac stress }\end{array}$ & Talk & $\begin{array}{l}\text { 83. Jahrestagung } \\
\text { DGK, Mannheim, } \\
2017\end{array}$ \\
\hline $\begin{array}{l}\text { IGFBP5 - a novel gene regulated in cardiac development } \\
\text { and disease }\end{array}$ & Poster & $\begin{array}{l}\text { DGK Herbsttagung, } \\
\text { Berlin, } 2016\end{array}$ \\
\hline $\begin{array}{l}\text { IGFBP5 - a developmental gene regulated upon cardiac } \\
\text { stress }\end{array}$ & Poster & $\begin{array}{l}\text { DGPT - German } \\
\text { Pharm-Tox Summit, } \\
\text { Berlin, } 2016\end{array}$ \\
\hline $\begin{array}{l}\text { IGFBP5 - a developmental gene regulated upon cardiac } \\
\text { stress }\end{array}$ & Poster & $\begin{array}{l}\text { DGK Herbsttagung, } \\
\text { Berlin, } 2015\end{array}$ \\
\hline $\begin{array}{l}\text { IGFBP5 - a developmental gene regulated upon cardiac } \\
\text { stress }\end{array}$ & Talk & $\begin{array}{l}\text { 3th DZHK Retreat and } \\
\text { 2th Young DZHK } \\
\text { Retreat, Potsdam, } \\
2015\end{array}$ \\
\hline
\end{tabular}




\section{List of Tables}

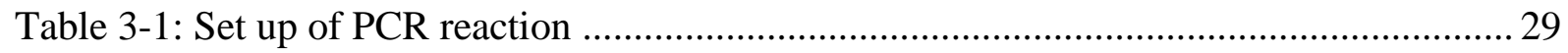

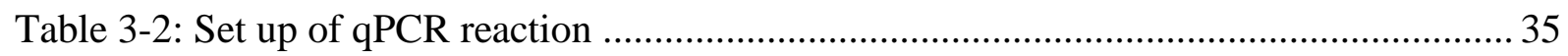

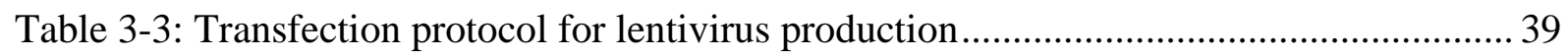

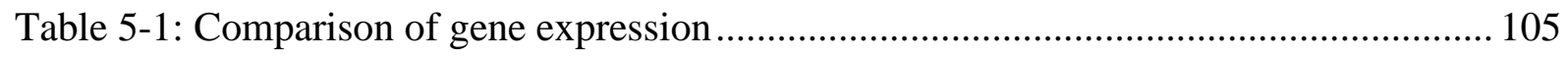




\section{List of Figures}

Figure 2-1: Igfbp5 expression during cardiogenesis in vivo...............................................

Figure 2-2: Igfbp5 expression in different cell populations of the adult murine heart.............. 9

Figure 2-3: Igfbp5 expression in mice upon TAC operation ................................................ 9

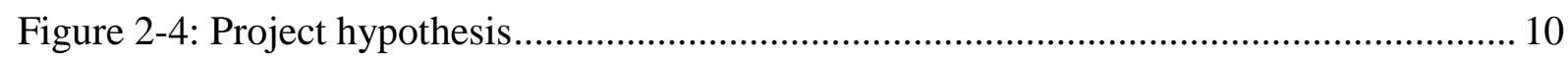

Figure 3-1: Immunoblot for customized IGFBP5 antibody ........................................... 46

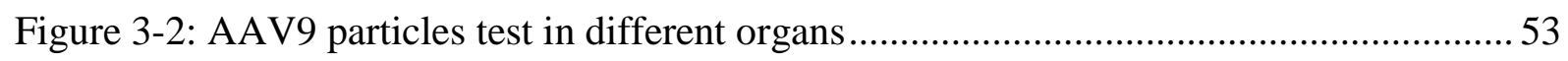

Figure 4-1: Expression dynamics of Igfbp5 upon transverse aortic constriction (TAC) .........57

Figure 4-2: Igfbp3 expression is not changed in the diseased murine heart............................ 58

Figure 4-3: Igfbp5 expression upon preserved cardiac function post-TAC ...........................58

Figure 4-4: hIGFBP5 expression and expression of hIGFBP5 targeting microRNAs in aortic

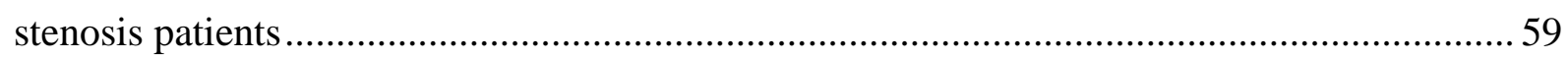

Figure 4-5:Validation of IGFBP5 protein expression in the diseased murine and human heart 60

Figure 4-6: Validation of AAV9 mediated expression of Igfbp5 in murine hearts in vivo...... 63

Figure 4-7: RNA sequencing results of murine hearts with AAV9 mediated Igfbp5

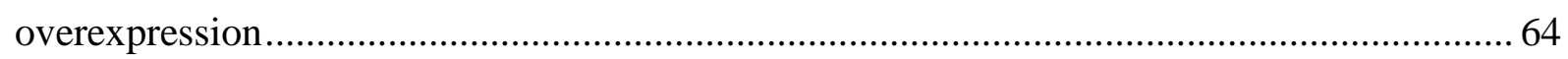

Figure 4-8: Analysis of murine hearts with AAV9 mediated Igfbp5 overexpression.............. 65

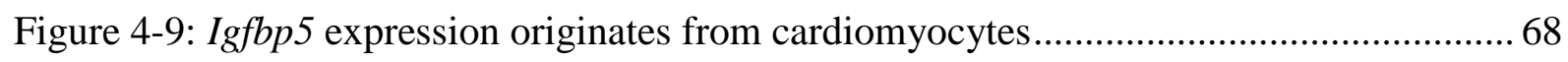

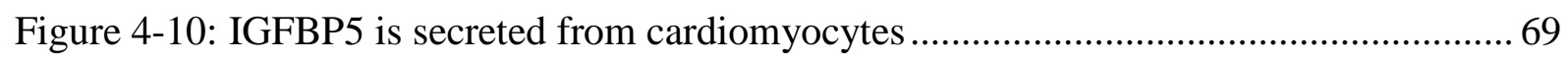

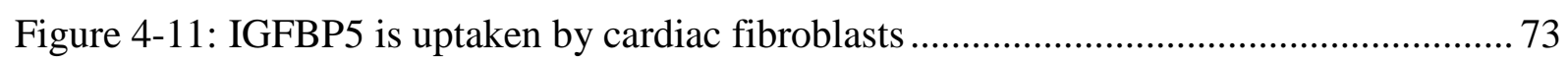

Figure 4-12: Effect of lentiviral overexpression of hIGFBP5 on human cardiac fibroblasts .. 74

Figure 4-13: Cardiac fibroblast specific overexpression of hIGFBP5 in engineered human

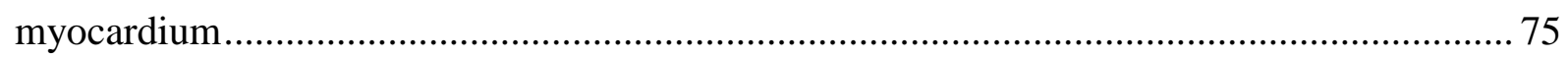

Figure 4-14: Myofibroblast activation and hIGFBP5 upregulation are not directly associated .76

Figure 4-15: Overexpressed hIGFBP5 binds to DNA and regulates promoter activity..... 79 
Figure 4-16: hNKX2.5 occupies same genomic regions as hIGFBP5 and regulates promoter activity..... 80

Figure 4-17: Generation of a hIGFBP5 knockout hES cell line using CRISPR/Cas9 technology .85

Figure 4-18: Validation of generated hIGFBP5 knockout hES cell clones .86

Figure 4-19: Characterisation of generated $h I G F B P 5$ knockout hES cell lines.

Figure 4-20: Spontaneous germ layer differentiation of hIGFBP5 knockout hES cell lines... 88

Figure 4-21: Characterisation of differentiated hIGFBP5 knockout cardiomyocytes ..... .89

Figure 4-22: Protein expression in differentiated hIGFBP5 knockout cardiomyocytes 90

Figure 4-23: 2D differentiation of $h I G F B P 5$ knockout hES cells to cardiomyocytes . 91

Figure 4-24: Igfbp5 expression upon norepinephrine and angiotensin II stimulation 93

Figure 5-1: Scheme of gene expression and interactions during cardiogenesis. 116

Figure 6-1: Conclusion figure 121

Figure 8-1: Vectors for lentivirus production 142

Figure 8-2: Vectors for AAV9 particle production 143

Figure 8-3: Overexpression vectors 143

Figure 8-4: Luciferase reporter vectors 144

Figure 8-5: Cas9/gRNA vector 144 


\section{Abbreviations}

\begin{tabular}{|c|c|}
\hline AAV & Adeno-associated virus \\
\hline ACE & Angiotensin converting enzyme \\
\hline Ang & Angiotensin \\
\hline ANOVA & Analysis of variance \\
\hline APS & Ammonium persulfate \\
\hline AWThd & Anterior wall thickness during diastole \\
\hline $\mathrm{BF}$ & Bright field \\
\hline $\mathrm{bp}$ & Base pair \\
\hline BSA & Bovine serum albumin \\
\hline BW & Body weight \\
\hline Cas9 & CRISPR associated protein 9 \\
\hline cDNA & Complimentary DNA \\
\hline CDS & Coding sequence \\
\hline $\mathrm{CH}$ & Compensated hypertrophy \\
\hline ChIP & Chromatin immunoprecipitation \\
\hline $\mathrm{CM}$ & Cardiomyocyte \\
\hline CMV & Cytomegalovirus \\
\hline $\mathrm{CO} 2$ & Carbon dioxide \\
\hline co-IP & Co-immunoprecipitation \\
\hline $\mathrm{CPC}$ & Cardiac progenitor cell \\
\hline CRE & Cyclization recombination \\
\hline CRISPR & Clustered regularly interspaced short palindromic repeats \\
\hline CT & Control \\
\hline CVD & Cardiovascular disease \\
\hline $\mathrm{d}$ & $\operatorname{Day}(\mathrm{s})$ \\
\hline DAPI & 4',6-diamidino-2-phenylindole, a fluorescent stain \\
\hline DCM & Dilated cardiomyopathy \\
\hline del & Deletion \\
\hline DEPC & Diethylpyrocarbonate \\
\hline $\mathrm{dF} / \mathrm{dT}$ & Rate (delta) of force by rate (delta) of time \\
\hline DMEM & Dulbecco's modified eagle's medium \\
\hline DMSO & Dimethyl sulfoxide \\
\hline DNA & Deoxyribonucleic acid \\
\hline DNase & Deoxyribonuclease \\
\hline dNTP & Deoxyribonucleotide triphosphate \\
\hline DSG & Disuccinimidyl glutarate \\
\hline E. coli & Escherichia coli \\
\hline EB & Embryoid body \\
\hline ECM & Extracellular matrix \\
\hline EDTA & Ethylenediaminetetraacetic acid \\
\hline EF & Ejection fraction \\
\hline EHM & Engineered heart muscle \\
\hline ELISA & Enzyme-linked immunosorbent assay \\
\hline ER & Endoplasmic reticulum \\
\hline
\end{tabular}




\begin{tabular}{|c|c|}
\hline ESC & Embryonic stem cell \\
\hline $\mathrm{EtOH}$ & Ethanol \\
\hline ev & Empty vector \\
\hline Ex & Exon \\
\hline FACS & Fluorescence-activated cell sorting \\
\hline FAS & Fractional area shortening \\
\hline FBS & Fetal bovine serum \\
\hline FGF & Fibroblast growth factor \\
\hline FLAG & Polypeptide protein tag \\
\hline FOC & Force of contractilition (systolic force amplitude) \\
\hline Fwd & Forward primer \\
\hline GFP & Green fluorescent protein \\
\hline GO & Gene ontology \\
\hline GOF & Gain of function \\
\hline gRNA & Guide RNA \\
\hline $\mathrm{H}_{2} \mathrm{O}$ & Water \\
\hline $\mathrm{H} 3 \mathrm{~K} 4 \mathrm{me}$ & Methylation at the 4th lysine residue of the histone h3 \\
\hline hCFB & Human cardiac fibroblast \\
\hline HEK & Human embryonic kidney cells \\
\hline HEPES & 4-(2-hydroxyethyl)piperazine-1-ethanesulfonic acid \\
\hline hES & Human embryonic stem cell \\
\hline HF & Heart failure \\
\hline HRP & Horseradish \\
\hline HW & Heart \\
\hline HW & Heart weight \\
\hline HW / BW & Heart to body weight ratio \\
\hline IF & Immunofluorescence \\
\hline $\operatorname{IgG}$ & Immunoglobulin \\
\hline ins & Insertion \\
\hline IP & Immunoprecipitation \\
\hline iPSC & Induced pluripotent stem cell \\
\hline IRES & Internal ribosome entry site \\
\hline KO & Knockout \\
\hline LOF & Loss-of-function \\
\hline Luc CT & Luciferase control \\
\hline LVID $_{\text {sys }}$ & Left ventricular inner diameter during systole \\
\hline mESC & Murine embryonic stem cell \\
\hline MHC & Myosin heavy chain \\
\hline MLC & Myosin light chain \\
\hline MNCF & Murine neonatal cardiac fibroblasts \\
\hline MNCM & Murine neonatal cardiomyocytes \\
\hline mock & Electroporated control hES cells \\
\hline mRNA & Messenger RNA \\
\hline $\mathrm{ms}$ & Mouse \\
\hline $\mathrm{n}$ & Number of biological replicates \\
\hline $\mathrm{NaCl}$ & Sodium chloride \\
\hline
\end{tabular}




\begin{tabular}{|c|c|}
\hline $\mathrm{NE}$ & Norepinephrine \\
\hline NEAA & Non-essential amino acids \\
\hline NF & Non-failing control hearts \\
\hline NLS & Nuclear localization sequence \\
\hline NP-40 & Nonoxinol \\
\hline $\mathrm{OE}$ & Overexpression \\
\hline ORF & Open reading frame \\
\hline $\mathrm{p}$ & P-value \\
\hline $\mathrm{P} / \mathrm{S}$ & Penicillin/streptomycin \\
\hline PBS & Phosphate buffered saline \\
\hline PCR & Polymerase chain reaction \\
\hline PFA & Paraformaldehyde \\
\hline PVDF & Polyvinylidene difluoride \\
\hline qPCR & Quantitative real time PRC \\
\hline RAAS & Renin angiotensin aldosterone system \\
\hline $\mathrm{rb}$ & Rabbit \\
\hline Rev & Reverse primer \\
\hline RFP & Red fluorescent protein \\
\hline RIME & Rapid immunoprecipitation of endogenous proteins \\
\hline RNA & Ribonucleic acid \\
\hline ROS & Reactive oxygen species \\
\hline RPKM & Reads per kilobase of transcript per million mapped reads \\
\hline $\mathrm{rpm}$ & Reads per milion \\
\hline RT & Reverse transcription \\
\hline RT & Room temperature \\
\hline SD & Standard deviation \\
\hline SDS & Sodium dodecyl sulfate \\
\hline SDS PAGE & Sodium dodecyl sulfate polyacrylamide gel electrophoresis \\
\hline SEM & Standard error of the mean \\
\hline Sham & Surgical control group \\
\hline SOC & Super optimal broth with catabolite repression \\
\hline TAC & Transverse aortic constriction \\
\hline TAE & Tris base, acetic acid and edta \\
\hline Taq & Thermus aquaticus \\
\hline TBS & Tris buffered saline \\
\hline TBS-T & Tris buffered saline -tween 20 \\
\hline TEMED & Tetramethylethylenediamine \\
\hline Tris & Trisamine \\
\hline TSA & Human embryonic kidney sv40 transformed cells \\
\hline TSS & Transcriptional start site \\
\hline TX & Tamoxifen \\
\hline Volsys & Endsystolic volume \\
\hline WB & Western blot \\
\hline WT & Wild type (control) \\
\hline$\beta$-Cat GOF & Cardiomyocyte specific $\beta$-catenin stabilization \\
\hline$\beta$-Cat LOF & Cardiomyocyte specific $\beta$-catenin ablation \\
\hline
\end{tabular}




\section{Units}

\begin{tabular}{|c|c|}
\hline$\%$ & Percent \\
\hline${ }^{\circ} \mathrm{C}$ & Degree Celsius \\
\hline $\mathrm{Da}$ & Dalton \\
\hline $\mathrm{g}$ & Gram \\
\hline $\mathrm{h}$ & Hour \\
\hline $\mathrm{Hz}$ & Hertz \\
\hline $\mathrm{k}$ & Kilo \\
\hline $\mathrm{kb}$ & Kilo base \\
\hline $\mathrm{kDa}$ & Kilo Dalton \\
\hline $\mathrm{L}$ & Litre \\
\hline $\mathrm{m}$ & Milli \\
\hline M & Molar \\
\hline $\min$ & Minute \\
\hline $\mathrm{n}$ & Nano \\
\hline $\mathrm{nm}$ & Nanometer \\
\hline $\mathrm{rcf}$ & Relative centrifugal force \\
\hline $\mathrm{rpm}$ & Rounds per minute \\
\hline $\sec$ & Seconds \\
\hline $\mathrm{U}$ & Units \\
\hline $\mathrm{V}$ & Volt \\
\hline $\mathrm{xg}$ & Gravity \\
\hline$\alpha$ & Alpha \\
\hline$\beta$ & Beta \\
\hline$\kappa$ & Kappa \\
\hline$\mu$ & Micro \\
\hline
\end{tabular}

\section{Genes and proteins}

\begin{tabular}{ll}
\hline ACTA2 & $\alpha$-smooth muscle actin gene \\
\hline AFP & $\alpha$-feto-protein \\
\hline ANP & Atrial natriuretic peptide \\
\hline Bc12 & B-cell lymphoma 2 \\
\hline BNP & BCL2-like 13 (apoptosis facilitator) or Bcl-rambo \\
\hline cKit & Brain natriuretic peptide \\
\hline cTnT & Tyrosine-protein kinase Kit or CD117 \\
\hline CX43 & Cardiac troponin T \\
\hline DDR2 & Connexin-43 \\
\hline Fis1 & Discoidin domain-containing receptor 2 \\
\hline Fn1 & Mitochondrial fission 1 protein \\
\hline GAPDH & Fibronectin \\
\hline HDAC & Glyceraldehyde-3-phosphate dehydrogenase \\
\hline Hsp90aa1 & Histone deacetylase \\
\hline IBP5 & Heat shock protein 90 \\
\hline IBP5 OE & IGFBP5 (short nomenclature) \\
\hline
\end{tabular}




\begin{tabular}{|c|c|}
\hline IGF & Insulin-like growth factor \\
\hline IGFBP & Insulin-like growth factor binding protein \\
\hline Igfbp5 & Murine Insulin-like growth factor binding protein 5 gene \\
\hline IGFBP5 & Human Insulin-like growth factor binding protein 5 gene \\
\hline IGFBP5 & Murine/human IGFBP5 protein \\
\hline Mef2c & Myocyte-specific enhancer factor $2 \mathrm{c}$ \\
\hline Myh6 & Myosin heavy chain alpha gene \\
\hline Myh7 & Myosin heavy chain beta gene \\
\hline MYL & Myosin light chain \\
\hline Mylk & Myosin light chain kinase \\
\hline Myocd & Myocardin \\
\hline NCAD & N-cadherin \\
\hline $\mathrm{NF}-\kappa \mathrm{B}$ & Nuclear factor kappa-light-chain-enhancer of activated B cells \\
\hline Nppa & Atrial natriuretic peptide gene \\
\hline Nppb & Brain natriuretic peptide gene \\
\hline NR1C1 & Peroxisome proliferator-activated receptor $\alpha$ gene \\
\hline OCT4 & Octamer-binding transcription factor 4 \\
\hline PDGF & Platelet-derived growth factor \\
\hline Pink1 & PTEN-induced putative kinase 1 \\
\hline $\mathrm{PKC} \alpha$ & Protein kinase $\mathrm{C}$ alpha \\
\hline PPAR & Peroxisome proliferator-activated receptor \\
\hline Prkca & Protein kinase $\mathrm{C}$ alpha gene \\
\hline RXR & Retinoid X receptor \\
\hline Sca-1 & Stem cells antigen- 1 \\
\hline SOX2 & SRY (sex determining region Y)-box 2 \\
\hline SOX9 & Transcription factor SOX-9 \\
\hline STAT & Signal transducer and activator of transcription \\
\hline Tbp & TATA-binding protein \\
\hline TBX5 & T-box transcription factor TBX5 \\
\hline $\operatorname{Tgfb} 2$ & Transforming growth factor beta gene \\
\hline TGF $\beta$ & Transforming growth factor beta \\
\hline $\mathrm{TNF} \alpha$ & Tumor Necrosis Factor $\alpha$ \\
\hline Tnnt2 & Cardiac troponin $\mathrm{T}$ gene \\
\hline Tpt1 & Translationally-controlled tumor protein \\
\hline VDR & Vitamin D Receptor \\
\hline$\alpha$-SMA & $\alpha$-Smooth Muscle Actin \\
\hline
\end{tabular}

\section{Gene nomenclature}

Gene names are written according to the guidelines for human gene nomenclature [1]. Example: murine gene (Igfbp5), human gene (IGFBP5), summary of human and mouse transcripts (IGFBP5), murine/human protein (IGFBP5). 


\section{Abstract}

The importance of elucidating mechanisms of cardiac regulatory networks during cardiogenesis is underscored by the re-activation of fetal gene expression in the diseased adult heart. To further understand this phenomenon, the insulin-like growth factor binding protein 5 (IGFBP5), an extracellular binding protein for IGF, possessing IGF-independent functions, was investigated. In this study, analysis of murine cardiac tissue at different developmental stages showed a progressive decrease in Igfbp5 expression with heart maturation, remaining significantly low in the adult heart. Moreover, sustained IGFBP5 expression in human embryonic stem cells arrested cardiomyocyte differentiation subsequent to progenitor specification. In line with these results, expression analysis in different cell populations of the adult murine heart showed very low Igfbp5 expression in cardiomyocytes in contrast to high levels expressed in Sca1-positive cardiac progenitor cells. Additionally, re-expression of $I G F B P 5$ was found in the transition to heart failure in murine and human hearts consequent to pressure overload and aortic stenosis, respectively. Furthermore, IGFBP5 expression detected in mice upon preserved cardiac function post-TAC, was at physiological levels. In the failing heart, cardiomyocytes were shown to express and secrete IGFBP5, which could also be detected in the blood serum. In turn, cardiac fibroblasts showed uptake of exogenous IGFBP5, whereas IGFBP5 overexpression in these cells regulated cardiac gene expression and influenced engineered heart muscle physiology. In vivo, AAV9-mediated cardiomyocyte specific overexpression of Igfbp5 in the adult healthy heart led to an atrophy-like phenotype with reduced heart size. Transcriptome analysis revealed a decrease in extra-cellular matrix and sarcomeric gene expression as well as a reduced junction and ion channel expression, indicating altered cardiac cell integrity. Key regulators of fibrotic processes were downregulated, while a positive effect on fatty acid metabolism could be observed. Notably, this study revealed that IGFBP5 has nuclear functions in cardiac cells including the occupancy of its own promoter and the repression of the TNNT2 promoter by antagonizing NKX2.5-mediated TNNT2 promoter activation. In conclusion, this study demonstrates that IGFBP5 has an important role to play in cardiac progenitor cell commitment and in the transition to heart failure, as a part of the fetal gene re-activation program. Additionally, it furnishes evidence to support an IGFBP5 mediated cardiomyocyte-fibroblast crosstalk, where IGFBP5 may alter gene expression via its transcriptional co-factor function. 


\section{Introduction}

\subsection{Heart failure}

\subsubsection{Cardiovascular disease and heart failure}

Cardiovascular diseases (CVD) are the leading cause of morbidity and mortality worldwide, claiming 17.7 million lives every year: one third of all global deaths (according to the WHO 2017). CVDs encompass multiple, heterogeneous disorders with multi-factorial pathophysiology, with heart failure (HF) being a final manifestation of many CVDs [2]. HF is a clinical syndrome caused by structural and functional cardiac abnormalities that lead to elevated intracardiac pressures and/or reduced cardiac output. HF symptoms include dyspnoea, fatigue, poor exercise tolerance, and fluid retention and can be clinically confirmed by a rise in jugular venous pressure, pulmonary crackles, and peripheral oedema. Finally, low cardiac output can lead to an imbalance in oxygen delivery and demand in tissues. Since the metabolic requirements of the cells cannot be maintained, decompensation of cardiac function is the consequence. HF is caused by many conditions that damage the heart muscle, including myocardial infarction, pressure overload (aortic stenosis, hypertension), inflammatory heart muscle disease (myocarditis), volume overload (valvular regurgitation) or idiopathic dilated cardiomyopathy. Before the onset of HF, the heart tries to compensate lost cardiomyocytes and counteracts an insufficient pump function by a process termed cardiac remodelling.

\subsubsection{Cardiac remodelling and fetal gene re-activation}

Cardiac remodelling constitutes molecular, cellular and interstitial changes and manifests itself as changes in size, shape, geometry (together termed hypertrophy) and function of the heart [3]. On a molecular level, hypertrophy, is the result of the activation of several signalling pathways and target genes which differ between physiological and pathological hypertrophy [4]. Mechanical stress in cardiomyocytes leads to oxidative stress [5], changes in local norepinephrine (NE) activity [6] and in increased angiotensin II (Ang II) [7] and endothelin [8] release. These neurohormonal factors, in turn, activate other signalling cascades and mediators like mitogen-activated protein kinases (MAPK), insulin-like growth factors 1 (IGF-1), phosphatidylinositol-3-kinase/protein kinase B (PI3K/PKB), histone deacetylases (HDACs) and calcineurin-mediated pathways, leading to an altered transcription and protein synthesis which mediates the hypertrophic response $[9,10]$. These molecular and morphological changes essentially represent an adaptation of the injured heart. Adaptive compensatory hypertrophy, the remodelling that occurs at the outset, is largely beneficial and appears to be at least partially 
reversible in some experimental and/or clinical models [11]. Sustained remodelling can lead to maladaptive decompensated hypertrophy, characterized by cardiomyocyte apoptosis, inflammation and fibrosis [12]. Collectively these factors lead to a reduction of cardiac force, tissue stiffening, wall stress, dilation and disturbed electrical conduction, culminating in $\mathrm{HF}$ [13]. Pathways and genes that are implicated in fetal heart development are shown to be expressed during cardiac remodelling following insult or injury. [10, 14]. Additionally, upon remodelling, cardiomyocytes show signs of dedifferentiation including disorganised sarcomeric structures [15], upregulation of the fetal actin isoform alpha skeletal actin [16] and the fetal myosin isoform myosin heavy chain beta (MYH7) [17]. However, the pathophysiology of fetalgene re-activation remains largely speculative. One example is the metabolic switch of the diseased heart. A potential hypothesis posits that the switch to fetal metabolism is an adaptation due to a changed energy/oxygen demand. Since fatty acid transport is impaired during cardiac hypertrophy and the oxygen supply is limited, a switch from fatty acid to glucose as a primary substrate allows the generation of greater energy (ATP) per molecule of oxygen. This reversal to the fetal program allows for greater efficiency in cellular energy production, thus averting cell death $[18,19]$. Emerging data indicates that evolutionarily conserved regulatory networks that drive cardiogenesis and maturation might also control aspects of heart regeneration [20]. Little is known about the signals that trigger differentiation of committed cardiac progenitor cells (CPCs) into cardiomyocytes, but fetal genes which are involved in cardiogenesis might have a role to play. Further investigations are essential to reveal the mechanisms that stimulate the proliferation and differentiation of residual cardiac progenitor cells as well as those that control cardiomyocyte dedifferentiation [20]. Understanding these mechanisms could point the way toward a therapeutic strategy that enhances cardiac repair and prevents HF progression via the re-activation of regenerative pathways [21,22].

\subsubsection{Regenerative capacity of the heart}

The postnatal mouse heart retains its regenerative potential for a few days after birth and fully regenerates in a model of neonatal myocardial infarction unlike its adult counterpart $[15,23]$. Intriguingly, similar to neonatal mice, new-born humans and infants seem to harbour a potent cardiac regenerative capacity as reported by Fratz et al. and Haubner et al. [24, 25]. While adult cardiomyocytes are cell cycle arrested (post-mitotic), cardiomyocytes of neonatal mice are capable of entering a proliferative state through dedifferentiation [15] in a process that has been studied extensively in the adult zebrafish [26]. Besides the neonatal regenerative potential via dedifferentiation, these studies assume that $30 \%$ of the regenerated cardiomyocytes are derived 
from unidentified stem or progenitor cell populations [27]. Even though the adult mammalian heart lacks a potent regenerative capacity, Bergmann et al. reported the approximate cardiomyocyte turnover in humans. The authors calculated that about $1 \%$ of cardiomyocytes are renewed per year, suggesting that fewer than $50 \%$ of cardiomyocytes are exchanged during a lifetime [28]. As discussed by Murry and Lee, this calculation has its pitfalls, but even though cardiomyocyte turnover is low, the fact that it occurs, suggests that it can potentially be therapeutically exploited, since it represents a potential endogenous sources for cell replacement [29]. There is still an ongoing debate whether cardiomyocyte turnover and cardiac regeneration are to be attributed to dedifferentiation and proliferation of cardiomyocytes [30] or to the differentiation of cardiac stem or progenitor cells [31, 32].

\subsubsection{Cardiogenic potential of cardiac progenitor cells}

The presence of cardiac progenitor cells (CPCs) in the fetal, as well as the adult heart has been described extensively in humans, as reviewed by Lee and Chong et al. [33]. In contrast to stem cells, CPCs are multipotent, but their division is limited. Cardiac side population cells (cSPCs), c-kit ${ }^{+}$and Sca- $1^{+}$cardiac cells are the different cell populations of the heart which are classified as CPCs according to criteria described by Mauretti et al. [32]. These populations can be identified by their different phenotypes and the expression of different surface markers. Even when CPC populations in the adult heart are rare, their application for cardiac regeneration is promising due to their capacity for differentiation $[34,35]$ and their ability to produce and remodel ECM proteins [36]. Interestingly, CPCs were found to proliferate and differentiate into the cardiac lineages upon myocardial infarction, indicating that these cells contribute to the limited regenerative capacity of the adult heart [30]. However, these authors went on to show that CPCs possess decreased telomerase activity in chronic infarcts with concomitant impaired cell division and cellular senescence, as well as increased CPC apoptosis which could point to why CPCs have such a limited regenerative capacity [30]. Other studies suggest that the hostile CPC microenvironment created by the MI is the cause of CPC senescence and apoptosis [32]. Taken together, insights into the mechanisms that control progenitor cell fate could open the door to new therapeutic approaches including activating these cells to enhance cardiac regeneration and potentially delaying HF progression [10].

\subsubsection{Current therapies}

To date, numerous drugs and implants can temporarily maintain cardiac function but these approaches are transient and only delay HF progression instead of reversing it. Cardiac transplantation remains the only feasible means to replace lost cardiac tissue and besides the 
lack of universal access, the procedure is not without its own pitfalls [37]. Current HF medications include diuretics, angiotensin-converting-enzyme inhibitors (ACE-I), $\beta$-blockers, Ang II receptor blockers (ARBs), hydralazine, and nitrates [38]. In first line, these drugs aim to reduce blood pressure, thus minimizing cardiac pressure overload and increase cardiac output. Pharmacological interventions cannot, however, compensate for the irreversible loss of cardiomyocytes. It follows that the future challenge of cardiovascular therapies lies in the functional regeneration of myocardial contractility through novel approaches which can include cell based therapy (e.g. transplantation of stem cells or differentiated cardiomyocytes), tissue engineering or the reprogramming of scar fibroblasts [39]. It is questionable whether the use of locally applied xenografts is useful in the event of HF, since cardiac dilation affects the heart globally and cannot be located to a specific spot like myocardial infarction does initially. Moreover, xenotransplantation harbours the risk of immune rejection and the reprogramming of cells can give rise to uncontrollable cell proliferation. In contrast, the stimulation of endogenous myocardial regeneration could offer a mechanism to improve HF regression while lowering the risk of severe side effects.

\subsection{The insulin-like growth factor binding protein 5}

\subsubsection{Insulin-like growth factor binding proteins}

The IGF (insulin-like growth factor) axis plays a crucial role in regulating cellular growth, differentiation and apoptosis which underscores the vital role it has to play in the development and regulation of many tissues [40]. The insulin-like growth factor binding protein (IGFBPs) family comprises six different IGF carrier proteins that form high-affinity complexes with both, IGF-I and IGF-II to modulate their functions [41]. More than $95 \%$ of IGFs in serum and other biological fluids are bound to IGFBPs. IGFs have a higher affinity for IGFBPs than to their own receptors [42] and this preference is controlled by phosphorylation, glycosylation, adherence to either cell-surface proteins or the extracellular matrix and, most importantly, by specific proteolysis [43]. Besides prolonging the half-life of the IGFs in circulation and inhibiting their metabolic effects by preventing them from binding their receptors [44], IGFBPs regulate cell activity in other ways [45]. IGFBPs which are strongly evolutionarily linked multifunctional proteins, share about 50\% homology with each other [46]. The cysteine-rich Nand C-terminal domains are highly conserved within the IGFBP family, while the central domain varies both within the family and across species. Different subdomains, or functional motifs, within each domain are presumed to contribute to their diverse roles. The precursor forms of all six IGFBPs have secretory signal peptides and the mature proteins are mostly found 
extracellularly [47]. IGFBPs are secreted in a tissue and developmental stage specific manner and are present in different concentrations in different organs [48, 49]. Functionally, IGFBPs are known to affect cell motility and adhesion, apoptosis and survival, and the cell cycle [50]. Largely independent of their IGF-binding activity, IGFBPs can modulate cell functions via interactions with other cell-surface proteins, like integrins, [51] and with nuclear receptors [52]. A classical bipartite nuclear localization signals (NLS), which shares homology with the DNAbinding domains of several transcription factors, was formerly only described for IGFBP3 and IGFBP5 [53, 54]. More recent work also showed NLS sequences that bear limited homology to those found in IGFBP3 and IGFBP5 in IGFBP6 [55] and IGFBP2 [56]. Apart from the nuclear activity of some IGFBPs, it is known that these proteins may participate in their own signalling pathways [50] and interact with many others [57].

\subsubsection{The insulin-like growth factor binding protein 5}

The insulin-like growth factor binding protein 5 (IGFBP5) is the most conserved IGFBP. It is present in all vertebrates and its amino acid sequence is more than $97 \%$ identical between human, mouse and rat [58]. The conserved N-terminal domain of IGFBP5 contains a hydrophobic patch which is the primary binding site for IGFs [59] while the C-terminal domain seems to be essential for a stable, high affinity IGF interaction [60]. The observation that both, the $\mathrm{C}$-terminal and the $\mathrm{N}$-terminal domains contain residues important for IGF binding implies the existence of an IGF-binding pocket involving both domains. Together with an acid-labile subunit (ALS), IGFBP5 can form ternary complexes with IGF-I or IGF-II and regulate the effects of these proteins [61]. Moreover, several proteolytic cleavage sites generate fragments which have reduced affinity for IGFs [62], while plasma proteolysis of IGFBP5 preferentially generates different C-terminal fragments, possibly acting in an IGF-dependent manner and bearing intrinsic biological functions [63]. The C-terminal domain also contains a consensus nuclear localisation signal [64] which is responsible for the nuclear translocation of IGFBP5 [65]. A basic residue rich region within the C-terminal domain is responsible for binding to the extracellular matrix components [66] and multiple extracellular proteins like heparin and heparan sulphate [67], serum glycoprotein ALS [68], plasminogen activator inhibitor-1 [69] and many more [50]. The central domain of IGFBP5 shows no structural conservation and is important for post-translational modifications, like serine/threonine phosphorylation [70], which is essential for its physiological role. IGFBP5 was found upregulated during the differentiation of neural [71], osteoblast [72] and myoblast [58] lineages and was identified as an essential regulator of physiological processes in bone, kidney and mammary glands [73]. 
Moreover, Igfbp5 is upregulated in several different types of cancer [42] and is suggested to be indicative of a poor prognosis [74]. Other investigators reported that IGFBP5 has tumour suppressor functions [75-77]. Transgenic mice with ubiquitous overexpression (OE) of Igfbp5 exhibited a significant increase in neonatal mortality, reduced female fertility, whole body growth inhibition, and retarded muscle development, whereas other Igfbp OE models show only modest changes or lack of a phenotype. The more severe phenotype observed in Igfbp5 overexpression mice compared to Igf-null mice suggests a dual function for IGFBP5: Both, as a modulator of IGF activity and as an IGF-independent signalling protein [78]. However, Igfbp5 knockout (KO) mice are not substantially different from normal mice with regard to wholebody growth, selected organ weights and body composition, presumably as a result of substantial compensation by the remaining members of the IGFBP family [79]. Several studies demonstrate an increase in body size and mild glucose intolerance mostly in Igfbp5 KO mice due to IGF-dependent effects [80]. IGFBP5 is known to regulate cell proliferation [81, 82], migration [83], and apoptosis/survival [84] in an IGF-independent manner. However, the IGFBP5-dependent regulation of these processes is cell and context specific, mediated by both IGF-dependent and independent mechanisms and can be both stimulating or repressing in nature [42]. The mechanistic basis of the ligand-independent actions of IGFBP5 are not well defined. A putative IGFBP5-receptor, which was reported but could not be cloned successfully may hold the key [57]. Considering the ability of IGFBP5 to enter cell nuclei via its nuclear localisation sequence, it can be inferred that IGFBP5 might have a transcriptional regulation function [65]. Consistent with this theory, the interaction of IGFBP5 with the transcriptional co-activator protein four-and-a-half LIM domain 2 (FHL2) [85], as well as its interaction with the histone-DNA complex in the nucleus of vascular smooth-muscle cells [86] were recently reported. These observations demonstrate that IGFBP5 might possesses both, an extracellular growth factor function as binding partner to IGF as well as a nuclear function as a potential transcriptional co-factor.

\subsubsection{IGFBP5 and the heart}

Regarding the embryonic heart, Igfbp5 is expressed in the early cardiac crescent in mouse embryos [87]. Several studies reported a link between sustained Igfbp5 expression and impaired cardiomyocyte differentiation, while enhanced cardiomyocyte differentiation correlated with decreasing Igfbp5 expression [87-89]. In rat neonatal cardiomyocytes, IGFBP5 was shown to mediate methamphetamine-induced apoptosis [90], whereas in rat neonatal fibroblasts IGFBP5 was revealed to be mediating high glucose induced profibrotic effects [91]. Thus far, there has 
been neither in vitro nor in vivo data available regarding the role of IGFBP5 in the cells of the healthy or diseased adult heart.

Previous work showed an upregulated expression of Igfbp5 in a mouse model with inducible, cardiac specific $\beta$-catenin stabilization ( $\beta$-Cat GOF) leading to experimentally induced cardiac hypertrophy with increased heart sizes, cardiac mass, myocyte cross-sectional area, fibrosis and high mortality [92, 93]. Apart from cardiac dysfunction, these mice displayed a limited cardiogenic differentiation potential of the undifferentiated cell pool [94]. Consistent with this result, Igfbp5 was upregulated in murine embryonic stem cells (mESCs) overexpressing Fhl2, which showed arrested cardiac differentiation in an early cardiogenic mesodermal progenitor state. Interestingly, Igfbp5 was found downregulated upon mESC differentiation to cardiomyocytes [89].

In preliminary unpublished work, analysis of murine cardiac tissue at different developmental stages showed a decreasing Igfbp5 expression with progressing heart maturation (Figure 2-1, $\mathrm{n}=3$ ). In the adult murine heart, Igfbp5 maintained higher expression levels in Sca- $1^{+}$progenitor cells in comparison to cardiomyocytes and fibroblasts (Figure 2-2, n=3). While investigating a mouse model with pressure-overload induced HF, upregulated $\operatorname{Ig} f b p 5 \mathrm{mRNA}$ levels were found in mice upon TAC (transverse aortic constriction) operation when compared to sham operated mice (Figure 2-3, $\mathrm{n}=8 / 12, \mathrm{P}<0.05$ ). Together, these observations suggest a role for IGFBP5 in cardiogenesis, in cardiac progenitor cells and in the adult diseased heart. 


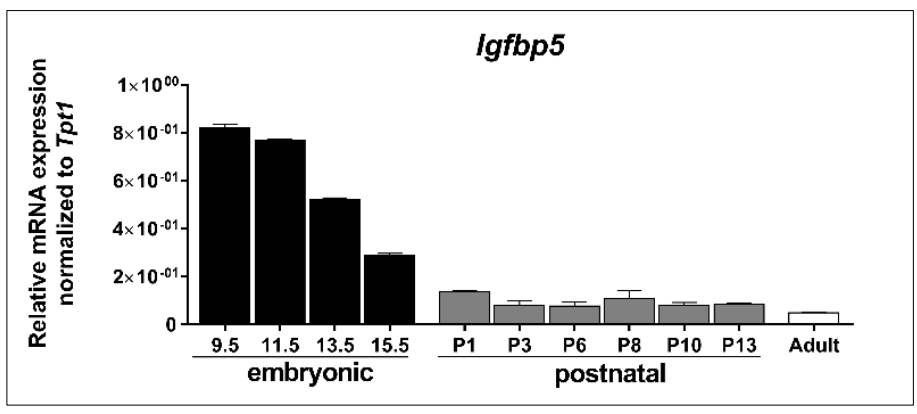

Figure 2-1: Igfbp5 expression during cardiogenesis in vivo

qPCR analysis of temporal changes in cardiac Igfbp5 expression in the developing and postnatal heart in vivo. Tpt1 (Tumor protein translationally-controlled 1) was used for normalization, $\mathrm{n}=3$.

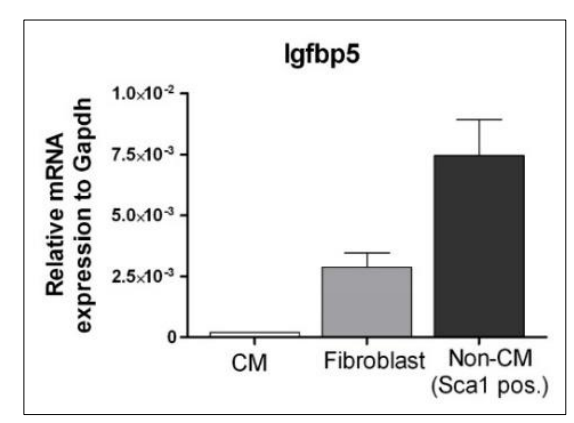

Figure 2-2: Igfbp5 expression in different cell populations of the adult murine heart

qPCR analysis of Igfbp5 in isolated adult cardiomyocytes [CM], fibroblasts and Sca- $1^{+}$positive progenitor cells [non$\mathrm{CM}$. Gapdh was used for normalization, $\mathrm{n}=3$.

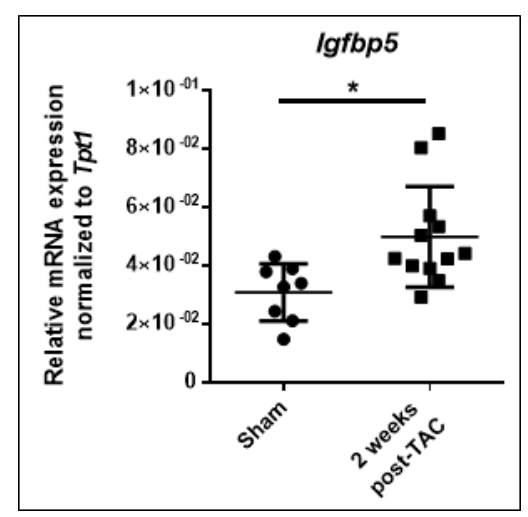

Figure 2-3: Igfbp5 expression in mice upon TAC operation

qPCR analysis of Igfbp5 expression in mice two weeks after transverse aortic constriction (TAC) and sham operation. Tpt1 (Tumor protein translationally-controlled 1) was used for normalization, $\mathrm{n}=8 / 12$, data are mean $\pm \mathrm{SEM}$; $\mathrm{t}$-test, * $\mathrm{P}<0.05$. 


\subsection{Project aim}

The main focus of this project was to investigate the role of IGFBP5 during cardiogenesis and in $\mathrm{HF}$ as a part of the fetal gene re-activation program.

This study tested the following specific hypotheses:

- Igfbp5 is regulated in the event of cardiac remodelling and HF

- IGFBP5 is critical for cardiac progenitor cell homeostasis

- Downregulation of Igfbp5 is necessary for cardiomyocyte maturation

- IGFBP5 functions as a transcriptional co-factor

The hypotheses were investigated using different transgenic mouse models and various cardiac disease models to study Igfbp5 expression in the heart and also in different cell populations. Additionally, a mouse model with a cardiac specific OE of Igfbp5 was used to study the gene's direct influence on the heart. To investigate the impact of IGFBP5 on cardiomyocyte differentiation in vitro, a gain-of function mutation was implemented in human stem cell. Different in vitro experiments were employed to investigate the responsiveness of cardiac cells to hypertrophic stimuli and IGFBP5. Moreover, chromatin immunoprecipitation (ChIP) experiments with subsequent promoter assays were used to investigate the transcriptional cofactor role of IGFBP5.

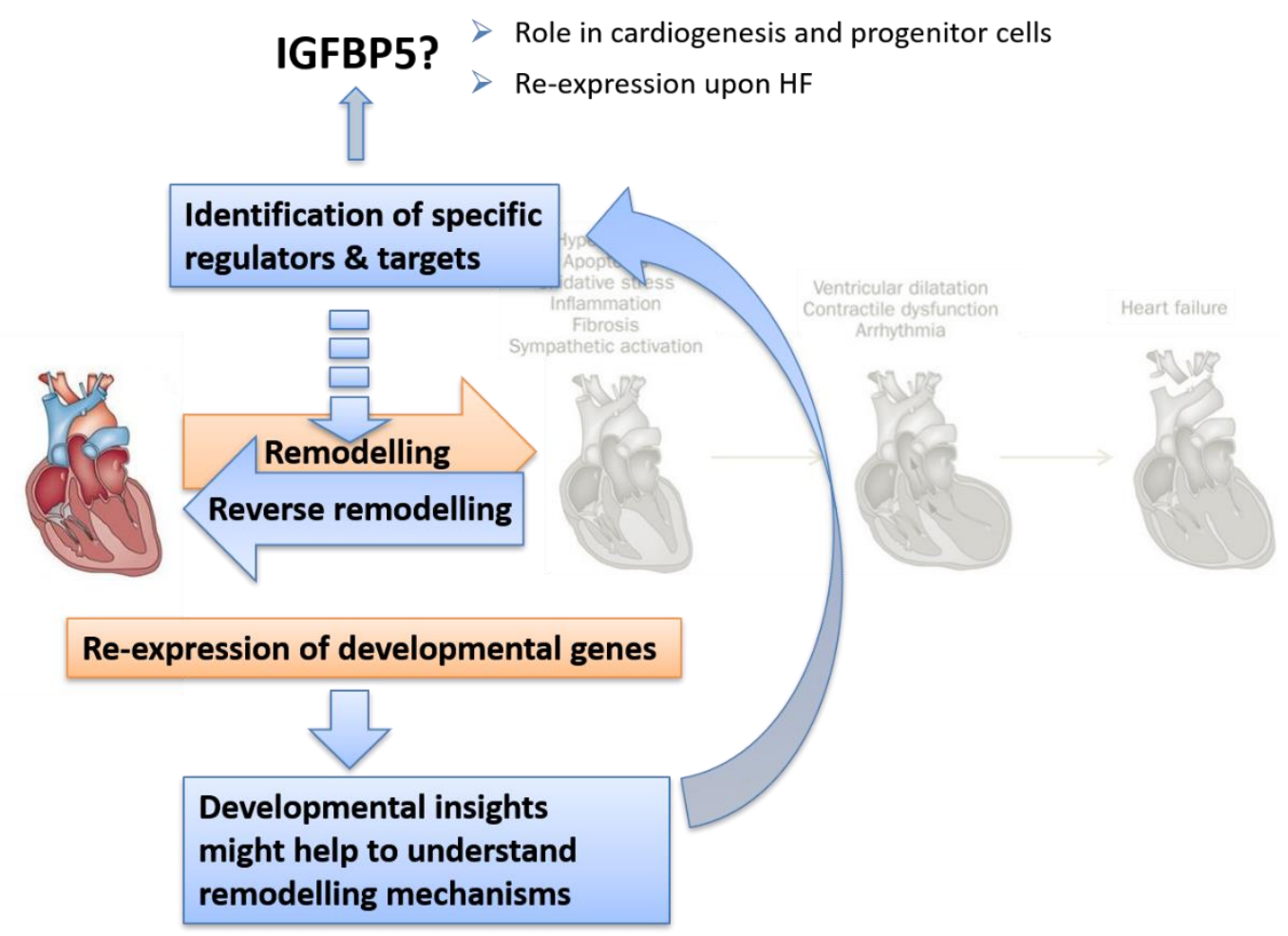

Figure 2-4: Project hypothesis 


\section{Material and Methods}

\subsection{Material}

\subsubsection{Consumables}

\begin{tabular}{|c|c|c|}
\hline Material & Type & Manufacturer \\
\hline 96-well & flat bottom & Sarstedt \\
\hline 384-well & $\begin{array}{l}\text { MicroAmp Optical 384-Well } \\
\text { Reaction Plate }\end{array}$ & Thermo Scientific \\
\hline 384-well adhesive film & MicroAmp Optical adhesive film & Thermo Scientific \\
\hline Bradford reagent & Rotiquant & Carl Roth \\
\hline DNA/RNA stain & MidoriGreen & Nippon Genetics \\
\hline Canules & l & B.Braun \\
\hline Cell culture plates & 96-, 48-, 24-, 12-, 6-well, & $\begin{array}{l}\text { Thermo Scientific (Nunc), } \\
\text { Greiner, Sarstedt }\end{array}$ \\
\hline Cell culture flasks & $25 \mathrm{~cm}^{2}, 75 \mathrm{~cm}^{2}, 175 \mathrm{~cm}^{2}$ & $\begin{array}{l}\text { Thermo Scientific (Nunc), } \\
\text { Greiner, Sarstedt }\end{array}$ \\
\hline Cell scraper & $16 \mathrm{~mm}$ & Sarstedt \\
\hline Chromatography paper & $3 \mathrm{~mm}$ & Whatman \\
\hline Cryo-vials & $1.8 \mathrm{ml}$ & Nunc, Greiner \\
\hline Falcon tubes & $15 \mathrm{ml}, 50 \mathrm{ml}$ & Greiner \\
\hline Filter tips, sterile & $0,5-10 \mu \mathrm{l}, 2-200 \mu \mathrm{l}, 1000 \mu \mathrm{l}$ & Labsolute \\
\hline Lentiviral Titer Test & Takara Clontech & LentiGo stick \\
\hline Glass cover slips & $12 \mathrm{~mm}$ & Thermo Scientific \\
\hline Hoechst & $10 \mathrm{mg} / \mathrm{ml}$ & Invitrogen/BD \\
\hline Object slides & Menzel-Gläser Superfrost & Thermo Scientific \\
\hline Pipet tips & $0,5-10 \mu \mathrm{l}, 2-200 \mu \mathrm{l}, 1000 \mu \mathrm{l}$ & Greiner \\
\hline Pipets, serological & $5 \mathrm{ml}, 10 \mathrm{ml}, 25 \mathrm{ml}$ & Sarstedt \\
\hline \multirow{2}{*}{ Plates } & 384 well & Applied Biosystems \\
\hline & 96 well & Sarstedt \\
\hline PVDF membrane & Roti $^{\circledR}$-PVDF, $0.45 \mu \mathrm{m}$ & Roth \\
\hline Reaction tubes & $0.5 \mathrm{ml}, 1.5 \mathrm{ml}, 2 \mathrm{ml}$ & Eppendorf \\
\hline Sterile filter & 0,2 and $0,45 \mu \mathrm{m}$ & Sartorius \\
\hline Syringe & $1,2,5,10,20$ and $50 \mathrm{ml}$ & Henke-Sass, Wolf,Braun \\
\hline Western blot substrate & Supersignal West Femto & Pierce Thermo Scientific \\
\hline Whatman Blotting Paper & I & Whatman \\
\hline
\end{tabular}




\subsubsection{Devices}

\begin{tabular}{|c|c|c|}
\hline Device & Type & Manufacturer \\
\hline $\begin{array}{l}\text { Agarose gel casting system and } \\
\text { electrophoresis unit }\end{array}$ & I & Generic \\
\hline Blot imager & VersaDoc $^{\mathrm{TM}}$ Imaging System & BioRad \\
\hline CASY cell counter & Model TT & Roche Innovatis AG \\
\hline \multirow{6}{*}{ Centrifuges } & Centrifuge $5417 \mathrm{C}$ & \multirow[b]{2}{*}{ Eppendorf } \\
\hline & $\begin{array}{l}\text { Centrifuge 5417R } \\
\text { Centrifuge 5810R }\end{array}$ & \\
\hline & Centrifuge Megafuge 1.0R & Thermo Scientific \\
\hline & Centrifuge MIKRO 22R & Hettich GmbH \& Co. KG \\
\hline & Biofuge pico & Heraeus \\
\hline & CombiSpin FVL-2400L & Peqlab Biotechnology $\mathrm{GmbH}$ \\
\hline Clean bench & HERAGUARD & Thermo Scientific \\
\hline \multirow{3}{*}{ Electrophoresis chamber } & PerfectBlue ${ }^{\mathrm{TM}}$ Maxi L & Peqlab \\
\hline & Mini Protean Tetra System & Biorad \\
\hline & Semi dry blotter unit & Scie Plas \\
\hline Electroporator & Nucleofector ${ }^{\mathrm{TM}} 2 \mathrm{~b}$ Device & Lonza \\
\hline FACS & LSRII flow cytometer & $\mathrm{BD}$ \\
\hline \multirow{3}{*}{ Freezer } & Freezer $\left(-20^{\circ} \mathrm{C}\right)$ & Liebherr \\
\hline & Freezer $\left(-80^{\circ} \mathrm{C}\right)$ & Heraeus, Thermo Scientific \\
\hline & Freezer $\left(-152^{\circ} \mathrm{C}\right)$ & Heraeus, Thermo Scientific \\
\hline Fridge & I & Liebherr \\
\hline Gel imager & $\begin{array}{l}\text { GelDoc }^{\mathrm{TM}} \\
\text { Imaging System }\end{array}$ & BioRad \\
\hline Heating block & I & Eppendorf \\
\hline $\begin{array}{l}\text { Isometric force measurement } \\
\text { apparatus }\end{array}$ & l & Customized \\
\hline Low Voltage Power Supply & Power Pack P25 & Biometra \\
\hline \multirow{2}{*}{ Incubator } & Hera Cell 150 & Heraeus, Thermo Scientific \\
\hline & Sanyo Incubator FCC free & Sanyo \\
\hline Laminar flow cabinet & Hera Safe & Heraeus, Thermo Scientific \\
\hline Luminometer & GLOMAX $^{\mathrm{TM}} 96$ Microplate & Promega \\
\hline Magnet stirrer & MR3001 & Heidolph Instruments GmbH \\
\hline \multirow{4}{*}{ Microscopes } & Axiovert 200 & Carl Zeiss \\
\hline & Leica M80 & Leica \\
\hline & LSM 710 & Carl Zeiss \\
\hline & SteReo Discovery.V8 & Carl Zeiss \\
\hline Multi-Mode Microplate Reader & FlexStation 3 & Molecular Devices \\
\hline PCR device & T Gradient & Biometra \\
\hline
\end{tabular}




\begin{tabular}{|c|c|c|}
\hline Device & Type & Manufacturer \\
\hline & $\begin{array}{l}\text { Veriti }^{\circledR} \text { 96-Well } \\
\text { Thermal Cycler }\end{array}$ & Applied Biosystems \\
\hline $\mathrm{pH}$ meter & l & Sartorius \\
\hline Pipets & $\begin{array}{l}0,1-2.5 \mu \mathrm{L} ; 2-20 \mu \mathrm{L} ; 20-200 \mu \mathrm{L} \\
100-1000 \mu \mathrm{L}\end{array}$ & Eppendorf/Sartorius/Gilson \\
\hline Power supply unit & Powerpack P25T & Biometra \\
\hline qRT-PCR device & $\begin{array}{l}7900 \text { HT Fast Real-Time PCR } \\
\text { System }\end{array}$ & Applied Biosystems \\
\hline \multirow{3}{*}{ Shaking devices } & innova 4300 Incubator Shaker & New Brunswick Scientific \\
\hline & "Rocky" & Schütt Labortechnik \\
\hline & Rocking Platform & Biometra \\
\hline Spectrophotometer & NanoDrop 1000 & Peqlab \\
\hline Sonicator & Biorupter & Diagenode \\
\hline Thermomixer & Thermomixer Compact & Eppendorf \\
\hline Tissue dissociator & gentleMACS ${ }^{\mathrm{TM}}$ Dissociator & Miltenyi Biotec \\
\hline UV Transilluminators & TI1 & Biometra \\
\hline Tissue Lyser & TissueLyser II & Quiagen \\
\hline \multirow{3}{*}{ Vortexer } & Biovortexer MHX (E) & Xenox \\
\hline & VF2 & Janke\&Kunkel IKA-Labortechnik \\
\hline & Peq Twist & PeqLab \\
\hline
\end{tabular}

\subsubsection{Software}

\begin{tabular}{|l|l|}
\hline \multicolumn{1}{|c|}{ Type } & \multicolumn{1}{c|}{ Company } \\
\hline AxioVision & Carl Zeiss \\
\hline FACS DIVA & BD \\
\hline Gentle V1.9.4 & Magnus Manske, Köln \\
\hline GLOWMAX 1.9.2 & Promega \\
\hline GraphPad Prism 6 & GraphPad Software \\
\hline Image Lab & Bio Rad \\
\hline Microsoft Office & Microsoft \\
\hline ND-1000 V3.8.1 & NanoDrop Technologies \\
\hline SDS 2.4 & Applied Biosystems \\
\hline Soft Max Pro5.4 & Molecular Devices \\
\hline Quantity One 4.6.7 & Bio Rad \\
\hline ZEN 2011 (blue version) & Carl Zeiss \\
\hline Zotero & Open source/freeware \\
\hline &
\end{tabular}




\subsubsection{Databases}

\begin{tabular}{|l|l|}
\hline \multicolumn{1}{|c|}{ Type } & \multicolumn{1}{c|}{ Manufacturer } \\
\hline BLAST & National Library of Medicine \\
\hline Ensembl & WTSI / EBI \\
\hline OligoCalc & Northwestern University Chicago \\
\hline
\end{tabular}

\subsubsection{Cell culture media and supplements}

\subsubsection{Supplements}

\begin{tabular}{|c|c|c|}
\hline Type & Cat \# & Manufacturer \\
\hline$\beta$-Mercaptoethanol & $31350-010$ & Sigma \\
\hline Bromodeoxyuridine (BrDU) & B5002 & Sigma \\
\hline Collagen (Rat tail) & l & In-house made \\
\hline $\begin{array}{l}\text { Dulbecco's Modified Eagle Medium } \\
\text { (DMEM) (Glutamax) }\end{array}$ & $61965-059$ & Life technologies/Gibco \\
\hline DMEM for TSA cells & $42430-082$ & Life technologies/Gibco \\
\hline DMSO & D2650 & Sigma \\
\hline $\begin{array}{l}\text { RPMI } 1640 \text { without glucose, without } \\
\text { HEPES }\end{array}$ & 11879020 & Life technologies/Gibco \\
\hline RPMI 1640 (Glutamax) & $61870-044$ & Life technologies/Gibco \\
\hline B27 supplement & $17504-044$ & Life technologies/Gibco \\
\hline TrypLE & 12604 & Life technologies/Gibco \\
\hline $\begin{array}{l}\text { StemPro }{ }^{\circledR} \text { Accutase } ® \text { Cell Dissociation } \\
\text { Reagent }\end{array}$ & A11105-01 & Life technologies/Gibco \\
\hline EDTA $0.5 \mathrm{mmol} / \mathrm{L}, 2 \mathrm{mmol} / \mathrm{L}$ & l & In-house made \\
\hline Polybrene & 107689 & Sigma \\
\hline Accutase Solution & SCR005, & Milipore \\
\hline Trypsin & & Life technologies/Gibco \\
\hline $\begin{array}{l}\text { Non-essential amino acids (NEAA) } 100 \mathrm{X} \\
(10 \mathrm{mmol} / \mathrm{L})\end{array}$ & 11140050 & Life technologies/Gibco \\
\hline Fetal bovine serum (FBS) & 11573397 & Life technologies/Gibco \\
\hline L-Glutamine, 100X (200 mmol/L) & 35050061 & Life technologies/Gibco \\
\hline 100X penicillin/streptomycin $(10.000 \mathrm{U} / \mathrm{ml})$ & 15140 & Life technologies/Gibco \\
\hline $100 \mathrm{X}$ sodium pyruvate $(\mathrm{NaP})(100 \mathrm{mmol} / \mathrm{L})$ & 11360 & Life technologies/Gibco \\
\hline $\begin{array}{l}\text { BD Matrigel Basement Membrane Matrix } \\
\text { Growth Factor Reduced }\end{array}$ & 354230 & $\mathrm{BD}$ \\
\hline Activin A & 338-AC & R\&D systems \\
\hline CHIR & 04-0004 & Stemgent \\
\hline bFGF & $130-093-841$ & Stemgent \\
\hline Laminin-521 (100 $\mu \mathrm{g} / \mathrm{ml})$ & LN521-03 & Biolamina \\
\hline Retinoic acid & $\mathrm{R} 2625$ & Sigma \\
\hline
\end{tabular}




\begin{tabular}{|l|l|l|}
\hline IWP4 & 04-0036 & Stemgent \\
\hline IGF & AF-100-11 & Peprotech \\
\hline FGF & AF-100-18B & Peprotech \\
\hline VEGF & AF-100-20 & Peprotech \\
\hline TGF $\beta$ & AF-100-21C & Peprotech \\
\hline L-ascorbic acid & A8960 & Sigma \\
\hline Rock inhibitor Y27632 (ROCKi) & $04-0012-10$ & Stemolecule \\
\hline $\begin{array}{l}\text { Matrigel Basement Membrane Matrix } \\
\text { Growth Factor Reduced }\end{array}$ & 354230 & BD \\
\hline DNaseI & 3750 & Calbiochem \\
\hline TeSR ${ }^{\text {TM-E8 }}$ KM Kit & 05940 & Stem Cell Technologies \\
\hline Transfection reagent, Turbofect & R0532 & Thermo Scientific \\
\hline Trypsin-EDTA (0.05\%), phenol red & 25300054 & Thermo Scientific \\
\hline FBM & CC-3131 & Lonza \\
\hline FGM-3 SingleQuots & CC-4525 & Lonza \\
\hline Polybrene - Hexadimethrine bromide & H9268 & Sigma \\
\hline Puromycin & A1113803 & Life technologies/Gibco \\
\hline
\end{tabular}

\subsubsection{Cell culture media}

\begin{tabular}{|c|c|c|}
\hline Medium for & Ingredient & Ingredient volume \\
\hline \multirow{2}{*}{ hCFB medium (FGM3) } & FBM medium & $500 \mathrm{ml}$ \\
\hline & FGM3 bullet kit & Total aliquot \\
\hline \multirow{2}{*}{ hES medium } & TeSR ${ }^{\text {TM_E8 medium }}$ & $500 \mathrm{ml}$ \\
\hline & supplements & Total aliquot \\
\hline \multirow{5}{*}{$\begin{array}{l}\text { Cardiomyocyte (hCM) } \\
\text { basal medium }\end{array}$} & RPMI 1640 with Glutamax & $500 \mathrm{ml}$ \\
\hline & Penicillin/streptomycin & $100 \mathrm{U} / \mathrm{ml}$ \\
\hline & sodium pyruvate & $1 \mathrm{mmol} / 1$ \\
\hline & B27 supplement & $2 \%$ \\
\hline & L-AAP & $200 \mu \mathrm{mol} / \mathrm{L}$ \\
\hline \multirow{5}{*}{$\begin{array}{l}\text { (hCM) Mesodermal induction } \\
\text { medium }\end{array}$} & CM basal medium & $500 \mathrm{ml}$ \\
\hline & CHIR & $1 \mu \mathrm{mol} / \mathrm{L}$ \\
\hline & BMP4 & $10 \mathrm{ng} / \mathrm{ml}$ \\
\hline & Activin A & $9 \mathrm{ng} / \mathrm{ml}$ \\
\hline & bFGF & $5 \mathrm{ng} / \mathrm{ml}$ \\
\hline \multirow{2}{*}{$\begin{array}{l}(\mathrm{CM}) \text { Cardiac specification } \\
\text { medium }\end{array}$} & CM basal medium & $500 \mathrm{ml}$ \\
\hline & IWP4 & $5 \mu \mathrm{mol} / \mathrm{L}$ \\
\hline \multirow{4}{*}{ (hCM) Lactate selection medium } & RPMI without Glucose & $500 \mathrm{ml}$ \\
\hline & Penicillin/streptomycin & $100 \mathrm{U} / \mathrm{ml}$ \\
\hline & Natrium lactate & $2.2 \mathrm{mmol} / \mathrm{L}$ \\
\hline & 2-mercaptoethanol & $0.1 \mathrm{mmol} / \mathrm{L}$ \\
\hline
\end{tabular}




\begin{tabular}{|c|c|c|}
\hline Medium for & Ingredient & Ingredient volume \\
\hline \multirow{9}{*}{ Murine adult cardiomyocytes } & MEM phenol red & $48 \mathrm{ml}$ \\
\hline & FBS & $0.5 \mathrm{ml}(1 \%$ final $)$ \\
\hline & Penicillin/Streptomycin 100x & $0.5 \mathrm{ml}$ \\
\hline & L-Glutamin & $0.5 \mathrm{ml}$ ( $1 \%$ final $)$ \\
\hline & ITS-X & $0.5 \mathrm{ml}$ ( $1 \%$ final $)$ \\
\hline & L-Carnitine & 19.766 mg (2 mM final) \\
\hline & Creatine & $32.785 \mathrm{mg}$ (5 mM final) \\
\hline & Taurine & $31.285 \mathrm{mg}$ (5 mM final) \\
\hline & BSA & $100 \mathrm{mg}(2 \mathrm{mg} / \mathrm{ml}$ final $)$ \\
\hline \multirow{5}{*}{ Murine neonatal cardiomyocytes } & $\begin{array}{l}\text { DMEM (Biochrom), } 1.0 \mathrm{~g} / 1 \mathrm{D}- \\
\text { glucose, with } 3.7 \mathrm{~g} / 1 \mathrm{NaHCO} \text {, } \\
\text { without L-glutamine }\end{array}$ & $450 \mathrm{ml}$ \\
\hline & FBS & $10 \%$ \\
\hline & Pen-Strep (100x) & $1 \%$ \\
\hline & $\mathrm{BrDU}$ & $100 \mu \mathrm{M}$ \\
\hline & Non-essential amino acids & $1 \%$ \\
\hline \multirow{4}{*}{ Murine adult/neonatal fibroblast } & DMEM & $500 \mathrm{ml}$ \\
\hline & FBS & $50 \mathrm{ml}$ (10\% final) \\
\hline & Penicillin-Streptomycin 100x & $5.5 \mathrm{ml}$ \\
\hline & Non-essential amino acids & $5.5 \mathrm{ml}$ ( $1 \%$ final $)$ \\
\hline \multirow{3}{*}{ TSA } & DMEM & $450 \mathrm{ml}$ \\
\hline & FBS & $50 \mathrm{ml}$ (19\% final) \\
\hline & Penicillin-Streptomycin 100x & $5 \mathrm{ml}$ \\
\hline \multirow{2}{*}{ Cell-freezing-liquid } & FBS & $90 / 80 \%$ \\
\hline & DMSO & $10 / 20 \%$ \\
\hline
\end{tabular}

\subsubsection{Buffers and compositions}

\subsubsection{Buffers}

\begin{tabular}{|l|l|l|}
\hline \multicolumn{1}{|c|}{ Buffer } & \multicolumn{1}{c|}{ Ingredient } & \multicolumn{1}{c|}{ Amount } \\
\hline \multicolumn{3}{|c|}{ Agarose gel electrophoresis } \\
\hline TAE buffer (50x) & Tris base & $242.2 \mathrm{~g} / \mathrm{L}$ \\
\hline & EDTA & $18.6 \mathrm{~g} / \mathrm{L}$ \\
\hline & Acetic acid & $57.1 \mathrm{~g} / \mathrm{L}$ \\
\hline \multirow{2}{*}{ Cell lysis } & $2.38 \mathrm{~g}$ \\
\hline \multirow{3}{*}{ Bäuerle buffer } & HEPES & $10.2 \mathrm{~g}$ \\
\hline & $\mathrm{NaCl}$ & $100 \mathrm{ml}$ \\
\hline
\end{tabular}




\begin{tabular}{|c|c|c|}
\hline Buffer & Ingredient & Amount \\
\hline & EDTA & $93 \mathrm{mg}$ \\
\hline & EGTA & $19 \mathrm{mg}$ \\
\hline & NP-40 & $5 \mathrm{ml}$ \\
\hline & & $\rightarrow$ Fill to $500 \mathrm{ml}$ with $\mathrm{ddH}_{2} \mathrm{O}$ \\
\hline \multirow{7}{*}{ Hypertonic buffer } & HEPES & $2.98 \mathrm{~g}$ \\
\hline & $\mathrm{KCl}$ & $0.93 \mathrm{~g}$ \\
\hline & $\mathrm{NaCl}$ & $4.38 \mathrm{~g}$ \\
\hline & EDTA & $0.009 \mathrm{~g}$ \\
\hline & DTT & $0.039 \mathrm{~g}$ \\
\hline & Glycerol & $25 \mathrm{ml}$ \\
\hline & \multicolumn{2}{|r|}{$\rightarrow$ Fill to $250 \mathrm{ml}$ with $\mathrm{ddH}_{2} \mathrm{O}$} \\
\hline \multirow{6}{*}{ Hypotonic buffer } & HEPES & $0.596 \mathrm{~g}$ \\
\hline & $\mathrm{KCl}$ & $0.186 \mathrm{~g}$ \\
\hline & $\mathrm{MgCl}_{2}$ & $0.102 \mathrm{~g}$ \\
\hline & EDTA & $0.009 \mathrm{~g}$ \\
\hline & DTT & $0.039 \mathrm{~g}$ \\
\hline & \multicolumn{2}{|r|}{$\rightarrow$ Fill to $250 \mathrm{ml}$ with $\mathrm{ddH}_{2} \mathrm{O}$} \\
\hline \multirow{3}{*}{ Lysis buffer } & Bäuerle buffer & $750 \mu 1$ \\
\hline & Proteinase inhibitor (10x) & $150 \mu \mathrm{l}$ \\
\hline & Phosphatase inhibitor (10x) & $100 \mu \mathrm{l}$ \\
\hline \multicolumn{3}{|c|}{ Chromatin immunoprecipitation } \\
\hline \multirow{7}{*}{ ChIP Wash buffer } & $\mathrm{LiCl} 8 \mathrm{M}$ & $15.625 \mathrm{ml}$ \\
\hline & EDTA pH 8.0, 0.5 M & $10 \mathrm{ml}$ \\
\hline & Tris $\mathrm{HCl} \mathrm{pH} 8.5,1 \mathrm{M}$ & $25 \mathrm{ml}$ \\
\hline & NP-40 10\% & $25 \mathrm{ml}$ \\
\hline & $\mathrm{NaF} 0.5 \mathrm{M}$ & $10 \mathrm{ml}$ \\
\hline & Sodium deoxycholate $10 \%$ & $25 \mathrm{ml}$ \\
\hline & \multicolumn{2}{|r|}{$\rightarrow$ Fill to $250 \mathrm{ml}$ with $\mathrm{ddH}_{2} \mathrm{O}$} \\
\hline \multirow{7}{*}{ Dilution buffer } & $\mathrm{NaCl} 5 \mathrm{M}$ & $7.5 \mathrm{ml}$ \\
\hline & EDTA pH 8.0, 0.5 M & $10 \mathrm{ml}$ \\
\hline & Tris $\mathrm{HCl} \mathrm{pH} 8,1 \mathrm{M}$ & $12.5 \mathrm{ml}$ \\
\hline & NP-40 10\% & $25 \mathrm{ml}$ \\
\hline & $\mathrm{NaF} 0.5 \mathrm{M}$ & $10 \mathrm{ml}$ \\
\hline & Sodium deoxycholate $10 \%$ & $12.5 \mathrm{ml}$ \\
\hline & \multicolumn{2}{|r|}{$\rightarrow$ Fill to $250 \mathrm{ml}$ with $\mathrm{ddH}_{2} \mathrm{O}$} \\
\hline \multirow{3}{*}{ IP buffer } & $\mathrm{NaCl} 5 \mathrm{M}$ & $7.5 \mathrm{ml}$ \\
\hline & EDTA pH 8.0, 0.5 M & $10 \mathrm{ml}$ \\
\hline & Tris $\mathrm{HCl} \mathrm{pH} 8,1 \mathrm{M}$ & $12.5 \mathrm{ml}$ \\
\hline
\end{tabular}




\begin{tabular}{|c|c|c|}
\hline Buffer & Ingredient & Amount \\
\hline & NP-40 10\% & $25 \mathrm{ml}$ \\
\hline & $\mathrm{NaF} 0.5 \mathrm{M}$ & $10 \mathrm{ml}$ \\
\hline & Sodium deoxycholate $10 \%$ & $12.5 \mathrm{ml}$ \\
\hline & SDS $10 \%$ & $2.5 \mathrm{ml}$ \\
\hline & & $\rightarrow$ Fill to $250 \mathrm{ml}$ with $\mathrm{ddH}_{2} \mathrm{O}$ \\
\hline \multirow{7}{*}{ Nuclear preparation buffer } & $\mathrm{NaCl} 5 \mathrm{M}$ & $3 \mathrm{ml}$ \\
\hline & EDTA pH 8.0, 0.5 M & $4 \mathrm{ml}$ \\
\hline & Tris $\mathrm{pH} 7.5,1 \mathrm{M}$ & $5 \mathrm{ml}$ \\
\hline & NP-40 10\% & $5 \mathrm{ml}$ \\
\hline & Triton-X-100 10\% & $10 \mathrm{ml}$ \\
\hline & $\mathrm{NaF} 0.5 \mathrm{M}$ & $4 \mathrm{ml}$ \\
\hline & \multicolumn{2}{|r|}{$\rightarrow$ Fill to $100 \mathrm{ml}$ with $\mathrm{ddH}_{2} \mathrm{O}$} \\
\hline \multirow{4}{*}{ Sonication buffer-1 } & EDTA pH 8.0, 0.5 M & $0.1 \mathrm{ml}$ \\
\hline & Tris $\mathrm{HCl} \mathrm{pH} 8,1 \mathrm{M}$ & $0.25 \mathrm{ml}$ \\
\hline & SDS $10 \%$ & $0.5 \mathrm{ml}$ \\
\hline & \multicolumn{2}{|r|}{$\rightarrow$ Fill to $5 \mathrm{ml}$ with $\mathrm{ddH}_{2} \mathrm{C}$} \\
\hline \multirow{6}{*}{ Sonication buffer- 2} & $\mathrm{NaCl} 5 \mathrm{M}$ & $6 \mathrm{ml}$ \\
\hline & EDTA pH 8.0, 0.5 M & $8 \mathrm{ml}$ \\
\hline & Tris $\mathrm{HCl} \mathrm{pH} 8,1 \mathrm{M}$ & $10 \mathrm{ml}$ \\
\hline & NP-40 10\% & $20 \mathrm{ml}$ \\
\hline & $\mathrm{NaF} 0.5 \mathrm{M}$ & $8 \mathrm{ml}$ \\
\hline & \multicolumn{2}{|r|}{$\rightarrow$ Fill to $100 \mathrm{ml}$ with $\mathrm{ddH}_{2} \mathrm{O}$} \\
\hline \multirow{3}{*}{ TE buffer } & Tris $\mathrm{HCl} \mathrm{pH} 8.0,1 \mathrm{M}$ & $2.5 \mathrm{ml}$ \\
\hline & EDTA pH 8.0, 0.5 M & $0.5 \mathrm{ml}$ \\
\hline & \multicolumn{2}{|r|}{$\rightarrow$ Fill to $250 \mathrm{ml}$ with dd $\mathrm{H}_{2} \mathrm{O}$} \\
\hline \multicolumn{3}{|c|}{ FACS buffer } \\
\hline \multirow{2}{*}{ Blocking buffer } & BSA & $5-10 \%$ \\
\hline & \multicolumn{2}{|r|}{$\rightarrow$ Dissolved in PBS } \\
\hline \multirow{2}{*}{ Nuclear staining buffer } & Hoechst & $5 \mu \mathrm{g} / \mathrm{ml}$ \\
\hline & \multicolumn{2}{|r|}{$\rightarrow$ Dissolved in blocking buffe } \\
\hline \multicolumn{3}{|c|}{ Immunofluorescence staining } \\
\hline \multirow[t]{3}{*}{ Permeabilization buffer } & BSA & $0.2 \%$ \\
\hline & Triton X 100 & $0.3 \%$ \\
\hline & \multicolumn{2}{|r|}{$\rightarrow$ Dissolved in PBS } \\
\hline \multirow[t]{3}{*}{ Blocking solution } & BSA & $5 \%$ \\
\hline & Triton X 100 & $0.1 \%$ \\
\hline & \multicolumn{2}{|r|}{$\rightarrow$ Dissolved in PBS } \\
\hline Antibody solution & BSA & $2 \%$ \\
\hline
\end{tabular}




\begin{tabular}{|c|c|c|}
\hline Buffer & Ingredient & Amount \\
\hline & Triton X 100 & $0.1 \%$ \\
\hline & \multicolumn{2}{|r|}{$\rightarrow$ Dissolved in PBS } \\
\hline \multirow{4}{*}{$\begin{array}{l}\text { Phosphate buffered saline (PBS), } \\
\text { pH 7.4 }\end{array}$} & $\mathrm{KH}_{2} \mathrm{PO}_{4}$ & $0,15 \mathrm{mmol} / \mathrm{L}$ \\
\hline & $\mathrm{Na}_{2} \mathrm{HPO}_{4}$ X $2 \mathrm{H}_{2} \mathrm{O}$ & $0,81 \mathrm{mmol} / \mathrm{L}$ \\
\hline & $\mathrm{KCl}$ & $0,27 \mathrm{mmol} / \mathrm{L}$ \\
\hline & $\mathrm{NaCl}$ & $24 \mathrm{mmol} / \mathrm{L}$ \\
\hline \multirow[t]{2}{*}{ Nuclear staining buffer } & Hoechst $(1 \mathrm{mg} / \mathrm{ml})$ & $1: 1000$ \\
\hline & \multicolumn{2}{|r|}{$\rightarrow$ Dissolved in antibody solutior } \\
\hline \multicolumn{3}{|c|}{ Lagendorff perfusion } \\
\hline \multicolumn{3}{|c|}{ 10x Perfusion Buffer (Stock) } \\
\hline $\mathrm{NaCl}$ & $120.4 \mathrm{mM}$ & $70.3 \mathrm{~g}$ \\
\hline $\mathrm{KCl}$ & $14.7 \mathrm{mM}$ & $11 \mathrm{~g}$ \\
\hline $\mathrm{KH}_{2} \mathrm{PO}_{4}$ & $0.6 \mathrm{mM}$ & $0.82 \mathrm{~g}$ \\
\hline $\mathrm{Na}_{2} \mathrm{HPO}_{4}-2 \mathrm{H}_{2} \mathrm{O}$ & $0.6 \mathrm{mM}$ & $1.1 \mathrm{~g}$ \\
\hline $\mathrm{MgSO}_{4}-7 \mathrm{H}_{2} \mathrm{O}$ & $1.2 \mathrm{mM}$ & $3 \mathrm{~g}$ \\
\hline HEPES & $10 \mathrm{mM}$ & $23.83 \mathrm{~g}$ \\
\hline \multicolumn{3}{|r|}{$\rightarrow$ Add $\mathrm{ddH}_{2} \mathrm{O}$ to $1 \mathrm{~L}$} \\
\hline \multicolumn{3}{|c|}{ 1x Perfusion Buffer } \\
\hline $\mathrm{NaHCO}_{3}$ & $4.6 \mathrm{mM}$ & $0.195 \mathrm{~g}$ \\
\hline Taurin & $30 \mathrm{mM}$ & $1.875 \mathrm{~g}$ \\
\hline Butanediome monoxime & $10 \mathrm{mM}$ & $0.5 \mathrm{~g}$ \\
\hline Glucose & $5.5 \mathrm{mM}$ & $0.5 \mathrm{~g}$ \\
\hline 10x Perfusion Buffer & & $50 \mathrm{ml}$ \\
\hline \multicolumn{3}{|r|}{$\rightarrow$ Add dd $\mathrm{H}_{2} 0$ to $500 \mathrm{~m}$} \\
\hline \multicolumn{3}{|c|}{ Digestion Buffer } \\
\hline Collagenase B & $2 \mathrm{mg} / \mathrm{ml}$ & $0.1 \mathrm{~g}(1 \mathrm{vial})$ \\
\hline $\mathrm{CaCl}_{2}$ & $40 \mu \mathrm{M}$ & $20 \mu 1$ \\
\hline \multicolumn{3}{|c|}{$\rightarrow$ Add to $50 \mathrm{ml}$ with $1 \mathrm{x}$ Perfusion Buffer } \\
\hline \multicolumn{3}{|c|}{ Stopping Buffer } \\
\hline FBS & $10 \%$ & $5 \mathrm{ml}$ \\
\hline $\mathrm{CaCl}_{2}$ & $12.5(100 / 400 / 900) \mu \mathrm{M}$ & $6.25 \mu \mathrm{l}(+50 /+200 /+450 \mu \mathrm{l})$ \\
\hline \multicolumn{3}{|c|}{$\rightarrow$ Add to $50 \mathrm{ml}$ with $1 \mathrm{x}$ Perfusion Buffer } \\
\hline \multicolumn{3}{|c|}{ Polyacrylamide gel electrophoresis } \\
\hline \multirow{5}{*}{ Separating gel $(12 \%, 2 \mathrm{x})$} & $\mathrm{ddH}_{2} \mathrm{O}$ & $3.3 \mathrm{ml}$ \\
\hline & Acrylamide $30 \%$ & $4.0 \mathrm{ml}$ \\
\hline & Tris $1.5 \mathrm{M}, \mathrm{pH} 8.8$ & $2.5 \mathrm{ml}$ \\
\hline & SDS $10 \%$ & $0.1 \mathrm{ml}$ \\
\hline & APS $10 \%$ & $0.1 \mathrm{ml}$ \\
\hline
\end{tabular}




\begin{tabular}{|c|c|c|}
\hline Buffer & Ingredient & Amount \\
\hline & TEMED & $0.004 \mathrm{ml}$ \\
\hline \multirow{6}{*}{ Stacking gel $(6 \%, 2 \mathrm{x})$} & $\mathrm{ddH}_{2} \mathrm{O}$ & $2.8 \mathrm{ml}$ \\
\hline & Acrylamide $30 \%$ & $0.85 \mathrm{ml}$ \\
\hline & Tris $0.5 \mathrm{M}$, pH 6.8 & $1.25 \mathrm{ml}$ \\
\hline & SDS $10 \%$ & $0.05 \mathrm{ml}$ \\
\hline & APS $10 \%$ & $0.05 \mathrm{ml}$ \\
\hline & TEMED & $0.005 \mathrm{ml}$ \\
\hline \multirow{4}{*}{ Running buffer (10x) } & Tris base & $30.3 \mathrm{~g}$ \\
\hline & Glycine & $144 \mathrm{~g}$ \\
\hline & SDS & $10 \mathrm{~g}$ \\
\hline & \multicolumn{2}{|r|}{$\rightarrow$ Fill to $1 \mathrm{~L}$ with $\mathrm{ddd}_{2} \mathrm{O}$} \\
\hline \multicolumn{3}{|c|}{ Protein quantification } \\
\hline \multirow{2}{*}{ Bradford reagent } & RotiQuant & $53.3 \mu \mathrm{l}$ \\
\hline & Sterile water & $146.7 \mu \mathrm{l}$ \\
\hline \multicolumn{3}{|c|}{ Western blot } \\
\hline \multirow{2}{*}{ Ponceau S solution } & Ponceau S & $0.1 \%$ \\
\hline & acetic acid & $0.5 \%$ \\
\hline \multirow{2}{*}{ Blocking solution } & Milk, non-fatty dried & $5 \%$ \\
\hline & \multicolumn{2}{|r|}{$\rightarrow$ Dissolved in TBST } \\
\hline \multirow{5}{*}{ Laemmli buffer (6x) } & Tris pH 6.8 & $0.35 \mathrm{~mol} / \mathrm{L}$ \\
\hline & Glycerol & $30 \%$ \\
\hline & SDS & $10 \%$ \\
\hline & Dithiotreit (DTT) & $9.3 \%$ \\
\hline & Bromphenol blue & $0.02 \%$ \\
\hline \multirow{4}{*}{ Transfer buffer (10x) } & Tris base & $75.6 \mathrm{~g}$ \\
\hline & Glycine & $74.4 \mathrm{~g}$ \\
\hline & SDS & $15 \mathrm{~g}$ \\
\hline & \multicolumn{2}{|r|}{$\rightarrow$ Fill to $1 \mathrm{~L}$ with $\mathrm{ddH}_{2} \mathrm{O}$} \\
\hline \multirow{3}{*}{ Transfer buffer $(1 \mathrm{x})$} & Transfer buffer (10x) & $10 \mathrm{ml}$ \\
\hline & Methanol & $20 \mathrm{ml}$ \\
\hline & \multicolumn{2}{|r|}{$\rightarrow$ Fill to $100 \mathrm{ml}$ with $\mathrm{ddH}_{2} \mathrm{O}$} \\
\hline \multirow{4}{*}{ TBST } & Tris/HCl 1 M, pH 7.6 & $20 \mathrm{ml}$ \\
\hline & $\mathrm{NaCl} 5 \mathrm{M}$ & $33 \mathrm{ml}$ \\
\hline & Tween 20 & \\
\hline & \multicolumn{2}{|r|}{$\rightarrow$ Fill to $1 \mathrm{~L}$ with $\mathrm{ddH}_{2} \mathrm{O}$} \\
\hline
\end{tabular}




\subsubsection{Inhibitors}

\begin{tabular}{|c|c|c|}
\hline Inhibitor & Concentration / Dilution & Manufacturer \\
\hline \multicolumn{3}{|c|}{ ChIP } \\
\hline Aprotinin / leupeptin & $1 \mu \mathrm{g} / \mathrm{mL}(1: 1000)$ & Roche \\
\hline$\beta$-glycerophosphate & 10 mM (1:100) & Roth \\
\hline Indole acetamide & $10 \mu \mathrm{M}(1: 10000)$ & Sigma \\
\hline N-Ethyl Maleimide & $1 \mathrm{mM}(1: 100)$ & Sigma \\
\hline $\mathrm{NiCl}_{2} \times 6 \mathrm{H}_{2} \mathrm{O}$ & $1 \mathrm{mM}(1: 1000)$ & Roth \\
\hline Pefablock & $1 \mathrm{mM}(1: 100)$ & Roth \\
\hline \multicolumn{3}{|c|}{ Protein lysis } \\
\hline $\begin{array}{l}\text { PhosSTOP Phosphatase Inhibitor } \\
\text { Cocktail }\end{array}$ & 1 tablet / $1 \mathrm{ml}(1: 10)$ & Roche \\
\hline $\begin{array}{l}\text { Protease Inhibitor Cocktail, } \\
\text { Complete Mini EDTA free }\end{array}$ & 1 tablet / $1.5 \mathrm{ml}(1: 10)$ & Roche \\
\hline
\end{tabular}

\subsubsection{Kits}

\begin{tabular}{|c|c|c|}
\hline Method & Kit type & Manufacturer \\
\hline DNA isolation & NucleoSpin $®$ Tissue & Macherey-Nagel \\
\hline Electroporation & Amaxa ${ }^{\circledR}$ Nucleofector $®$ Technology & Lonza \\
\hline \multirow{2}{*}{ ELISA kit } & Human IGFBP-5 ELISA Kit & Sigma \\
\hline & Mouse IGFBP-5 ELISA Kit & Sigma \\
\hline Gel extraction \& PCR clean-up & NucleoSpin ${ }^{\circledR}$ Gel and PCR Clean-up & Macherey-Nagel \\
\hline Lentivirus isolation & $\begin{array}{l}\text { Vivapure }^{\mathrm{TM}} \text { LentiSELECT } 40 \text { Purification } \\
\text { and Concentration Kit }\end{array}$ & Sartorius \\
\hline Luciferase assay & Dual-Luciferase ${ }^{\circledR}$ Reporter Assay System & Promega \\
\hline Nonatal cell isolation & Neonatal Heart Dissociation Kit mouse\&rat & Miltenyi Biotec \\
\hline Plasmid isolation (Mini) & NucleoSpin $®$ Plasmid (NoLid) & Macherey-Nagel \\
\hline Plasmid isolation (Midi) & NucleoBond® Xtra Midi & Macherey-Nagel \\
\hline RNA isolation & NucleoSpin $\circledR_{\text {RNA }}$ & Macherey-Nagel \\
\hline
\end{tabular}

\subsubsection{Enzymes and supplemented buffers}

\begin{tabular}{|l|l|l|}
\hline \multicolumn{1}{|c|}{ Method } & \multicolumn{1}{|c|}{ Substance / Enzyme } & \multicolumn{1}{|c|}{ Manufacturer } \\
\hline \multirow{3}{*}{ Dephosphorylation } & $\begin{array}{l}\text { Fast AP Thermosensitive Alkaline Phosphatase } \\
1 \mathrm{U} / \mu \mathrm{L}\end{array}$ & \multirow{2}{*}{ Thermo Scientific } \\
\cline { 2 - 3 } & $10 \mathrm{x}$ reaction buffer for AP & Thermo Scientific \\
\hline DNAse & 20000 units & \multirow{2}{*}{ Thermo Scientific } \\
\hline \multirow{2}{*}{ Ligation } & T4 DNA Ligase $5 \mathrm{U} / \mu \mathrm{L}$ & \multirow{2}{*}{ Thermo Scientific } \\
\hline \multirow{2}{*}{ PCR } & $10 \mathrm{x}$ T4 DNA Ligase buffer & \\
\hline
\end{tabular}




\begin{tabular}{|c|c|c|}
\hline & & \multirow{4}{*}{ Applied Biosystems } \\
\hline & AmpliTaq & \\
\hline & 10X PCR Buffer & \\
\hline & $\mathrm{MgCl}_{2}$ Solution & \\
\hline \multirow{2}{*}{ qPCR } & GoTaq® qPCR MasterMix 2x & \multirow{2}{*}{ Promega } \\
\hline & CXR Reference Dye & \\
\hline \multirow{2}{*}{ Restriction digest } & Fast Digest Enzymes & \multirow{2}{*}{ Thermo Scientific } \\
\hline & 10x Fast Digest Green buffer & \\
\hline \multirow{2}{*}{ Reverse transcription } & M-MLV RT 5x Buffer & \multirow{2}{*}{ Promega } \\
\hline & M-MLV Reverse Transcriptase $200 \mathrm{U} / \mu \mathrm{L}$ & \\
\hline
\end{tabular}

\subsubsection{Ladder}

\begin{tabular}{|l|l|l|}
\hline \multicolumn{1}{|c|}{ Ladder type } & \multicolumn{1}{|c|}{ Type } & \multicolumn{1}{|c|}{ Manufacturer } \\
\hline \multirow{4}{*}{ DNA ladder } & GeneRuler 100 bp DNA Ladder & \multirow{2}{*}{ Thermo Scientific } \\
\cline { 2 - 2 } & GeneRuler 1 kb DNA Ladder & \\
\cline { 2 - 3 } & MassRuler DNA Ladder Mix & \\
\cline { 2 - 3 } & 6x Loading Dye & Thermo Scientific \\
\hline Protein ladder & Spectra Multicolor Broad Range Protein Ladder & \\
\hline
\end{tabular}

\subsubsection{Antibodies}

\begin{tabular}{|c|c|c|c|c|c|c|}
\hline \multirow{2}{*}{ Antibody target } & \multirow{2}{*}{ Species } & \multirow{2}{*}{ Company } & \multicolumn{4}{|c|}{ Dilution } \\
\hline & & & WB & IF & ChIP & FACS \\
\hline anti- $\alpha$-Actinin & $\mathrm{ms}$ & Sigma & - & $1: 500$ & - & - \\
\hline anti- $\alpha$-Smooth muscle actin & $\mathrm{ms}$ & Sigma & - & $1: 500$ & - & - \\
\hline anti- $\alpha$-Tubulin & $\mathrm{ms}$ & Sigma & $1: 3000$ & - & - & - \\
\hline anti-cardiac troponin $\mathrm{T}$ & $\mathrm{ms}$ & Abcam & $1: 1000$ & $1: 200$ & - & - \\
\hline anti-Connexin43 & $\mathrm{rb}$ & Sigma & - & $1: 200$ & - & - \\
\hline anti-FLAG M2 & $\mathrm{ms}$ & Sigma & $1: 1000$ & $1: 200$ & - & - \\
\hline anti-FLAG & $\mathrm{rb}$ & Sigma & $1: 1000$ & - & $2 \mu \mathrm{g}$ & - \\
\hline anti-IGFBP5 & $\mathrm{rb}$ & $\begin{array}{l}\text { Sigma / } \\
\text { customized }\end{array}$ & $1: 500$ & $1: 50$ & $2 \mu \mathrm{g}$ & - \\
\hline anti-Ncadherin & $\mathrm{rb}$ & Santa Cruz & - & $1: 100$ & - & - \\
\hline anti-NKX2.5 & $\mathrm{ms}$ & abcam & $1: 1000$ & - & - & - \\
\hline $\begin{array}{l}\text { anti-OCT3/4 } \\
\text { (Alexa Fluor 647) }\end{array}$ & $\mathrm{ms}$ & $\begin{array}{l}\text { BD } \\
\text { Biosiences }\end{array}$ & - & - & - & $1: 100$ \\
\hline anti-TBX5 & $\mathrm{rb}$ & Millipore & $1: 1000$ & $1: 20$ & - & - \\
\hline $\begin{array}{l}\text { anti-TRA-1-60 } \\
\text { (Alexa Fluor 647) }\end{array}$ & $\mathrm{ms}$ & $\begin{array}{l}\text { BD } \\
\text { Biosiences }\end{array}$ & - & - & - & $1: 100$ \\
\hline anti-TPT1 & $\mathrm{ms}$ & Sigma & $1: 1000$ & - & - & - \\
\hline normal mouse $\mathrm{IgG}_{1}$ & $\mathrm{~ms}$ & Santa Cruz & - & $1: 200$ & - & - \\
\hline normal rabbit IgG & $\mathrm{rb}$ & Santa Cruz & - & $1: 500$ & $2 \mu \mathrm{g}$ & - \\
\hline
\end{tabular}




\begin{tabular}{|l|l|l|l|l|l|}
\hline \multicolumn{7}{|c|}{ Secondary Antibodies } \\
\hline anti-ms-Alexa Fluor 488 & goat & Invitrogen & - & $1: 200$ & - \\
\hline anti-ms-Alexa Fluor 494 & goat & Invitrogen & - & $1: 200$ & - \\
\hline anti-rb-Alexa Fluor 488 & goat & Invitrogen & - & $1: 200$ & - \\
\hline anti-rb-Alexa Fluor 494 & goat & Invitrogen & - & $1: 200$ & - \\
\hline HRP conjug. anti-mouse-IgG & rb & Dako & $1: 10000$ & - & - \\
\hline HRP conjug. anti-rabbit-IgG & goat & Dako & $1: 5000$ & - & - \\
\hline
\end{tabular}

\subsubsection{Plasmids}

\begin{tabular}{|c|c|c|}
\hline Name & Insert / utilization & Source \\
\hline pcDNA3.1 & puromycin resistance & own production \\
\hline pcDNA3.1-hIGFBP5-FLAG-Puro & $\begin{array}{l}\text { C-FLAG-hIGFBP5, puromycin } \\
\text { resistance / OE vector }\end{array}$ & own production \\
\hline pds-hTnnT-rluc & $\begin{array}{l}\text { Luciferase reporter / OE vector for } \\
\text { AAV9 production }\end{array}$ & $\begin{array}{l}\text { Prof. Mueller, Klinik } \\
\text { Innere Medizin III, } \\
\text { Kiel }\end{array}$ \\
\hline pds-hTnnT-msIgfbp5-FLAG & $\begin{array}{l}\text { ms-Igfbp5-FLAG insert, removed } \\
\text { luciferase reporter / OE vector for } \\
\text { AAV9 production }\end{array}$ & own production \\
\hline pEXPR-221-EF1a-eGFP & eGFP / OE vector & $\begin{array}{l}\text { Dr. A. Rhoa, } \\
\text { Phamakologie } \\
\text { Goettingen }\end{array}$ \\
\hline pEXP-221-EF1a-hNKX2.5 & hNKX2.5 insert / OE vector & $\begin{array}{l}\text { Dr. A. Rhoa, } \\
\text { Phamakologie } \\
\text { Goettingen }\end{array}$ \\
\hline pGIPZ & $\begin{array}{l}\text { eGFP /IRES/puromycin resistance / OE } \\
\text { vector for lentivirus production }\end{array}$ & Thermo Scientific \\
\hline pGIPZ-hIGFBP5-FLAG & $\begin{array}{l}\text { C-FLAG-hIGFBP5, removed eGFP, } \\
\text { IRES, puromycin resistance / vector for } \\
\text { lentivirus production }\end{array}$ & own production \\
\hline pGL4.10 & firefly luciferase CDS / reporter vector & Promega \\
\hline pGL4.10-hIGFBP5 & $\begin{array}{l}\text { hIGFBP5 ChIP peak with firefly } \\
\text { luciferase CDS }\end{array}$ & own production \\
\hline pGL4.10- hTNNT2 & $\begin{array}{l}\text { hTNNT2 ChIP peak, firefly luciferase } \\
\text { CDS / reporter vector }\end{array}$ & own production \\
\hline pMD2.G & $\begin{array}{l}\text { Vector encoding lentivirus envelope } \\
\text { proteins / lentivirus production }\end{array}$ & $\begin{array}{l}\text { Addgene } 12259 \text { Lab of } \\
\text { Didié Trono }\end{array}$ \\
\hline psPAX2 & $\begin{array}{l}\text { Lentiviral packaging plasmid / lentivirus } \\
\text { production }\end{array}$ & $\begin{array}{l}\text { Addgene } 12260 \text { Lab of } \\
\text { Didié Trono }\end{array}$ \\
\hline $\mathrm{pRL}$ & Renilla luciferase CDS / reporter vector & $\begin{array}{l}\text { Dr. J.C. Gross, Dev. } \\
\text { Biochemistry, } \\
\text { Goettingen }\end{array}$ \\
\hline pX335A-hCas9-D10A & Human CAS9 nickase / OE vector & $\begin{array}{l}\text { Prof. Greber, MPI } \\
\text { Münster }\end{array}$ \\
\hline $\begin{array}{l}\text { pX335A-hCas9-D10A-hIGFBP5- } \\
\text { gRNAs }\end{array}$ & $\begin{array}{l}4 \text { different vectors with hIGFBP5 } \\
\text { targeting gRNAs, hCAS9 nickase / OE } \\
\text { vector }\end{array}$ & own production \\
\hline
\end{tabular}




\subsubsection{Oligonucleotides}

\subsubsection{Primers for ChIP peaks}

\begin{tabular}{|l|l|l|l|}
\hline \multicolumn{1}{|c|}{ Primer name } & \multicolumn{1}{|c|}{ Sequence $\mathbf{5}^{\mathbf{6}} \rightarrow \mathbf{3}^{\mathbf{6}}$} & Product size \\
\hline \multirow{2}{*}{$\begin{array}{l}\text { hIGFBP5 ChIP peak } \\
\text { (promoter region) }\end{array}$} & fwd & GCTCCAATTCCGGGGTGCA & $980 \mathrm{bp}$ \\
\cline { 2 - 5 } $\begin{array}{l}\text { hTNNT2 ChIP peak } \\
\text { promoter region) }\end{array}$ & fwd & CCTGCACATCTGGTCGTTCT & $1372 \mathrm{bp}$ \\
\cline { 2 - 4 } & rev & AGTGCATGTGCATGGTCAGA & \\
\hline
\end{tabular}

\subsubsection{Primers for CRISPR approach}

\begin{tabular}{|c|c|c|c|}
\hline Primer name & & Sequence $5^{6} \rightarrow 3^{6}$ & Product size \\
\hline \multicolumn{4}{|c|}{ gRNA cloning primers (gRNA pair \#1) } \\
\hline \multirow{2}{*}{ gRNA-pair \#1-1 } & fwd & CACCGGGCTGGGGTGCCTGCGAGC & \multirow{2}{*}{ l } \\
\hline & rev & AAACGCTCGCAGGCACCCCAGCCC & \\
\hline \multirow{2}{*}{ gRNA-pair \#1-2 } & fwd & CACCGTCTACATTTTTGCAAGTGTC & \multirow{2}{*}{ I } \\
\hline & rev & AAACGACACTTGCAAAAATGTAGAC & \\
\hline \multicolumn{4}{|c|}{ gRNA cloning primers (gRNA pair \#2) } \\
\hline \multirow{2}{*}{ gRNA-pair \#2-1 } & fwd & CACCGGAGAGGGCTTTCTCGTCGC & \multirow{2}{*}{ l } \\
\hline & rev & AAACGCGACGAGAAAGCCСТCTCC & \\
\hline \multirow{2}{*}{ gRNA-pair \#2-2 } & fwd & CACCGCCTGGGCTGCGAGCTGGTCA & \multirow{2}{*}{ / } \\
\hline & rev & AAACTGACCAGCTCGCAGCCCAGGC & \\
\hline \multicolumn{4}{|c|}{ Plasmid sequencing primers } \\
\hline \multirow{2}{*}{ gRNA SeqRev } & fwd & Forward gRNA oligo & \multirow{2}{*}{$182 \mathrm{bp}$} \\
\hline & rev & CTCTAGAGCCATTTGTCTGCAG & \\
\hline \multicolumn{4}{|c|}{ Genotyping primers for $\mathrm{c}$} \\
\hline \multirow{2}{*}{ hIBP5-geno-II } & fwd & TTTCTCCGGCCTCCGCTCA & \multirow{2}{*}{499 bp } \\
\hline & rev & GGAACAAAAAGGGGGAAAAAAGC & \\
\hline \multicolumn{4}{|c|}{ Genotyping primers for cDNA } \\
\hline \multirow{2}{*}{ cDNA-geno } & fwd & ATGGTGTTGCTCACCGCGG & \multirow{2}{*}{892 bp } \\
\hline & rev & ATTGTGACCGCAAAGGATTC & \\
\hline
\end{tabular}

\subsubsection{3 qPCR primers}

\begin{tabular}{|c|c|c|c|}
\hline Gene & & Sequence $5^{6} \rightarrow 3^{6}$ & Fragment size \\
\hline \multicolumn{4}{|c|}{ Mouse primer } \\
\hline \multirow{2}{*}{ ms-Gapdh } & fwd & ATGTTCCAGTATGACTCCACTCACG & \multirow{2}{*}{$171 \mathrm{bp}$} \\
\hline & rev & GAAGACACCAGTAGACTCCACGACA & \\
\hline \multirow{2}{*}{ ms-Igfbp3 } & fwd & AGATGCTCCGTGCCACATAA & \multirow{2}{*}{$170 \mathrm{bp}$} \\
\hline & rev & GTGAGTTAGGGGGCAGATGG & \\
\hline \multirow{2}{*}{ ms-Igfbp5 } & fwd & AGGTGGTGACAGAGCAGGTG & \multirow{2}{*}{$130 \mathrm{bp}$} \\
\hline & rev & GCCGCAGAACAGGTAAGAGG & \\
\hline
\end{tabular}




\begin{tabular}{|c|c|c|c|}
\hline \multirow{2}{*}{ ms-Igfbp5-FLAG } & fwd & CAAAGCCAGCCCACGCATGG & \multirow{2}{*}{$249 \mathrm{bp}$} \\
\hline & rev & TACTTGTCATCGTCGTCCTTGTAATC & \\
\hline \multirow{2}{*}{ ms-Mef2c } & fwd & TGATCAGCAGGCAAAGATTG & \multirow{2}{*}{$220 \mathrm{bp}$} \\
\hline & rev & ATCAGACCGCCTGTGTTACC & \\
\hline \multirow{2}{*}{ ms-Myh7 } & fwd & ATGTGCCGGACCTTGGAA & \multirow{2}{*}{$170 \mathrm{bp}$} \\
\hline & rev & CCTCGGGTTAGCTGAGAGATCA & \\
\hline \multirow{2}{*}{ ms-Myocd } & fwd & CTGTGTGGAGTCCTCAGGTCAAAC & \multirow{2}{*}{$109 \mathrm{bp}$} \\
\hline & rev & GATGTGCTGCGGGCTCTTCAG & \\
\hline \multirow{2}{*}{ ms-Nkx2.5 } & fwd & CGACAGCGGCAGGACCAGAC & \multirow{2}{*}{$133 \mathrm{bp}$} \\
\hline & rev & CGTAGGCGGGAGCGTAGGC & \\
\hline \multirow{2}{*}{ ms-Nppa } & fwd & CATCACCCTGGGCTTCTTCCT & \multirow{2}{*}{$405 \mathrm{pb}$} \\
\hline & rev & TGGGCTCCAATCCTGTCAATC & \\
\hline \multirow{2}{*}{ ms-Tbp } & fwd & CCAGAACAACAGCCTTCCACC & \multirow{2}{*}{$322 \mathrm{bp}$} \\
\hline & rev & CAACGGTGCAGTGGTCAGAGT & \\
\hline \multirow{2}{*}{ ms-Tnnt2 } & fwd & AAGCAGCAGAAATACGAAATCAACG & \multirow{2}{*}{$183 \mathrm{bp}$} \\
\hline & rev & GCCAAGGAGGACCCAGAG C & \\
\hline \multirow{2}{*}{ ms-Tpt1 } & fwd & GTTGCTCTCCTGGACTACCG & \multirow{2}{*}{$224 \mathrm{bp}$} \\
\hline & rev & AAAAACAATGCCACCACTCC & \\
\hline \multicolumn{4}{|c|}{ Human primer } \\
\hline \multirow{2}{*}{ h-ACTA2 } & fwd & GGAAAAGATCTGGCACCACTC & \multirow{2}{*}{$196 \mathrm{bp}$} \\
\hline & rev & GCGTCCAGAGGCATAGAGAG & \\
\hline \multirow{2}{*}{ h-AXIN2 } & fwd & GTGTGAGGTCCACGGAAACT & \multirow{2}{*}{$153 \mathrm{bp}$} \\
\hline & rev & AATCATCCGTCAGCGCATCA & \\
\hline \multirow{2}{*}{ h-CyclinD1 } & fwd & CCCTCGGTGTCCTACTTCAA & \multirow{2}{*}{$149 \mathrm{bp}$} \\
\hline & rev & AGGAAGCGGTCCAGGTAGTT & \\
\hline \multirow{2}{*}{ h-GAPDH } & fwd & AAGGCTGTGGGCAAGGTCATC & \multirow{2}{*}{$248 \mathrm{bp}$} \\
\hline & rev & GCGTCAAAGGTGGAGGAGTGG & \\
\hline \multirow{2}{*}{ h-GDF15 } & fwd & ACTCACGCCAGAAGTGCGG & $260 \mathrm{bn}$ \\
\hline & rev & CCGTGCGGACGAAGATTCTG & $200 \mathrm{op}$ \\
\hline h ICГDD5 & fwd & TGCACCTGAGATGAGACAGG & \\
\hline 11-IUTDTJ & rev & GAATCCTTTGCGGTCACAAT & $228 \mathrm{bp}$ \\
\hline h MYOCD & fwd & GGGTCTGAGCATTCCTTGCT & $124 \mathrm{bn}$ \\
\hline DC D & rev & CTGGACGTTTCAGTGGTGGT & $124 \mathrm{op}$ \\
\hline $\mathrm{h}_{-} \mathrm{NKX}_{2} 5$ & fwd & АCСТCAACAGCTCCCTGACTCT & $155 \mathrm{hn}$ \\
\hline$\Pi 1-N \Lambda \Lambda 2 . J$ & rev & ATAATCGCCGCCACAAACTCTCC & $135 \mathrm{op}$ \\
\hline$b_{\mathrm{SO}} \mathrm{SOY}$ & fwd & ATGCACCGCTACGACGTGA & $127 \mathrm{hn}$ \\
\hline 11-SUA2 & rev & CTTTTGCACCCCTCCCATTT & $43 / \mathrm{DP}$ \\
\hline $\mathrm{h}_{-} \mathrm{STC1}$ & fwd & CACTCAGGGAAAAGCATTCGT & $97 \mathrm{hn}$ \\
\hline 11-51-1 & rev & GAAAGTGGAGCACCTCCGAA & (1) Dp \\
\hline
\end{tabular}




\begin{tabular}{|l|l|l|l|}
\hline \multirow{2}{*}{ h-TXNIP } & fwd & CCCTGAAAAGGTGTACGGCA & \multirow{2}{*}{$210 \mathrm{bp}$} \\
\cline { 2 - 4 } & rev & TTCTCACCTGTTGGCTGGTC & \\
\hline
\end{tabular}

\subsubsection{Sequencing primers for plasmids}

\begin{tabular}{|l|l|l|}
\hline \multicolumn{1}{|c|}{ Plasmid } & \multicolumn{1}{|c|}{ Primer } & \multicolumn{1}{c|}{ Sequence $\mathbf{5}^{\mathbf{}} \rightarrow \mathbf{3}^{\mathbf{6}}$} \\
\hline \multirow{2}{*}{ pcDNA } & CMV fwd & CGCAAATGGGCGGTAGGCGTG \\
\cline { 2 - 3 } & BGH rev & TAGAAGGCACAGTCGAGG \\
\hline \multirow{2}{*}{ pGIPZ } & XL79 fwd & CGAGGTGCCCGAAGGA \\
\hline \multirow{2}{*}{ pGL4.10 } & M100 rev & CAGCGTATCCACATAGCGT \\
\hline
\end{tabular}

\subsubsection{Animals}

\begin{tabular}{|l|l|l|}
\hline \multicolumn{1}{|c|}{ Mouse strain } & \multicolumn{1}{c|}{ Age } & \multicolumn{1}{c|}{ Application } \\
\hline NMRI & $12-20$ weeks & Embryo isolation \\
\hline NMRI & $1-3$ days & Heart/cell isolation \\
\hline BL/6J & 12 weeks & TAC / Ang II / AAV9 experiments \\
\hline $\begin{array}{l}\alpha \text { Mhc-MerCreMer/ } \\
\beta \text {-catenin } \Delta \text { ex3 }\end{array}$ & $12-20$ weeks & Heart/cell isolation \\
\hline $\begin{array}{l}\alpha \text { Mhc-MerCreMer/ } \beta- \\
\text { catenin } \Delta \text { ex2-6 }\end{array}$ & $12-20$ weeks & Heart/cell isolation \\
\hline \multicolumn{3}{|c|}{ Animal approval } \\
\hline $\begin{array}{l}\text { Animal experiments were approved by the Niedersachsen (AZ-G 15-1840) } \\
\text { animal review board }\end{array}$ \\
\hline
\end{tabular}

\subsubsection{Bacteria}

\begin{tabular}{|l|l|l|}
\hline \multicolumn{1}{|c|}{ Species } & \multicolumn{1}{|c|}{ Type } & \multicolumn{1}{c|}{ Source } \\
\hline E. coli & NEB 10-beta & NEB \\
\hline E. coli & dam-/dcm- Competent E. coli & NEB \\
\hline
\end{tabular}

\subsubsection{Cell Lines}

\begin{tabular}{|l|l|l|l|}
\hline \multicolumn{1}{|c|}{ Cell type } & \multicolumn{1}{|c|}{ Abbreviation } & \multicolumn{1}{c|}{ Source } & \multicolumn{1}{c|}{ Application } \\
\hline $\begin{array}{l}\text { Human embryonic } \\
\text { stem cells with RFP } \\
\text { tag }\end{array}$ & hES2 RFP & $\begin{array}{l}\text { Kindly provided by } \\
\text { Gordon Keller [95] }\end{array}$ & $\begin{array}{l}\text { Cell line generation, cardiomyocyte } \\
\text { differentiation }\end{array}$ \\
\hline \multicolumn{3}{|c|}{ Ethical approval } \\
\hline $\begin{array}{l}\text { German Stem Cell Act by the Robert-Koch-Institute to Wolfram-H. Zimmermann, } \\
\text { permit \#12, reference number: 1710-79-1-4-16 }\end{array}$ & $\begin{array}{l}\text { Lonza, NHCF-V } \\
\text { (CC2904, \#26025) } \\
\text { Ventricular human } \\
\text { cardiac fibroblasts }\end{array}$ & hCFB & generation \\
\hline
\end{tabular}




\begin{tabular}{|c|c|c|c|}
\hline $\begin{array}{l}\text { Murine adult } \\
\text { cardiomyocytes }\end{array}$ & l & \multirow[t]{2}{*}{$\begin{array}{l}\text { Fresh isolation from } \\
\text { adult heart (post-TAC } \\
\text { or } \beta \text {-Cat GOF) }\end{array}$} & IF, RNA, WB, ELISA \\
\hline $\begin{array}{l}\text { Murine adult } \\
\text { Fibroblasts }\end{array}$ & I & & RNA \\
\hline $\begin{array}{l}\text { Murine neonatal } \\
\text { cardiomyocytes }\end{array}$ & MNCM & \multirow[t]{2}{*}{$\begin{array}{l}\text { Fresh isolation from } \\
\text { neonatal heart } \\
\text { (2-3-day old mice) }\end{array}$} & RNA \\
\hline $\begin{array}{l}\text { Murine neonatal } \\
\text { fibroblasts }\end{array}$ & MNFB & & RNA \\
\hline $\begin{array}{l}\text { Human embryonic } \\
\text { kidney SV } 40 \\
\text { transformed cells }\end{array}$ & TSA & ATCC® CRL-1573 & $\begin{array}{l}\text { Plasmid validation, virus production, } \\
\text { conditioned medium production, } \\
\text { Luciferase assay }\end{array}$ \\
\hline
\end{tabular}

\subsubsection{Chemicals}

\begin{tabular}{|c|c|}
\hline Substance & Manufacturer \\
\hline 1,4 Dithiotreit (DTT) & Roth \\
\hline Acetic Acid & Merck \\
\hline Acrylamide $30 \%$ & AppliChem \\
\hline Agarose UltraPure ${ }^{\mathrm{TM}}$ & AppliChem \\
\hline Ammonium chloride & Carl Roth \\
\hline Ammonium persulfate (APS) & Life technologies \\
\hline Ampicillin & AppliChem \\
\hline Bromophenol blue & AppliChem \\
\hline BSA (bovine serum albumin) & Sigma-Aldrich \\
\hline Bromphenol blue & Sigma Aldrich \\
\hline Butanediome monoxime & Sigma Aldrich \\
\hline Calcium chloride dihydrate & Carl Roth GmbH \& Co. KG \\
\hline Collagen & Internal production \\
\hline Collagenase & Roche \\
\hline$\beta$-Mercaptoethanol & AppliChem \\
\hline Dimethyl sulfoxide (DMSO) & AppliChem / Thermo Scientific \\
\hline dNTP PCR Nucleotide-Mix (10 mM) & Promega \\
\hline DSG (disuccinimidyl glutarate) & Thermo Scientific \\
\hline EDTA & AppliChem \\
\hline EGTA & AppliChem \\
\hline Ethanol & Carl Roth \\
\hline Ethidium bromide & Sigma \\
\hline Formaldehyde & Carl Roth \\
\hline Gelatin & Sigma-Aldrich \\
\hline
\end{tabular}




\begin{tabular}{|c|c|}
\hline Glucose & Carl Roth \\
\hline Glycerol & Gerbu \\
\hline Glycine & AppliChem \\
\hline HEPES, ultrapure & Carl Roth \\
\hline Ethanol & Carl Roth \\
\hline Ethanol molecular grade & Carl Roth \\
\hline Hydrochloric acid (HCl) $25 \%$ & Carl Roth \\
\hline L-ascorbic acid 2 phosphate sesquimagnesium (L-AAP) & Sigma \\
\hline LB Agar / LB Medium & AppliChem \\
\hline Lithium chloride & AppliChem \\
\hline Magnesium chloride & Carl Roth \\
\hline Magnesium sulfate & Carl Roth \\
\hline Methanol & Carl Roth \\
\hline Milk, non-fatty dried & Carl Roth \\
\hline Monopotassium phosphate & Merck \\
\hline Mowiol 4-88 & AppliChem \\
\hline NP-40 & Sigma \\
\hline Ponceau S & AppliChem \\
\hline Potassium bicarbonate & Carl Roth \\
\hline Potassium chloride & Carl Roth \\
\hline Potassium hydrogenphosphate & Carl Roth \\
\hline ProLong $®$ Gold antifade & Molecular Probes \\
\hline ProLong®Gold antifade with DAPI & Molecular Probes \\
\hline 2-Propanol & AppliChem \\
\hline Protein A Sepharose CL-4B & Sigma \\
\hline SDS (Sodiumdodecylsulfat) & AppliChem \\
\hline Sepharose 4B & Sigma \\
\hline Sodium citrate & Sigma \\
\hline Sodium chloride & Carl Roth \\
\hline Sodium deoxycholate & Carl Roth \\
\hline Sodium fluoride & Carl Roth \\
\hline Taurine & Sigma-Aldrich \\
\hline TEMED & AppliChem \\
\hline Tris Base, ultrapure & Carl Roth \\
\hline Tris-hydrochloride & Carl Roth \\
\hline TritonX-100 & AppliChem \\
\hline Tween-20 & Sigma-Aldrich \\
\hline
\end{tabular}




\subsection{Methods}

\subsubsection{Molecular biological methods}

\subsubsection{Polymerase chain reaction $(\mathrm{PCR})$}

To generate vector inserts (from gene cDNA sequences or genomic regions), cloning primers were designed, which flank the sequence of interest with restriction enzyme sequences found in the destination vector. For efficient PCR product digestion, additional nucleotides were added at the end of the restriction enzyme sequence. For insert amplification, the Phusion polymerase, which possesses high fidelity, was used. $100 \mathrm{ng}$ of template (plasmid) DNA were used in a total volume of $20 \mu \mathrm{l}$ reaction mixture containing $5 \mathrm{x}$ Phusion reaction buffer, $200 \mu \mathrm{M}$ dNTPs, $0.5 \mu \mathrm{M}$ of each primer and $0.01 \mathrm{U} / \mu 1$ Phusion polymerase. In addition, $3 \%$ DMSO were used to relax DNA for denaturation. To determine optimal primer annealing temperature, a gradient PCR was performed.

Table 3-1: Set up of PCR reaction

\begin{tabular}{|l|l|l|l|}
\hline \multicolumn{1}{|c|}{ Cycle step } & Temp. & Time & Cycles \\
\hline Initial denaturation & $98^{\circ} \mathrm{C}$ & $30 \mathrm{sec}$ & $1 \mathrm{x}$ \\
\hline Denaturation & $98^{\circ} \mathrm{C}$ & $10 \mathrm{sec}$ & \\
\cline { 1 - 2 } Annealing & $\mathrm{X}^{\circ} \mathrm{C}$ & $30 \mathrm{sec}$ & $35 \mathrm{x}$ \\
\hline Extension & $72^{\circ} \mathrm{C}$ & $30 \mathrm{sec}$ & \\
\hline Final extension & $72^{\circ} \mathrm{C}$ & $10 \mathrm{~min}$ & $1 \mathrm{x}$ \\
\hline & $4^{\circ} \mathrm{C}$ & Hold & \\
\hline
\end{tabular}

\subsubsection{Agarose gel electrophoresis}

Agarose gel electrophoresis was used to examine and purify PCR products. The constant charge to mass ratio of DNA allows a separation of fragments by length. By use of the intercalating agent ethidium bromide-, it is possible to visualize DNA fragments with UV light. After PCR reaction, desired PCR samples were supplemented with 6x loading dye and were loaded on a $1 \%$ agarose gel which contained $0.002 \%$ ethidium bromide. After analysis, desired fragments were extracted and purified.

\subsubsection{Gel/PCR product extraction}

To purify PCR fragments from agarose gel, the "NucleoSpin ${ }^{\circledR} \mathrm{Gel}$ and PCR Clean-up kit" from Macherey-Nagel was used according to the manufacturer's protocol. The cut gel band was mixed with binding buffer and heated to dissolve the agarose and the DNA was bound to the 
silica membrane of a NucleoSpin ${ }^{\circledR}$ Gel and PCR Clean-up Column. Contaminations were removed by different washing steps. Finally, DNA was eluted in $50 \mu 1$ water. The concentration was determined with NanoDrop spectrophotometer.

\subsubsection{Enzymatic digestion}

Restriction enzymes (endonuclease) are enzymes that produce a double-stranded cut in the DNA at, or near to, specific recognition nucleotide sequences known as restriction sites. In molecular cloning, these enzymes are used to generate "puzzle-like" fragments with blunt or sticky overhangs, which can be re-ligated using ligase enzyme. Double digestion of purified PCR product (insert) and of desired vector was performed in $20 \mu 1$ reaction mixture each, which contained $2 \mu \mathrm{l}$ of FastDigest Green Buffer, $1 \mu \mathrm{l}$ of each restriction enzyme and $1 \mu \mathrm{g}$ DNA (insert/vector). Reactions were incubated at $37^{\circ} \mathrm{C}$ for 1 hour and inactivation was performed by heating to $80^{\circ} \mathrm{C}$ for $5 \mathrm{~min}$.

\subsubsection{Vector dephosphorylation}

Dephosphorylation of 5'-phosphate groups from cloning vectors after enzymatic digestion is necessary to prevent re-circularisation during ligation step. One unit of the Fast calf-intestinal alkaline phosphatase was directly added to the inactivated digestion reaction mixture and was incubated at $37^{\circ} \mathrm{C}$ for $30 \mathrm{~min}$. Enzymatic reaction was inactivated by heating to $75^{\circ} \mathrm{C}$ for $5 \mathrm{~min}$.

\subsubsection{Ligation}

The process of ligation is used to create recombinant DNA molecules. The enzyme T4 DNA ligase joins DNA fragments together by the formation of phosphodiester bonds. The molar mass of insert should be higher than the molar mass of vector. To calculate the molar ratios the following formula was used:

$$
\text { ng of insert }=\frac{\text { ng of vector }(=50) \times \mathrm{kb} \text { size of insert }}{\mathrm{kb} \text { size of vector }} \times \text { molar ratio } \frac{\text { insert }}{\text { vector }}
$$

Digested and dephosphorylated cloning components were purified by agarose gel electrophoresis following extraction. Concentrations were determined to calculate the required amount of vector and insert DNA. Molar ratios between 1:5 to 1:10 (vector:insert) were used. $50 \mathrm{ng}$ vector and the required amount of insert were added in a total volume of $20 \mu 1$ with 10x ligation buffer and one unit T4 DNA ligase. Ligation was performed overnight at $16^{\circ} \mathrm{C}$ with an additional incubation at room temperature for two hours. 


\subsubsection{Transformation}

The uptake of exogenous genetic material by microorganisms is known as transformation. In molecular cloning this process is used to amplify genetically modified DNA. Artificial competence of $E$. coli can be induced thermic under cold conditions, before being exposed to a heat pulse (heat shock). By this process the cell membrane becomes passively permeable for DNA. Chemically competent NEB-10beta E. coli cells were used according to the manufacturer's protocol. Cells were thawed on ice and $50 \mu \mathrm{l}$ were transferred to a $1.5 \mathrm{ml}$ Eppendorf tube. 2-5 $\mu$ l of ligation mixture was added to the E. coli cells and the tube was carefully flicked 4-5 times. Mixture was placed on ice for $30 \mathrm{~min}$ and was heat shocked at $42^{\circ} \mathrm{C}$ for exactly $45 \mathrm{sec}$. After $5 \mathrm{~min}$ on ice, $450 \mu \mathrm{l}$ of room temperature SOC medium was added into the mixture and placed on a thermomixer at $37^{\circ} \mathrm{C}$ for $60 \mathrm{~min}$ and $300 \mathrm{rpm}$. 100-200 $\mu \mathrm{l}$ of transfected culture was plated on a LB-agar ampicillin selection plate $(100 \mu \mathrm{g} / \mathrm{ml}$ ampicillin) and incubated overnight at $37^{\circ} \mathrm{C}$. Colonies were picked with a sterile pipette tip and transferred to $4 \mathrm{ml}$ LB-medium supplemented with $100 \mu \mathrm{g}$ ampicillin/ml. Cultures were shaken overnight with $220 \mathrm{rpm}$ at $37^{\circ} \mathrm{C}$.

\subsubsection{Plasmid isolation (Mini Prep)}

To isolate amplified plasmids and to verify successful cloning, the "NucleoSpin ${ }^{\circledR}$ Plasmid kit" from Macherey-Nagel was used according to the manufacturer's protocol. Overnight cultures were pelleted and resuspended in supplied buffer. Plasmid DNA was released from the $E$. coli host cells by SDS/alkaline lysis. Precipitated protein, genomic DNA, and cell debris were then pelleted by a centrifugation step. The supernatant was loaded onto a NucleoSpin ${ }^{\circledR}$ Plasmid Column where plasmid DNA was bound to the silica membrane of the column. Contaminations were removed by different washing steps. Finally, plasmid DNA was eluted in $50 \mu 1$ of doubledistilled water. Concentration was determined with NanoDrop spectrophotometer. For a first verification of successful cloning, $500 \mathrm{ng}$ plasmid DNA was digested with enzymes used for cloning and was analysed by agarose gel electrophoresis.

\subsubsection{Sequencing}

After successful enzymatic digestion of cloned vectors, plasmid sequencing is required to verify error-free introduction of insert in vector backbone. Sanger DNA sequencing is performed by SEQLAB Sequence Laboratories Goettingen $\mathrm{GmbH}$, while primers from the offered "standard primer list" or the cloning primers were used for sequencing. 


\subsubsection{Plasmid isolation (Midi Prep)}

After verification by sequencing, a glycerol stock of bacteria with positive tested plasmids was prepared using $1200 \mu \mathrm{l}$ overnight culture plus $800 \mu 150 \%$ glycerol. These stocks were stored at $-80^{\circ} \mathrm{C}$. To prepare a high concentration of desired plasmid, a culture of bacteria in $3 \mathrm{ml} \mathrm{LB}-$ medium supplemented with $100 \mu \mathrm{g}$ ampicillin/ml was shacked with $220 \mathrm{rpm}$ at $37^{\circ} \mathrm{C}$ for six hours. The culture was then transferred to $250 \mathrm{ml} \mathrm{LB}$-medium supplemented with $100 \mu \mathrm{g}$ ampicillin/ml and was shacked overnight with $220 \mathrm{rpm}$ at $37^{\circ} \mathrm{C}$. To isolate amplified plasmids, the "NucleoBond ${ }^{\circledR}$ Xtra Midi kit" from Macherey-Nagel was used according to the manufacturer's protocol.

\subsubsection{DNA isolation}

Isolation of genomic DNA from human embryonic stem cell (hES) clones was done to verify a successful deletion of the sequence of interest. For this purpose, the "NucleoSpin ${ }^{\circledR}$ Tissue kit" from Macherey-Nagel was used according to the manufacturer's protocol. Cells were lysed by incubation with proteinase K/SDS solution. Appropriate conditions for binding of DNA to the silica membrane in the NucleoSpin ${ }^{\circledR}$ Tissue Columns were archived by the addition of chaotropic salts and ethanol to the lysate. The binding process is reversible and specific to nucleic acids. Contaminations were removed by subsequent washing with two different buffers. Pure genomic DNA was finally eluted in $50 \mu 1$ volume under low ionic strength conditions in an elution buffer.

\subsubsection{RNA isolation}

For isolating RNA, the "NucleoSpin ${ }^{\circledR}$ RNA kit" from Macherey-Nagel was used according to the manufacturer's protocol. Cells were scrapped and then lysed by incubation with the provided lysis buffer. Tissue samples were homogenized in lysis buffer using a bead mill for $30 \mathrm{sec}$ with $30 \mathrm{~Hz}$. Contaminating DNA was removed using provided rDNase solution directly applied onto the silica membrane during the preparation. Washing steps removed salts, metabolites and macromolecular cellular components. Pure RNA was eluted with RNase-free water.

\subsubsection{RNA sequencing}

RNA sequencing was performed at the Transcriptome and Genome Analysis Laboratory (TAL, University Medical Center, Goettingen), in biological triplicates for murine hearts and in technical triplicates for hCFBs. RNA was extracted using the "NucleoSpin ${ }^{\circledR}$ RNA kit" from Macherey-Nagel. Quality and integrity of RNA was assessed with the Fragment Analyzer from 
Advanced Analytical by using the standard sensitivity RNA Analysis Kit (DNF-471). All samples selected for sequencing exhibited an RNA integrity number over 8. RNAseq libraries were performed using a modified stranded-specific, massively-parallel cDNA sequencing (mRNAseq) protocol from Illumina, using the TruSeq stranded mRNA prep Kit. The optimized protocol included the dilution of the adapter concentration to increase the ligation efficiency (>94\%). Furthermore, a reduced number of PCR cycles was used to avoid PCR duplication artefacts as well as primer dimers in the final library product. Using a strand-specificity protocol, differences in coverage, agreement with known annotations, and accuracy for expression profiling were observed. Finally, the incorporation of dot during the second strand synthesis was done to perform total stranded RNA sequencing. For accurate quantitation of cDNA libraries, a fluorometric based system (QuantiFluor ${ }^{\mathrm{TM}}$ dsDNA System from Promega) was used. The size of final cDNA libraries was determined by using the dsDNA 905 Reagent Kit (Fragment Analyzer from Advanced Bioanalytical) exhibiting a sizing of $300 \mathrm{bp}$ in average. Libraries were pooled and sequenced on an Illumina HiSeq 4000 (Illumina) generating 50 bp single-end reads (30-40 Mio reads/sample). Sequence images were transformed with the Illumina software BaseCaller to BCL files, which was demultiplexed to fastq files with bcl2fastq v2.17.1.14. The quality check was done using FastQC (Andrews, Simon. "FastQC a quality-control tool for high-throughput sequence data", Bioinformaticsbabraham.ac. uk/projects/fastqc (2014), version 0.11.5, Babraham Bioinformatics). Sequence reads were aligned to the mouse reference assembly (UCSC version mm9) using Bowtie 2.0. [96]. For each gene, the number of mapped reads was counted and DESeq 2 was used to analyse the differential expression [97]. Gene ontology (GO) analyses were performed using default parameters and stringency in 'ClueGO': a Cytoscape plug-in [98]. The significant 'GO Biological Processes' were shown with $\mathrm{P} \leq 0.05$.

\subsubsection{Reverse transcription}

Quantitative (q)PCR was used to quantify mRNA levels. Since mRNA cannot be used as a PCR template, transcription to complementary DNA (cDNA) by reverse transcription is necessary. RNA was transcribed to cDNA using the moloney murine leukaemia virus reverse transcriptase (M-MLV RT). For amplification, an oligo(dT) 20 primer was used. This primer consists of a string of 20 desoxythymidylic acid residues that hybridizes to the poly(A) tail of mRNA. For each reaction 150-500 ng RNA was used together with $1 \mu$ l oligo(dT) $)_{20} \operatorname{primer}(500 \mathrm{ng} / \mu \mathrm{l}), 1 \mu \mathrm{l}$ dNTPs $(10 \mathrm{mM})$ and was supplemented with water to $15.5 \mu 1$. To eliminate any secondary template structures, the mixture was incubated at $65^{\circ} \mathrm{C}$ for $5 \mathrm{~min}$ and cooled down to $4^{\circ} \mathrm{C}$ to 
prevent reforming of these structures. 0.5 $\mu 1$ M-MLV RT (200 U/ $\mu 1$ ) and $4 \mu 1$ M-MLV RT 5x buffer were added to each sample. One sample was prepared without reverse transcriptase (-RT control) to determine genomic DNA contamination in isolated RNA samples. Reverse transcription was done at $42^{\circ} \mathrm{C}$ for $50 \mathrm{~min}$. The enzyme was inactivated by incubation at $70^{\circ} \mathrm{C}$ for $15 \mathrm{~min}$.

\subsubsection{Primer design}

Cloning primers were flanked with chosen restriction sites and three extra base pairs were added to ensure that the restriction enzyme cuts the site correctly. The freeware "Oligo Calc" was used to calculate corresponding oligonucleotide properties like salt adjusted melting temperature ( $\left.\mathrm{T}_{\mathrm{M}}\right)$, GC content and to verify the reverse complement strand ( $5^{\prime}$ to $3^{\prime}$ ) and self-complementary. To ensure that only the target sequence is amplified by the primers, the "Basic Local Alignment Search Tool" (BLAST) was used to predict primer binding on other potential templates. qPCR primers were designed using the Primer-BLAST tool (NCBI). Settings were adjusted to generate a qPCR product from an exon-exon junction with a size of 70-250 bp. An optimal primer melting temperature was set to $60^{\circ} \mathrm{C}$.

\subsubsection{Standard curve preparation}

There are two methods to calculate PCR based quantification of molecules; the absolute and the relative quantification. For absolute quantification using the standard curve method, a dilution series of DNA with known copy number is quantified together with the samples. For each primer pair a standard curve was prepared. For that, qPCR was run with desired primers and a cDNA template. qPCR product was controlled by melting curve analysis and gel electrophoresis with subsequent extraction and sequencing. The concentration of the qPCR product was determined and the copy number of molecules per microliter was calculated (see formula below). A dilution of the qPCR product with $10^{9}$ molecules/ $\mu 1$ in a volume of $110 \mu 1$ was prepared and a serial 1:10 dilution was done using $11 \mu \mathrm{l}$ of higher dilution, diluted in $99 \mu 1$ water. For every primer pair, standards of $10^{8}-10^{3}$ molecules/ $\mu 1$ were prepared and run in duplicates for qPCR.

$$
\text { copy number }\left(\frac{\text { molecules }}{\mu \mathrm{l}}\right)=\frac{\text { DNA concentration in } \frac{\mathrm{g}}{\mu \mathrm{l}}}{\text { DNA lenght in bp x } 660} \times 6.022 \times 10^{\wedge} 23
$$




\subsubsection{SYBR green based quantitative real time PCR}

Real-time PCR monitors the progress of DNA amplification throughout the PCR process. SYBR green dye intercalates and detects PCR products when they accumulate during PCR cycles, while the increase in fluorescence intensity increases proportional to the amount of PCR product produced. The threshold cycle $\left(\mathrm{C}_{\mathrm{t}}\right)$ is the intersection of the amplification curve to the threshold line. It is a relative measure of the concentration of target in the PCR reaction. Using a standard curve, the concentrations of the samples can be calculated. For qPCR the GoTaq ${ }^{\circledR}$ qPCR Master Mix was used which already contains the buffer with $\mathrm{MgCl}_{2}$, nucleotides and the polymerase. $5 \mu 1 \mathrm{GoTaq}^{\circledR}$ qPCR Master Mix was supplemented with $0.1 \mu \mathrm{l}$ carboxy-Xrhodamine $(\mathrm{CXR})$ reference dye, $1 \mu \mathrm{l}$ of each primer (stock concentration $3 \mu \mathrm{M}$ ) and $0.9 \mu \mathrm{l}$ RNAse-free water. $1 \mu 1$ of 1:5 diluted cDNA or of standard dilution was added to a total volume of $10 \mu \mathrm{l}$ in a 384-well plate. cDNA samples, -RT control and water control were run in triplicates, standards in duplicates. The plate was sealed, centrifuged and when needed stored for a short time at $-20^{\circ} \mathrm{C}$. Gene expression was normalized to the indicated housekeeper in every experiment. Copy numbers were calculated using the SDS2.4 software with a relative standard curve obtained using the log dilutions of cDNA of gene of interest. The thermal cycler conditions were set as follows:

Table 3-2: Set up of $q P C R$ reaction

\begin{tabular}{|l|l|l|l|}
\hline Cycle step & Temp. & Time & Cycles \\
\hline & $50^{\circ} \mathrm{C}$ & $2 \mathrm{~min}$ & $1 \mathrm{x}$ \\
\hline Initial denaturation & $95^{\circ} \mathrm{C}$ & $10 \mathrm{~min}$ & \\
\hline Denaturation & $95^{\circ} \mathrm{C}$ & $15 \mathrm{sec}$ & \multirow{2}{*}{$40 \mathrm{x}$} \\
\hline Annealing & $60^{\circ} \mathrm{C}$ & $1 \mathrm{~min}$ & \\
\hline Extension & $95^{\circ} \mathrm{C}$ & $15 \mathrm{sec}$ & \\
\hline Final extension & $60^{\circ} \mathrm{C}$ & $15 \mathrm{sec}$ & $1 \mathrm{x}$ \\
\hline Inactivation & $95^{\circ} \mathrm{C}$ & $15 \mathrm{sec}$ & \\
\hline
\end{tabular}

\subsubsection{Cell culture}

\subsubsection{Thawing, freezing and counting of cells}

All used cell types were grown in a humified incubator with $37^{\circ} \mathrm{C}$ and $5 \% \mathrm{CO}_{2}$. For the thawing process, the outer part of the frozen cell suspension in the cryovial was melted. Then, $1 \mathrm{ml}$ medium (according to cell type) was added before frozen cells were transferred and resuspended in a total volume of $10 \mathrm{ml}$ medium in a $15 \mathrm{ml}$ falcon. Cells were centrifuged at 
$300 \mathrm{x} \mathrm{g}$ for $4 \mathrm{~min}$ at $4^{\circ} \mathrm{C}$. Supernatant was removed and remaining cell pellet was resuspended in corresponding volume of medium. For freezing, cells were dissociated (according to the cell type) and were centrifuged at $300 \mathrm{x} g$ for $4 \mathrm{~min}$ at $4^{\circ} \mathrm{C}$. Supernatant was removed and remaining cell pellet was resuspended in corresponding volume of FCS supplemented with $10 \%$ DMSO (stem cells with $20 \% \mathrm{DMSO}$ ) and were frozen in $1 \mathrm{ml}$ aliquots at $-80^{\circ} \mathrm{C}$ in a freezing container. For long time storage, cells were transferred to $-152^{\circ} \mathrm{C}$. Standardized cell counting, and viability verifications were done by electrical current exclusion using the CASY ${ }^{\circledR}$ TT cell counter and analyzer system. For measurement, required cell dilution (mostly 1:500) was prepared in $10 \mathrm{ml}$ $\mathrm{CASY}^{\circledR}$ ton and was measured with the corresponding counting program.

\subsubsection{Isolation, cultivation and stimulation of murine neonatal cardiomyocytes and fibroblasts}

For isolation of murine neonatal cardiomyocytes (MNCM) and cardiac fibroblasts (NMCF), NMRI mice with large offspring numbers were used. About 50 (two- till four-day old) neonatal mice were decapitated and hearts were removed from the thorax. After collection and rinsing in ice cold PBS, vessels and atria were removed. For cell isolation, the "Neonatal Heart Dissociation Kit mouse and rat" from Miltenyi Biotec was used according to the manufactures instructions. Shortly, neonatal hearts were dissociated into single cell suspensions by combining enzymatic degradation of the extracellular matrix and mechanical dissociation with the gentleMACS ${ }^{\mathrm{TM}}$ Dissociator (difference to protocol: incubation without agitation, only two mechanical dissociation steps with ms_neonheart program, after enzymatic digestion addition of $10 \mathrm{ml}$ medium). After dissociation, the suspension was applied on a $70 \mu \mathrm{m}$ filter to remove any remaining larger particles and was centrifuged for $20 \mathrm{~min}$ with $50 \mathrm{rpm}$ at $4{ }^{\circ} \mathrm{C}$. To separate fibroblast cell fraction from cardiomyocytes, the cells were resuspended in $20 \mathrm{ml}$ cardiomyocyte medium (DMEM with $1 \mathrm{~g} / \mathrm{L}$ glucose, $3.7 \mathrm{~g} / \mathrm{L} \mathrm{NaHCO}_{3}$, without L-glutamine, $10 \%$ FCS, $1 \%$ Pen-Strep, $1 \%$ NEAA, supplemented with $100 \mu \mathrm{M}$ bromodeoxyuridine to prevent non-myocyte proliferation). Then, suspension was pre-plated on a $15 \mathrm{~cm}$ dish for $30 \mathrm{~min}$ in a humidified incubator $\left(37^{\circ} \mathrm{C}, 5 \% \mathrm{CO}_{2}\right)$. During this time the fibroblasts adhered to the cell culture dish, while cardiomyocytes mostly remained in the medium. After incubation, supernatant was removed and pre-plated again for $15 \mathrm{~min}$. Remaining fibroblasts from first preplating step were grown for one week (DMEM GlutaMAX with $1 \mathrm{~g} / \mathrm{L}$ glucose, $10 \%$ FCS, $1 \%$ Pen-Strep), whereas medium was replaced every second day. About $5 \times 10^{5}$ cardiomyocytes were cultured in $0.1 \%$ gelatin coated 12 -well plates. Medium was replaced every second day. After $48 \mathrm{~h}$, beating cardiomyocytes were stimulated with $1 \mu \mathrm{M}$ norepinephrine for $48 \mathrm{~h}$, 
whereas medium was replaced with fresh norepinephrine after $24 \mathrm{~h}$. After $48^{\circ} \mathrm{h}$, cardiomyocytes were rinsed with PBS and were processed for RNA isolation. Fibroblasts were grown till 95\% confluence and were dissociated with $4 \mathrm{ml}$ 0.05\% trypsin-EDTA. After 3-5 min incubation at $37^{\circ} \mathrm{C}$, detachment of cells was monitored under a light microscope. The enzymatic activity of trypsin was halted by addition of $8 \mathrm{ml}$ medium. Cell number and viability were measured by CASY TT system. 5 × $10^{5}$ neonatal fibroblasts were seeded in a 6-well plate and were culture for $48^{\circ} \mathrm{h}$ in a humidified incubator $\left(37^{\circ} \mathrm{C}, 5 \% \mathrm{CO} 2\right)$. Then, cells were stimulated with $1 \mu \mathrm{M}$ norepinephrine for $48 \mathrm{~h}$, whereas medium was replaced with fresh norepinephrine after $24 \mathrm{~h}$. After $48^{\circ} \mathrm{h}$, fibroblasts were rinsed with PBS and were processed for RNA isolation. For reuptake experiments, $5 \times 10^{5}$ neonatal fibroblasts were seeded in a 6-well plate and were culture for $48^{\circ} \mathrm{h}$ in a humidified incubator $\left(37^{\circ} \mathrm{C}, 5 \% \mathrm{CO}_{2}\right)$. Then, medium was replaced with fresh IGFBP5-FLAG-conditioned medium (see chapter 0 ). After $48^{\circ} \mathrm{h}$, fibroblasts were rinsed with PBS and were processed for protein isolation.

\subsubsection{Isolation and cultivation of murine adult cardiomyocytes and fibroblasts}

Heart excision was done under total anaesthesia using about $100 \mu \mathrm{l}$ of a mixture of xylazine and ketamine ( $200 \mu \mathrm{l}$ xylazine, $400 \mu \mathrm{l}$ ketamine and $400 \mu \mathrm{l}$ saline solution for $1 \mathrm{ml}$ ) which was injected intraperitoneally. Beating hearts were removed quickly by cutting across the arch of the aorta and were cleaned from blood in ice cold PBS. Then, hearts were transferred to perfusion buffer supplemented with Butanedione monoxime to arrest beating. Before perfusion, the ascending aorta was mounted on a blunted 20-gauge cannula on ice to achieve retrograde perfusion. The heart was fixed with yarn and was manually perfused with a perfusion buffer manually to control cannulation. Subsequently, the cannulated heart was transferred to the Langendorff perfusion system and was kept at $37^{\circ} \mathrm{C}$. The temperature of the perfusate was regulated via a heating coil that surrounds the perfusion tubing. Perfusion was done for $1 \mathrm{~min}$ with perfusion buffer and a flow rate of $4 \mathrm{ml} / \mathrm{min}$. To break down the extracellular matrix, perfusion was changed to enzymatic digestion buffer and was done for $8-9$ min with $0.3 \mathrm{U} / \mathrm{mg}$ collagenase. After enzymatic digest was completed, the heart was taken down from the cannula and the ventricle was dissected. The preparation was cut into small pieces and cardiomyocyte dissociation was achieved by gently triturated with a plastic transfer pipette and the use of stopping buffer containing $10 \%$ FCS. To enrich the cell suspension with viable cardiomyocytes and to remove undigested tissue, suspension was sedimented by gravity for $1 \mathrm{~min}$. Supernatant was then transferred to a new $15 \mathrm{ml}$ tube and cardiomyocytes were sedimented for $8 \mathrm{~min}$. This process allowed separation of cardiomyocytes from other cell types and from dead myocytes. 
The sedimentation was repeated several times, while $\mathrm{Ca}^{2+}$ concentration was gradually increased in several steps. This allowed cells to gradually return to normal cytosolic $\mathrm{Ca}^{2+}$ levels. Supernatants with non-myocytes were collected separately. Non-myocyte cell suspension and sedimented cardiomyocytes were then centrifuged for 4 min with $300 \mathrm{x}$ g. Supernatants were aspirated and pellets were stored at $-20^{\circ} \mathrm{C}$ until RNA or protein preparation. For cardiomyocytes culture, sedimented cardiomyocytes were seeded on laminin coated wells (one heart in two 12 well wells) or coverslips and were incubated for $1 \mathrm{~h}$ in a humidified incubator $\left(37^{\circ} \mathrm{C}, 5 \%\right.$ $\mathrm{CO}_{2}$ ), before addition of $600 \mu \mathrm{l}$ cardiomyocyte medium. $24 \mathrm{~h}$ after seeding, supernatants were collected, centrifuged for 4 min with $300 \mathrm{x}$ g to remove cell debris and were snap frozen and stored at $-80^{\circ} \mathrm{C}$ until processing. Cells on cover slips were fixed for immunofluorescence (IF) staining as described in chapter 3.2.4.1.

\subsubsection{Cultivation, stimulation and transduction of human cardiac fibroblasts}

Human cardiac fibroblasts, isolated from normal, adult heart ventricle (50-year-old male), were purchased from LONZA at passage 2. Cells were cultured with FGM ${ }^{\mathrm{TM}_{-}}$-3 fibroblast growth medium with $10 \%$ FCS, $0.5 \%$ recombinant human insulin and FGF under standard conditions $\left(37^{\circ} \mathrm{C}, 5 \% \mathrm{CO}_{2}\right)$. When confluence reached about $95 \%$, cells were washed with PBS and were dissociated with $2 \mathrm{ml}$ TrypLE express dissociating enzyme at RT. Digestion was stopped using $8 \mathrm{ml} \mathrm{FGM} \mathrm{medium} \mathrm{and} \mathrm{cell} \mathrm{count} \mathrm{was} \mathrm{determined} \mathrm{with} \mathrm{CASY} \mathrm{TT} \mathrm{system.} \mathrm{5x} 10^{5}$ cells were seeded on cover slips in a 12 -well plate and $2.5 \times 10^{6}$ on 6 -well plates. $48 \mathrm{~h}$ after seeding, cells were stimulated with $10 \mu \mathrm{M}$ norepinephrine or $1 \mathrm{ng} / \mathrm{ml} \mathrm{TGF} \beta$ for $48 \mathrm{~h}$, whereas medium was replaced with fresh norepinephrine or TGF $\beta$ after $24 \mathrm{~h}$. After $48^{\circ} \mathrm{h}$, fibroblasts were rinsed with PBS and were processed for RNA isolation or IF staining. For reuptake experiments, growth medium was replaced with fresh IGFBP5 conditioned medium (see 0 ). After $48^{\circ} \mathrm{h}$, fibroblasts were rinsed with PBS and were processed for protein isolation or IF staining. For transduction, FGM medium was supplemented with $2.5 \mu \mathrm{l} / \mathrm{ml}$ purified lentivirus and $8 \mu \mathrm{g} / \mathrm{ml}$ polybrene. Transduction was done for $48 \mathrm{~h}$ with subsequent medium change. Cells were kept in culture for 4 days for recovery and transgene expression. Medium change was done every alternate day. 6 days after transduction, fibroblasts were rinsed with PBS and were processed for RNA isolation or IF staining.

\subsubsection{Cultivation and transient transfection of TSA201 cells}

TSA201 cells were cultured in T75 flasks and were split 1:5 two times weekly. For seeding in wells or on cover slips, surfaces were coated with $1 \%$ rat tail collagen (in house made) for $1 \mathrm{~min}$ and were air dried before use. $24 \mathrm{~h}$ prior transfection, cells were seeded to have a confluence of 
about $80 \%$ on the day of transfection. About $200 \mathrm{ng}$ total DNA was used per $\mathrm{cm}^{2}$, whereas DNA to TurboFect transfection reagent ratio was 1:2. Required DNA and transfection reagent were added to serum free medium, vortexed and incubated for $20 \mathrm{~min}$ at RT. Transfection solution was added to cells and medium was replaced after $6 \mathrm{~h}$. Cells were harvested $48 \mathrm{~h}$ after transfection.

\subsubsection{Generation and purification of lentivirus particles in TSA201 cells}

To generate non-replicating transducing lentiviral particles for $h I G F B P 5$ overexpression, Cterminal FLAG tagged $h I G F B P 5$ was cloned in the HIV-based pGIPZ Lentiviral shRNA vector via removing the shRNA-IRES-Puromycin cassette. pGIPZ vectors contain integration and packaging elements of lentivirus particles and a SV40 origin of replication (ori), enabling replication in cell lines expressing the large $\mathrm{T}$ antigen and allows high-level expression. For particle production, three separate plasmids for expression of lentiviral proteins and the transgene were co-transfected: pMD2.G encodes for a glycoprotein of the vesicular stomatitis virus, pPAX2 is a packaging plasmid containing the viral structural genes, and pGIPZ, either for overexpressing $h I G F B P 5$ or as an empty vector with a GFP reporter. TSA201 cells were cultured in T75 flasks until 80\% confluence and transfection was done according to table 3-3. Medium was replaced $6 \mathrm{~h}$ after transfection with $10 \mathrm{ml}$ fresh medium and cells were kept in culture for $72 \mathrm{~h}$. Lentivirus particle-containing supernatants were harvested, supernatants from four T75 flasks were pooled (40 ml total) and filtered with a $45 \mu \mathrm{m}$ syringe filter to remove cell debris. Virus particle production was confirmed using the LentiGo sticks from Takara. For purification and concentration of the viral particles, the "Vivapure"M LentiSELECT 40 Purification and Concentration Kit" from Sartorius was used according to the manufactures instructions. Purified particles were aliquoted, snap frozen and stored at $-80^{\circ} \mathrm{C}$.

Table 3-3: Transfection protocol for lentivirus production

\begin{tabular}{|l|l|}
\hline Reagent & Amount \\
\hline pGIPZ with GOI & $5.11 \mu \mathrm{g}$ \\
\hline pPAX.2 & $5.11 \mu \mathrm{g}$ \\
\hline pMD2.G & $3.41 \mu \mathrm{g}$ \\
\hline DMEM & $500 \mu \mathrm{l}$ \\
\hline TurboFect & $27 \mu \mathrm{l}$ \\
\hline
\end{tabular}




\subsubsection{Generation of conditioned medium in TSA201 cells}

To produce medium containing secreted hIGFBP5, TSA201 cells were cultured in T75 flasks until $80 \%$ confluence and were transfected with $13.5 \mu \mathrm{g}$ DNA from pGIPZ overexpression plasmid or corresponding empty vector control. Medium was replaced $6 \mathrm{~h}$ after transfection with $10 \mathrm{ml}$ fresh medium and cells were kept in culture for $48 \mathrm{~h}$. Supernatants were harvested, filtered with a $45 \mu \mathrm{m}$ syringe filter to remove cell debris and were directly applied on target cells.

\subsubsection{Cultivation of human embryonic stem cells (hES)}

The human embryonic stem cell line "HES2" (Embryonic Stem Cell International, Singapore), genetically modified to stably and ubiquitously express a tandem dimer red fluorescence protein (tdRFP) from the ROSA26 locus (finally designated hES2.R26) was kindly provided by Gordon Keller [99]. hES2-RFP cells were maintained and later differentiated under serum free conditions [100]. hES2-RFP cells (later also clones and mock control) were cultured under feeder free conditions on Matrigel (1:120 diluted in PBS) coated flasks in TeSR-E8 medium under standard conditions $\left(37^{\circ} \mathrm{C}, 5 \% \mathrm{CO}_{2}\right)$. Twice a week, when cells reached a confluence of $90 \%$, cells were passaged. After rinsing with PBS, $4 \mathrm{ml} 0.5 \mathrm{mmol} / \mathrm{L}$ EDTA solution was added and incubated at $37^{\circ} \mathrm{C}$ for $4 \mathrm{~min}$. EDTA solution was aspirated and cells were resuspended using $10 \mathrm{ml}$ TeSR-E8 with $10 \mu \mathrm{M}$ Rock inhibitor. Cell count was determined using the CASY TT system. After seeding, cells were kept in culture with $10 \mu \mathrm{M}$ Rock inhibitor for $24 \mathrm{~h}$. Then, TeSR-E8 medium change was done every day without Rock supplementation.

\subsubsection{Generation of a hES knock out cell line using CRISPR/Cas9 technology}

\section{gRNA design and cloning}

To obtain a knock out of the human IGFBP5 gene, the CRISPR/Cas9 nickase system was used according to [101]. CRISPR gRNAs were designed to target the transcription start site to generate a frame shift or to shift transcription to a next ATG to generate a truncated transcript. To avoid off-target effects, a " $4 \mathrm{n}$ approach" was applied using four different gRNAs and a CAS9 nickase enzyme to generate four independent single strand breaks releasing a $300 \mathrm{bp}$ long DNA fragment. gRNAs were designed as described by Noack et. al [101]using the "DNA2.0" online tool. gRNA offset was set between 0-20 bp with a NGG PAM region. Transcription start site was manually set as target sequence for gRNA search. Restriction sites for $\mathrm{BbsI} / \mathrm{BpiI}$ were added to each of the obtained gRNA sequence and a complementary sequence was designed for each gRNAs. gRNAs and complementary sequences were 
synthetized like PCR primers from MWG. Purchased oligos were phosphorylated and annealed using $1 \mu \mathrm{l}$ of $100 \mu \mathrm{M}$ from each gRNAs and $1 \mu \mathrm{l}$ of $100 \mu \mathrm{M}$ of its complementary oligo. For the reaction, $0.5 \mu \mathrm{l}$ of T4 PNK was used and incubation was done for $30 \mathrm{~min}$ with subsequent cool down of $5^{\circ} \mathrm{C} / \mathrm{min}$ to $25^{\circ} \mathrm{C}$. For cloning, the modified pX335 containing GFPT2Apuromycin cassette and SpCas9-D10A nickase vector [102] was used. The vector was digested with BbsI enzyme, dephosphorylated and purified as described in 3.2.1.3. $1 \mu 1$ of a 1:250 dilution of the annealed oligo mix was ligated overnight and transformed into high efficiency competent E. coli (all cloning steps like described in 3.2.1.2 to 3.2.1.10). Positive clone identification was done using PCR. For the reaction, $1 \mu$ plasmid DNA was used with $0.2 \mu 1$ Dream Taq polymerase. For every construct, the specific forward oligo used for cloning was used together with a universal reverse primer binding in the vector sequence. Positive clones were identified on an agarose gel.

\section{Electroporation and selection of hES cells}

For electroporation, HES2-RFP cells were dissociated with 0.5 mM EDTA (see section 3.2.2.8) and $2 \times 10^{6}$ were centrifuged for $4 \mathrm{~min}$ at $300 \mathrm{x}$ g. After supernatant removal, cell pellet was resuspended in nucleofection solution supplemented with $1 \mu \mathrm{g}$ gRNA/Cas9n plasmid each (total DNA amount $4 \mu \mathrm{g}$ ) using the Human Stem Cell Nucleofector Kit 1 (LONZA) according to the manufacturer's instruction. Suspension was electroporated with the Nucleofector $2 b$ device (program B16). Subsequently, cells were resuspended in $12 \mathrm{ml}$ TeSR-E8 with $10 \mu \mathrm{M}$ Rock inhibitor and were distributed on a Matrigel (1:60 in PBS) coated 6-well plate. After $24 \mathrm{~h}$, cell selection was done with different concentrations of puromycin $(0.2-0.8 \mu \mathrm{g} / \mathrm{ml})$ for $24 \mathrm{~h}$. After colony formation (about 6-8 days) colonies were reseeded when colonies were fused or were directly picked and transferred to a 96-well plate for separation. After $48 \mathrm{~h}$, colonies were washed with PBS and dissociated with $0.5 \mathrm{mM}$ EDTA and TeSR-E8 with $10 \mu \mathrm{M}$ Rock inhibitor. Cell suspension from each colony was separated. Half of the volume was seeded on a Matrigel (1:60 in PBS) coated 48-well plate, the second half was used for DNA isolation and subsequent genotyping. Positive colonies were expanded further and cryo-conserved.

\section{DNA and RNA genotyping}

Genomic DNA was isolated using the NucleoSpin Tissue kit (Macherey-Nagel). Genotyping PCR was performed using $0.02 \mathrm{U} / \mu 1$ Phusion polymerase, $200 \mu \mathrm{M}$ dNTPs, 5\% DMSO and $1 \mu \mathrm{M}$ of each genotyping primer flanking the deleted DNA fragment. PCR products were analysed using a 1\% agarose gel. For band extraction, the NucleoSpin Gel and PCR Clean-Up kit (Macherey-Nagel) was used and DNA was sequenced at Seqlab Goettingen. For RNA 
genotyping, RNA was isolated and transcribed to cDNA as described in3.2.1.12 and 3.2.1.14. qPCR was done as described in 3.2.1.17. The forward primer was designed to bind the deleted transcriptional start site, whereas reverse primers bind in the next exons.

\subsubsection{Spontaneous germ layer differentiation}

Embryoid body (EB) formation was done as described by El-Battrawy et al. [103] in the Stem Cell Unit (SCU), UMG, Goettingen (experiment done by Martina Grohe). Shortly, For EB formation, $5 \times 10^{4} \mathrm{hES}$ cell together with $2.5 \times 10^{4}$ mouse embryonic fibroblasts were plated in each well of a 96-well U-bottom plate in hES medium composed of DMEM-F12, 15\% knockout serum replacement, 1x NEAA, $50 \mu \mathrm{M} \beta$-mercaptoethanol and $2 \mu \mathrm{M}$ thiazovivin, the plate was centrifuged at $250 \mathrm{xg}$ for $5 \mathrm{~min}$ and co-cultures were cultivated in suspension to form multicellular EB aggregates. At day two, medium was changed to differentiation medium composed of IMDM Glutamax, 20\% fetal bovine serum, 1x NEAA and $450 \mu \mathrm{M}$ 1-thioglycerol for further 6 days with medium change every other day. At day eight, EBs were plated onto $0.1 \%$ gelatin coated 6-well plates and cultured for up to one month in differentiation medium with medium change every other day.

\subsubsection{Differentiation of hES cells to cardiomyocytes}

hES cell differentiation to cardiomyocytes was done according to the protocol from Tiburcy et al. [100]. Three days prior differentiation, hES cells were passaged (as described in 3.2.2.8) and $2 \times 10^{5}$ cells (clones and mock control) seeded in a density of $2 \times 10^{5}$ cells on Matrigel (1:120 diluted in PBS) coated T25 flasks in TeSR-E8 medium under standard conditions $\left(37^{\circ} \mathrm{C}, 5 \%\right.$ $\mathrm{CO}_{2}$ ). For differentiation, stem cells were cultured in basal medium (RPMI, 2\% B27, $200 \mu \mathrm{mol} / \mathrm{L}$ L-ascorbic acid, $1 \mathrm{mmol} / \mathrm{L}$ Na-pyruvate, $100 \mathrm{U} / \mathrm{mL}$ penicillin, $100 \mu \mathrm{g} / \mathrm{mL}$ streptomycin). For mesodermal induction $9 \mathrm{ng} / \mathrm{mL}$ Activin A, $1 \mu \mathrm{mol} / \mathrm{L} \mathrm{CHIR} 99021,5 \mathrm{ng} / \mathrm{mL}$ BMP4, and $5 \mathrm{ng} / \mathrm{mL} \beta$-FGF were added for three days. For cardiac differentiation, cells were cultured in basal medium supplemented with $5 \mu \mathrm{mol} / \mathrm{L}$ IWP4 from day four till 13. Differentiated cardiomyocytes were metabolically purified by glucose deprivation using selection medium (RPMI without glucose and glutamine, $2.2 \mathrm{mmol} / \mathrm{L}$ Na-lactate, $100 \mu \mathrm{mol} / \mathrm{L}$ $\beta$-mercaptoethanol, $100 \mathrm{U} / \mathrm{mL}$ penicillin, $100 \mu \mathrm{g} / \mathrm{mL}$ streptomycin) for five days.

\subsubsection{Dissociation, cultivation and fixation of hES derived cardiomyocytes}

To dissociate differentiated monolayer cardiomyocytes from T25 flasks, cells were washed twice with PBS and were incubated with $1.5 \mathrm{ml}$ room temperature Accutase/DNAse mix. Incubation was done for 10-30 min at room temperature under consistent observation until cells 
dissociated. Digestion was stopped with $4 \mathrm{ml}$ of basal medium (RPMI, 2\% B27, $200 \mu \mathrm{mol} / \mathrm{L} \mathrm{L}$ ascorbic acid, $1 \mathrm{mmol} / \mathrm{L}$ Na-pyruvate, $100 \mathrm{U} / \mathrm{mL}$ penicillin, $100 \mu \mathrm{g} / \mathrm{mL}$ streptomycin) supplemented with a final concentration of $5 \mu \mathrm{M}$ Rock inhibitor. Cell suspension was homogenized by careful triturating. Cell count was determined using the CASY TT system. About $1 \times 10^{6}$ cells were collected for RNA isolation, 2x $10^{6}$ cells were collected for protein isolation and for cryoconservation. $5 \times 10^{5}$ cells were collected for flow cytometry analysis and for IF staining, $5 \times 10^{5}$ cells were seeded per cover slip. Independent on downstream application, dissociated cells were centrifuged at 300x g for $5 \mathrm{~min}$ and supernatants were removed. For RNA, protein and flow cytometry sample collection, cell pellets were washed with PBS and were centrifuged again. RNA and protein samples were frozen at $-20^{\circ} \mathrm{C}$ until processing. Flow cytometry samples were fixed with $1 \mathrm{ml}$ ice cold $70 \%$ ethanol and stored for maximum one week at $4^{\circ} \mathrm{C}$ until analysis. Cell pellets for cryoconservation were resuspended in $1 \mathrm{ml} \mathrm{FCS}$ with $10 \%$ DMSO and were frozen in a freezing container at $-80^{\circ} \mathrm{C}$. Cell pellets for IF staining were resuspended in basal medium without Rock inhibitor and plated on Matrigel (1:120 in PBS) coated cover slips. Prior treatment, cells recovered for at least four days. Medium was replaced every alternate day.

\subsubsection{Generation of engineered human myocardium (EHM)}

For construction of engineered human myocardium (EHM, experiment was done by Dr. Norman Liaw, Pharmacology and Toxicology, UMG Goettingen) all materials required were pre-chilled and all steps performed on ice. Transduced hCFBs and hES2 derived cardiomyocytes were cultured and dissociated as described in 3.2.2.12. Cell counts were determined with CASY TT system and the required cell number of hCFBs and hES2 derived cardiomyocytes were combined and centrifuged at $300 \mathrm{x}$ g for $5 \mathrm{~min}$ at RT. Then, cells were resuspended in basal medium to achieve appropriate dilution as described by Tiburcy et al. [100]. A master mix of bovine collagen type I and concentrated culture medium (2x RPMI, pH adjusted to 7.4) was mixed on ice. Then, cell suspension and collagen master mix were carefully combined and mixed without air bubble formation. After distributing cell suspension/collagen master mix into custom-made circular moulds, mixture was transferred to humidified incubator at $37^{\circ} \mathrm{C}$ and $5 \% \mathrm{CO}_{2}$ to consolidate for $1 \mathrm{~h}$. After consolidation, $6 \mathrm{ml}$ SFMM containing TGF $\beta 1$ was added to each mould. Medium was replaced with fresh SFMM containing TGF $\beta 1$ the next day. On culture day three, EHMs were transferred to custom-made silicone dynamic stretchers and were cultured in SFMM medium without TGF $\beta 1$. During this phase, EHMs were treated with $3 \mu \mathrm{M}$ Rock inhibitor. Medium was changed every second day and EHMs were cultured 
for two weeks. After culture, EHM underwent isometric force measurements as described in Tiburcy et al. [100]. Then, EHMs were snap frozen and were processed for RNA isolation.

\subsubsection{Biochemical methods}

\subsubsection{Protein isolation}

To isolate proteins from different cell components, cells are physical disrupted with the use of detergents. The cell components can then be separated by different densities using centrifugation. Total protein lysates were obtained from cells grown in 6-well or 12-well format. Cells were washed twice in PBS and were kept on ice. $300 \mu 1$ Bäuerle lysis buffer, with supplemented proteinase and phosphatase inhibitors, was added to each well and the cells were scraped off the plate. Tissue samples were homogenized in $300 \mu \mathrm{l}$ Bäuerle lysis buffer using a bead mill for $60 \mathrm{sec}$ with $30 \mathrm{~Hz}$. Lysates were transferred to cold tubes on ice and were triturated with a pipette tip and vortexed vigorously. After $15 \mathrm{~min}$ of incubation lysates were vortexed again and centrifuged for $15 \mathrm{~min}$ with $13000 \mathrm{rpm}$ at $4^{\circ} \mathrm{C}$. Supernatants containing proteins were transferred to new tubes and were stored at $-20^{\circ} \mathrm{C}$.

\subsubsection{Bradford protein quantification}

The Bradford protein assay is a spectroscopic analytical procedure used to measure the concentration of protein in a solution. This colorimetric method is based on an absorbance shift of the dye Coomassie Brilliant Blue G-250. Under acidic conditions the red form of the dye is converted into its blue complexing with the protein being assayed which leads to an absorbance shift from $470 \mathrm{~nm}$ to $595 \mathrm{~nm}$. The increase of absorbance at $595 \mathrm{~nm}$ is proportional to the amount of protein. Using a standard curve with different known concentrations of bovine serum albumin (BSA), the concentration of protein can be calculated. The assay was performed in a 96-well format with a total volume of $50 \mu$ diluted sample or standard and $150 \mu 1$ Bradford reagent (110 $\mu \mathrm{l}$ water plus $40 \mu \mathrm{l}$ Bradford reagent). The standard curve was prepared in duplicates with water blank and five different BSA concentrations diluted from a BSA stock concentration of $1 \mathrm{mg} / \mathrm{ml}$. The protein samples were prepared by diluting $2 \mu \mathrm{l}$ sample in $48 \mu \mathrm{l}$ water and were measured in triplicates. Absorbance was measured rapidly after reagent supplementation in a Multi-Mode Microplate Reader.

\subsubsection{Sodium dodecyl sulphate polyacrylamide gel electrophoresis (SDS-PAGE)}

To discriminate different proteins, denaturating SDS-PAGE was used. SDS disrupts noncovalent bonds in the proteins, denatures them, and provides them with a negative charge. 
Separation occurs via traveling of the negatively charged proteins to the positively charged electrode through the acrylamide gel mesh and are separated according to size (molecular weight in kilodaltons, $\mathrm{kDa}$ ). Protein samples were prepared with similar protein concentration (20-50 $\mu \mathrm{g}$ ) and were boiled at $95^{\circ} \mathrm{C}$ for $5 \mathrm{~min}$ in Laemmli-buffer. Samples were loaded on a $12 \%$ polyacrylamide gel, which consisted of two parts; the stacking gel and the separation gel. Voltage was adjusted to $70 \mathrm{~V}$ for about $20 \mathrm{~min}$, what led to migration and concentration of samples in the stacking gel. During entering the separation gel the voltage was adjusted to $140 \mathrm{~V}$ for around 90-120 min until proteins were completely separated. A pre-stained protein marker was carried along with the samples. The ladder allows monitoring the progress of SDSpolyacrylamide gel electrophoresis and is necessary to estimate the approximate size of separated proteins after Western blotting. Electrophoresis was stopped when loading buffer was passing through the gel.

\subsubsection{Western Blot assay}

To make proteins accessible for antibody detection, they must be transferred onto a membrane. In a wet environment (semi-dry-technique) negatively charged proteins move from the gel onto the hydrophobic polyvinylidene difluoride (PVDF) membrane while maintaining the organization they had within the gel. For blotting the PVDF membrane was activated in methanol for 30 seconds and was washed with water and with transfer buffer. For equilibration, the Whatman-papers and the polyacrylamide gel where soaked in transfer buffer for $2 \mathrm{~min}$. The membrane and the gel were placed air bubble free in between six layers of Whatman-paper and the transfer was done with $140 \mathrm{~mA}$ for $50 \mathrm{~min}$. The transfer was controlled with a reversible Ponceau S staining and membrane was cut when needed. All following washing and incubation steps were performed on a rocker. After removing Ponceau S with TBS-T buffer, the membrane was blocked for unspecific antibody binding with 5\% milk powder resolved in TBS-T buffer for one hour at room temperature. Primary antibody was diluted in 5\% milk/TBS-T and membrane was incubated overnight at $4^{\circ} \mathrm{C}$. After three washing steps with TBS-T for $10 \mathrm{~min}$ each, the membrane was incubated for one hour at room temperature with the secondary, horseradish peroxidase (HRP) conjugated, antibody diluted in 5\% milk/TBS-T. Following three washing steps with TBS-T for $10 \mathrm{~min}$ each, the membrane was shortly incubated with a luminol-based chemiluminescent substrate and a peroxide buffer in equal volumes. In the presence of hydrogen peroxide, HRP converts luminol to an excited intermediate dianion which emits light. This reaction was visualized with the VersaDocTM Imaging System and was evaluated with the ImageLab software. 


\section{Validation of a customized IGFBP5 antibody}

Since neither murine nor human IGFBP5 (neither endogenous nor an artificial overexpression) could be detected with commonly available antibodies (even when these were published), a customized IGFBP5 antibody was produced by Thermo Fisher Scientific. Amino acids 255272 (last 13 amino acids in IGFBP5 peptide) were chosen as antigen for antibody generation in rabbits, since these amino acids are not conserved within the IGFBP-family. Further these IGFBP5-amino acids are conserved among different species, aiming to detect IGFBP5 in different samples from different animals. To test the antibody in different samples from different antibody, an immunoblot was done. This blot shows two bands in all different species at $\sim 35 \mathrm{kDa}$ and $32 \mathrm{kDa}$. These two bands can be attributed to IGFBP5 with and without signal peptide. A third, larger band can be detected upon overexpression of IGFBP5 fused to a FLAG protein.
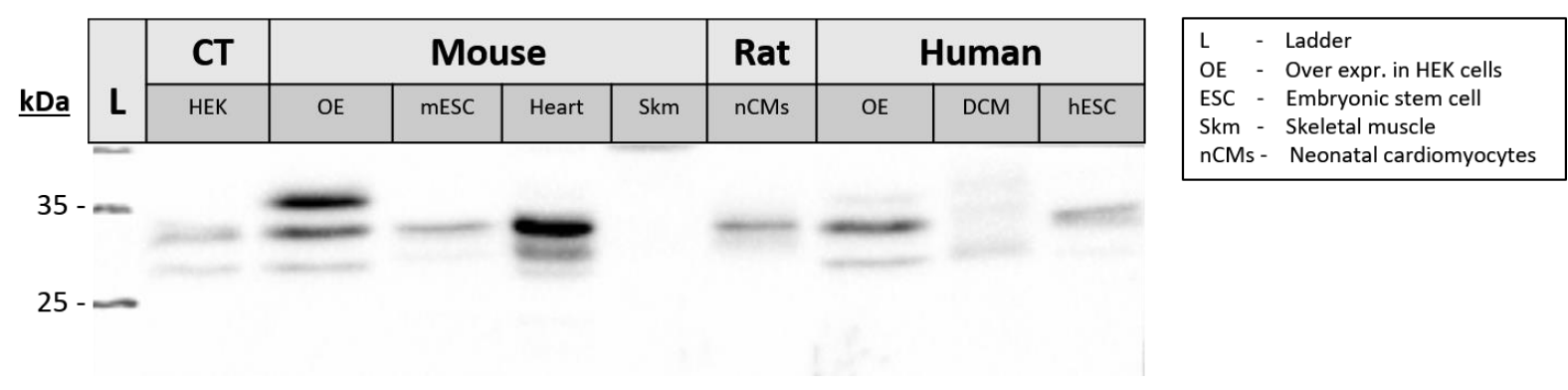

Figure 3-1: Immunoblot for customized IGFBP5 antibody

\subsubsection{Chromatin immunoprecipitation (ChIP) and rapid immunoprecipitation of endogenous proteins (RIME)}

\section{Two step cross-linking of cells}

Since IGFBP5 has no DNA binding motive it might act as a coactivator which is not directly associated to DNA. The conventional single-step crosslinking technique does not preserve all protein-DNA interactions, therefore a "two-step" XChIP method that involves sequential protein-protein fixation followed by protein-DNA fixation was used according to Nowak et al. 2005. Briefly, cells were washed with PBS and fixed with $2 \mathrm{mM} \mathrm{DSG}$ in PBS/Mg/Ca for 45 min. Subsequent DNA cross-linking was done using $1 \%$ formaldehyde in PBS with proteinase inhibitors for $15 \mathrm{~min}$. Reaction was quenched with $125 \mathrm{mM}$ glycine for $5 \mathrm{~min}$ and a subsequent PBS wash on a low speed shaker. Before nuclei isolation, cells were frozen at $20^{\circ} \mathrm{C}$. 


\section{Chromatin immunoprecipitation (ChIP)}

ChIP is used to investigate the interaction between proteins and DNA in the cell. It aims to determine whether specific proteins are associated with specific genomic regions, such as transcription factors on promoters or other DNA binding sites. Protein are cross-linked to its associated chromatin, then, the DNA-protein complexes are then sheared into DNA fragments by sonication. Cross-linked DNA fragments associated with the protein of interest are selectively immunoprecipitated using a specific antibody for the protein of interest. The associated DNA fragments are purified, and their sequence can be analysed. The precipitated chromatin is quantified via sequencing. All following steps until DNA isolation were performed on ice. $3 \mathrm{ml}$ cold nuclear preparation buffer (all buffers were freshly supplemented with inhibitors; see material part 3.1.7) was added to a T75 flask and cells were scrapped. Lysate was distributed on two $1.5 \mathrm{ml}$ tubes and was homogenized with gentle triturating. Then lysates were centrifuged with $12000 \times \mathrm{g}$ for $2 \mathrm{~min}$ at $4^{\circ} \mathrm{C}$, supernatants were aspirated before adding $700 \mu 1$ of nuclear preparation buffer. Cell pellets were solubilised with gentle triturating and lysates from one flask were combined again. After centrifugation with $12000 \times \mathrm{g}$ for 2 min at $4^{\circ} \mathrm{C}$, supernatants were aspirated and $750 \mu 1$ sonication buffer 1 and $750 \mu 1$ sonication buffer 2 were added. Cell pellets were solubilised with gentle triturating and incubation was done for $10 \mathrm{~min}$ on ice. Every sample was split on three $1.5 \mathrm{ml}$ TPX Diagenode tubes and sonication was done for 20 cycles. Then, the samples were centrifuged at $12.000 \times \mathrm{g}$ for $2 \mathrm{~min}$ at $4^{\circ} \mathrm{C}$ and supernatants were combined again in a $2 \mathrm{ml}$ tube. For pre-clearing $200 \mu \mathrm{l}$ sepharose beads (50\% slurry in dilution buffer) were added and were incubated for 1 hour at $4{ }^{\circ} \mathrm{C}$ on a rotating wheel. Samples were centrifuged at $2.000 \mathrm{x} g$ for $5 \mathrm{~min}$ at $4^{\circ} \mathrm{C}$. A total of $1300 \mu \mathrm{l}$ supernatant was used for IP, whereas $130 \mu \mathrm{l}(10 \%)$ of supernatants were stored as inputs at $-20^{\circ} \mathrm{C}$. For precipitation, supernatants were supplemented with $650 \mu \mathrm{l}$ IP buffer and $2 \mu \mathrm{g}$ FLAG-antibody. Precipitation was done overnight at $4{ }^{\circ} \mathrm{C}$ on a rotating wheel. On the next day, $60 \mu 1$ protein Asepharose was added to each sample and was incubated for 2 hours at $4{ }^{\circ} \mathrm{C}$ on a rotating wheel. After centrifugation at $12.000 \mathrm{xg}$ for $2 \mathrm{~min}$ at $4^{\circ} \mathrm{C}$ the ChIP immune complexes were washed twice with $800 \mu \mathrm{l}$ ice cold IP buffer (inhibitors were not necessary), twice with ice cold ChIP wash buffer, again twice with ice cold IP buffer and last, twice with ice cold TE buffer. For each washing step tubes were inverted several times and were centrifuged at $2.000 \mathrm{x} g$ for $2 \mathrm{~min}$ at $4^{\circ} \mathrm{C}$. Supernatant was completely removed and $150 \mu \mathrm{l}$ Elution Buffer was added and incubated at $65^{\circ} \mathrm{C}$ for $30 \mathrm{~min}$ with vigorous shaking. The input samples were thawed and $150 \mu \mathrm{l}$ Elution Buffer was added. The inputs samples were left at room temperature till DNA isolation. The samples were transferred to new tubes and $6 \mu$ l sodium chloride solution $(5 \mathrm{M})$ and $2 \mu 1$ 
Proteinase K $(20 \mathrm{mg} / \mathrm{ml})$ was added to samples and to inputs. After an incubation time of 90 min at $65^{\circ} \mathrm{C}$, the DNA was isolated form samples and inputs using the "Macherey-Nagel "PCR clean-up kit" with buffer NTB (for samples with more than $0.1 \%$ SDS). Then, the extracted chromatin was analysed by sequencing.

\section{Rapid immunoprecipitation of endogenous proteins (RIME)}

Instead of purifying the precipitated DNA fragments, the cross-linked proteins including associated proteins can be analysed via Western blot assay. For this, beats with ChIP immune complexes were incubated with $40 \mu \mathrm{l}$ of $4 \times$ Laemmli buffer for $10 \mathrm{~min}$ at $95^{\circ} \mathrm{C}$ with $700 \mathrm{rpm}$. After cooling, eluate was centrifuged at $2000 \times \mathrm{g}$ for $5 \mathrm{~min}$ and eluate was collected and directly used for Western blotting.

\section{ChIP sequencing}

ChIP sequencing was performed at the Transcriptome and Genome Analysis Laboratory (TAL, University Medical Center, Goettingen), in biological triplicates. ChIPseq library preparation was performed using the "TruSeq ChIP Library Preparation Kit - Set A from Illumina as per manual's instructions. DNA libraries were amplified and sequenced by using the cBot and iSeq2500 from Illumina (25-30 million reads per sample). Since there was a high background and low signal throughout, relevant regions had to be manually identified. Published/public ChIPseq datasets for $\mathrm{H} 3 \mathrm{~K} 4 \mathrm{me} 3$ ChIP from hCFBs were used from: https://www.encodeproject.org/experiments/ENCSR000DTE/.

\subsubsection{Dual-Luciferase reporter gene (DLR $\left.{ }^{\mathrm{TM}}\right)$ assay}

Genomic regions which showed a peak in IGFBP5 ChIP were amplified and cloned upstream the firefly luciferase reporter gene in NheI and HindIII digested pGL4.10 vector (Promega). In this assay, reporter expression indicates promoter activity. The activities of firefly (Photinus pyralis) and Renilla (Renilla reniformis) luciferases are measured sequentially from a single sample. The term "dual reporter" refers to the simultaneous expression and measurement of these two individual reporter enzymes within a single system. Typically, the "experimental" reporter (firefly luciferase) is correlated with the effect of specific experimental conditions, while the activity of the co-transfected "control" reporter (Renilla luciferase) provides an internal control that serves as the baseline response used for normalizing. TSA201 cells were transfected with either pGL4.10-empty vector, pGL4.10-hIGFBP5-ChIP-promoter or pGL4.10-hTNNT2-ChIP-promoter. Co-transfection was done with pExp-hNKX2.5 or pcDNA3.1-hIGFBP5. Empty plasmids were used for adjustment of equal DNA content per 
transfection. Transfection mixture was prepared in DMEM without supplements and TurboFect transfection reagent in a ratio 1:2 for DNA amount:TurboFect reagent. After $48 \mathrm{~h}$, cells were washed with PBS and were passively lysed by adding $100 \mu$ Passive Lysis Buffer and rocking with $400 \mathrm{rpm}$ for $15 \mathrm{~min}$. Lysates were then transferred to tubes placed on ice, were vortexed vigorously and centrifuged. For the Dual-Luciferase reporter gene (DLR) assay $20 \mu 1$ of each lysate sample was pipetted in triplicates in a 96-well plate. The firefly and Renilla luciferase reporter were sequentially detected in the GloMax-96 Microplate Luminometer (Promega) with reagent auto-injectors. Luciferase activity was normalized to Renilla luciferase activity and expressed as fold change against the empty vector pGL4.10. Every experiment was done in technical and biological triplicates.

\subsubsection{Immunochemistry}

\subsubsection{Immunofluorescence staining}

Immunohistochemistry (IHC) or Immunocytochemistry (ICC) are used to detect antigens, for example distinct proteins, in living or fixed cells and in tissue sections by maintaining the morphology. To detect the proteins of interest, antibodies-, against specific antigens on these proteins are used. Visualising an antibody-antigen interaction is accomplished for example by a fluorophore-conjugated secondary antibody. For IF staining, cells were washed with PBS and were fixed with $4 \%$ paraformaldehyde for $20 \mathrm{~min}$. After three-times rinsing with PBS cells were permeabilized with buffer A for $10 \mathrm{~min}$ and were rinsed once for $5 \mathrm{~min}$ with PBS. Then, coverslips were incubated with blocking buffer B for 60 min or kept in buffer B at $4^{\circ} \mathrm{C}$ until staining. The primary antibody or and a corresponding IgG antibody was diluted 1:200 in buffer C. In a dark humid chamber, coverslips were placed upside down on a $30 \mu 1$ droplet of antibody solution and were incubated overnight at $4^{\circ} \mathrm{C}$. Coverslips were placed in a 12 -well plate again and were carefully rinsed three times with PBS. The secondary fluorophoreconjugated antibody was diluted 1:200 in buffer $\mathrm{C}$ and coverslips were placed upside down on a $30 \mu \mathrm{l}$ droplet of antibody solution. Incubation was done for $60 \mathrm{~min}$ at room temperature in a dark humid chamber. Again, coverslips were placed in a 12-well plate and were carefully rinsed three times with PBS. Hoechst 33342 dye $(1 \mathrm{mg} / \mathrm{ml})$ was diluted 1:1000 in buffer $\mathrm{C}$ and nucleus staining was done by incubation with of $500 \mu$ l of Hoechst 33342 solution on each cover slip for $5 \mathrm{~min}$ at room temperature. Then, cover slips were rinsed with PBS and consecutive PBS dilutions with distilled water to prevent crystallisation of PBS on cover slips. For embedding, coverslips were placed upside down on a $20 \mu \mathrm{l}$ droplet of SlowFade Gold antifade reagent. Stained cells were examined with a confocal laser scanning microscope. 


\subsubsection{Flow cytometry}

(Experiment was done by Dr. Farah Raad, Pharmacology and Toxicology, UMG Goettingen). Dissociated and with 4\% PFA fixed hES cells were washed with PBS. After centrifugation for 4 min with $300 \mathrm{xg}$ at $4^{\circ} \mathrm{C}$, cells were resuspended in PBS and were kept at $4^{\circ} \mathrm{C}$ until flow cytometry. Pellets from dissociated hES derived cardiomyocytes were fixed with $1 \mathrm{ml}$ ice cold $70 \%$ ethanol and stored for maximum one week at $4{ }^{\circ} \mathrm{C}$. For flow cytometry, fixed cells were centrifuged for $4 \mathrm{~min}$ with $300 \mathrm{xg}$ at $4^{\circ} \mathrm{C}$ and were resuspended in blocking buffer (PBS supplemented with 5\% FBS, $1 \%$ bovine serum albumin, $0.5 \%$ Triton X-100 and sodium azide; used for internal markers) or 5\% FBS in PBS (for cell surface markers) and permeabilized for $10 \mathrm{~min}$ at $4{ }^{\circ} \mathrm{C}$. Then cells were filtered using a cell strainer $(40 \mu \mathrm{m})$. Samples were incubated for 45 min at $4^{\circ} \mathrm{C}$ with primary antibodies (see 3.1.11), followed by two washing steps with blocking buffer prior to incubation with secondary antibodies in blocking buffer. Nuclei staining with Hoechst 33342 was done for $30 \mathrm{~min}$ at $4^{\circ} \mathrm{C}$. Samples were then again washed with blocking buffer and resuspended in PBS for analysis with a BD LSRII flow cytometer (BS Biosystems). Viable cells were first gated based on Hoechst staining. Single cells were gated based on forward scatter signal, IgG controls were used to determine non-specific staining. BD FACSDiva Software (version 6.1.3, BD Biosciences) was used for analysis.

\subsubsection{Enzyme-linked immunosorbent assay (ELISA)}

ELISA (enzyme-linked immunosorbent assay) is a plate-based assay used to detect and quantify soluble antigens like e.g. on proteins. Here, a direct sandwich ELISA assay was used, where the capture antibody is immobilized on the solid surface of the plate. After incubation with the soluble antigen (protein), the formed complexed is detected with an antibody that is linked to an enzyme. Detection is accomplished by assessing the conjugated enzyme activity via incubation with a substrate to produce a measurable product. Samples were generated as the following: Mouse serum was purified from whole blood directly collected from mouse hearts. Blood was centrifuged for $10 \mathrm{~min}$ with $2000 \mathrm{x}$ g at $4^{\circ} \mathrm{C}$ to separate serum from blood cells. Cell supernatants from cell culture were filtered using a $45 \mu \mathrm{m}$ filter to remove cells and debris. All samples were snap frozen and stored at $-80^{\circ} \mathrm{C}$. Prior to assay procedure, samples were thawed on ice. Mouse serum was diluted 1:200 and cell supernatant was diluted 1:10 with provided dilution buffer. All steps were done according to the manufacturer's instructions. Shortly, $100 \mu 1$ of diluted samples and prepared standards were applied on ELISA plate and were incubated overnight at $4^{\circ} \mathrm{C}$ with gentle shaking. On the next day, samples were aspirated, and plate was washed 4 times with provided washing buffer. Then, $100 \mu \mathrm{l}$ of prepared detection 
antibody was applied and incubated for $1 \mathrm{~h}$ at RT with gentle shaking. Solution was discarded and washing steps were repeated. Then, $100 \mu \mathrm{l}$ of prepared Streptavidin solution was applied and incubated for 45 min at RT with gentle shaking. Solution was discarded and washing steps were repeated. After aspirating the remaining solution, $100 \mathrm{ml}$ of TMB substrate was applied and incubated for $30 \mathrm{~min}$ at RT with gentle shaking. Reaction was stopped with $50 \mu 1$ stopping solution and absorbance was read at $450 \mathrm{~nm}$ immediately in a Multi-Mode Microplate Reader. Protein quantities were calculated using the standard curve with known protein concentrations.

\subsubsection{Animal work}

\subsubsection{Induction of cardiac specific Wnt gain of function and loss of function}

Inducible, cardiac specific $\beta$-catenin gain of function $\left(\beta\right.$-catenin $\left.{ }^{\Delta e x 3}\right)$ as well as loss of function $\left(\beta\right.$-catenin $\left.{ }^{\Delta \text { ex2-6 }}\right)$ was achieved by mating $\alpha$ MHC-merCremer mice with either $\beta$-catenin ${ }^{\text {floxed-ex } 3}$ and $\beta$-catenin ${ }^{\text {floxed-ex2-6 }}$ (Jackson Lab). Heart-specific expression of the Cre recombinase under control of the $\alpha \mathrm{MHC}$ promoter was activated by administration of Tamoxifen (T5648, $30 \mathrm{mg} / \mathrm{kg}$ body weight/day) i.p. for 3 days in 12-20 weeks old mice. Excision of loxP-flanked exon 3 of the $\beta$-catenin coding region in $\alpha M H C-m e r C r e m e r / \beta$-catenin ${ }^{\text {floxed-ex } 3}$ resulted in a nondegradable mutant of $\beta$-catenin and in $\alpha \mathrm{MHC}$-merCremer/ $\beta$-catenin ${ }^{\text {floxed-ex2-6 }}$ in non-functional $\beta$-catenin. Littermates WT at $\beta$-catenin locus and positive for Cre recombinase were used as control as well as WT without Cre recombinase expression.

\subsubsection{Murine model of Ang-II induced cardiac hypertrophy}

Angiotensin II (Ang II) is known as an important hormonal mediator of cardiac hypertrophy and fibrosis [104] and is commonly used in in vivo experiments. For induction of cardiac hypertrophy, micro-osmotic pumps (model 1002, Alzet) releasing Ang II or sodium chloride solution as a control (Sigma; $1.4 \mu \mathrm{g} \mathrm{x} \mathrm{kg}^{-1} \mathrm{x} \mathrm{min}^{-1}$, solvent $0.9 \% \mathrm{NaCl} / 0.01 \mathrm{~N}$ acetic acid) were implanted subcutaneously in 12-weeks old BL/6J mice after anaesthesia with ketamine/xylazine $\left(30 \mathrm{mg} / 10 \mathrm{mg} \mathrm{x} \mathrm{kg}^{-1}\right.$ intraperitoneal). Development of hypertrophy was assessed by echocardiography two weeks after minipump implantation. Experiment was performed in two different set-ups. First, two weeks after minipump implantation and second, 4 weeks after implantation, while Ang II infusion was expected to be depleted already two weeks after minipump implantation. 


\subsubsection{Transverse aortic constriction model}

Transverse aortic constriction (TAC) in mice is an experimental model for pressure overloadinduced cardiac hypertrophy and HF. Surgery was done in 12 weeks-old mice. The intervention was performed by tying a non-absorbable braided 5-0 polyviolene suture ligature around the aorta and a blunted 26-gauge needle and subsequent removal of the needle. For sham controls the suture was not tied. TAC was confirmed by echocardiography and measurement of blood flow gradient. To determine the level of pressure overload by aortic ligation, a high frequency Doppler probe was used to measure the ratio between blood flow velocities in right and left carotid arteries. Heart function was analysed by echocardiography. All these procedures were performed by the SFB 1002 service unit (S01 Disease Models). The observer was unaware. All animal experiments were approved by the Niedersachsen (AZ-G 15-1840) animal review board.

\subsubsection{AAV9 mediated gene transfer}

To overexpress FLAG tagged Igfbp5 in the heart, AAV serotype 9 (AAV9) was used, which exhibits the highest cardiac tropism in mice resulting in a homogeneous long-term transfer of intact cDNA throughout the heart [105]. A murine Igfbp5-FLAG-fragment was generated using a validated overexpression vector (pcDNA-Igfbp5-FLAG) as a template. The overexpression construct was inserted with $\mathrm{NheI} / \mathrm{XbaI}$ into a self-complementary AAV vector genome plasmid, derived from pdsCMV-MLC0.26-EGFP, under control of the human troponin $\mathrm{T}$ promoter (hTNNT2) [106], resulting in pds-hTNNT2-msIgfbp5-FLAG. AAV9 particle production for expression of Igfbp5 or luciferase (LUC control) was done by the laboratory of Prof. O. Mueller (Klinik für Innere Medizin III, UKSH, Kiel). Shortly, vectors were generated by co-transfection of pds-hTNNT2-msIgfbp5-FLAG or pds-hTNNT2-LUC together with pDP9rs, a derivate from pDP2rs with the AAV9 cap gene from p5E18-VD2-9, in HEK293T cells using polyethylenimine AAV was purified and titrated. 12-week old BL/6J mice received a systemic single dose of $2 \times 10^{12}$ AAV9 vectors by intravenous injection via the tail vein under anaesthesia using $2.4 \%$ isoflurane inhalation. Echocardiography was done pre-injection and was repeated after six-, ten and 18 weeks post-injection. Then mice were sacrificed for characterization.

\section{AAV9 particle test}

In a previous experiment (not part of this study), a cardiac specific downregulation of Igfbp5 was achieved using the same approach as described above. Instead of an overexpression construct, a shRNAmir construct was used to target murine Igfbp5 while a non-silencing shRNAmir served as a control. qPCR analysis of heart-, liver-, and spleen tissue revealed a 
downregulation of Igfbp5 in the heart but not in the liver or the spleen, confirming the cardiac tropism of these particles.

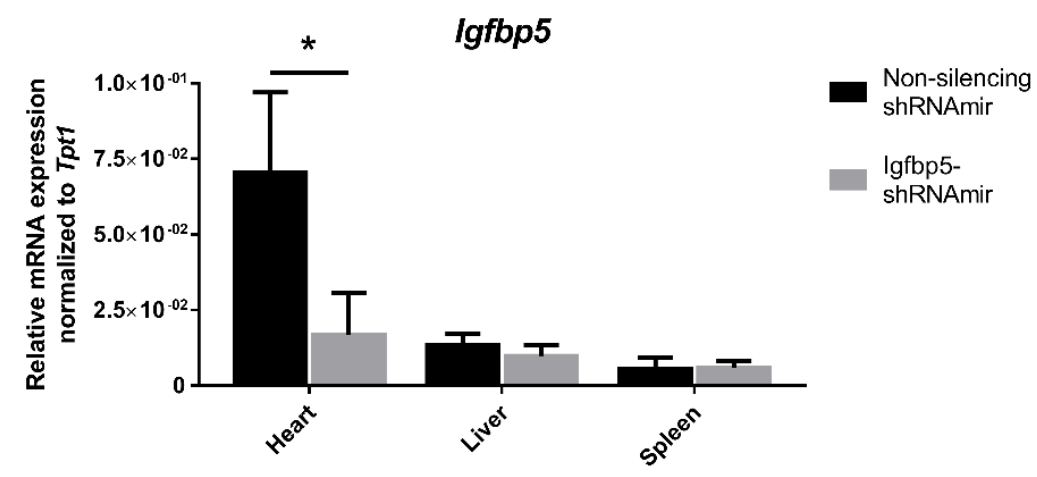

Figure 3-2: AAV9 particles test in different organs

\subsubsection{Echocardiography}

For echocardiography mice were anesthetized by $2.4 \%$ isoflurane inhalation and ventricular measurements were done with a VisualSonics Vevo 2100 Imaging System equipped with a MS400, 30MHz MicroScan transducer. The observer was unaware of the genotypes and treatments.

\subsubsection{Statistical analysis}

Differences between experimental groups were analysed using the two-tailed Student's t-test. Data is presented as mean \pm SEM. $\mathrm{p}<0.05$ values were considered significant. For RNAsequencing analyses, adjusted $\mathrm{p}$-value of $\leq 0.05$ was considered for statistical significance respectively. 


\section{Results}

\subsection{IGFBP5 is upregulated during the transition to heart failure}

\subsubsection{Igfbp5 is upregulated upon murine heart failure}

Previous experiments indicated an association between increased Igfbp5 expression in murine failing hearts upon induced cardiac specific Wnt/ $\beta$-catenin activation. So far, no evidence was provided that the upregulation of Igfbp5 in these mice was Wnt/ $\beta$-catenin-dependent. Therefore, the expression of Igfbp5 was analysed in a cardiac disease model leading to HF. Transversal aortic constriction (TAC) pressure overload-induced cardiac hypertrophy and failure is a wellestablished experimental mouse model for mimicking cardiac disease. In preliminary work, Igfbp5 was found significantly upregulated in mice upon TAC operation when compared to sham operated mice (see Figure 2-3, n=8/12, $\mathrm{P}<0.05$ ). In this study the expression dynamics of Igfbp5 during the progression to HF was investigated. Murine hearts were analysed at different time points after TAC surgery, namely three days, one week, two weeks and eight weeks postTAC operation (scheme in Figure 4-1A). This analysis showed no significant changes in Igfbp5 expression during the early stage of hypertrophic remodelling (three days post-TAC). A significant upregulation of Igfbp5 was observed eight weeks post-TAC when compared to sham operated mice (Figure 4-1B, $\mathrm{n}=6 / 8$ per group, $\mathrm{P}<0.05$ ), while $\mathrm{HF}$ was indicated by echocardiographic analysis of cardiac function (Figure 4-1D-E, $\mathrm{n}=6 / 8$ per group, $\mathrm{P}<0.05$; $\mathrm{P}<0.01$ ). Measurement of anterior wall thickness (AWThd) showed a significant increase in wall diameter starting one week post-TAC, indicating hypertrophic remodelling (Figure 4-1C, $\mathrm{n}=24 / 38$ per group, $\mathrm{P}<0.01 ; \mathrm{P}<0.001$ ). Concomitant with the upregulation of Igfbp5 eight weeks post-TAC, fractional area shortening (FAS) and ejection fraction (EF), indicators for HF, were significantly reduced when compared to sham controls (Figure 4-1D-E, n=6/8 per group, $\mathrm{P}<0.05 ; \mathrm{P}<0.01)$. Since both IGFBP7 and IGFBP3 are described in the context of cardiovascular disease [107-109], the expression of one of these IGFBP family members was investigated. Studying Igfbp3 expression during early hypertrophic response and upon HF, its expression was examined three days and eight weeks post-TAC as described before. No difference in Igfbp3 expression was observed in TAC mice in comparison to sham mice, neither three days (Figure 4-2A, n=7 per group) nor eight weeks post-TAC (Figure 4-2B, n=6/7 per group).

This data suggests a role for IGFBP5 during the transition to HF but not during early hypertrophic remodelling. 


\subsubsection{Igfbp5 expression is normalized upon preserved cardiac function post-TAC}

To investigate whether the upregulation of Igfbp5 is directly linked to the transition state to HF, a TAC rescue experiment was studied. Wnt-transcriptional activation is known to drive hypertrophic remodelling and HF. Consequently, blocking cardiac Wnt-transcriptional activation in mice subjected to Ang II and upon TAC has beneficial effects, as previously shown [92, 93]. Cardiac Wnt-transcriptional repression is achieved by inducible, cardiomyocyte specific $\beta$-catenin loss of function ( $\beta$-Cat LOF). $\beta$-Cat LOF and control mice which underwent TAC and sham surgery were analysed (scheme of experimental set up in Figure 4-3A). Echocardiographic analysis post-TAC showed a significant decrease in ejection fraction (EF) in non-transgenic TAC mice when compared to non-transgenic sham mice. In contrast, EF was preserved in TAC mice with cardiac $\beta$-Cat LOF in comparison to transgenic and non-transgenic sham mice (Figure $4-3 B, n(C T)=3 / 5$ per group and $n(\beta-C a t L O F)=3 / 6$ per group). As expected, the molecular hypertrophy marker natriuretic peptide B (Nppb) was significantly upregulated upon TAC in comparison to sham operated mice, while this elevation was attenuated in $\beta$ Cat LOF hearts when compared to sham mice. (Figure $4-3 C, n(C T)=8 / 5$ per group and $n(\beta$ Cat $L O F)=12 / 8$ per group, $\mathrm{P}<0.01$ ). Regarding Igfbp5 expression, transcript levels were significant upregulated in non-transgenic TAC mice in comparison to sham operated mice, confirming previous results (Figure $4-3 \mathrm{D}, \mathrm{n}(\mathrm{CT})=8 / 5$ per group, $\mathrm{P}<0.05$ ). In contrast, there was no significantly elevated Igfbp5 expression comparing sham and TAC operated $\beta$-Cat LOF mice, which showed preserved function post-TAC (Figure $4-3 \mathrm{D}, \mathrm{n}(\beta-\mathrm{Cat} \mathrm{LOF})=13 / 8$ per group).

Collectively these data confirm that regulation of $I g f b p 5$ is directly linked to the disease state of the heart and is only upregulated during HF progression.

\subsubsection{IGFBP5 is upregulated in human heart failure with a concomitant downregulation of IGFBP5 targeting microRNAs}

IGFBP5 is the most evolutionary conserved of all IGFBPs and is more than 97\% identical among human, mouse and rat [110]. To investigate whether it is also regulated upon HF in human, RNA sequencing data from ventricle samples from human aortic stenosis patients were used to analyse IGFBP5 expression (Dr. Sarah Khadjeh, Department of Cardiology and Pneumology, UMG). There was no significant IGFBP5 regulation in patients with preserved ejection fraction (ejection fractions $>55 \%$ ) in comparison to ventricular samples from nonfailing control patients, even when a trend could be observed. In contrast, IGFBP5 expression was significantly upregulated in samples from patients with HF (ejection fractions <55\%) in 
comparison to ventricular samples from non-failing control patients. (Figure 4-4A, $\mathrm{n}=\mathrm{NF} 4 / \mathrm{CH} 5 / \mathrm{HF} 5$, cut off $>100 \%$ change in expression, adjusted p-value $\mathrm{P}<0.05$ ). Concomitant with the increasing IGFBP5 transcript abundance in diseased ventricles, mir146b$5 \mathrm{p}$ and mir139-5p, two microRNAs predicted to target the IGFBP5 transcript, are gradually downregulated in aortic stenosis patients (Figure 4-4B, n=4). RNA sequencing data showed in total 650 genes upregulated from non-failing control samples to HF, while only 95 genes showed a dynamic increase in expression from non-failing control-, to compensated hypertrophy-, to HF (Figure 4-4C). In line with this, RNA sequencing data from mice, one week and eight weeks post-TAC (data from Dr. Sarah Khadjeh, Department of Cardiology and Pneumology, UMG) showed a similar result. From a total of 114 genes upregulated from sham hearts- to failing hearts (eight weeks post-TAC), only 64 genes showed a dynamic increase in expression from sham hearts to compensated hyperopic hearts (one weeks post-TAC) to failing hearts (eight weeks post-TAC). Only 14 of these dynamically upregulated genes were found conserved between mice and humans, including IGFBP5.

These data collectively confirm a conserved upregulation of IGFBP5 during the transition to HF in mice and in humans.

\subsubsection{Intracellular protein levels of IGFBP5 are not altered in the diseased heart}

To confirm results obtained from mRNA analysis, IGFBP5 protein expression in failing hearts from mice and humans was validated. Immunoblot analysis of murine failing hearts post-TAC did not show any difference between the TAC and sham group (Figure 4-5A, n=6/8 per group, blot was done twice). To investigate IGFBP5 protein expression in human HF, protein quantification was done in left ventricular heart tissue samples from patients with dilated cardiac myopathy (DCM). There was no consistent difference between patient tissue and tissue from human control heart samples detectable as shown in Figure 4-5B ( $n=3 / 10$ per group, blot was done twice).

Collectively these data show that an increased IGFBP5 transcript abundance is not represented on intracellular protein levels. 
A

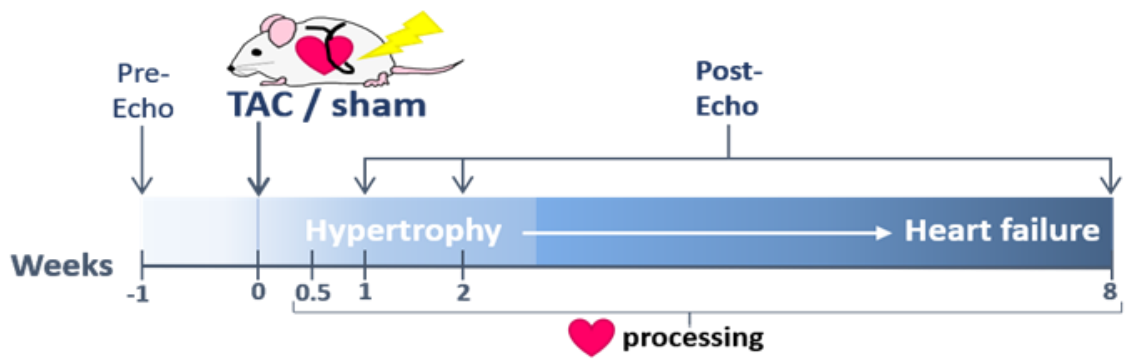

B
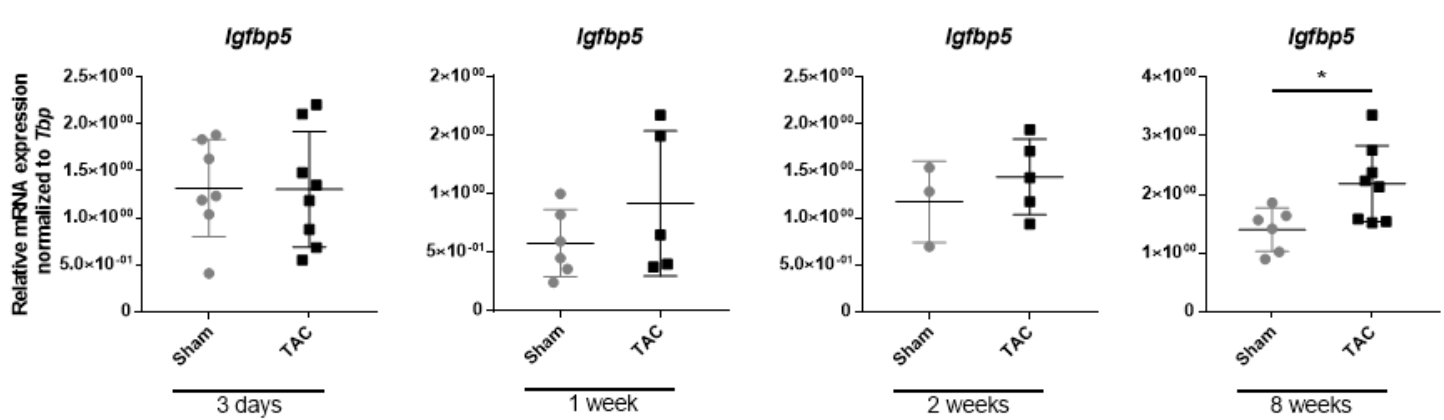

C

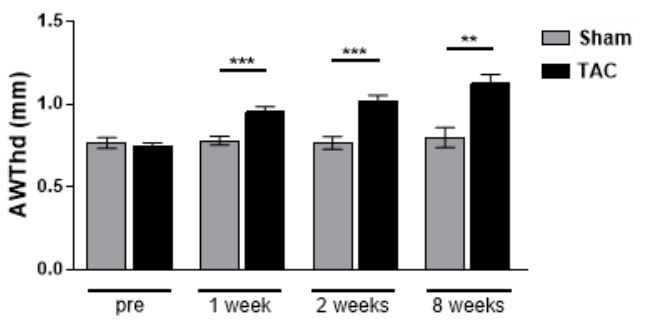

D

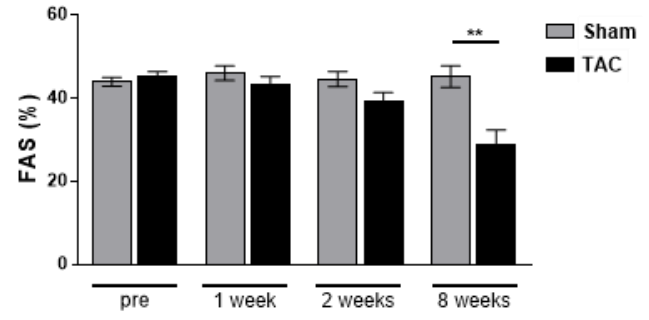

E

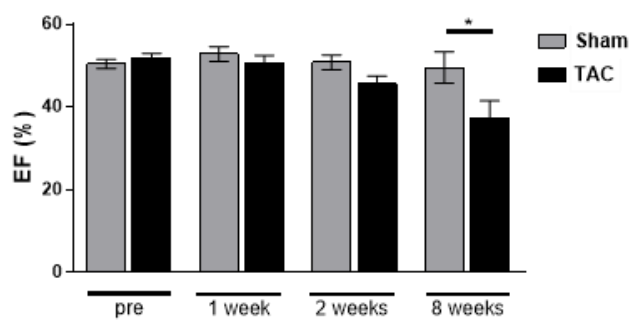

Figure 4-1: Expression dynamics of Igfbp 5 upon transverse aortic constriction (TAC)

(A) Timeline of performed TAC operations and echocardiographic analysis. (B) qPCR data shows mRNA expression of Igfbp5. Data is normalized to Tbp (TATA-binding protein). $\mathrm{n}=7 / 8$ per group. (C) Echocardiographic analysis showing change in anterior wall thickness during diastole in mm [AWThd], (D) fractional area shortening in \% [FAS], and (E) ejection fraction $[\mathrm{EF}]$ in $\%$. Animal number for echocardiographic analysis are $\mathrm{n}($ pre-echo $)=24 / 40$ per group, $\mathrm{n}(1$ week $)=$ $24 / 38$ per group, $\mathrm{n}(2$ weeks $)=18 / 27$ per group, $\mathrm{n}(8$ weeks $)=6 / 8$ per group. Data are mean $\pm \mathrm{SEM}$; t-test, ${ }^{*} \mathrm{P}<0.05 ; * *$ $\mathrm{P}<0.01, * * * \mathrm{P}<0.001$. 
A

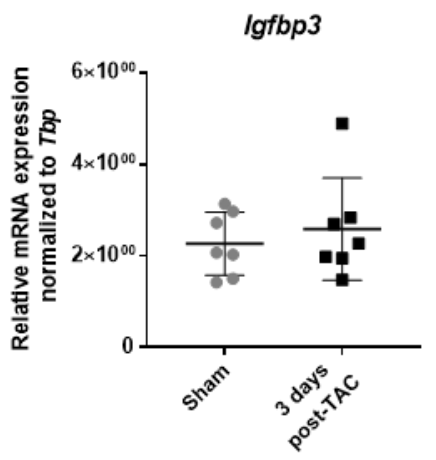

B

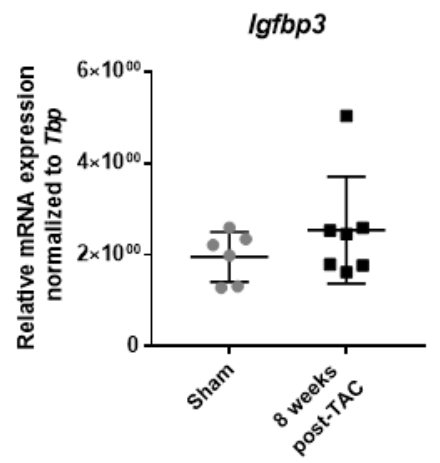

Figure 4-2: $\operatorname{Ig} f b p 3$ expression is not changed in the diseased murine heart

(A) Igfbp 3 expression 3 days and (B) 8 weeks post-TAC. $n(A)=7$ per group, $n(B)=6 / 7$ per group. Tbp (TATA-binding protein) was used for normalization.

A

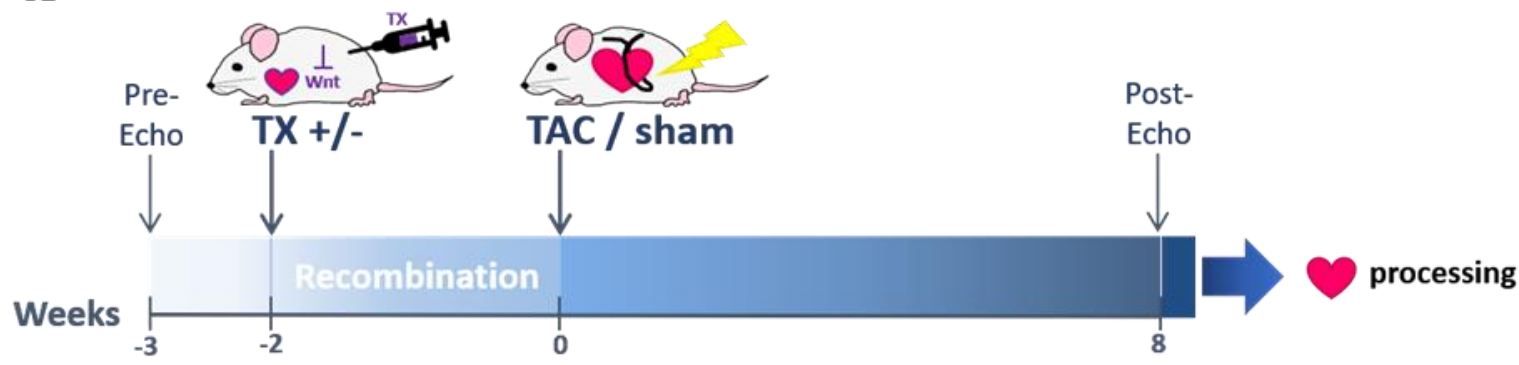

B

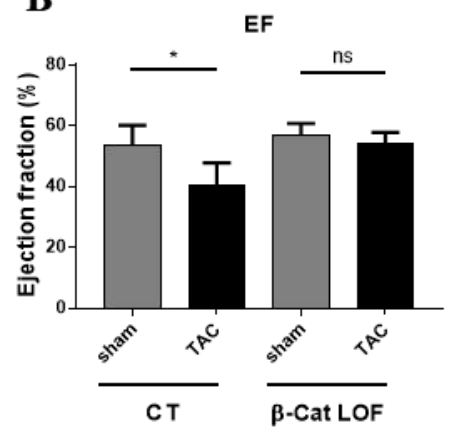

C

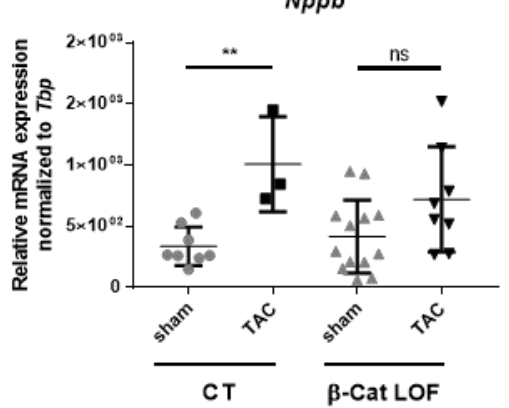

D

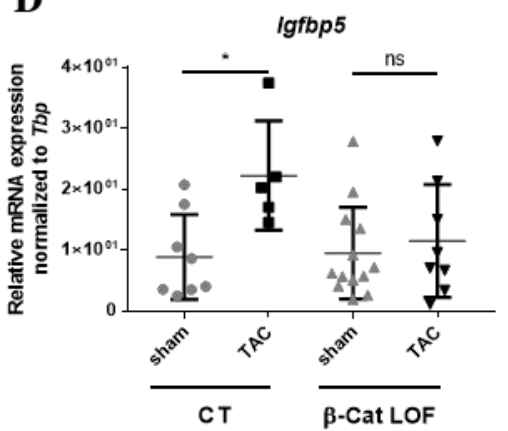

Figure 4-3: Igfbp5 expression upon preserved cardiac function post-TAC

(A) Scheme of TAC rescue experiment using mice with inducible cardiomyocyte specific $\beta$-catenin depletion [ $\beta$-Cat LOF]. TX=tamoxifen. (B) Cardiac function depicted by ejection fraction [EF] in \% comparing control mice with transgenic mice upon TAC and sham operation. $\mathrm{n}(\mathrm{CT})=3 / 5$ per group and $\mathrm{n}(\beta-\mathrm{Cat} \mathrm{LOF})=3 / 6$ per group. $(\mathbf{C}) \mathrm{Nppb}$ and (D) Igfbp 5 expression in TAC versus sham operated control mice and in mice with $\beta$-Cat LOF. Data is normalized to Tbp (TATA-binding protein). $\mathrm{n}(\mathrm{CT})=8 / 5$ per group and $\mathrm{n}(\beta$-Cat LOF $)=12 / 8$ per group. $\mathrm{n}(\mathrm{CT})=6 / 3$ per group and $\mathrm{n}(\beta$ Cat LOF $)=13 / 7$ per group. Data mean $\pm \mathrm{SD}$; t-test, (ns) not significant, $* \mathrm{P}<0.05$, ** $\mathrm{P}<0.01$. 
A

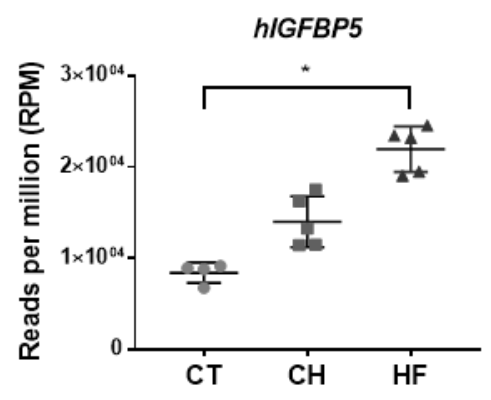

C

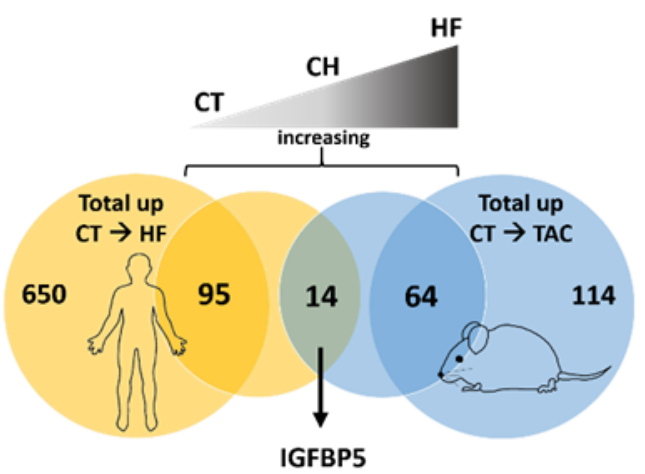

B

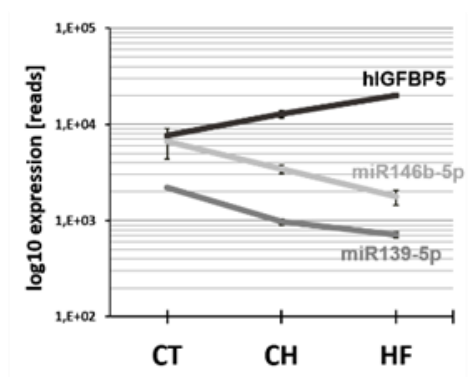

Figure 4-4: $h I G F B P 5$ expression and expression of $h I G F B P 5$ targeting microRNAs in aortic stenosis patients (A) Analysis of transcriptome of non-failing control patients [CT], compensated hypertrophy (ejection fractions $>55 \%$ ) $[\mathrm{CH}]$ and heart failure (ejection fractions $<55 \%$ ) $[\mathrm{HF}]$ patients. $\mathrm{n}=4 / 5 / 5$ per group. Cut off $>100 \%$ change in expression, adjusted p-value * $\mathrm{P}<0.05$. (B) hIGFBP5 and hIGFBP5-targeting microRNA expression (miR146b-5p [light grey], miR139-5p [dark grey]) in aortic stenosis patients. (C) Expression of genes found increasingly upregulated from nonfailing to compensated hypertrophy, to heart failure in mice and humans depicted in outer intersects. Middle intersect shows conserved increasingly upregulated genes. (Data provided by Dr. Sara Khadjeh, Department of Cardiology and Pneumology, UMG, Khadjeh et al., unpublished). 
A

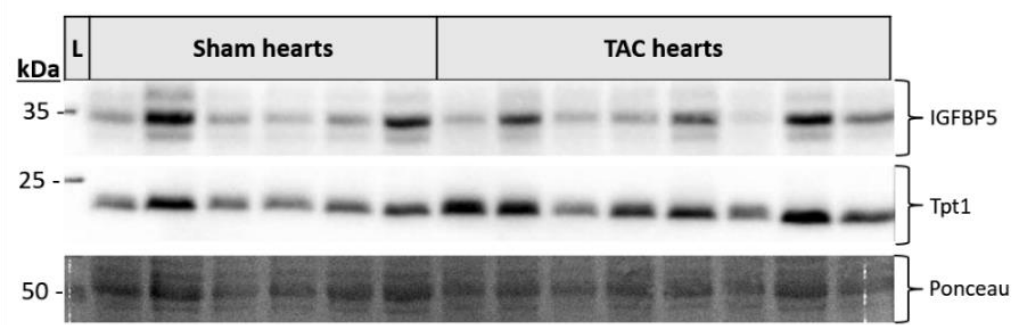

B

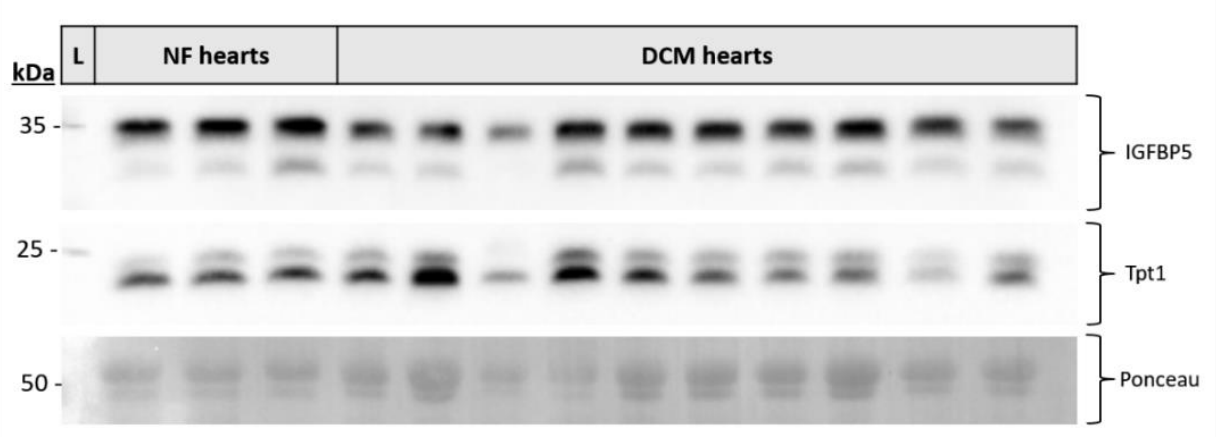

Figure 4-5:Validation of IGFBP5 protein expression in the diseased murine and human heart

(A) Immunoblot analysis from murine hearts upon experimental heart failure (TAC versus sham operated) showing hIGFBP5 protein. $n=6 / 8$ per group. (B) Immunoblot analysis from patients with dilated cardiomyopathy [DCM] versus non-failing control hearts [NF] showing hIGFBP5 protein. $n=3 / 10$ per group. Tpt1 (Translationally-controlled tumor protein 1), and Ponceau-S staining were used as loading controls, $\mathrm{L}=$ ladder, blots are done twice. 


\subsection{Cardiac overexpression of Igfbp5 alters function and gene expression in the murine heart}

To investigate the direct effect of IGFBP5 on the murine heart in vivo, an adeno-associated viral (AAV) vector mediated approach was used (see experimental setup Figure 4-6B). AAV9 mediated gene transfer is a robust approach for cardiomyocyte specific OE of a gene of interest. Serotype 9 AAVs process high cardiac tropism and only show little genome distribution in other tissues [105]. To further achieve cardiomyocyte specificity, the GOI was expressed under the control of the human cardiac troponin $\mathrm{T}$ promoter. For this experimental setup, a C-terminal FLAG tagged murine Igfbp5 overexpression (IBP5 OE, representing the Igfbp5 cDNA), construct and a corresponding luciferase control (Luc CT) construct were cloned in a pSSV9 vector (see scheme in Figure 4-6A) and were used for AAV9 particle production (done by the laboratory of Prof. O. Mueller, Klinik für Innere Medizin III, UKSH, Kiel). With an age of 16 weeks mice underwent baseline echocardiography to determine cardiac functionality. Mice were divided in two treatment groups (IBP5 OE or Luc CT) and received a single dose of $2 \times 10^{12}$ AAV9 particles via tail vein injection. Echocardiography was repeated after six-, ten and 18 weeks post-injection and mice were subsequently sacrificed for characterization.

To verify the expression of the artificial IBP5 OE in the murine heart, qPCR validation was done using a primer covering the artificial FLAG sequence. This analysis showed a qPCR product amplification in samples from mice with IBP5 OE, whereas there was no qPCR product in hearts from Luc CT mice (Figure 4-6CD, n(gel)=9/7 per group, n(qPCR)=9 per group, $\mathrm{P}<0.01$ ). Further, analysis of total Igfbp5 expression (endogenous Igfbp5 plus artificial IBP5 OE) showed a significant upregulation in IBP5 OE mice in comparison to Luc CT mouse heart samples (Figure 4-6E, $\mathrm{n}=9$ per group, $\mathrm{P}<0.001$ ). To confirm the IBP5 OE on protein level, heart lysates were investigated via immunoblotting and FLAG detection. FLAG detection showed several unspecific bands, but no band at $37 \mathrm{kDa}$, where the tagged IGFBP5 protein was expected (Figure 4-6F, arrow, n=4/9 per group). Since IGFBP5-FLAG shows a separate and lager band $(\sim 37 \mathrm{kDa})$ than the endogenous IGFBP5 (35 kDa and $33 \mathrm{kDa})$, detection was also done with a customized IGFBP5 antibody, to detect all variants. There was neither an additional IGFBP5-FLAG band at $37 \mathrm{kDa}$ nor an increased protein abundance at $35 \mathrm{kDa}$ for the endogenous IGFBP5 in IBP5 OE heart samples detectable.

Comparing RNA sequencing (RNAseq) data from Luc CT and IBP5 OE heart samples with heart samples from mice which did not receive virus particles (termed $\mathrm{Wt}$ ), revealed a strong AAV9-mediated effect on gene expression (Figure 4-7AB, see intersects of regulated genes). 
Gene ontology analysis of AAV9-mediated gene regulation clustered the upregulated genes into regulation of transport, signalling, apoptotic signalling pathways and regulation of cell growth, while downregulated genes included cellular response to stress, cell cycle and chromatin organization. Gene ontology analysis of IGFBP5 mediated gene regulation clustered the downregulated genes into ECM organization, tissue morphogenesis, cell junction organization and heart contraction, while the upregulated genes are clustered in carboxylic acid metabolic process, oxidation-reduction process and lipid metabolic process (Figure 4-7C). Interestingly, gene associated with the diseased heart are upregulated in Luc CT mice when compared to non-treated mice (Figure 4-7C). Echocardiographic analysis of Wt mice which did not receive AAV9 particles, as well as Luc CT AAV9 and IBP5 OE AAV9 receiving mice 18 weeks post-virus administration was done. Analysis showed a significant smaller left ventricular inner diameter during systole (LVIDS) as well as a reduced end systolic volume ( Vol $\left._{\text {sys }}\right)$ in IBP5 OE mice when compared to age-matched non-treated Wt mice and the Luc CT mice (Figure 4-8AB, $\mathrm{n}(\mathrm{Wt})=3, \mathrm{n}($ Luc $C T)=6, \mathrm{n}(\mathrm{IBP} 5 \mathrm{OE})=5$ mice per group, $\mathrm{P}<0.05, \mathrm{P}<0.01)$. Heart- to body weight ratio was significantly reduced in mice which received IBP5 OE AAVs in comparison to mice which received the Luc CT AAVs, but did not reach statistical significance in comparison to the Wt mice (Figure 4-8C, $n(\mathrm{Wt})=3, \mathrm{n}($ Luc CT $)=6, \mathrm{n}(\mathrm{IBP} 5 \mathrm{OE})=5$ mice per group, $\mathrm{P}<0.05, \mathrm{P}<0.01)$. Next, transcript expression of the cytoskeletal genes $M y h 7$ and cardiac troponin $\mathrm{T}$ (Tnnt2) were analysed and showed a significant downregulation in IBP5 OE mice when compared to Luc CT mice (Figure 4-8DE, $\mathrm{n}=9 / 6$ per group, $\mathrm{P}<0.05$; $\mathrm{P}<0.01)$. Further, the developmental genes myocardin (Myocd), Nkx2.5 and myocyte-specific enhancer factor 2C (Mef2c) were significantly downregulated in IBP5 OE mice when compared to Luc CT mice (Figure 4-8F-H, n=9/6 per group, $\mathrm{P}<0.05$ ). Since a direct effect of the Luc CT construct on the heart cannot be exclude, an additional control will be used to further validate this study

Taken together, these data indicate that IBP5 OE in vivo seems to affect cardiac physiology and gene expression, independent from an AAV9-mediated effect on gene expression. 
$\mathbf{A}$

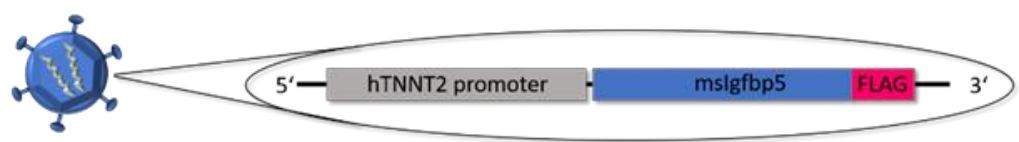

B

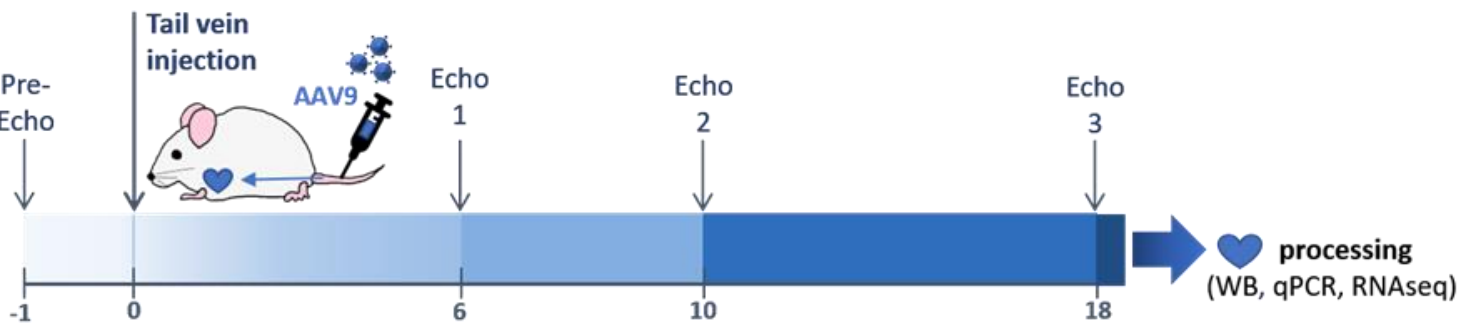

C

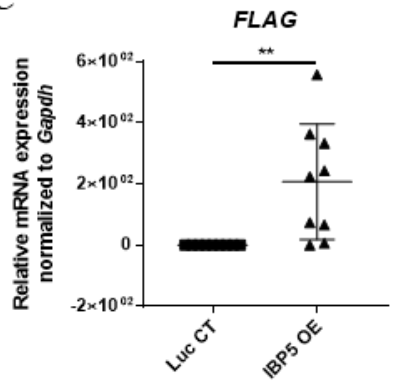

$\mathbf{E}$

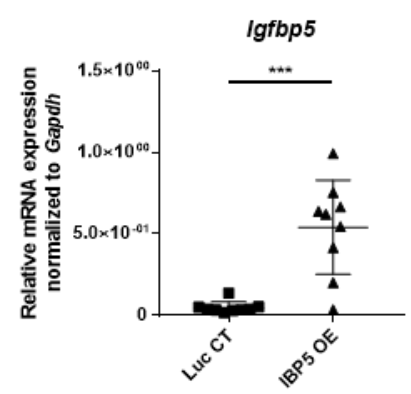

D

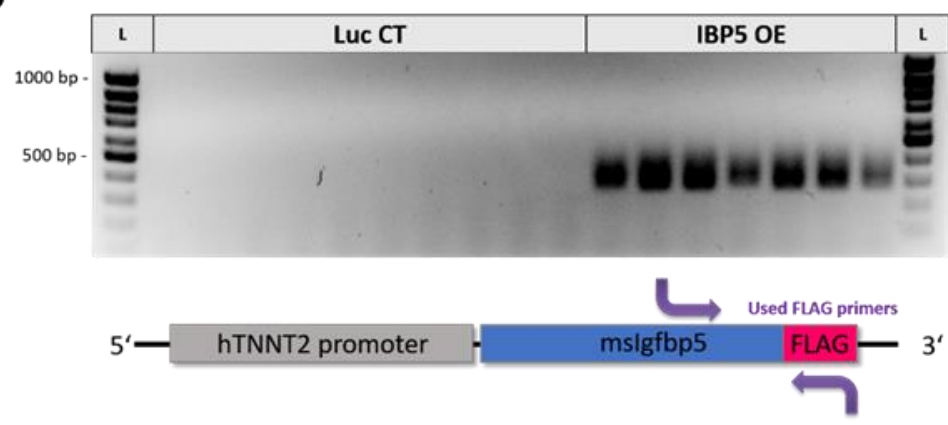

$\mathbf{F}$

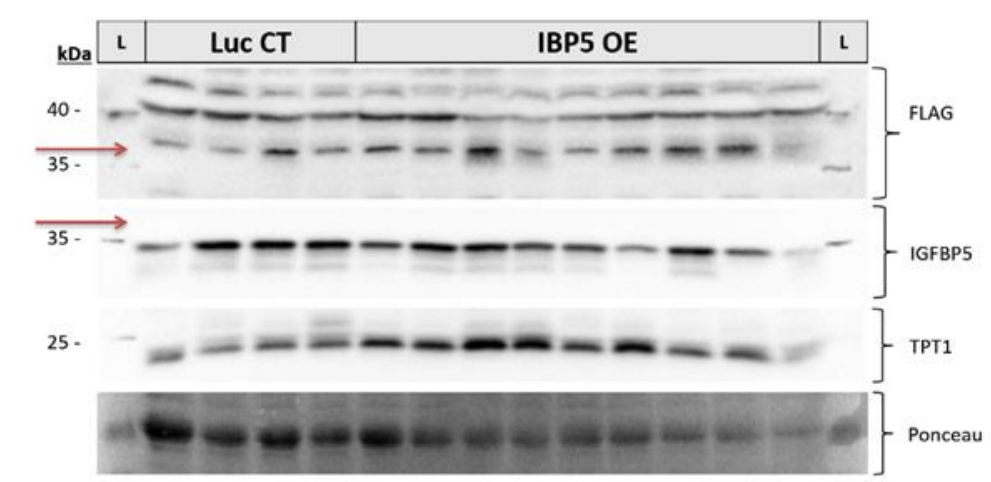

Figure 4-6: Validation of AAV9 mediated expression of Igfbp5 in murine hearts in vivo

(A) Scheme of Igfbp5 expression-construct in AAV particles. (B) Timeline of AAV9 mediated gene transfer in vivo. (C, D) cDNA genotyping of artificial Igfbp5-FLAG expression from heart samples 18 weeks post virus application (with scheme of used primers) and (E) qPCR analysis of total Igfbp5 expression. Gapdh is used for normalization in (C) and (E). $n(C, E)=9$ per group, $n(D)=9 / 7$ per group. $(\mathbf{F})$ Immunoblot analysis of heart/cardiomyocyte specific FLAG-tagged IGFBP5 overexpression in murine hearts. Tumor protein translationally-controlled 1 [TPT1] and Ponceau-S staining were used as loading controls. Arrows indicate where tagged protein should appear. $n=4 / 9$ per group. Data are mean \pm SEM; t-test, ** $\mathrm{P}<0.01 ; * * * \mathrm{P}<0.001$. 


\begin{tabular}{|l|l|l|l|}
\hline A Upregulated genes & B \\
\hline $\begin{array}{l}\text { AAV9-mediated } \\
\text { gene expression }\end{array}$
\end{tabular}

C

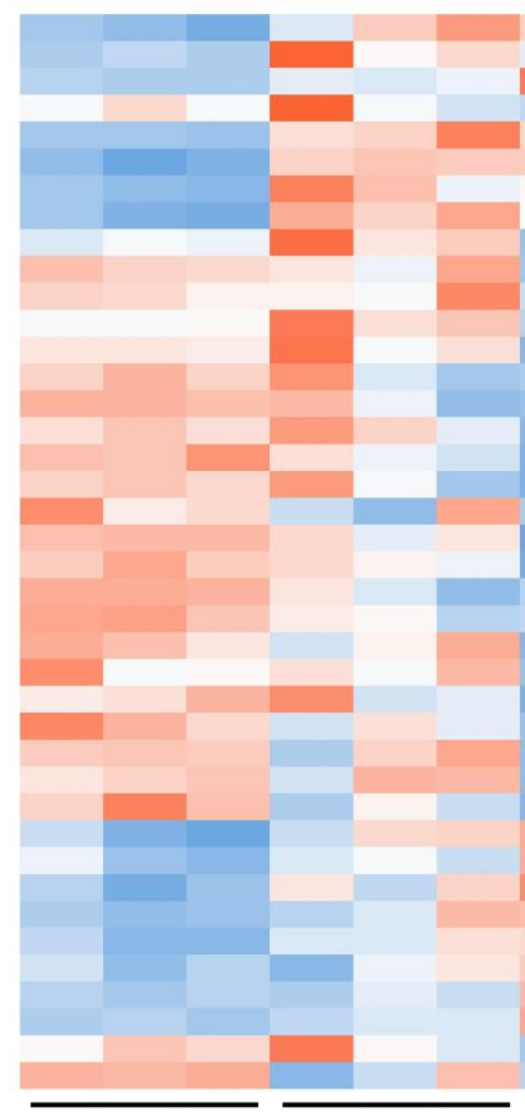

Wt

Luc CT

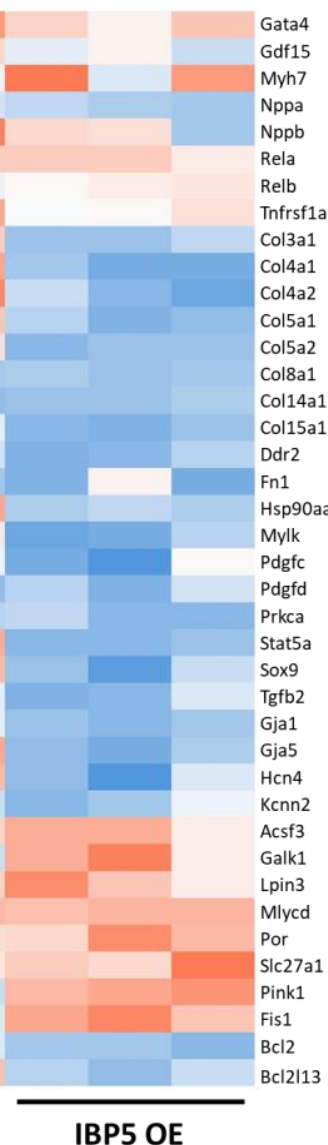

\section{Hypertrophy}

Immune response

Extra cellular matrix 1

\section{Conduction/}

cell communication

Lipid metabolism

Mitochondria turnover

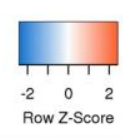

Figure 4-7: RNA sequencing results of murine hearts with AAV9 mediated Igfbp5 overexpression

RNA sequencing analysis showing (A) upregulated and (B) downregulated genes in Luc control virus- [Luc CT] and Igfbp 5 overexpression [IBP5 OE] virus treated mice in comparison to non-treated mice [Wt]. Intersect shows AAV9 mediated gene expression. Gene ontology analysis of AAV9-mediated and IGFBP5 mediated gene regulation shows clustering of genes to processes. (C) Heatmap depicting raw Z-scores of RPKMs of regulated genes involved in hypertrophy, immune response, extra cellular matrix, conduction/cell communication, lipid metabolism and mitochondria turnover. 
A

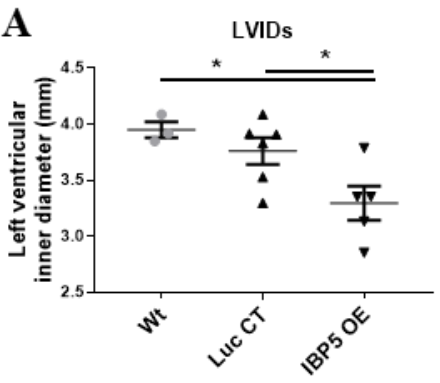

D

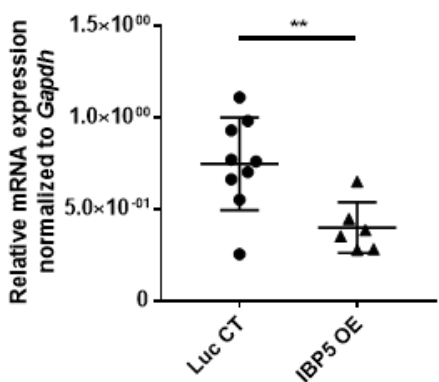

G

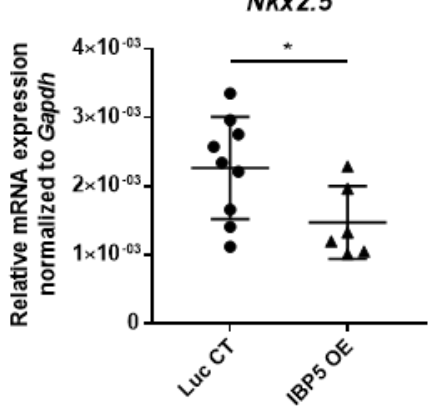

B

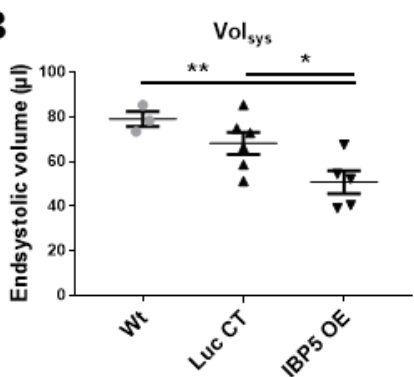

$\mathbf{E}$

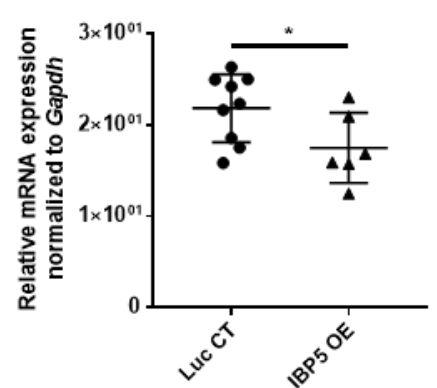

$\mathbf{H}$

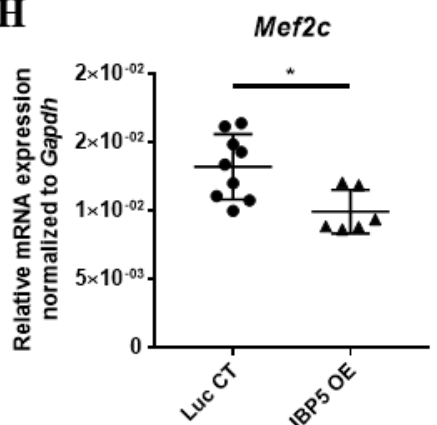

C

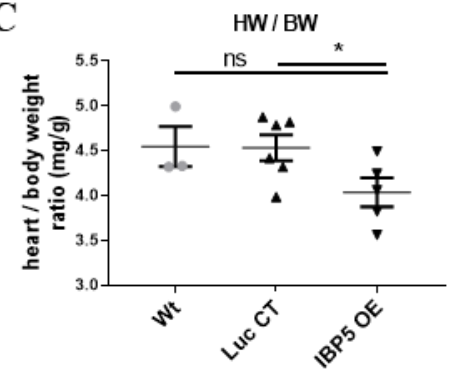

$\mathbf{F}$

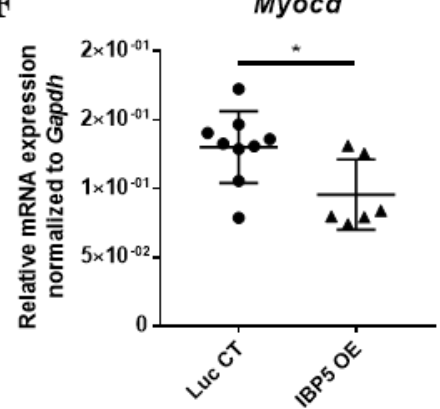

Figure 4-8: Analysis of murine hearts with AAV9 mediated Igfbp5 overexpression

Echocardiographic analyses of Luc control virus [Luc CT] and Igfbp5 overexpression [IBP5 OE] virus treated mice in comparison to non-treated mice [Wt]. (A) Left ventricular inner diameter during systole [LVIDs], (B) end systolic volume $\left[\mathrm{Vol}_{\text {sys }}\right]$ and $(\mathbf{C})$ heart- to body weight ratio 18 weeks post AAV9 administration. $\mathrm{n}(\mathrm{A}-\mathrm{C})=3 / 6 / 5$ mice per group. (D-H) qPCR analysis of Igfbp5 overexpression (IBP5 OE) hearts in comparison to Luc control [Luc CT] hearts. (D) myosin heavy chain beta [Myh7], (E) cardiac troponin T [Tnnt2], (F) myocardin [Myocd], (G) Nkx2.5 and (H) myocytespecific enhancer factor $2 \mathrm{C}[\mathrm{Mef} 2 c]$ expression. $\mathrm{n}(\mathrm{D}-\mathrm{H})=6-9$ hearts per group. Data are mean $\pm \mathrm{SEM}$; $\mathrm{t}$-test, $* \mathrm{P}<0.05$; ** $\mathrm{P}<0.01$. 


\subsection{IGFBP5 originates from cardiomyocytes of the diseased murine heart and can be detected in blood serum}

To investigate which cell population in the diseased murine heart is responsible for the upregulation of $I g f b p 5$, cardiomyocyte and non-myocyte cell populations were examined upon TAC-induced HF. Mice underwent TAC and sham operation and cell populations were isolated using the Langendorff perfusion technique (see scheme for sample utilization in Figure 4-9A). qPCR analysis of the non-myocyte population showed no difference in Igfbp5 expression comparing TAC and sham-derived non-myocytes (Figure 4-9B, n=4 mice/isolations per group). In contrast, a significant upregulation of Igfbp5 expression could be observed in the cardiomyocyte population comparing TAC with sham-derived cardiomyocytes (Figure 4-9C, $\mathrm{n}=5$ mice/isolations per group, $\mathrm{P}<0.05)$. Further, the hypertrophy marker $N p p b$ showed a significant upregulation in cardiomyocyte isolated from TAC hearts, when compared to cardiomyocytes from sham hearts (Figure 4-9D, $\mathrm{n}=5$ mice/isolations per group, $\mathrm{P}<0.05$ ). Moreover, Langendorff isolated cell populations from hearts with cardiomyocyte specific $\beta$ catenin gain of function ( $\beta$-Cat GOF), which developed HF, showed a comparable result. Expression analysis of the non-myocyte population showed no difference in Igfbp5 expression comparing control and $\beta$-Cat GOF heart-derived non-myocytes (Figure 4-9E, $n=5$ mice/isolations per group). In contrast, Igfbp5 expression was significantly upregulated in cardiomyocytes with $\beta$-Cat GOF in comparison to cardiomyocytes from control hearts (Figure 4-9F, $\mathrm{n}=5$ mice/isolations per group, $\mathrm{P}<0.0001$ ). Since the expression of Igfbp5 was very strong in cardiomyocyte with $\beta$-Cat GOF, protein quantification was done. There was no difference between $\beta$-Cat GOF and control cardiomyocytes detectable (Figure 4-10A, n=6/8 per group, blot was done twice). IF staining from isolated $\beta$-Cat GOF cardiomyocytes further confirmed these results. No difference in IGFBP5 staining intensity could be observed comparing IF staining from $\beta$-Cat GOF cardiomyocytes to control cardiomyocytes (Figure 4-10B, one representative picture/group). Since IGFBPs have secretory signal peptides and are mainly found extracellularly [111], it was hypothesized that increased protein quantities are immediately secreted. To test this hypothesis, control and $\beta$-Cat GOF cardiomyocytes were isolated and cultured for 24 hours. Secreted IGFBP5 in cell supernatant was quantified using ELISA assay. This analysis revealed a significant increase in IGFBP5 protein abundance in cell supernatants from $\beta$-Cat GOF cardiomyocytes in comparison to supernatants from control cardiomyocytes (Figure $4-10 \mathrm{C}, \mathrm{n}=4$ isolations, $\mathrm{P}<0.0001$ ). To investigate whether secreted IGFBP5 from diseased cardiomyocytes might enter the circulation and is also detectable in blood serum, ELISA protein detection of IGFBP5 was done (see scheme of sample origin, 
Figure 4-10A). Serum IGFBP5 quantities from TAC mice and from mice with cardiac $\beta$ Cat GOF were compared to serum from control mice. This analysis showed a significant increase of serum IGFBP5 in mice post-TAC and in mice with $\beta$-Cat GOF in comparison to control mice (Figure 4-10D, n(CT/TAC/ $\beta$-Cat GOF=11/9/4 per group, $\mathrm{P}<0.05)$. Collectively this data indicate that $I g f b p 5$ is mainly expressed from cardiomyocytes of the diseased heart, while increased protein quantities are found extracellularly. 


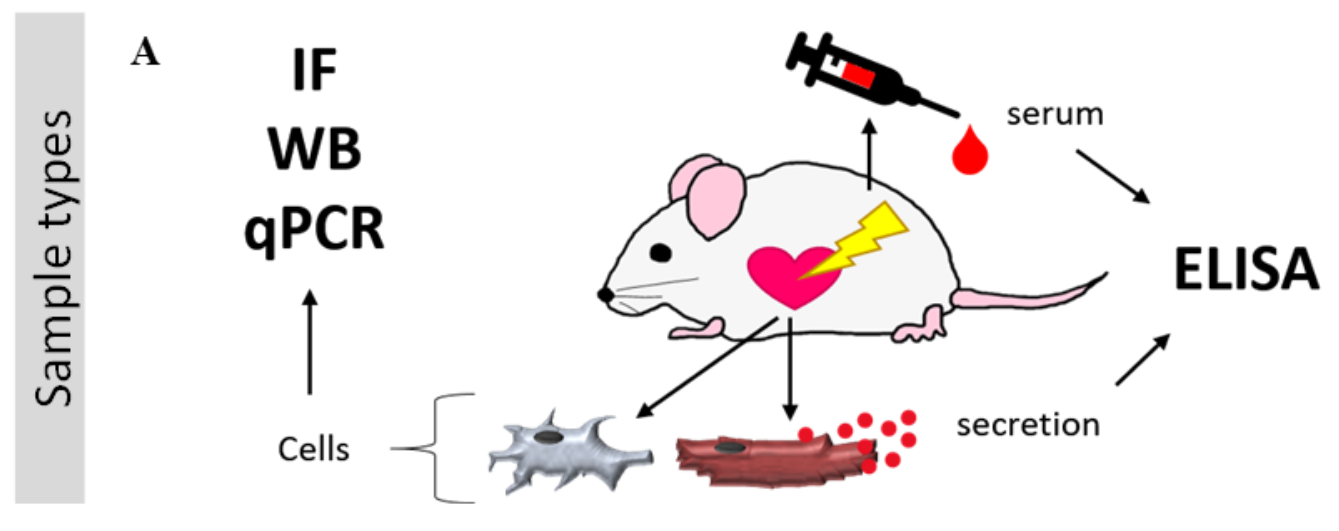

B

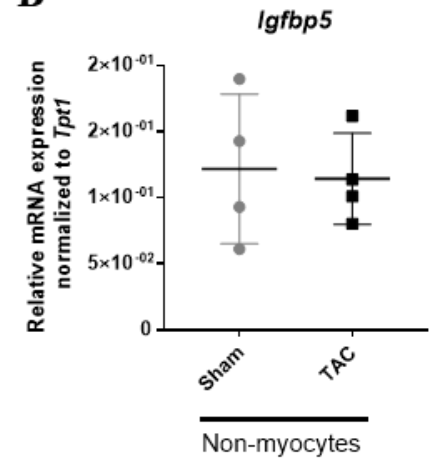

C

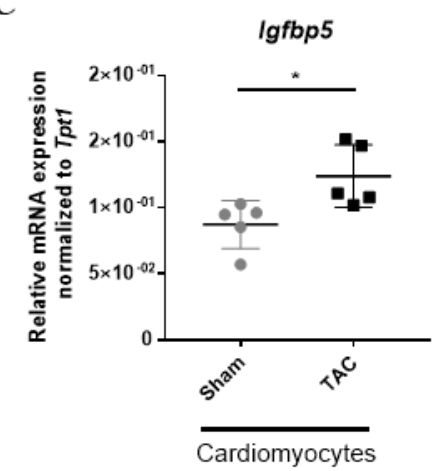

D

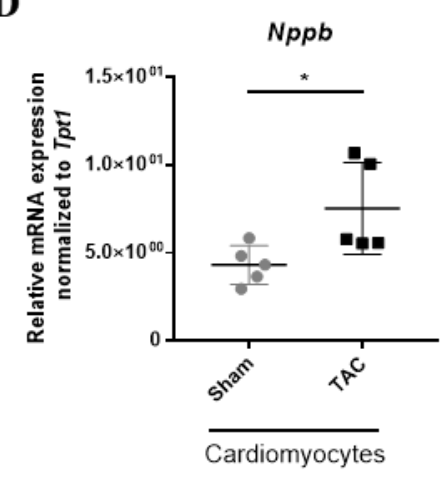

E

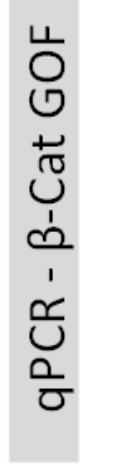

Igfbp5

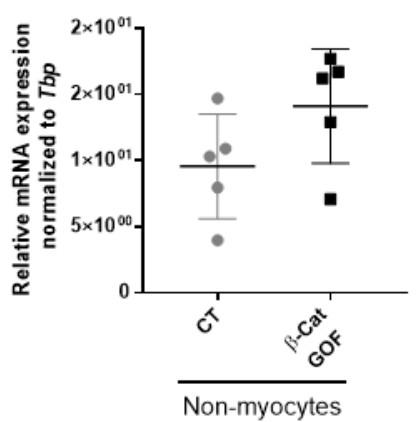

F

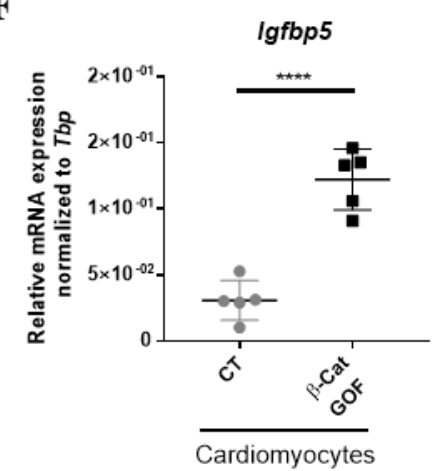

Figure 4-9: Igfbp5 expression originates from cardiomyocytes

(A) Scheme of Langendorff-cell and serum utilization. (B) Igfbp5 expression in isolated non-myocytes and (C) cardiomyocytes from TAC and sham operated mice. (D) Nppb expression in isolated cardiomyocytes. Data is normalized to Tpt1 (Translationally-controlled tumor protein 1). $\mathrm{n}$ (cardiomyocytes) $=5$ mice/isolations per group, $\mathrm{n}$ (nonmyocytes $)=4$ mice/isolations per group. Data mean $\pm \mathrm{SD}$; $\mathrm{t}$-test, $* \mathrm{P}<0.05$. (E) Igfbp5 expression in isolated nonmyocytes and (F) cardiomyocytes from mice with cardiomyocyte specific $\beta$-catenin stabilization [ $\beta$-Cat GOF]. Data is normalized to $\operatorname{Tbp}$ (TATA-binding protein). $\mathrm{n}$ (cardiomyocytes) $=5$ mice/isolations per group, $\mathrm{n}($ non $-\mathrm{myocytes})=5$ mice/isolations per group. Data are mean $\pm \mathrm{SEM}$; t-test, $* * * * \mathrm{P}<0.0001$. 

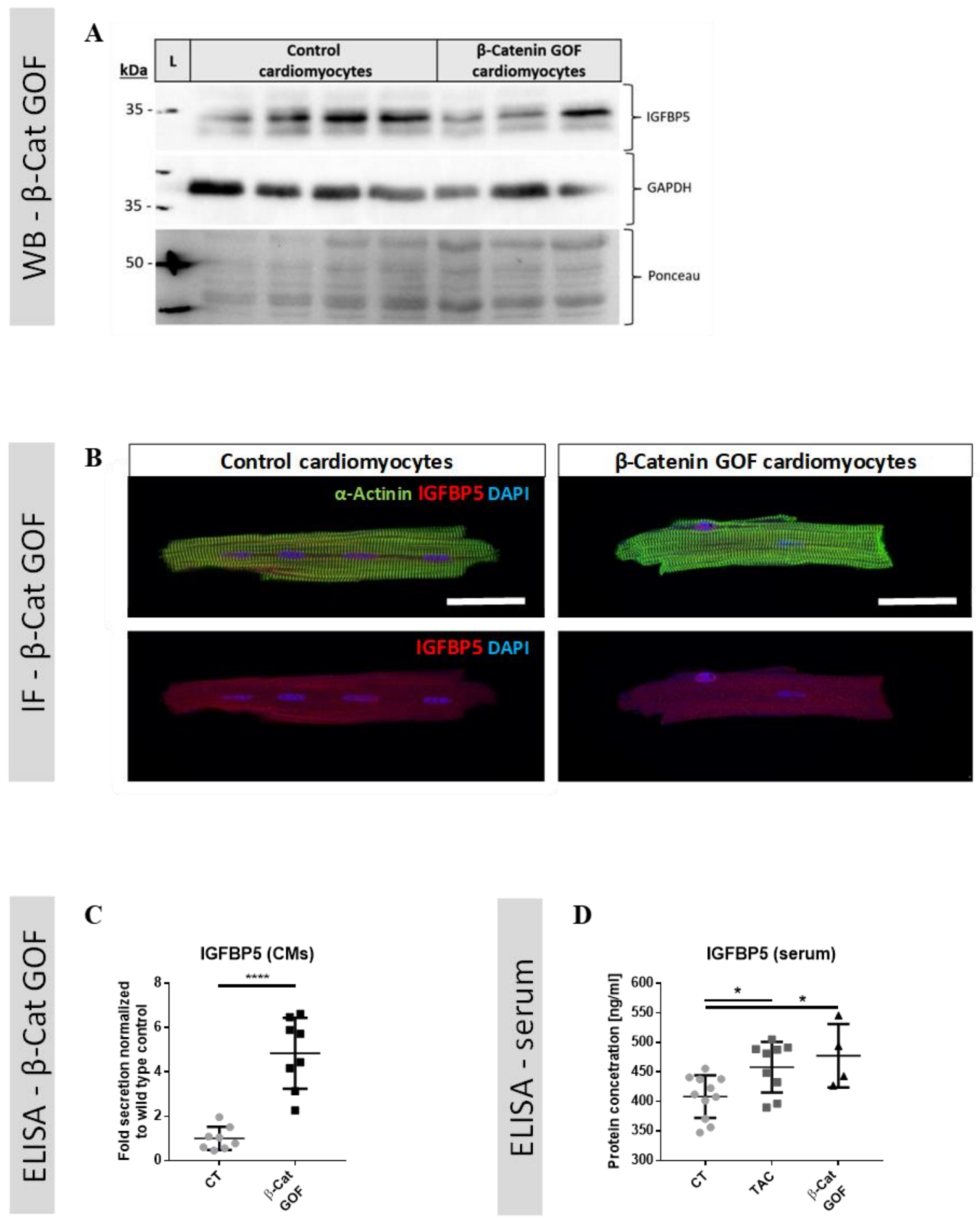

Figure 4-10: IGFBP5 is secreted from cardiomyocytes

(A) Immunoblot analysis and (B) immunofluorescence staining from isolated cardiomyocytes from mice with cardiomyocyte specific $\beta$-catenin stabilization $[\beta$-Cat GOF] showing IGFBP5 protein. $n(b l o t)=4 / 5$ isolations per group, one representative picture/group. $\alpha$-actinin (green), IGFBP5 (red), DAPI nuclei staining (blue). Scale bar is $100 \mu \mathrm{m}$. (C) ELISA quantification of IGFBP5 protein in supernatants from $24 \mathrm{~h}$ cultured cardiomyocytes from mice with cardiomyocyte specific $\beta$-catenin stabilization $[\beta-C a t$ GOF] $n=4$ isolations, cell culturing in duplicates. (F) ELISA quantification of IGFBP5 protein in blood serum from mice with TAC and with $\beta$-Cat GOF. $n=11 / 9 / 4$ per group. Data are mean \pm SEM; t-test, $* \mathrm{P}<0.05$; **** $\mathrm{P}<0.0001$. 


\subsection{IGFBP5 can be uptaken by cardiac fibroblasts affects gene expression}

\subsubsection{IGFBP5 can be uptaken by cardiac fibroblasts and activates its own expression}

Since IGFBP5 was found highly secreted from cardiomyocytes in the diseased heart, it was of interest to investigate whether secreted IGFBP5 can act in a paracrine manner on adjacent cells. Since bidirectional cardiomyocyte-fibroblast crosstalk is a well-known mechanism in both normal and diseased hearts, it was examined whether IGFBP5 can be uptaken by cardiac fibroblasts. For this, human cardiac fibroblasts (hCFBs) were treated for $48 \mathrm{~h}$ with IGFBP5FLAG conditioned medium, while uptaken IGFBP5 was later detected using a FLAG antibody (see scheme for experimental setup in Figure 4-11A). IF imaging showed a FLAG staining in cardiac fibroblasts treated with IGFBP5-FLAG conditioned medium, while no FLAG expression was detectable in control medium treated cells (Figure 4-11B, n=2 representative pictures/group). However, it was not possible to detect IGFBP5-FLAG in samples of conditioned medium treated hCFBs via immunoblotting. Possibly this was due to an insufficient uptake of detectable IGFBP5 amounts, which could be explained by a rapidly decreasing proliferation rate of hCFBs in vitro. To overcome this problem, highly proliferative murine embryonic cardiac fibroblasts (MEFs) were used. Immunoblot analysis of MEFs treated with IGFBP5-FLAG conditioned medium showed an additional band of about $37 \mathrm{kDa}$ using a FLAG-antibody. This band represents FLAG tagged IGFBP5, while there was no band detectable in control medium treated MEFs (Figure 4-11D, n=3/group, blot was done twice). Further, IGFBP5 conditioned medium treated hCFBs were examined on RNA level. Analysis of IGFBP5 expression showed a significant upregulation of the transcript in IGFBP5-FLAG conditioned medium treated cells in comparison to control cells (Figure 4-11C, n=4 different passages, $\mathrm{P}<0.05)$.

These data suggest that secreted IGFBP5 can be reuptaken by cardiac fibroblasts and changes its own expression.

\subsubsection{Molecular and physiologic effect of IGFBP5 on human cardiac fibroblasts}

Since exogenous IGFBP5 was shown to affect cardiac fibroblasts (hCFBs), cellular events triggered by IGFBP5 in these assumed receiver cells were investigated. To achieve a consistent and robust artificial expression of hIGFBP5 in hCFBs, lentiviral particles with an IBP5 OE construct were generated and cells were transduced. Lentiviral particles with a GFP OE construct served as control (see experimental setup in Figure 4-12A, see GFP transduction efficiency in Figure 4-12B). After cell processing, IBP5 OE was confirmed on RNA level 
(Figure 4-12C, $\mathrm{n}=3$ different passages, $\mathrm{P}<0.0001)$. Alpha-smooth muscle actin $($ ACTA2), which was often described to be upregulated upon IBP5 OE was not regulated in cells with IBP5 OE when compared to GFP CT cells (Figure 4-12D, n=3 different passages). Other RNAs were detected using RNA sequencing (done by Transcriptome and Genome Analysis Laboratory (TAL) Goettingen). Data analysis (done by Lavanya M. Iyer, Institute of Pharmacology and Toxicology, UMG Goettingen) revealed in total twelve differentially expressed genes comparing IBP5 OE versus a GFP CT (Figure 4-12E, n=3, technical triplicate, $\log 2 \mathrm{FC} \pm 0.5$, $\mathrm{P}<0.05)$. Some of the downregulated genes were already described in the context of cardiovascular disease, like MYOCD [112], stanniocalcin-1 (STC1) [113], thioredoxininteracting protein (TXNIP) [114], CC-chemokine ligand 2 (CCL2) [115] and hyaluronan synthase 2 (HAS2) [116]. Also, among the upregulated genes some could be assigned to cardiovascular diseases like growth differentiation factor 15 (GDF15) [117] and NR3C2 (nuclear receptor subfamily 3 group C member 2) [118]. Validation of the most relevant differentially expressed genes showed an expression according to the RNA sequencing results (Figure 4-12F, $\mathrm{n}=3$ technical replicates in one passage, $\mathrm{P}<0.05 ; \mathrm{P}<0.01 ; \mathrm{P}<0.001 ; \mathrm{P}<0.0001$ ).

The previous results showed that IGFBP5 can alter gene expression of hCFBs. To investigate the functional performance of these hCFBs with IBP5 OE, engineered human myocardium (EHM) was generated (see scheme in Figure 4-13A. Experiment was done by Dr. Norman Liaw, Pharmacology and Toxicology, UMG Goettingen). This tissue model allows to measure functional performance by determining differences in contraction force. EHMs were produced by casting of hCFBs with lentiviral IBP5 OE or GFP CT together with stem-cell derived cardiomyocytes into a collagen matrix. Stable transduction efficiency after tissue generation and maturation was visualized via fluorescence microscopy, showing a GFP CT hCFBs in EHMs (Figure 4-13B, representative picture). Functional performance was measured as force of contraction (FOC) in response to extracellular calcium concentration (Figure 4-13B, $\mathrm{n}=6 /$ group) and as beating frequency per minute (Figure 4-13D, n=6/group), while there was no difference between EHMs with GFP CT hCFBs and EHMs with hCFBs with IBP5 OE. In contrast to the velocity of tissue contraction, the time to $50 \%$ tissue relaxation was significantly reduced in EHMs with IBP5 OE hCFBs when compared to the control (Figure 4-13F, $\mathrm{n}=6$ /group, 3 independent measurements, $\mathrm{P}<0.05$ ). Moreover, rate of isometric contraction and rate of isometric relaxation was significantly reduced in EHMs with IBP5 OE hCFBs when compared to EHMs with GFP CT hCFBs (Figure 4-13K-L). To investigate whether the IBP5 OE in hCFBs was stable 20 days post transduction and if it has an influence on expression of other genes in the engineered tissue, qPCR analysis of the generated EHMs was done. 
Validation of IGFBP5 showed a significant higher expression in EHMs generated with IBP5 OE hCFBs than in EHMs generated with GFP CT hCFBs (Figure 4-13I, n=6 EHMs per group, $\mathrm{P}<0.001)$. Regulated genes found upon RNA sequencing analysis of IBP5 OE in hCFBs like GDF15, MYOCD as well as STC1 were not regulated in EHMs generated with IBP5 OE hCFBs when compared to control EHMs (Figure 4-13J-L, n(I-L)=4-6 EHMs per group).

These findings confirm that IGFBP5 has an effect on cardiac fibroblasts and influences gene expression. Moreover, the increased IGFBP5 expression in cardiac fibroblasts in an EHM influences tissue physiology.

\subsubsection{Myofibroblast activation and IGFBP5 upregulation are not directly associated}

Several publications provide evidence that IGFBP5 has a pro-fibrotic effect in different tissues (see chapter 5.4.4). Interestingly, this study showed that Igfbp5 is upregulated upon HF, while the cardiomyocytes were found being the source for Igfbp5 upregulation suggesting no direct association between cardiac fibrosis and $I g f b p 5$ expression. To investigate whether pro-fibrotic effects and IGFBP5 expression are not associated in cardiac cells, hCFBs were treated with $10 \mu \mathrm{M}$ NE and with $1 \mathrm{ng} / \mathrm{ml}$ TGF $\beta$ for $48 \mathrm{~h}$ to activate myofibroblast transformation [119] (see experimental setup in Figure 4-14A). After $48 \mathrm{~h}$ of stimulation, qPCR analysis shows a significant upregulation of ACTA2, which is commonly used as a marker of myofibroblast formation, after TGF $\beta$ and NE treatment in comparison to non-treated controls (Figure 4-14B, $\mathrm{n}=3$ passages, $\mathrm{P}<0.01 ; \mathrm{P}<0.001)$. Moreover, NE treatment showed an upregulation of IGFBP5 in comparison to non-treated controls, while there was no regulation upon TGF $\beta$ treatment (Figure $4-14 C, \mathrm{n}=3$ passages, $\mathrm{P}<0.001$ ).

These data provide evidence that cardiac fibroblasts are not only receiver cells being responsive to IGFBP5, they also possess the capability to regulate IGFBP5 in response to NE, however myofibroblast activation and IGFBP5 upregulation are not directly associated. Importantly, in vivo data from this study (see chapter 4.2) further supports this assumption and even indicates an anti-fibrotic effect of IGFBP5. 
A

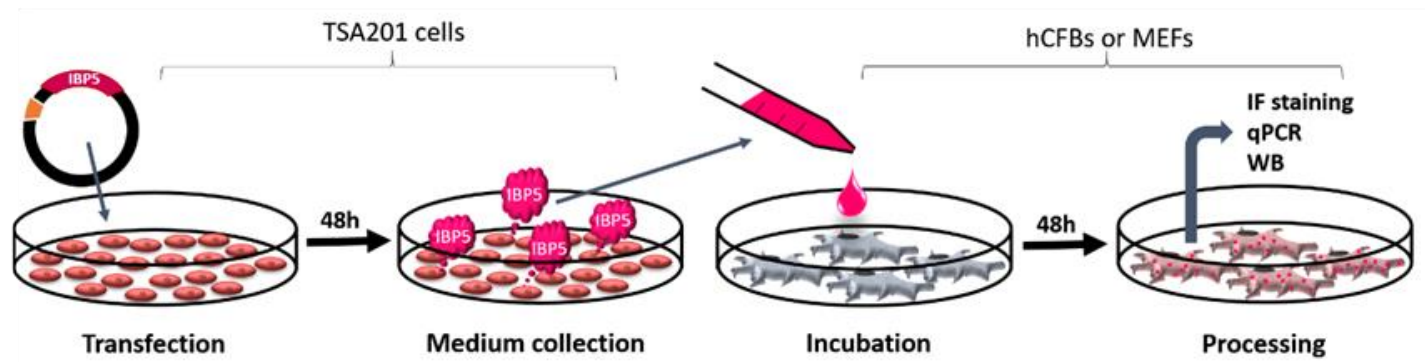

B
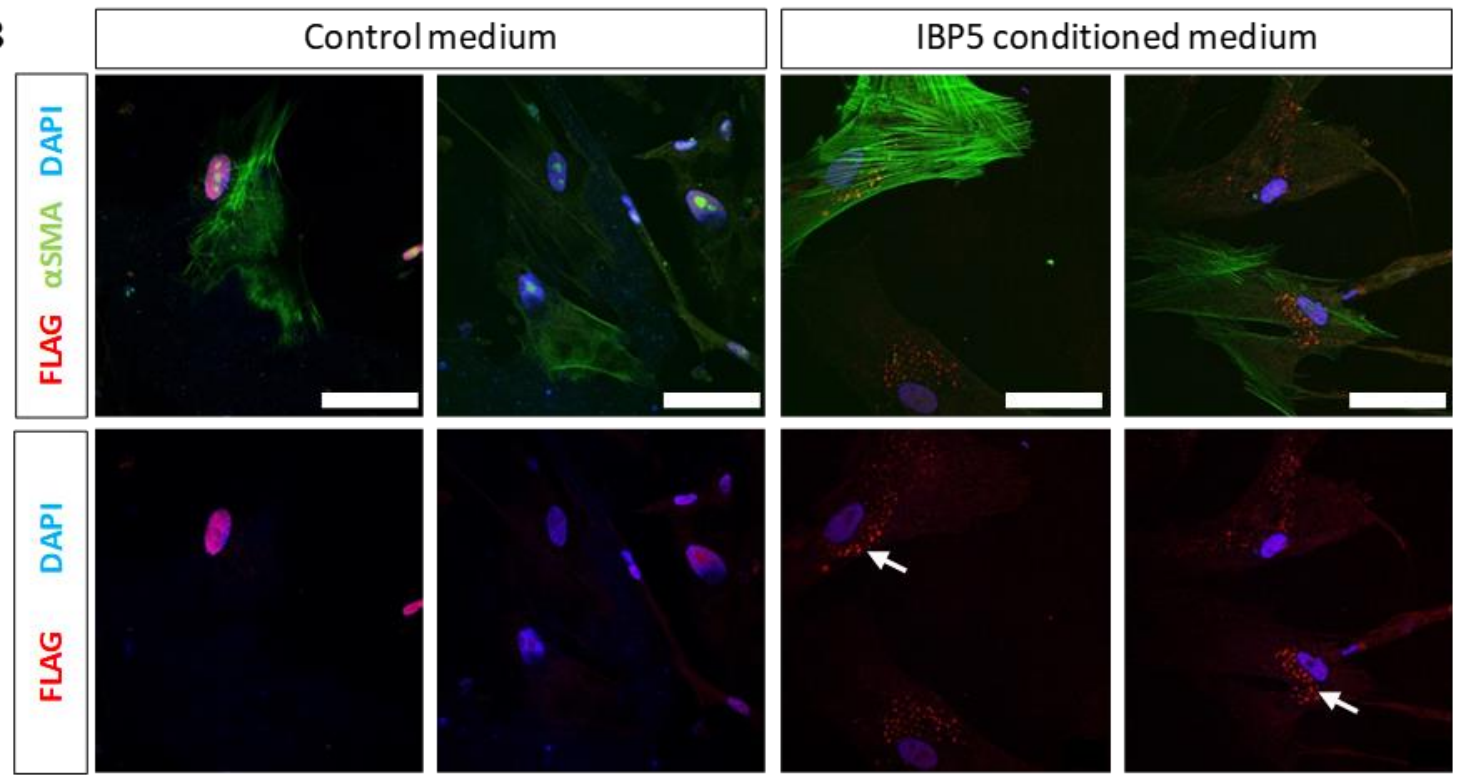

C

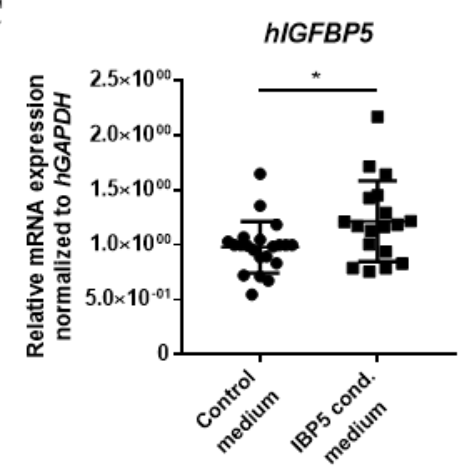

D

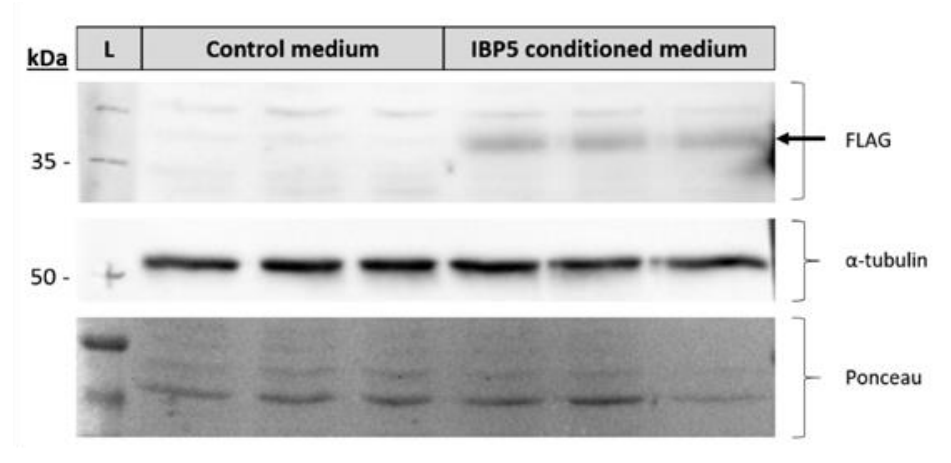

Figure 4-11: IGFBP5 is uptaken by cardiac fibroblasts

(A) Scheme of sample generation. (B) Immunofluorescence staining and (C) hIGFBP5 qPCR validation of human cardiac fibroblasts treated with IGFBP5-FLAG conditioned medium for $48 \mathrm{~h} . \mathrm{n}(\mathrm{IF})=2$ representative pictures/group. $\alpha$ smooth muscle actin [ $\alpha \mathrm{SMA}$ ] (green), FLAG (red), DAPI (blue). Scale bar is $50 \mu \mathrm{m}$. Arrows indicates IGFBP5-FLAG protein. $\mathrm{n}(\mathrm{qPCR})=4$ different passages in technical multiplicates. $h G A P D H$ is used for normalization. Data are mean \pm SEM; t-test, * $\mathrm{P}<0.05$. (D) Immunoblot analysis of neonatal cardiac fibroblasts treated with IGFBP5-FLAG conditioned medium for $48 \mathrm{~h}$. $\alpha$-tubulin and Ponceau-S staining are used as loading controls. $\mathrm{n}=3$ /group, blots are done twice. 
A

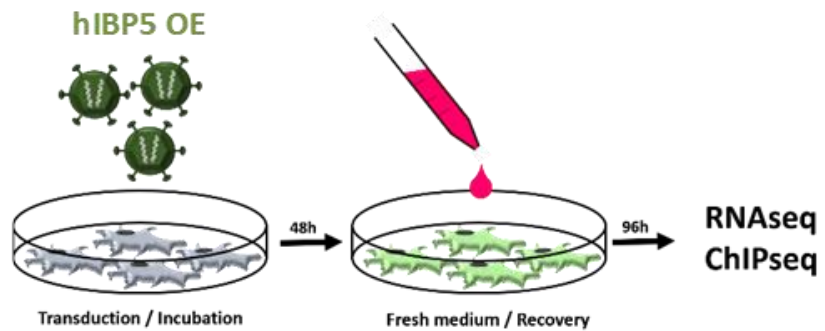

C

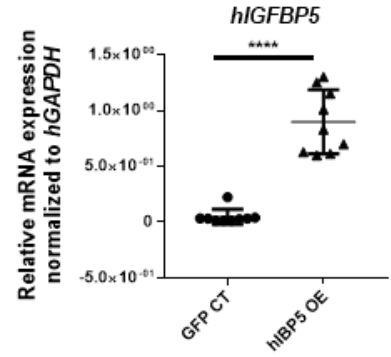

D

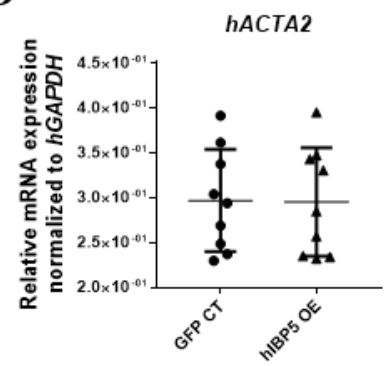

B
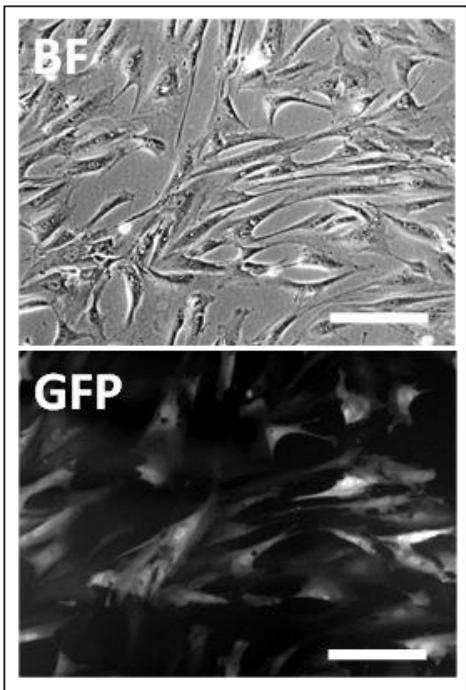

$\mathbf{E}$

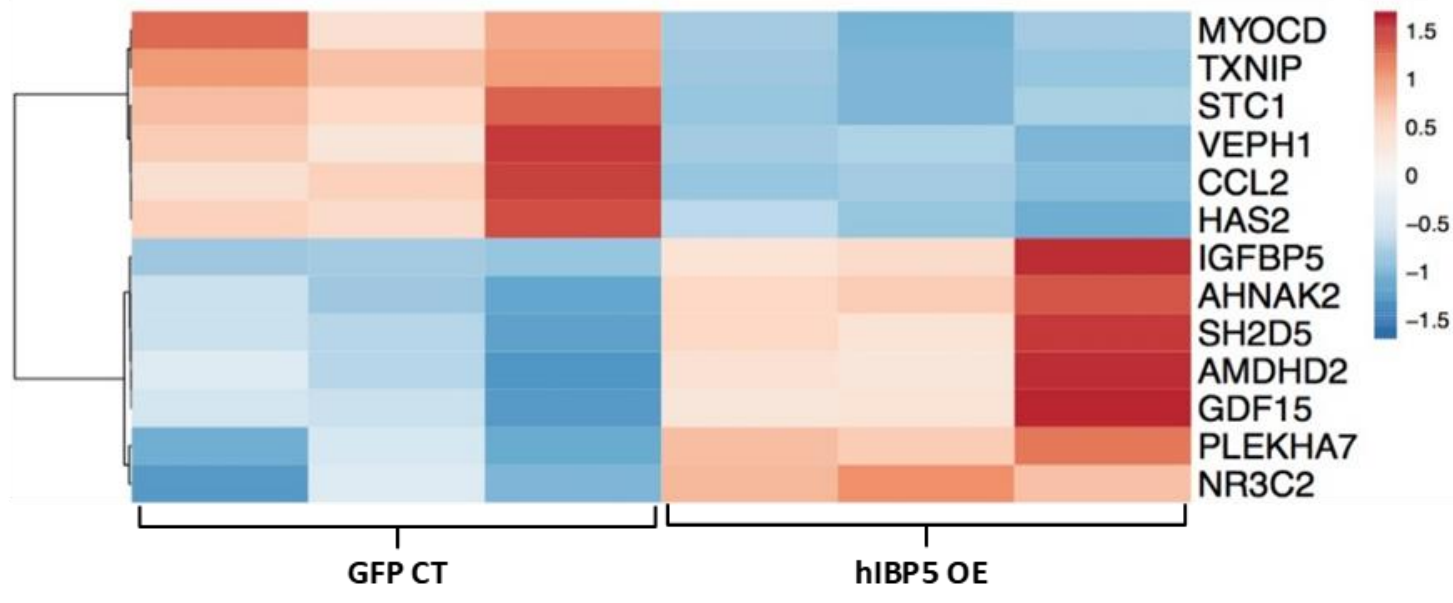

$\mathbf{F}$
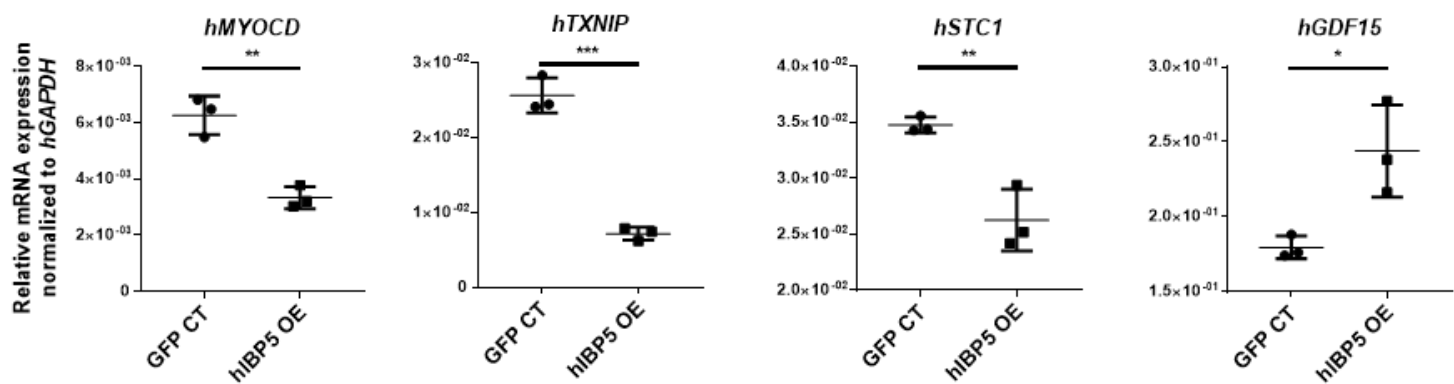

Figure 4-12: Effect of lentiviral overexpression of $\mathrm{hIGFBP5}$ on human cardiac fibroblasts

(A) Scheme of lentiviral overexpression (OE) of hIGFBP5 in human cardiac fibroblasts (hCFB). (B) Representative pictures of expression efficiency of GFP control virus in hCFBs. BF=bright field. Scale bar $200 \mu \mathrm{m}$. (C) qPCR validation of $h I G F B P 5$ overexpression [hIBP5 OE] and (D) $h A C T A 2$ expression. $\mathrm{n}=3$ passages. (E) Heatmap depicting normalized counts of differentially expressed genes ( $\log 2 \mathrm{FC} \pm 0.5, \mathrm{p}<0.05$ ). (F) qPCR validation of some RNAseq results from hCFBs after hIBP5 OE. $h G A P D H$ is used for normalization. $\mathrm{n}(\mathrm{E}-\mathrm{F})=3$ technical replicates, data are mean $\pm \mathrm{SEM}$; $\mathrm{t}$-test, $* \mathrm{P}<0.05 ; * * \mathrm{P}<0.01 ; * * * \mathrm{P}<0.001 ; * * * * \mathrm{P}<0.0001$. 
A

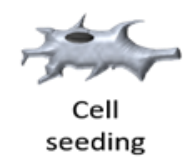

hIBP5 OE

$\downarrow$
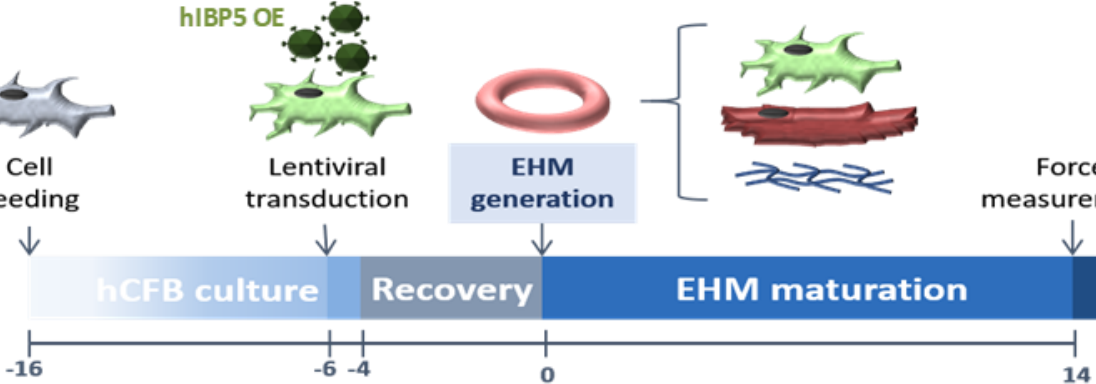

Lentiviral

transduction
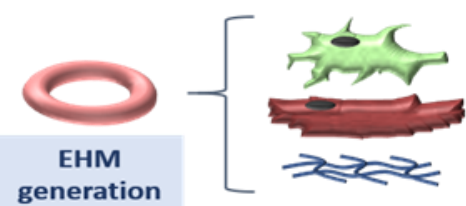

Force

measurement

B

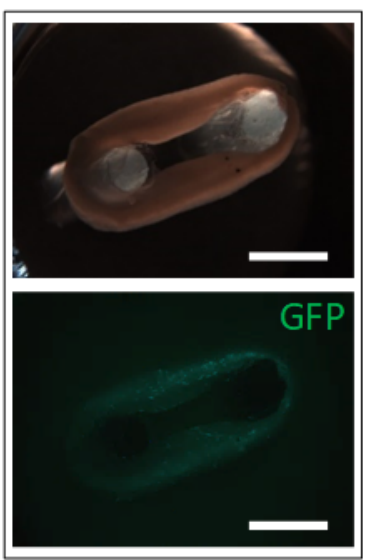

C Extracellular $\mathrm{Ca}^{2+}$ concentration-response

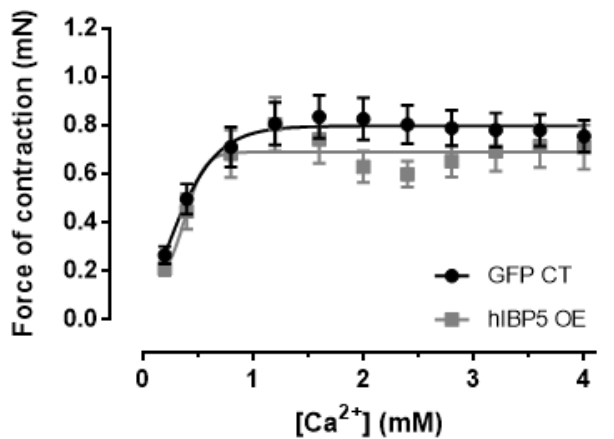

F Time to $50 \%$ relaxation (T2) (at $4.0 \mathrm{mM} \mathrm{Ca}{ }^{2+}, 1.5 \mathrm{~Hz}$ )

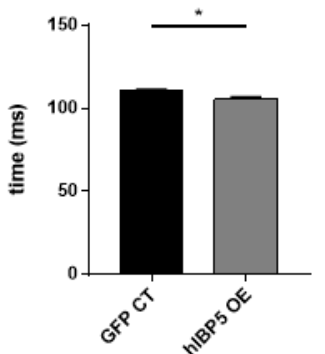

I

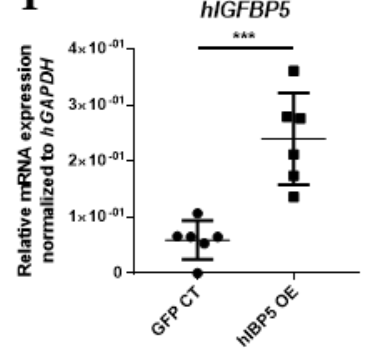

\section{$\mathbf{J}$}

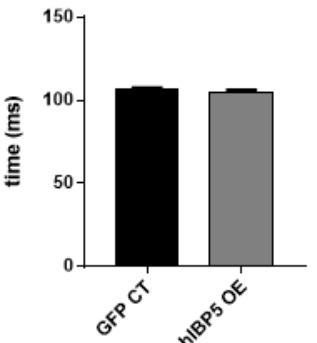

$1 \times 10$

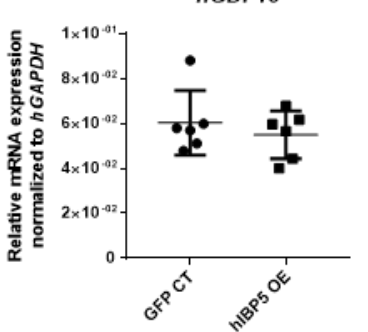

G Rate of isometric contraction (at $4.0 \mathrm{mM} \mathrm{Ca}^{2+}, 1.5 \mathrm{~Hz}$ )

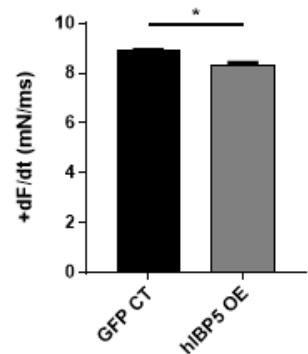

K

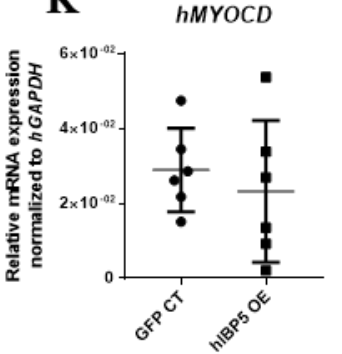

D

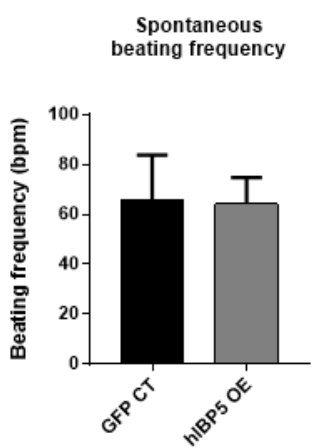

H Rate of isometric relaxation (at $4.0 \mathrm{mM} \mathrm{Ca}^{2+}, 1.5 \mathrm{~Hz}$ )

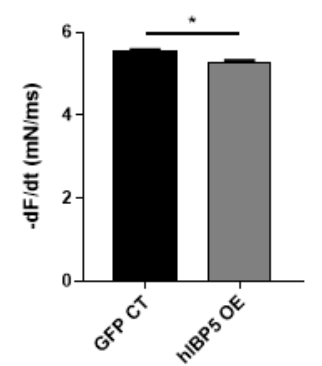

L

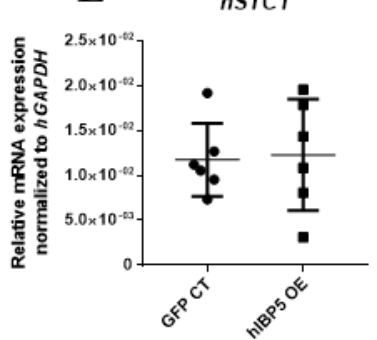

Figure 4-13: Cardiac fibroblast specific overexpression of hIGFBP5 in engineered human myocardium

(A) Schematic overview of engineered human myocardium (EHM) generation with hIGFBP5 overexpression [hIBP5 OE] transduced human cardiac fibroblasts (hCFB). (B) Representative pictures of GFP control virus transduced hCFBs in EHMs. Scale bar $1 \mathrm{~cm}$. (C) Force of contraction (FOC) in response to extracellular calcium concentration in EHMs with GFP control hCFBs [GFP CT] and hCFBs with hIBP5 OE. n= 6/group. (D) Beating frequency per minute (bpm) of control versus IBP5 OE hCFB EHMs. n= 6/group. (E) Time to 90\% contraction, (F) time to 50\% relaxation, (G) rate of isometric contraction and $(\mathbf{H})$ rate of isometric relaxation in control- versus IBP5 OE hCFB EHMs. $\mathrm{n}=6 /$ group, 3 measurements. (I) qPCR analysis of overexpressed hIGFBP5 and some potential target genes like (J) $h G D F 15$ and (K) $h M Y O C D$ and (L) $h S T C l$. $\mathrm{n}=6$ EHMs per group. Data are mean \pm SEM; t-test and 2 way ANOVA, * $\mathrm{P}<0.05 ; * * * \mathrm{P}<0.001$. Experiment done by Dr. Norman Liaw, Pharmacology and Toxicology, UMG Goettingen. 
$\mathbf{A}$

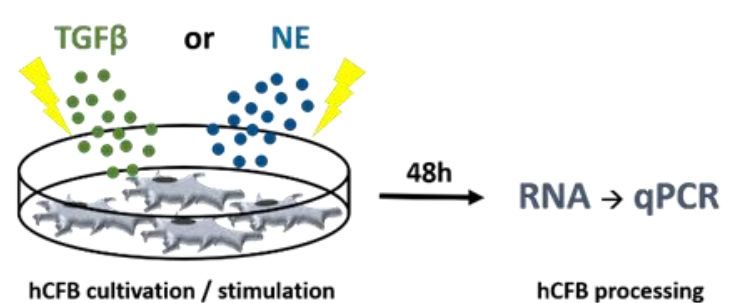

B

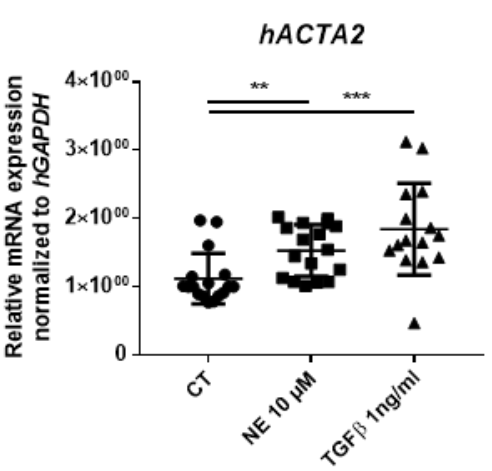

C

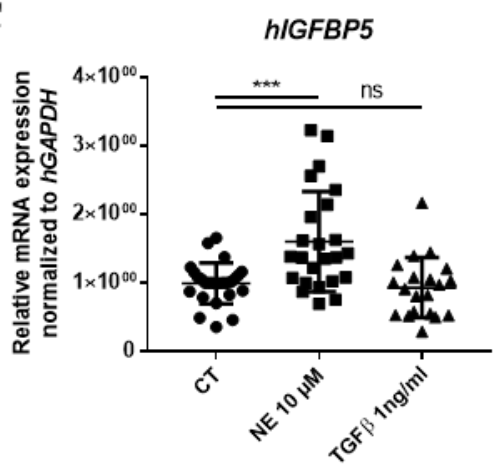

Figure 4-14: Myofibroblast activation and $h I G F B P 5$ upregulation are not directly associated

(A) Schematic overview of hCFB treatment. (B) mRNA expression of hACTA2 and (C) hIGFBP5 in human cardiac fibroblasts treated with $10 \mu \mathrm{M} \mathrm{NE}$ and $1 \mathrm{ng} / \mathrm{ml} \mathrm{TGF} \beta . \mathrm{n}=3$ passages in technical multiplicates. qPCR data is normalized to $h$ GAPDH. Data are mean \pm SEM; t-test, (ns) not significant, $* * \mathrm{P}<0.01 ; * * * \mathrm{P}<0.001$. 


\subsection{IGFBP5 acts as a transcriptional co-factor}

\subsubsection{IGFBP5 binds to DNA and regulates promoter activity}

The previous results show that IGFBP5 can be uptaken by hCFBs and influences gene expression in these possible receiver cells. In the following, the direct influence of IGFBP5 on gene expression was investigated. A nuclear localisation sequence enables IGFBP5 to enter nuclei. Several authors already showed that IGFBP5 might has transcriptional co-regulator functions [85, 120], but so far, no direct IGFBP5 binding to DNA with subsequent target activation was shown. To determine whether IGFBP5 is associated to genomic regions, ChIP was used. As a preliminary experiment, it was tested whether overexpressed, FLAG tagged IGFBP5 enters the cell nucleus and can be precipitated. For this, rapid immunoprecipitation of endogenous proteins (RIME) was used. RIME follows the exact protocol used for ChIP, but instead of purifying the precipitated chromatin, the precipitated protein of interest and associated proteins are detected using immunoblotting. For this experiment, TSA201 cells (human embryonal kidney cells) with flag tagged IBP5 OE or an empty vector control were used for ChIP. IGFBP5-FLAG was precipitated using a FLAG antibody, a customized antiIGFBP5 antibody or an IgG control. The precipitated proteins were investigated using immunoblotting and FLAG detection. Whereas there was no visible band at $37 \mathrm{kDa}$ (representing the artificially FLAG-tagged IGFBP5) from IgG precipitated samples, samples with IBP5 OE showed a band at $37 \mathrm{kDa}$ when precipitated with FLAG antibody and with customized anti-IGFBP5 antibody. No band was detectable at $37 \mathrm{kDa}$ in samples with an empty vector control (Figure 4-15A, n=2 different precipitations). Since IBP5 OE protein could be precipitated from TSA201 nuclei using a FLAG antibody, ChIP was done with FLAG antibody using samples from hCFBs with lentiviral-mediated IBP5 OE. Precipitated chromatin was analysed via whole genome sequencing (done by Transcriptome and Genome Analysis Laboratory (TAL) Goettingen, analysis was done by Lavanya M. Iyer, Institute of Pharmacology and Toxicology, UMG Goettingen). Validation of the precipitated chromatin revealed binding to gene loci of IGFBP5 (Figure 4-15B) and TNNT2 (Figure 4-15C, n=2 precipitations/sequencing per conditions respectively). Precipitated IGFBP5 and TNNT2 chromatin partially covered the first exon and the chromatin upstream the ATG of both genes, representing putative promoter regions. Published ChIP data from reference hCFBs for methylation at the 4th lysine residue of the histone $\mathrm{H} 3$ protein ( $\mathrm{H} 3 \mathrm{~K} 4 \mathrm{me})$, which marks accessible chromatin, was compared to IGFBP5 bound loci. This comparison revealed a recruitment of $\mathrm{H} 3 \mathrm{~K} 4 \mathrm{me}$ in cardiac fibroblasts to the IGFBP5-bound IGFBP5 locus, but not to 
the TNNT2 locus. To analyse the effect of IGFBP5 on its own putative promoter region and on the putative TNNT2 promoter region, the IGFBP5-occupied gene loci (ChIP peaks, referred as “promoters") were cloned in a luciferase reporter system (see scheme in Figure 4-15D). The cloned reporter vectors were co-transfected with an IBP5 OE vector in TSA201 cells. Validation of luciferase activity for the cloned IGFBP5 promoter did not give any conclusive data due to a very high baseline promoter activation when compared to the empty luciferase vector. Validation of the cloned TNNT2 promoter showed a significant lower TNNT2 promoter activation when compared to the empty luciferase vector. Moreover, co-transfection of IGFBP5 leads to a significant reduction of TNNT2 promoter luciferase activity when compared to empty-vector co-transfection (Figure 4-15E, $\mathrm{n}=4$ independent, $\mathrm{P}<0.05$ ).

This data confirms that IGFBP5 can enter cell nuclei where it acts as a transcriptional co-factor repressing the TNNT2 promoter.

\subsubsection{NKX2.5 occupies and regulates same genomic regions as IGFBP5}

In silico analysis of the IGFBP5-occupied loci (IGFBP5 and TNNT2 promoter) predicted potential NKX2.5 binding motifs (Figure 4-16AB). To analyse whether NKX2.5 can bind to these predicted regions and to validate its potential effect on the promoter activity, the cloned IGFBP5 promoter (ChIP peak) was co-transfected with a NKX2.5 overexpression construct in TSA201 cells. Luciferase signal quantification revealed a significant increase in luciferase intensity already at baseline (with co-transfection of an empty vector) when compared to a luciferase empty vector control. Co-transfection of NKX2.5 leads to a significant increase of the IGFBP5 promoter luciferase activity when compared to empty-vector co-transfection (Figure 4-16C, $\mathrm{n}=4$ independent experiments, $\mathrm{P}<0.05 ; \mathrm{P}<0.01$ ). Investigation of the interplay of IGFBP5 with NKX2.5 on the putative IGFBP5 promoter was not possible due to du a very high baseline promoter activation when compared to the empty luciferase vector. To investigate the interplay of both factors on the putative TNNT2 promoter, a double co-transfection experiment was done. A significant repressive effect of co-transfected IGFBP5 on the TNNT2 promoter was observed as before (Figure 4-15E). As already shown by Kobayashi et al., cotransfection of NKX2.5 led to a significant activation of the TNNT2 promoter. Interestingly, double co-transfection of NKX2.5 and IGFBP5 had a repressive effect on the TNNT2 promoter, decreasing the luciferase activity below baseline activity (Figure 4-16D, 4 independent experiments, $\mathrm{P}<0.05 ; \mathrm{P}<0.01)$

Together, these data provide evidence that IGFBP5 antagonizes the activating effect of NKX2.5 on the TNNT2 promoter. 


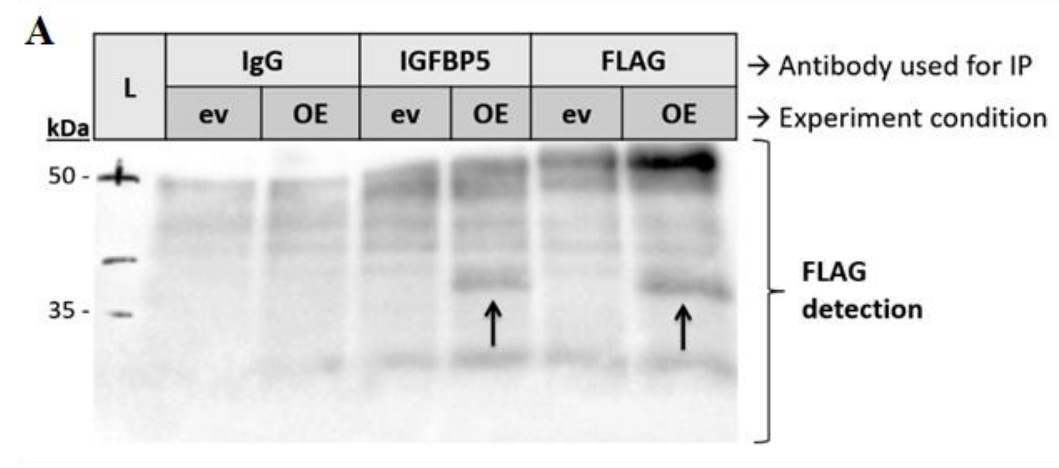

B

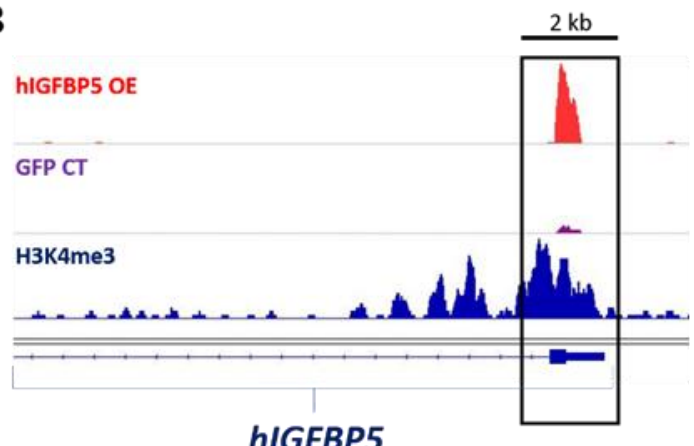

hIGFBP5
C

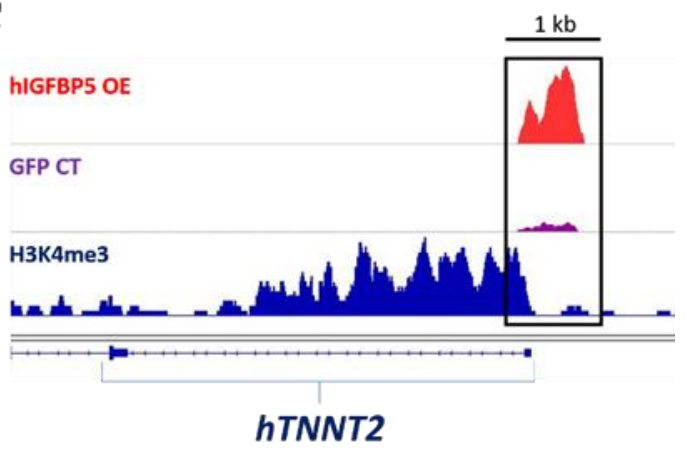

D $5^{\prime}-$ hIGFBP5 or hTNNT2 ChIP peak (promoter) - Luciferase

$\mathbf{E}$

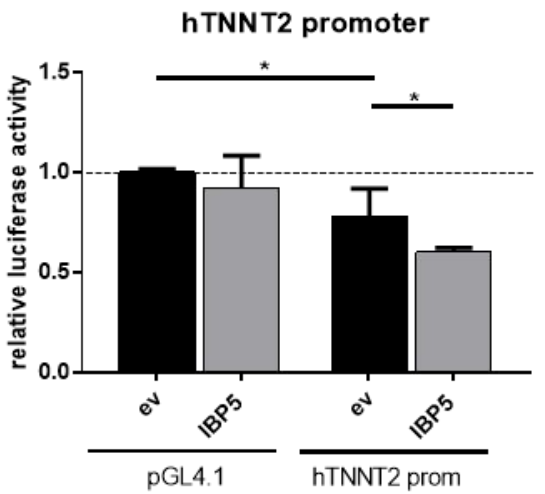

Figure 4-15: Overexpressed hIGFBP5 binds to DNA and regulates promoter activity

(A) Immunoblot analysis of overexpressed and precipitated hIGFBP5-FLAG [OE] from TSA201 nuclei, using an IGFBP5 antibody, a FLAG antibody and an IgG control. An empty vector [ev] was used as control. Detection was done with FLAG antibody. n=2 IPs. (B) Occupancy profile of hIGFBP5 locus and (C) hTNNT2 locus after chromatin immunoprecipitation (ChIP) in human cardiac fibroblasts (hCFB) with hIGFBP5-FLAG overexpression [hIBP5 OE] (red) and GFP control [GFP CT] (purple). ChIP was done with FLAG antibody and subsequent sequencing. Published data for $\mathrm{H} 3 \mathrm{~K} 4 \mathrm{me}$ (blue) from normal hCFBs marking accessible chromatin was used as a reference. Blue brackets show gene body. $\mathrm{n}=2$ precipitations/sequencing per conditions. (D) Scheme of luciferase constructs. (E) Relative luciferase activation by overexpressed hIGFBP5 [IBP5] (grey bars) binding to the cloned hTNNT2 promoter (prom) region in comparison to activation by an empty vector control [ev] (black bars). Basal luciferase activity was set as 1 (dashed line). Renilla luciferase expression was used for normalization, $n=4$ independent experiments. Data are mean $\pm \mathrm{SEM}$; $\mathrm{t}$ test, $* \mathrm{P}<0.05 ; * * \mathrm{P}<0.01, * * * \mathrm{P}<0.001$. 
A

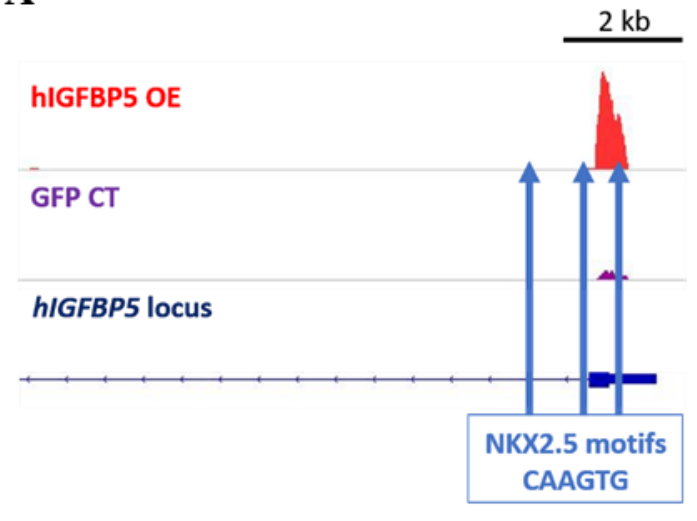

C

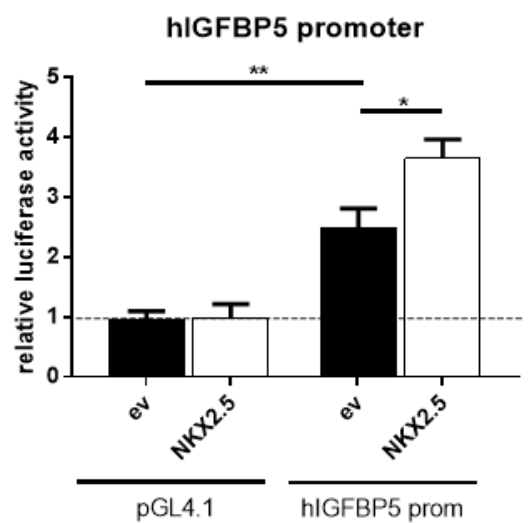

B

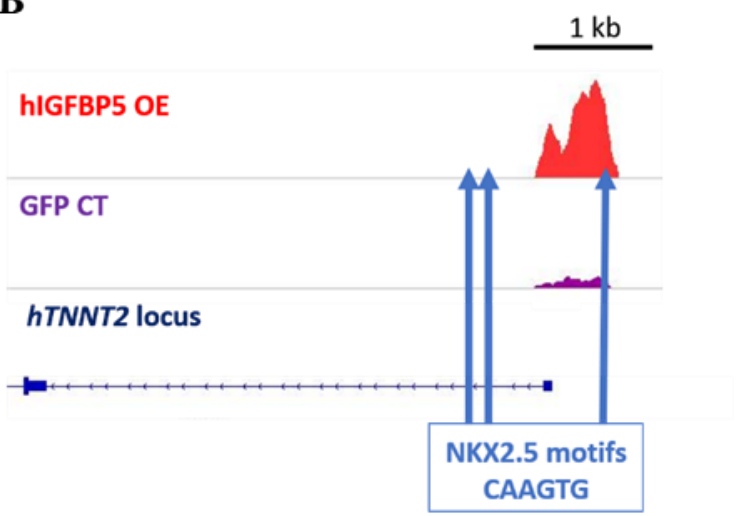

D

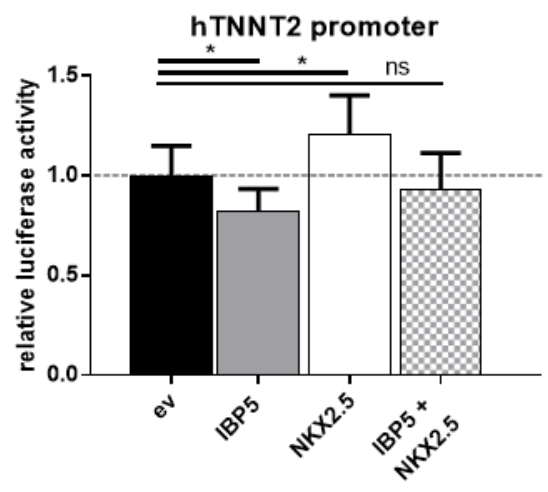

Figure 4-16: hNKX2.5 occupies same genomic regions as hIGFBP5 and regulates promoter activity

(A) In silico prediction of potential NKX2.5 binding sites/motifs (blue arrows) in the identified hIGFBP5 and (B) hTNNT2 promoter regions bound by hIGFBP5 (red peaks). (C) Relative luciferase activation by overexpressed hNKX2.5 (white bars) binding to the cloned hIGFBP5 ChIP promoter region in comparison to activation by an empty vector control [ev] (black bars). (D) Relative luciferase activation of the cloned hTNNT2 promoter region. Activation is achieved by overexpression of $h N K X 2.5$ (white bars), hIGFBP 5 (grey bar), the combination of $h N K X 2.5$ with $h I G F B P 5$ (grey-squared bar) or by an empty vector control [ev] (black bar). Basal luciferase activity was set as 1 (dashed line). Renilla luciferase expression was used for normalization, $\mathrm{n}(\mathrm{C}-\mathrm{D})=4$ independent experiments. Data are mean $\pm \mathrm{SEM}$; $\mathrm{t}-$ test, $* \mathrm{P}<0.05 ; * * \mathrm{P}<0.01$. 


\subsection{IGFBP5 controls human cardiac cell commitment}

\subsubsection{Generation and validation of an IGFBP5 knockout hES cell line using the CRISPR/Cas9 technology}

Previous reports associate sustained IGFBP5 expression with impaired stem cell and cardiac progenitor cell differentiation, while IGFBP5 downregulation was associated with cardiomyocyte differentiation $[87,89,92]$. To investigate the impact of IGFBP5 on stem cell commitment and cardiomyocyte differentiation, a KO hES cell line was generated using a double-paired CRISPR/Cas9-D10A nickase (Cas9n) genome editing approach. CRISPR gRNAs were designed to target the transcription start site in the IGFBP5 locus (see scheme in Figure 4-17A) to prevent transcription or to generate a frame shift mutation. To avoid off-target effects, a “4n approach" was applied using four different gRNAs and a CAS9 nickase enzyme generating four independent single strand breaks and releasing a $300 \mathrm{bp}$ long DNA fragment (see scheme in Figure 4-17B). The work flow of the KO hES cell line generation included gRNA design and synthesis, gRNA cloning in a SpCas9-D10A nickase vector, electroporation of hES cells with gRNA vectors including a Cas expression cassette, clone selection and single clone isolation, genotyping and subsequent characterization (see scheme in Figure 4-17C). A control cell line (mock control) was generated using hES cells electroporated without plasmids but with subsequent single clone selection.

To validate a successful cell line generation, genotyping of isolated single clones was done using primers flanking the deleted DNA fragment including the TSS. Genotyping PCR of control hES cells show a 500 bp long IGFBP5 wildtype PCR product. PCR analysis of two different hES cell clones revealed one truncated PCR product (deletion, homozygous) for clone K22 and two longer PCR products for the second clone K12 (insertion, heterozygous) (Figure 4-18A). Immunoblot analysis of genotyped clones showed no difference between deletion and insertion clones in comparison to mock control (Figure 4-18B, n=2/group, blot was done twice). To examine whether the corresponding transcript was expressed, a qPCR forward primer was designed to bind the deleted TSS on the transcript (see scheme in Figure 4-18C). qPCR analysis for wildtype hES cells and mock control cells showed a product of $\sim 700 \mathrm{bp}$ and a longer qPCR product for the insertion clone (Figure 4-18D). The deletion clone as well as the corresponding controls did not show any qPCR products.

To investigate a potential impact of IGFBP5 KO on the hES cells, hES cells were morphologically, physiologically and molecularly characterized. Morphologically, there was no apparent difference between hES cells derived from the deletion clone (K22) and the 
insertion clone (K12) when compared to the mock control (Figure 4-19A, representative pictures). Cell size was determined using automated "CASY TT" cell counter and analyser system, whereas the mean diameter of cells from the insertion clone (K12) was significantly smaller in in comparison to the deletion clone (K22) and the mock control (Figure 4-19B, n=8 different passages, $\mathrm{P}<0.05)$. Pluripotency of the stem cell lines was assessed by flowcytometry (Experiment was done by Dr. Farah Raad, Pharmacology and Toxicology, UMG Goettingen) using the stemness markers OCT4 and TRA1-60. 90.0\% of cells from the mock control and $88.7 \%$ cells of the deletion clone (K22) were positive for OCT4 and TRA1-60, whereas only $70.7 \%$ cells of the insertion clone (K12) were positive for both markers (Figure 4-19C, n=3, $\mathrm{P}<0.05)$. A significant reduced stemness of the insertion clone (K12) in comparison to the deletion clone (K22) and the mock control can also be detected on qPCR level, determining the expression of SOX2 (Figure 4-19D, $\mathrm{n}=7$ different passages, $\mathrm{P}<0.05$ ). Since the pluripotency of the insertion clone (K12) was reduced, it was of interest to validate whether all used cell lines possessed the capacity to differentiate into all three germ layers. To test the spontaneous differentiation potential of the generated IGFBP5 KO hES cell lines, embryoid body (EB) formation was done as described by El-Battrawy et al. [103] in the Stem Cell Unit (SCU), UMG, Goettingen (experiment done by Martina Grohe). Germ layer-specific markers such as $\alpha$-feto-protein (AFP, endodermal), $\alpha$-smooth muscle actin ( $\alpha$-SMA, mesodermal), as well as $\beta$ III-tubulin (ectodermal) were detected using IF staining of formed EBs. In this preliminary experiment, no apparent difference in germ layer differentiation potential between the deletion clone (K22) and the insertion clone (K12) was detectable, when compared to the mock control (Figure 4-20A-C, n=2 differentiations, representative pictures).

Altogether these data showed the successful use of the CRISPR/Cas9 technology to generate two different IGFBP5 KO hES cell lines with genomic changes in the IGFBP5 locus. These genomic changes comprise the homozygous deletion of the TSS in clone 22 and a heterozygous random integration of plasmid DNA in clone 12. Although both cell lines do not show major morphological changes and possess the capacity to differentiate in all three germ layers, clone 12 owns a reduced pluripotent potential.

\subsubsection{Characterization of directed cardiomyocyte differentiation in IGFBP5 knockout cells}

To investigate the suitability of the generated IGFBP5 KO hES cell lines to differentiate in cardiomyocytes, directed 2D differentiation followed by metabolic lactate selection was performed to obtained spontaneously beating cardiomyocytes (see schematic overview in 
Figure 4-21A). Differentiated cardiomyocytes were morphologically-, physiologically and molecularly characterized. Examining the beating frequency of the differentiated cardiomyocytes, the deletion clone (K22) and the insertion clone (K12) showed a significant higher beating frequency when compared to the mock control (Figure 4-21B, n=3 different differentiations, counting at 3 different areas, $\mathrm{P}<0.05 ; \mathrm{P}<0.01)$. After cell dissociation, cell size was determined using the automated "CASY TT" cell counter system. Compared to the mock control, the deletion clone (K22) and the insertion clone (K12) showed a significant smaller cell size (Figure 4-21C, $\mathrm{n}=4$ different differentiations with technical duplicates, $\mathrm{P}<0.01$; $\mathrm{P}<0.001)$. To investigate whether the decreased cell size can be correlated with increased cell proliferation, the expression of cell G1/S-specific cycle marker cyclin D1 was determined. In comparison to the mock control and the deletion clone (K22), the insertion clone (K12) showed a significant upregulation of cyclin D1 expression (Figure 4-21D, $n=3$ different differentiations, $\mathrm{P}<0.05)$. Evaluation of the expression of IGFBP5 in the $\mathrm{KO}$ cardiomyocytes revealed a significant upregulation of the transcript in the insertion clone (K12), whereas there was a non-significant trend towards upregulation in the deletion clone (K22) when compared to the mock control (Figure 4-21E, $\mathrm{n}=3$ differentiations, $\mathrm{P}<0.01$ ). To investigate whether the increased transcript abundance was also represented on protein level, ELISA quantification of secreted IGFBP5 in cell supernatants was done. Analysis revealed a significant higher concentration of IGFBP5 in cell supernatants of the insertion clone (K12) in comparison to the mock control, while the slightly higher concentration of IGFBP5 in supernatants of the deletion clone (K22) did not reach statistical significance (Figure 4-21F, n=2 different passages, $\mathrm{P}<0.05)$. To examine cardiac progenitor cell commitment, the expression of developmental genes was determined. $N K X 2.5$ was significantly upregulated in the insertion and deletion clone (Figure 4-21G, $\mathrm{n}=3$ differentiations, $\mathrm{P}<0.01 ; \mathrm{P}<0.0001$ ), while $M Y O C D$ was only upregulated in the insertion clone (K12) when compared to the mock control (Figure 4-21H, n=3 differentiations, $\mathrm{P}<0.01)$. Active $\mathrm{Wnt}$ signalling, which indicates impaired cardiomyocyte differentiation, was detected in the insertion clone (K12), showing upregulated AXIN2 expression in comparison to the deletion clone and the mock control (Figure 4-21I, $n=3$ differentiations, $\mathrm{P}<0.001)$. Immunoblot analysis from differentiated cardiomyocytes confirmed qPCR results and showed a stronger NKX2.5 protein expression in the insertion and deletion clone compared to the mock control (Figure 4-22A, n=3 differentiations). Further, an increased protein abundance of the transcription factor TBX5, a regulator of cardiogenesis, was detected in the insertion and deletion clone when compared to the mock control (Figure 4-22B, $n=3$ differentiations). This observation was confirmed by IF images shown in Figure 4-23A. To 
determine a cardiomyocyte specific protein, immunoblot analysis of cTNT was done. Nearly no cTNT protein expression was detected in the insertion clone (K12), whereas a reduced expression was detected in the deletion clone (K22) in comparison to the mock control (Figure 4-22C, $n=3$ differentiations). This was also appreciated in IF images which showed less cTNT signal in the insertion clone (K12) in comparison to the mock control (Figure 4-23A). In addition, IF staining also showed a decreased signal for $\alpha$-sarcomeric-actinin in the insertion clone (K12) and the deletion clone (K22) in comparison to the mock control (Figure 4-23BC). Further, IGFBP5 KO cardiomyocytes and the mock control showed quite comparable signal intensities of the gap junction protein connexin-43 (CX43). Of note, the protein expression of CX43 appeared to be more circumferential in the insertion clone (K12), whereas in the deletion clone and the mock control, the protein was rather polarized to intercalated disks (Figure 4-23B). In line with this, IF images of the cell adhesion component N-cadherin (NCAD) showed higher and more organized expression in the mock control when compared to the IGFBP5 KO cardiomyocytes (Figure 4-23C).

Collectively, these data suggest that the insertion of genomic material in clone 12 resulted in an IGFBP5 gain-of function (GOF) mutation, indicated by increased transcript and extracellular protein abundance. This phenotype could potentially be due to a subcellular protein accumulation of IGFBP5 with a subsequent positive feedback regulation of IGFBP5 transcription. Interestingly, the GOF clone showed a decreased potential in cardiomyocyte differentiation and maturation with a concomitant increased cyclin D1 expression, assuming an arrested cardiac cell commitment. 


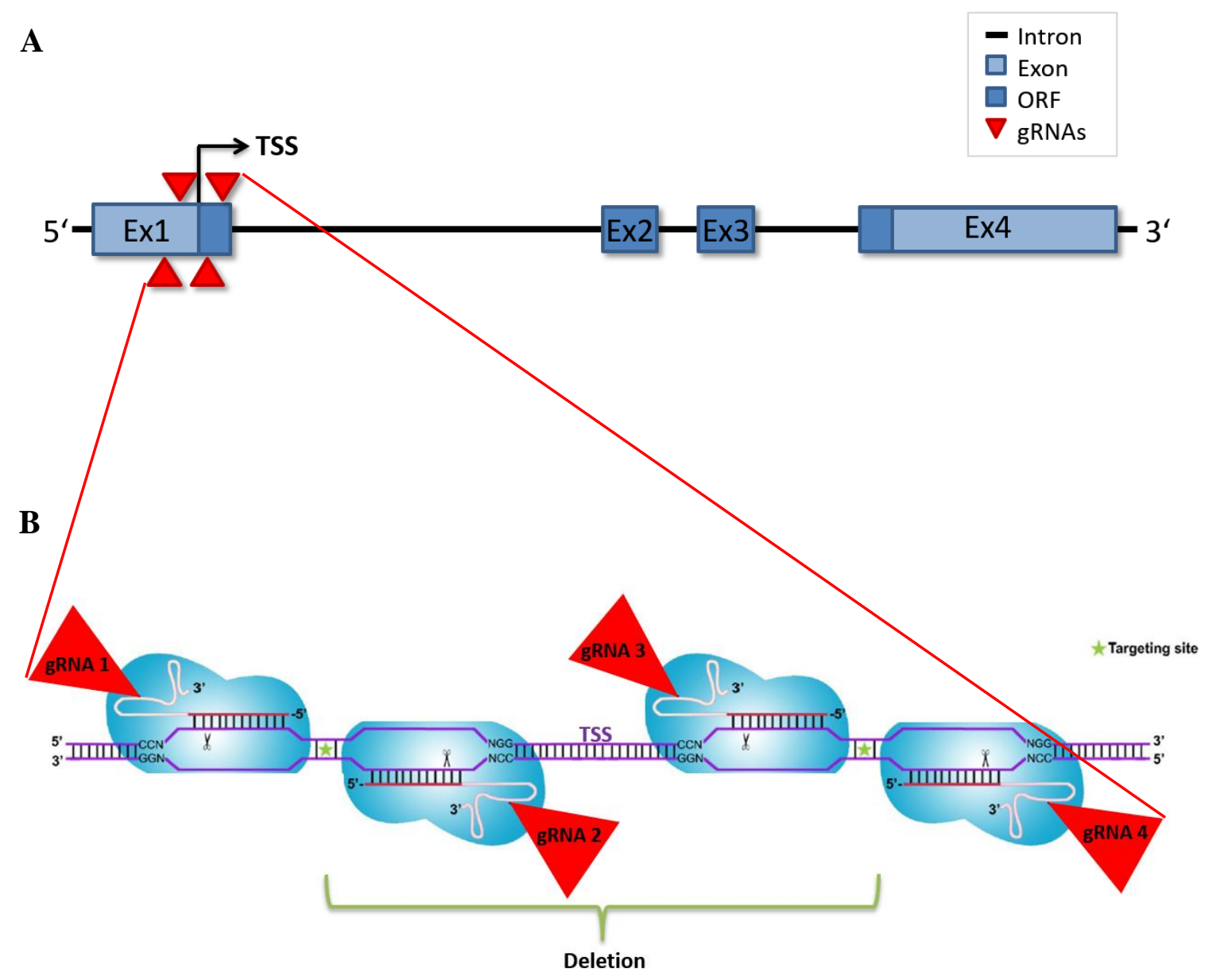

C

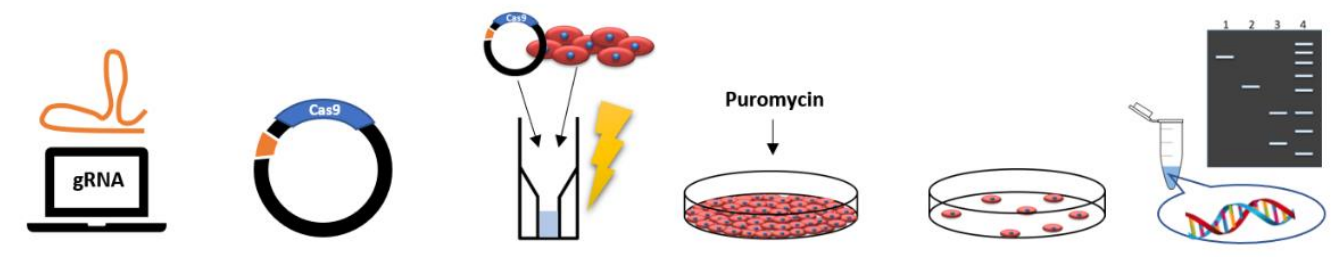

gRNA design

Figure 4-17: Generation of a IGFBP5 knockout hES cell line using CRISPR/Cas9 technology

(A) Illustration of the 4n CRISPR/Cas9-D10A nickase (Cas9n) genome editing strategy for targeting the transcriptional start site (TSS) of hIGFBP5. Four different gRNAs are indicated with red arrows, cutting offset of $\sim 300$ bp including the TSS. (B) Magnification of schematic overview. (C) Work flow of knockout cell line generation. 
A

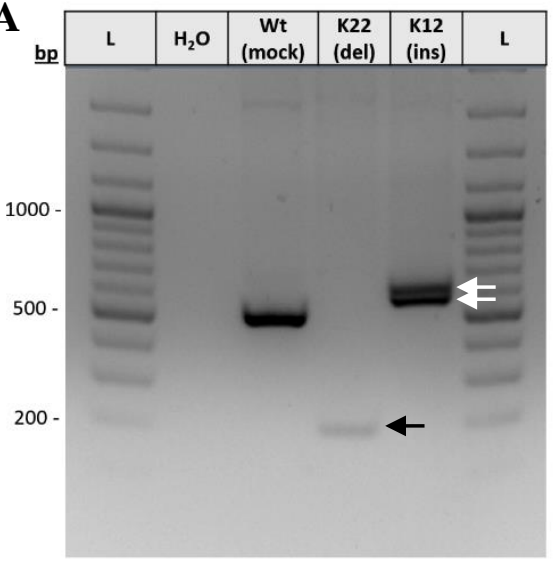

C

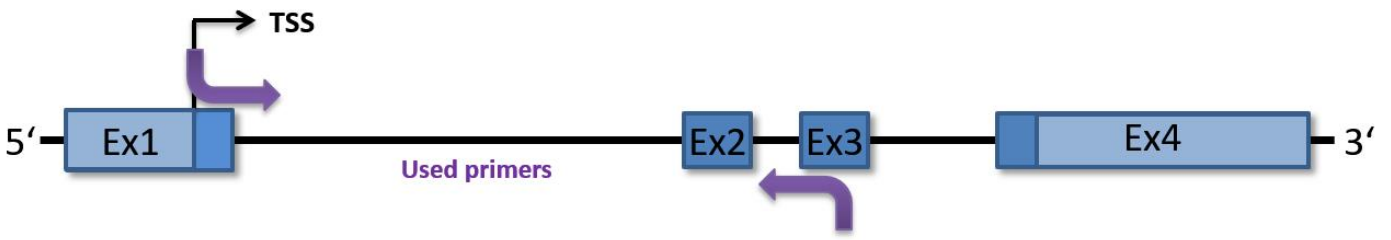

B

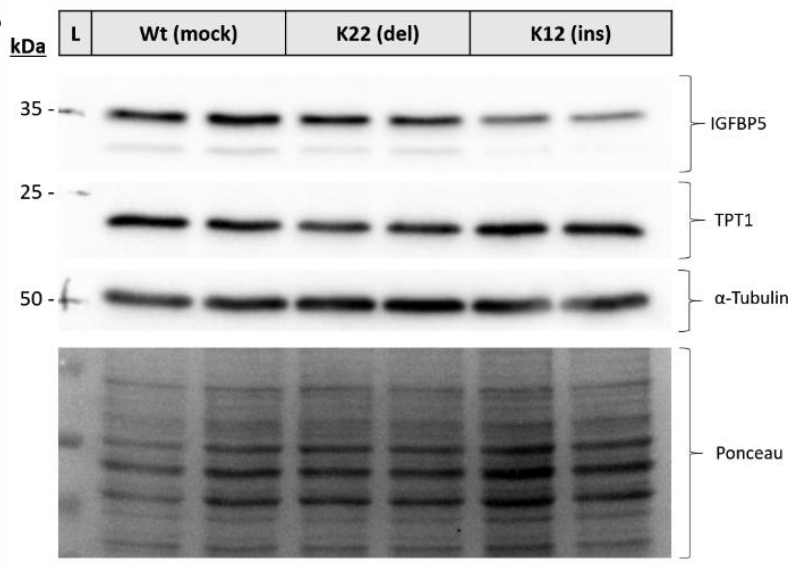

D
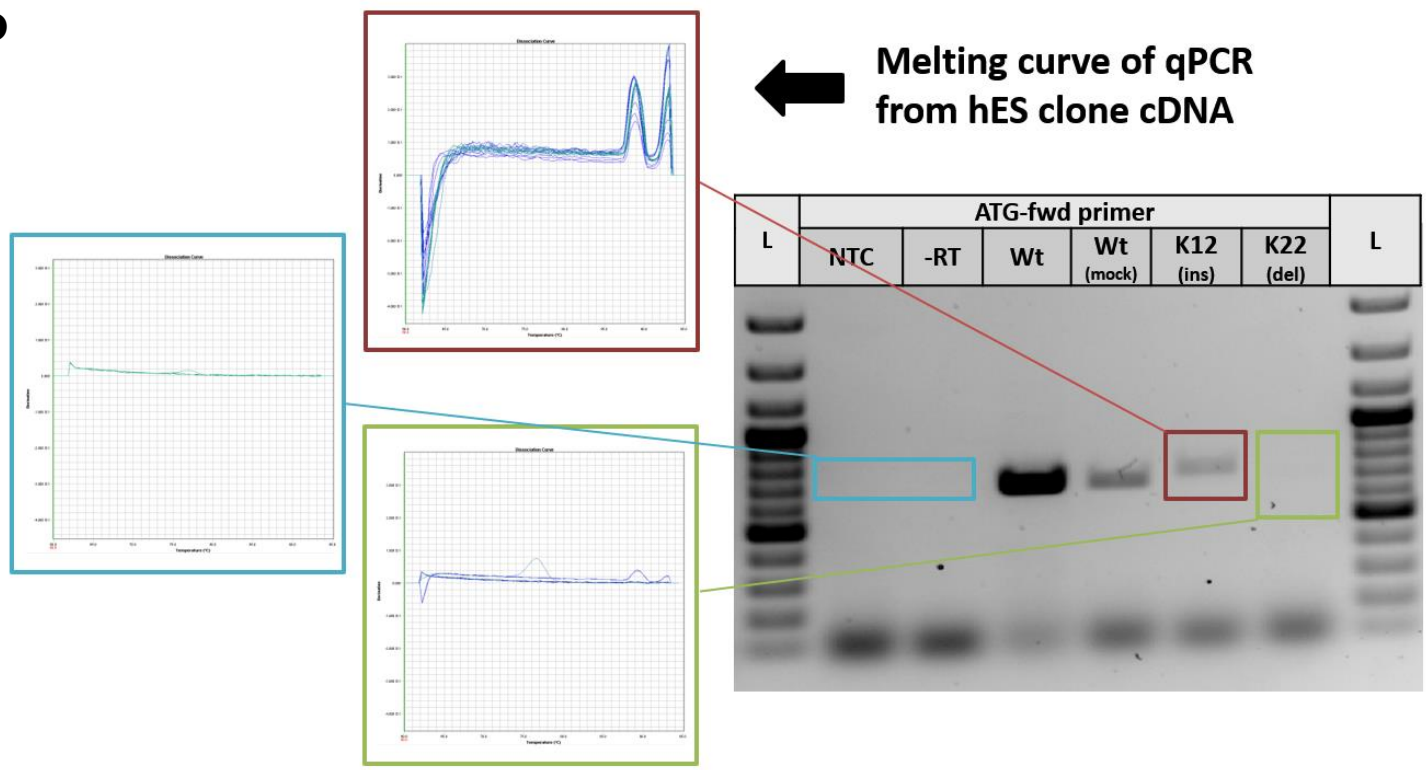

from hES clone cDNA

Figure 4-18: Validation of generated $h I G F B P 5$ knockout hES cell clones

(A) Genotyping PCR of two different hES cell clones [K=clone with individual number] and an electroporated mock control [Wt (mock)]. Primers are framing the deleted TSS, amplifying a $500 \mathrm{bp}$ long hIGFBP5 wild type PCR product. Black arrow indicates a shorter fragment, white arrows indicate two longer fragments. (B) Immunoblot analysis of hIGFBP5 protein. Tumor protein translationally-controlled 1 [TPT1], $\alpha$-Tubulin and Ponceau-S staining were used as loading controls. (C) Scheme of cDNA genotyping approach of hES cell clones. Forward primer was designed to cover the deleted TSS (purple). (D) qPCR amplification with described primers for wild type hES cells and mock control with a PCR product of $\sim 700$ bp and a longer PCR product size for K12 (ins). Clone K22 (del) shows no PCR product. Nontemplate control [NTC] and minus reverse transcriptase control [-RT] were used to detect potential DNA contaminations and show no qPCR product. Melting curve analysis shows peaks of amplified PCR products corresponding to gel bands. NTC and -RT (blue frame), K12(ins) (red frame), K22(del) (green frame). 

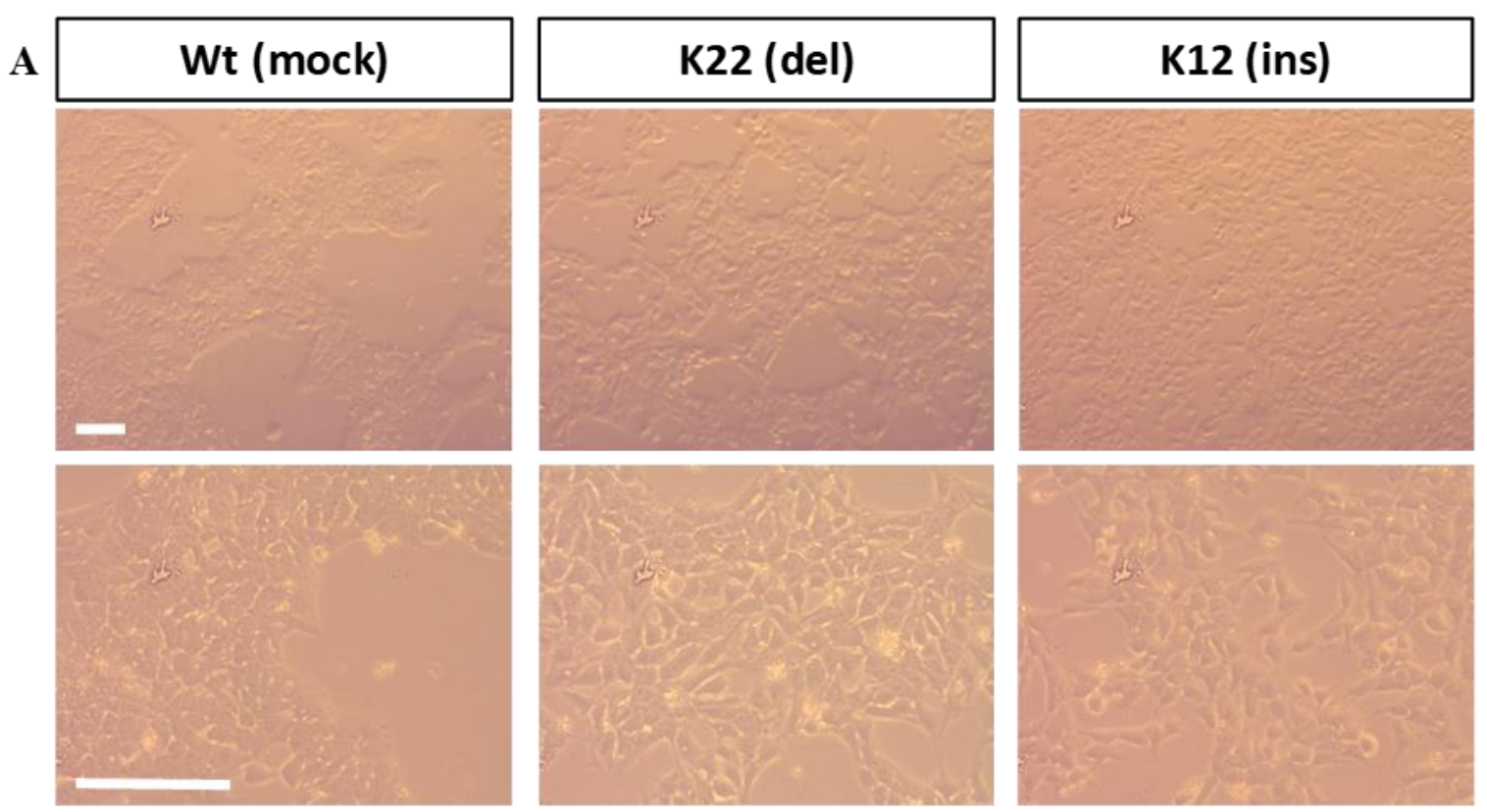

B

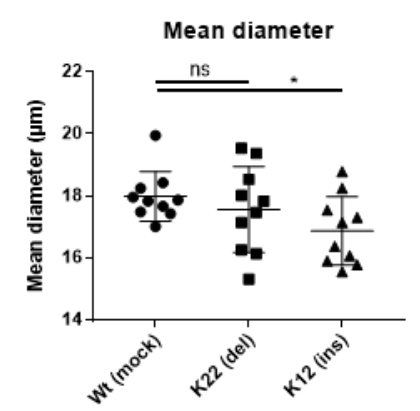

C

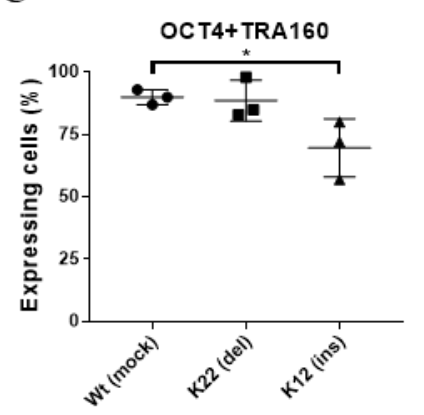

D

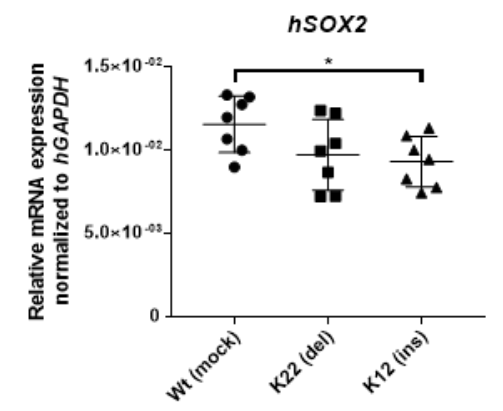

Figure 4-19: Characterisation of generated hIGFBP5 knockout hES cell lines

(A) Light microscopy pictures of cultured hES cells showing mock control cells [Wt (mock)], clone with targeted deletion [K22 (del)] and clone with insertion [K12 (ins)]. Scale bar $100 \mu \mathrm{M}$. (B) Mean diameter of dissociated hES cells measured with automated "CASY TT" cell counter and analyser system, $n=8$ different passages. (C) FACS analysis (done by Dr. Farah Raad, Pharmacology and Toxicology, UMG Goettingen) of pluripotency markers OCT4 and TRA160 expressing hES cell clones and control cells, $\mathrm{n}=3$ different passages. (D) qPCR analysis of pluripotency marker $h S O X 2$ in $\mathrm{hES}$ cell clones and control, $\mathrm{n}=7$ different passages. Data are mean \pm SEM; t-test, (ns) not significant, $* \mathrm{P}<0.05$. 


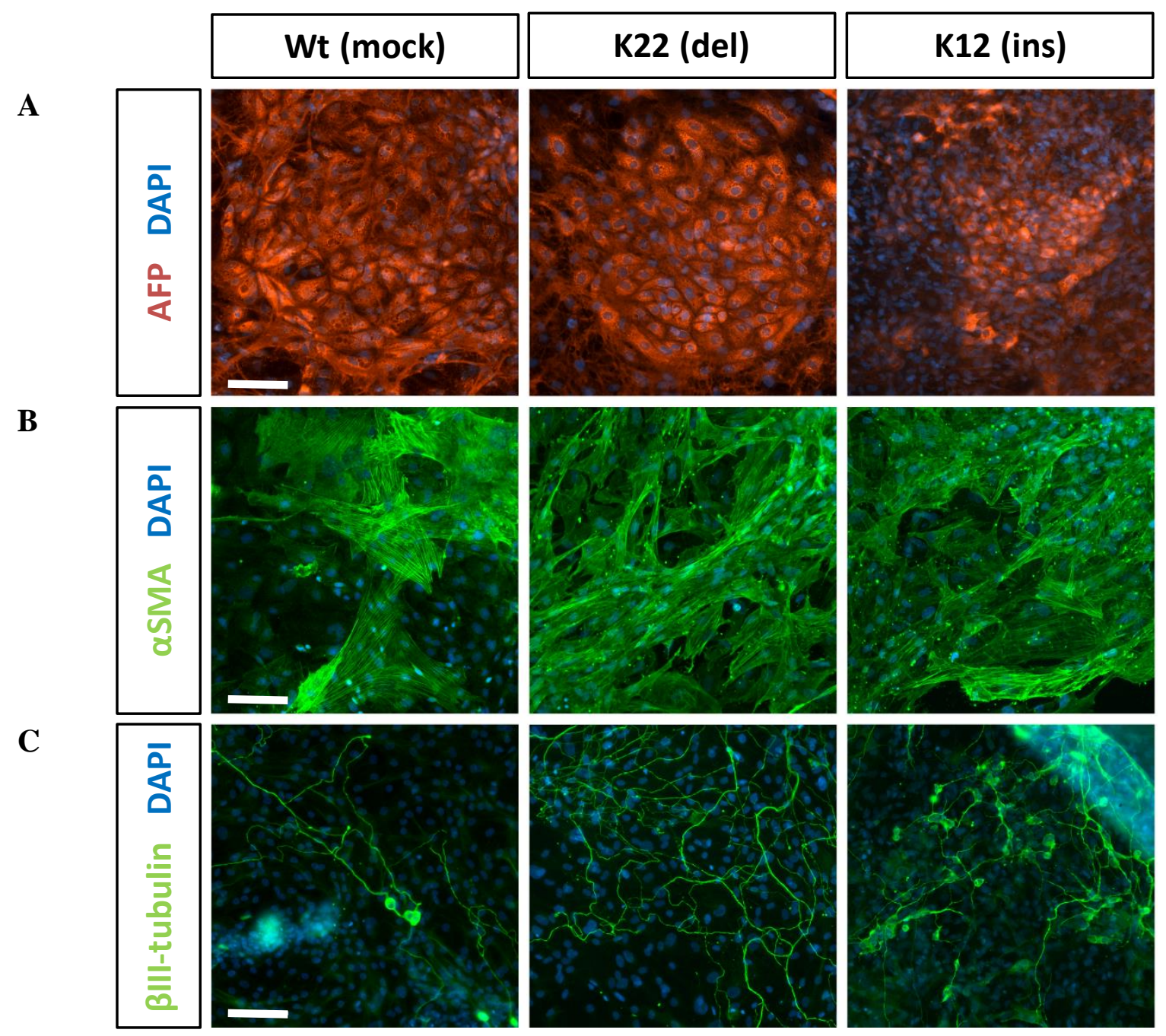

Figure 4-20: Spontaneous germ layer differentiation of $h I G F B P 5$ knockout hES cell lines

Differentiation in three germ layers is shown by immunofluorescence staining of formed embryoid bodies (EBs). (A) $\alpha$ feto-protein [AFP] (red) is used as endodermal marker. (B) $\alpha$-smooth muscle actin [ $\alpha$-SMA] (green) is used as a mesodermal marker. (C) $\beta$ III-tubulin (green) is used as an ectodermal marker. DAPI nuclear staining in blue, scale bar is $100 \mu \mathrm{m}$. Experiment done by Martina Grohe/Lukas Cyganek, Stem cell unit, UMG Goettingen. 


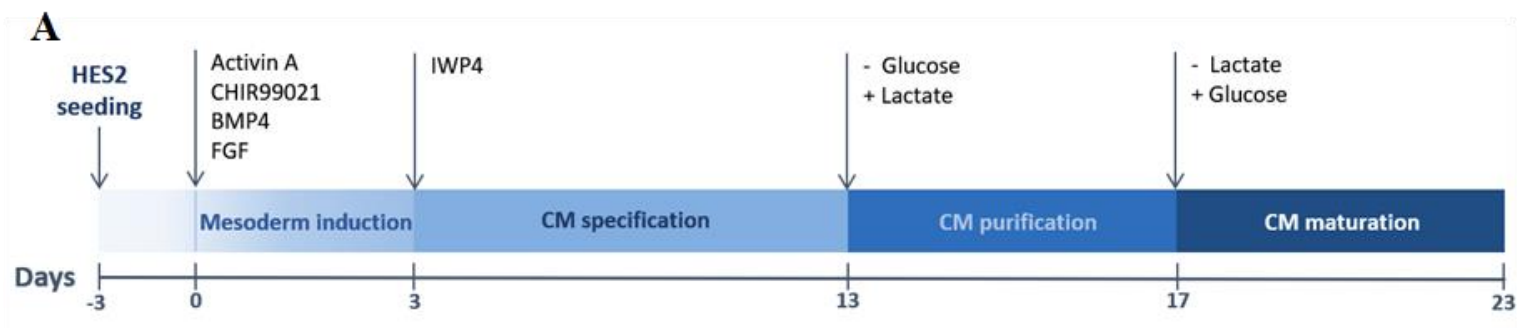

B

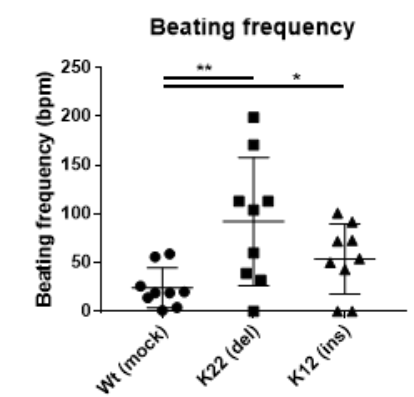

$\mathbf{E}$

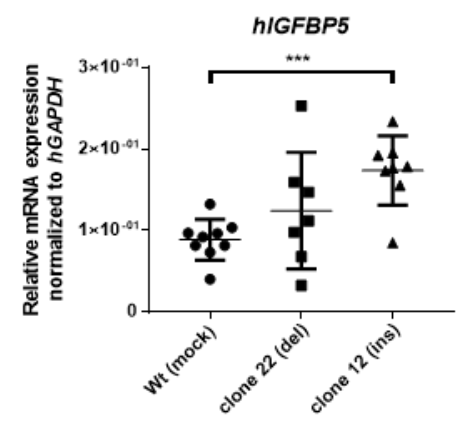

G

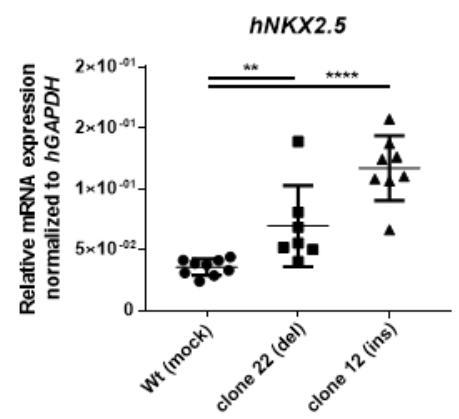

C

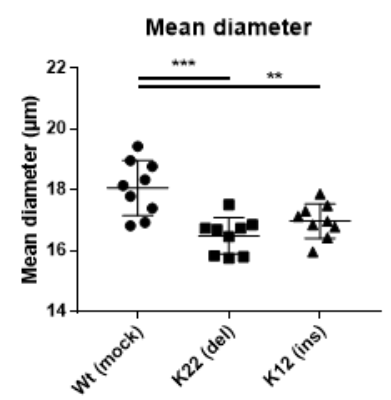

$\mathbf{F}$

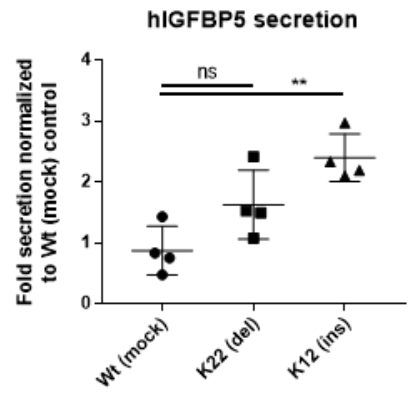

H

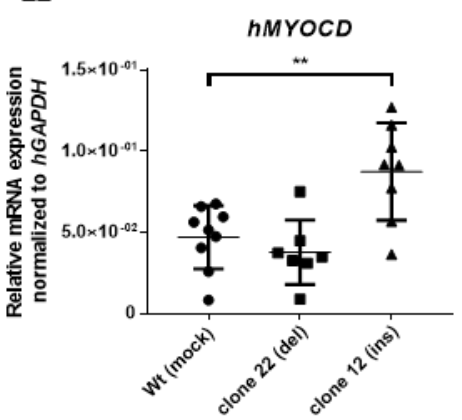

D

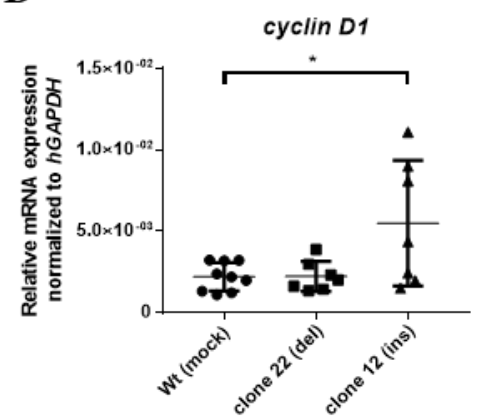

I

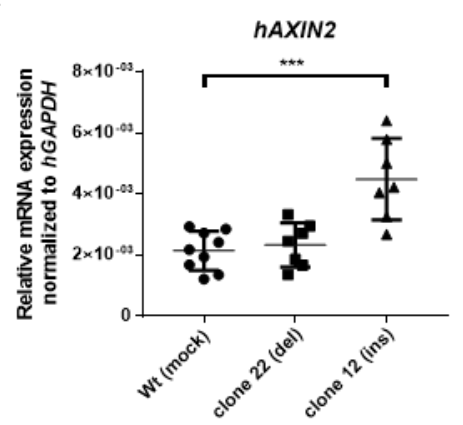

Figure 4-21: Characterisation of differentiated $h I G F B P 5$ knockout cardiomyocytes

(A) Schematic overview of 2D hES cell differentiation to cardiomyocytes (CMs). (B) Spontaneous beating frequency in beats per minute (bpm), measured by manual counting. $n=3$ different differentiations, counting at 3 different areas, before and after re-seeding of cells. (C) Mean diameter of dissociated CMs measured with automated "CASY TT" cell counter system. $\mathrm{n}=4$ different differentiations with technical duplicates. (D) qPCR analysis of proliferation marker cyclin D1 in differentiated CMs. $\mathrm{n}=3$ different differentiations with technical duplicates or triplicates. (E) qPCR analysis of hIGFBP5 in differentiated CMs. $\mathrm{n}=3$ different differentiations with technical duplicates or triplicates. (F) ELISA protein quantification in cell supernatants. $\mathrm{n}=2$ different passages, technical duplicates. (G) qPCR analysis of $h N K X 2.5,(\mathbf{H})$ myocardin $[h M Y O C D]$ and (I) the Wnt target gene Axin2 [hAXIN2] in CMs. $\mathrm{n}(\mathrm{D}-\mathrm{F})=3$ different differentiations with technical duplicates or triplicates. Data are mean \pm SEM; t-test, (ns) not significant, ${ }^{*} \mathrm{P}<0.05 ;{ }^{*} \mathrm{P}<0.01 ;{ }^{*} * * \mathrm{P}<0.001$; $* * * * \mathrm{P}<0.0001$. 
A

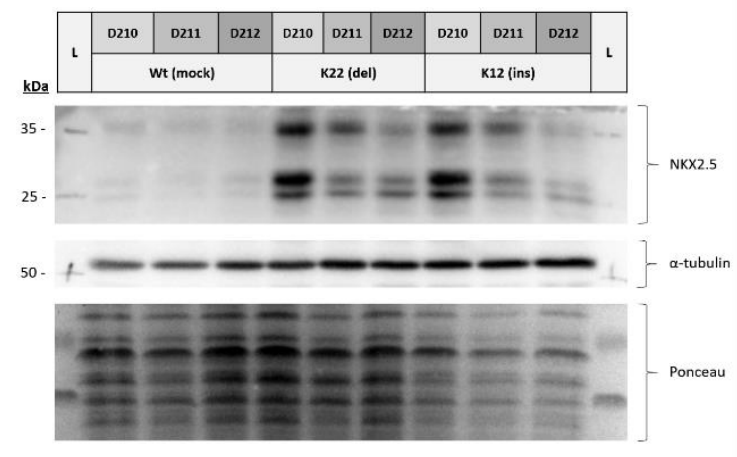

C

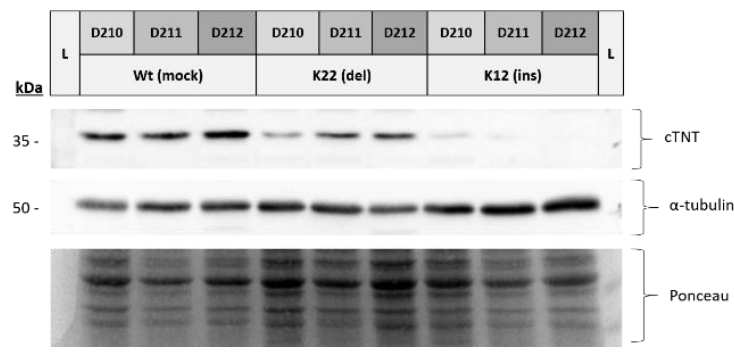

B

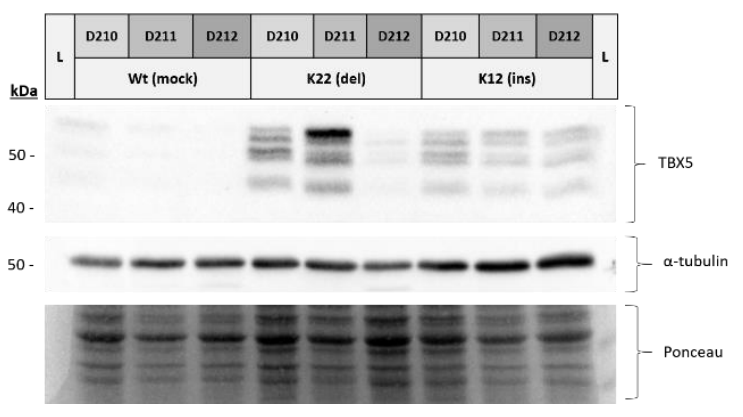

Figure 4-22: Protein expression in differentiated hIGFBP5 knockout cardiomyocytes

(A) Immunoblot from cardiomyocytes of three different differentiations [D210-D212] showing NKX2.5 protein, (B) TBX5 and (C) cardiac troponin T [cTNT]. $\alpha$-tubulin and Ponceau-S staining were used as loading controls. L=ladder. $\mathrm{n}=3$ different differentiations, blots are done twice. 


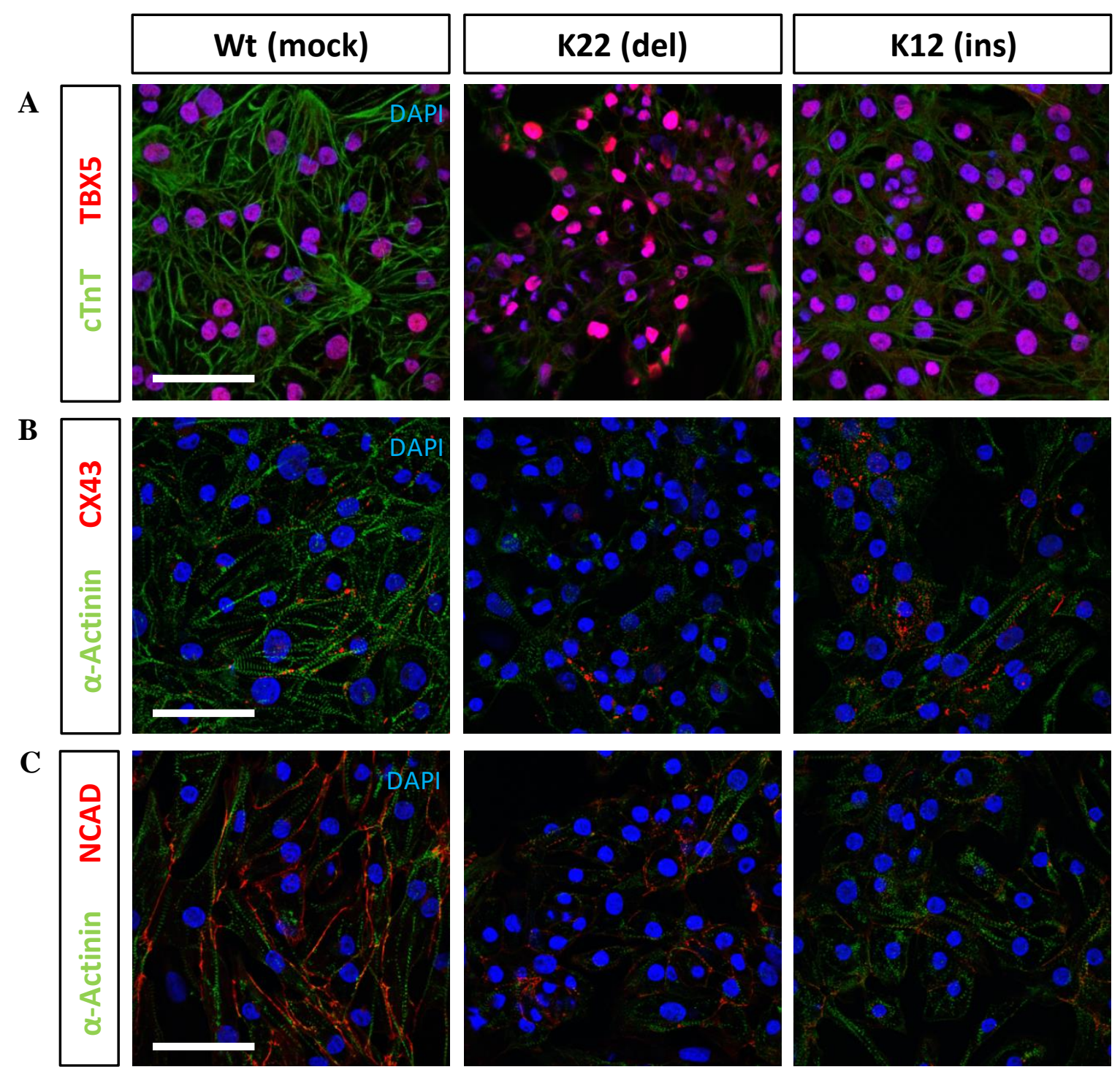

Figure 4-23: 2D differentiation of hIGFBP5 knockout hES cells to cardiomyocytes

(A) Immunofluorescence staining of cardiomyocytes showing cardiac troponin $\mathrm{T}$ [cTnT] (green) with transcription factor TBX5 (red). (B) $\alpha$-sarcomeric-actinin (green) with gap junction protein connexin-43 [CX43] (red) and (C) $\alpha$ sarcomeric-actinin (green) with cell adhesion component N-cadherin [NCAD] (red). Representative pictures. DAPI nuclear staining in blue, scale bar is $50 \mu \mathrm{M}$. 


\subsection{Igfbp5 is downregulated upon norepinephrine and angiotensin II mediated hypertrophy}

Physiological hypertrophy is an essential part of cardiomyocyte maturation in the developing heart. NE as an $\alpha$ and $\beta$-adrenergic receptor agonist is known to have a potential role in physiological cardiomyocyte maturation in vitro [102, 121, 122]. Also Ang II, the principal circulating hormone of the renin-angiotensin system and mediator cardiac hypertrophy in vivo [123], was shown to increase fetal cardiomyocyte maturation in sheep [124]. To study the role of IGFBP5 in the context of cardiac maturation, NE and Ang II treated murine neonatal cardiomyocytes (MNCM) were used (see scheme in Figure 4-24A). Upon a 48h treatment with $1 \mu \mathrm{M}$ NE or $1 \mu \mathrm{M}$ Ang II, a significant downregulation of Igfbp5 was observed in treated MNCMs in comparison to non-treated controls (Figure 4-24BC, n=3 different isolations of several neonatal hearts, $\mathrm{P}<0.01 ; \mathrm{P}<0.001)$. Further, treated MNCMs showed a significant downregulation of the predominant fetal cardiac muscle filament gene $M y h 7$ isoform (Figure 4-24D, $n=3$ different isolations with multiple hearts).

Ang II is known as an important hormonal mediator of cardiac hypertrophy and fibrosis [104] and is commonly used in vitro and in vivo models. After the described in vitro experiments with neonatal cardiomyocytes, it was of interest to investigate the expression of Igfbp5 in an Ang II disease model. Mice were examined two weeks after minipump implantation and in a second set-up, 4 weeks after implantation, while Ang II infusion was expected to be depleted already two weeks after minipump implantation (see timeline in Figure 4-24E). Comparing the expression of Igfbp5 in mice with chronic Ang II infusion for two weeks to control mice, treated with saline solution, Igfbp5 was significantly downregulated (Figure 4-24F, n=9/8 per group, $\mathrm{P}<0.05$ ), while the pro-hypertrophic gene Nppa was significantly upregulated in Ang II mice (Figure 4-24G, $\mathrm{n}=9$ /group, $\mathrm{P}<0.001$ ). In the second experimental setup, four weeks after minipump implantation, Igfbp5 was significantly downregulated (Figure 4-24H, n=6/group, $\mathrm{P}<0.05$ ), while there was no significant regulation of Nppa (Figure 4-24I, n=6/group).

Taken together, these findings provide evidence that Igfbp5 is downregulated during NE and Ang II mediated hypertrophy in vitro as well as in vivo. 


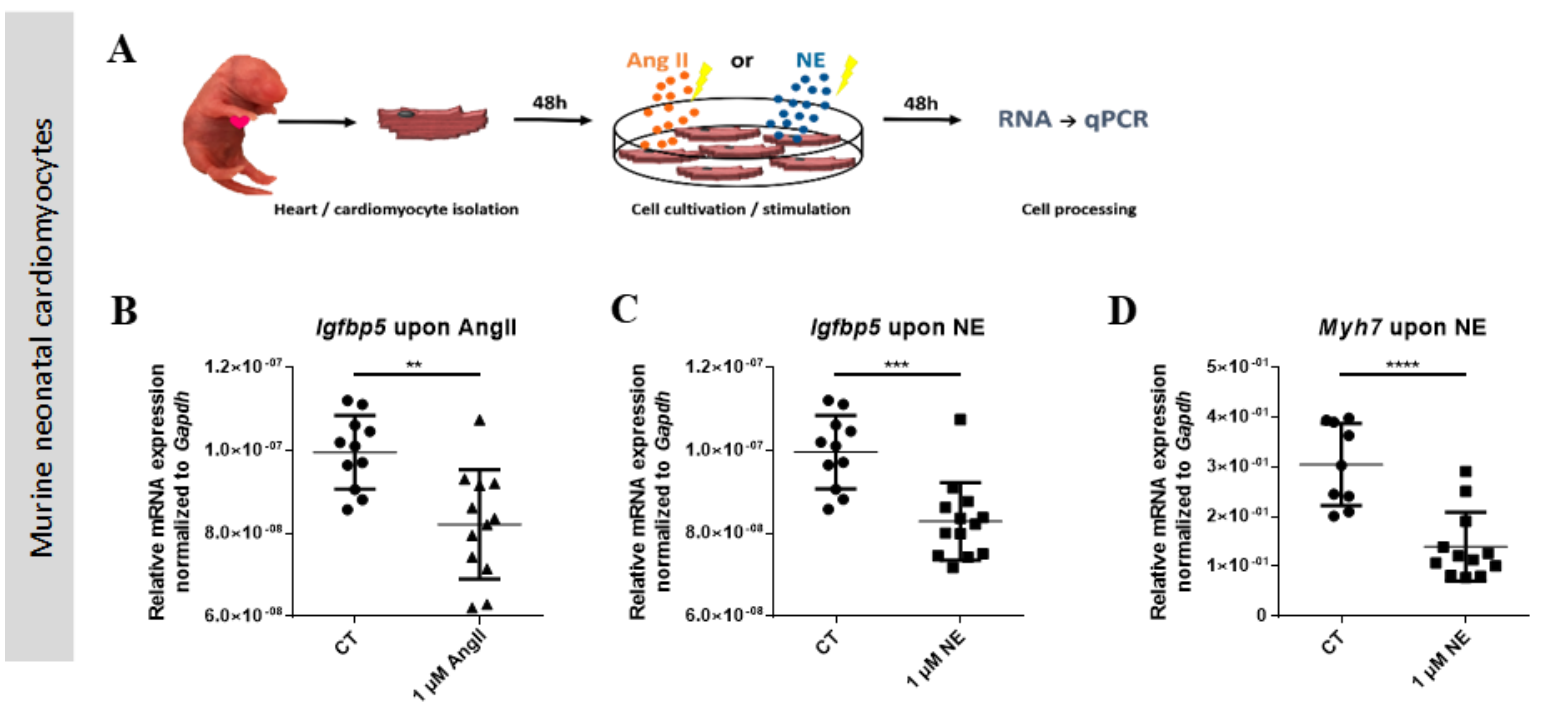

$\mathbf{E}$

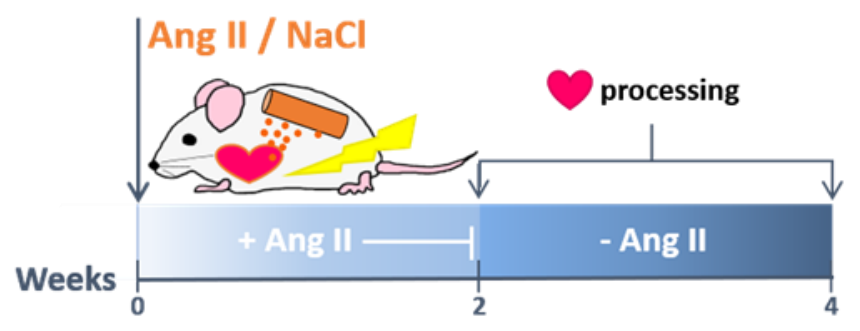

$\mathbf{F}$
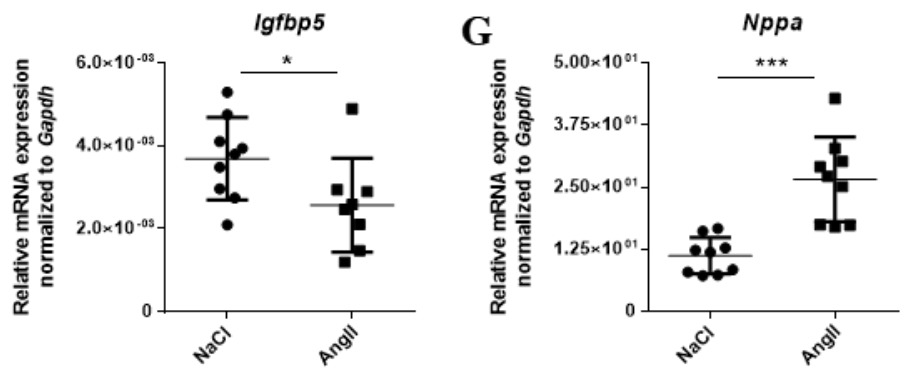

H
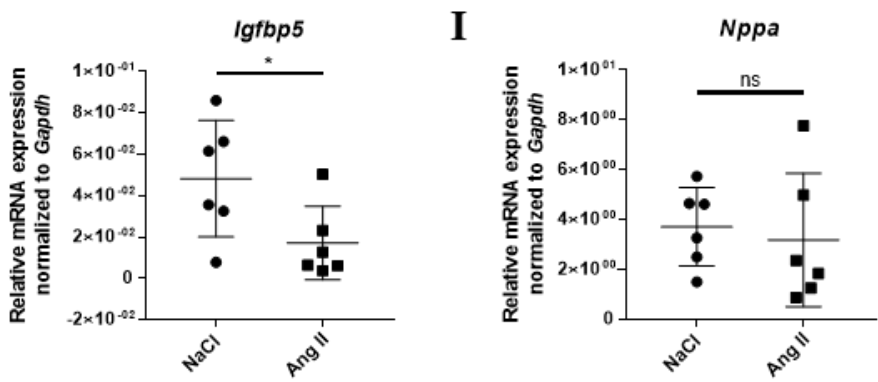

Figure 4-24: Igfbp 5 expression upon norepinephrine and angiotensin II stimulation

(A) Scheme of murine neonatal cardiomyocyte (MNCM) isolation and stimulation. (B) Igfbp5 expression in MNCMs upon angiotensin II [Ang II] stimulation $(1 \mu \mathrm{M} ; 48 \mathrm{~h})$. (C) Igfbp5 and (D) $M y h 7$ expression in NMCMs upon norepinephrine [NE] stimulation $(1 \mu \mathrm{M} ; 48 \mathrm{~h}) . \mathrm{n}=3$ different isolations. (E) Time line of Ang II and saline solution [NaCl] infusion via osmotic minipumps. (F) Igfbp5 and (G) Nppa expression in Ang II and NaCl treated mice 2 weeks after minipump implantation. $\mathrm{n}=6$ per group. (H) Igfbp5 and (I) Nppa expression in Ang II and NaCl treated mice 4 weeks after minipump implantation. $\mathrm{n}=9$ per group. Gapdh was used for normalization. Data are mean $\pm \mathrm{SEM}$; $\mathrm{t}$-test, $* \mathrm{P}<0.05$; $* * \mathrm{P}<0.01 ; * * * \mathrm{P}<0.001 ; * * * * \mathrm{P}<0.0001 ; \mathrm{ns}=$ not significant. 


\section{Discussion}

\subsection{IGFBP5, a conserved developmental gene, is re-activated during the transition to heart failure}

\subsubsection{IGFBP5 is upregulated during the transition to heart failure in mice and in humans}

Investigation of the $\mathrm{Wnt} / \beta$-catenin pathway, a well-characterized developmental signalling pathway that is re-activated in the diseased heart, revealed an upregulation of $\operatorname{Igfbp5}[92,93]$. The inducible, cardiac specific $\beta$-Cat GOF in mice led to cardiac hypertrophy with increased heart sizes, cardiac mass, myocyte cross-sectional area, fibrosis and increased mortality culminating in HF. Igfbp5 expression consequent to murine HF was studied to investigate whether the regulation of Igfbp5 is directly related to Wnt activation or rather is a consequence of disease progression. An upregulation of Igfbp5 was detected in a murine TAC model. Determining the expression dynamics of $I g f b p 5$ revealed an upregulation upon HF initiation post-TAC, but not during early compensatory hypertrophy phase three days post TAC, when hypertrophy markers like Nppb and associated pathways like the Wnt signalling pathway [93] were already activated. A direct association between Igfbp5 upregulation and HF was demonstrated in a TAC-rescue experiment. Previous data showed that inhibiting Wnttranscriptional activation in the murine heart upon TAC abrogates HF progression [93]. In this setup, Igfbp5 was only upregulated when echocardiographic parameters indicated HF, whereas transgenic mice with preserved cardiac function post-TAC showed no significantly regulation of Igfbp5 expression. In line with observations in mice, IGFBP5 was also found highly expressed in heart samples from patients with aortic stenosis in comparison to non-failing control samples. Interestingly, even when the regulation of IGFBP5 in samples from patient with compensated hypertrophy showed a trend, IGFBP5 was not significantly upregulated in comparison to non-failing control samples, similar to observations made in the TAC mouse model. As in mice, human IGFBP5 was only found significantly upregulated upon HF. Intriguingly, RNA sequencing data from mice and humans consequent to HF revealed that only very few genes show a dynamic increase in expression from the non-failing heart, to compensated hypertrophy, to HF. Moreover, only 25 of these dynamically upregulated genes are found conserved between mice and humans, including IGFBP5. IGFBP3 is the most similar IGFBP to IGFBP5 [50] and has been associated with an increased risk of ischemic heart disease and found upregulated upon HF [108, 109]. However, no significant regulation of Igfbp3 was 
observed upon compensated hypertrophy or in HF, neither in mice nor in humans in this study. Taken together, these results show an upregulation of IGFBP5 in the context of the failing heart in mouse and in human, providing evidence that IGFBP5 might play a conserved role during the transition to HF.

Concomitant with the upregulation of the IGFBP5 transcript in ventricles from aortic stenosis patients, miR-139-5p and miR-146b-5p, two micro RNAs (miRNAs) which can potentially target the human IGFBP5 transcript, were found progressively downregulated in patients with pathologies extending from compensatory hypertrophy to HF. miRNAs are small endogenous non-coding RNAs that play important gene-regulatory roles, either regulating gene expression via mRNA silencing (degradation) or via post-transcriptional regulation (preventing translation) (Lee et al., 1993). Decreased levels of miR-139-5p were also reported in patients with different classes of HF [125-127] as well as in patients with left ventricular ischemia [128]. miR-139-5p, is also predicted to target $N R 3 C 2$, a gene which is upregulated in patients with congestive HF [118]. Interestingly, NR3C2 was found to be a potential target of IGFBP5 (see chapter 4.4.2), suggesting a dual regulatory role for miR-139-5p on expression of both genes during HF. Another link between IGFBP5 and miR-146b-5p is the gene CCL2, also found to be a potential target of IGFBP5 (see chapter 4.1.3), whereas CCL2 was shown to be downregulated by miR-146b-5p [129]. In aortic stenosis patients, when miR-146b-5p expression decreased, both potentially targeted transcripts (IGFBP5 and CCL2) were upregulated. The concomitant upregulation of transcripts with downregulation of their targeting miRNAs indicates their mutually dependent expression. This data indicates how tightly controlled gene regulation and expression is on every regulatory level and provides evidence that IGFBP5 and its targets can be regulated by the same miRNAs.

\subsubsection{IGFBP5 is part of the fetal gene program}

Cardiac remodelling is accompanied by a re-activation of genes (mostly transcription factors) which have important functions during cardiogenesis [10, 130]. The restoration of these genes in the adult heart in response to disease stimuli promotes the compensatory hypertrophic response, as part of the so-called "fetal gene program". However, the signalling mechanisms mediating the critical transition from compensated hypertrophy to decompensated HF remain elusive. Igfbp5 expression is high in the early cardiac crescent in mouse embryos [87] and was shown to decrease during cardiogenesis with progressing heart maturation in this study. Several authors associated persistent expression of Igfbp5 with impaired cardiomyocyte differentiation, whereas enhanced cardiomyocyte differentiation was correlated with decreasing Igfbp5 
expression [87-89]. Hence, a downregulation of Igfbp5 during cardiogenesis seems to be important for cardiomyocyte differentiation and cardiac maturation. The expression pattern of Igfbp5 during cardiogenesis and its upregulation upon HF supports the hypothesis that the fetal gene program is re-activated in the diseased heart. Similarly, HAND2, a developmental transcription factor, essential for right ventricle development [131] is re-employed in the diseased and failing heart [132]. Dirkx et al. reported that this re-activation led to pathological hypertrophy, whereas cardiac specific HAND2 deletion upon TAC led to a marked resistance to TAC-induced hypertrophy, fibrosis, and ventricular dysfunction [132]. This example shows that revealing the precise role of genes from the re-activation program could provide a mechanistic link to understand cardiac hypertrophy progression and might help to identify novel approaches to delay or even prevent HF. Collectively this data indicates diverging functions of IGFBP5 during cardiogenesis and HF.

Since previous data and data from this study sheds light upon the impact of Igfbp5 on cardiac progenitor cell (CPC) homeostasis (see 2.2.3 and 4.6.2), it can be speculated that a re-activation of IGFBP5 in the diseased heart has an effect on residual CPCs. Some authors advocate the idea that CPCs reside in specific niches with a certain microenvironment characterized by hitherto unknown key components [32]. A change in the microenvironments changes the behaviour of the CPCs on the one hand inducing senescence and apoptosis [30], on the other promoting CPC migration, as well as proliferation and differentiation [32]. The role of $I g f b p 5$ re-activation on CPC behaviour in the adult diseased heart must be further investigated.

\subsection{IGFBP5 stimulates atrophic and anti-fibrotic processes in vivo}

\subsubsection{IGFBP5 mediates atrophy in the normal heart via downregulation of ECM and sarcomeric genes}

To investigate the direct effect of IGFBP5 on the murine heart in vivo, an adeno-associated viral (AAV) vector mediated approach was used. For the comparison of transcriptome data from Luc $\mathrm{CT}$ and IBP5 OE heart samples, mice which did not receive virus particles were included, since AAV9 particle mediated gene transfer can trigger undesirable immune responses. It was reported that innate immune responses to AAV vectors are primarily mediated by the TLR9MyD88 pathway which induces the production of pro-inflammatory cytokines by activating the NF- $\kappa \mathrm{B}$ (nuclear factor kappa-light-chain-enhancer of activated B cells) pathway [133]. In the heart, NF- $\kappa \mathrm{B}$ signalling promotes $\mathrm{HF}$ by eliciting signals that trigger chronic inflammation through enhanced elaboration of cytokines or interleukin signalling [134]. In the current study, 


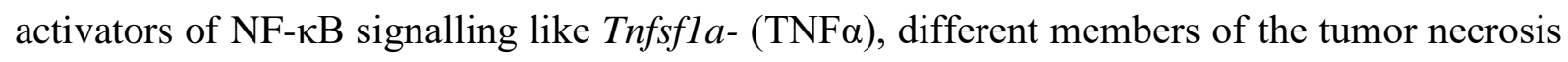
factor ligand superfamily- (Tnfsf) as well as Rela (p56) and Relb, two family members of the $\mathrm{NF}-\kappa \mathrm{B}$ family were found significantly upregulated in AAV9 treated mice when compared to

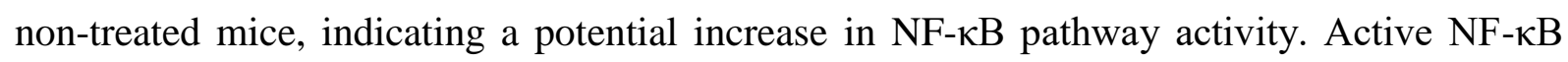
signalling and upregulation of TNF $\alpha$ are not only indicative of a host response to AAV particles, but also of cardiac impairment $[134,135]$. In line with this, upregulation of markers of the diseased heart like Myh7, Nppb, Gdf15 and Gata4 [130,136] were found in AAV9 treated mice indicating an early hypertrophic cardiac response. Gene ontology (GO) analysis clustered the upregulated genes into apoptotic signalling pathways and those involved in the regulation of cell growth, whereas downregulated genes included those related to cellular response to stress and cell cycle. To evaluate potential IGFBP5 targets which are regulated independently of the AAV9-mediated transcriptional activation, the intercept of regulated genes found in IBP5 OE and Luc CT expressing hearts was excluded (see scheme in Figure 4-7A).

To investigate whether IGFBP5 influences cardiac physiology, echocardiographic analyses was done 18 weeks post AAV9 administration. Parameters like left ventricular inner diameter, endsystolic volume and heart to body weight ratio showed a significant decrease in mice which received IBP5 OE particles in comparison to Luc CT mice and untreated mice, all indicating a decrease in heart size. The decrease in the size of a tissue or organ due to cellular shrinkage is called atrophy, whereas the decrease in cell size can be caused by the loss of organelles, cytoplasm and proteins [137]. Several publications indicate an association of IGFBP5 with atrophy in skeletal muscle, whereas in these studies, Igfbp5 was found downregulated and associated with inflammation in an IGF-dependent manner [138-141]. RNAseq data from IBP5 OE heart samples with hearts from untreated mice, revealed a downregulation of several genes which are important for the structural integrity of the heart. For instance, pro-fibrotic genes like collagens, TGF $\beta$ (Tgfb2) [119], Ddr2 [142], fibronectin (Fn1) [143], platelet-derived growth factor-C and D (Pdgfc, $P d g f d)$ [144, 145] and Sox9 [146], were downregulated upon IBP5 OE, indicating an anti-fibrotic or even a potential ECM destabilizing effect. Recently, SOX9 was reported to be a key regulator of cardiac fibrosis during ischemic injury [146]. These authors showed that SOX9 is a common transcriptional regulator of a large portion of the fibrosisrelated genes, whereas lineage-tracing experiments indicated that the majority of collagenpositive fibroblasts stem from a pool of Sox9-expressing cells. Moreover, it could be shown that in vivo loss of Sox9 reduces the cardiac fibrotic response upon ischemic injury, which supports observations made in this study. COLA4A1 and COLA4A2 are the major structural components of the cardiomyocyte basement membrane, linking the sarcolemma of individual 
myocytes to the surrounding ECM and interstitial cells [147]. Downregulation of both genes upon cardiomyocyte specific IBP5 OE suggests a loss of cell integrity. In line with this, the gap junction proteins CX43 (Gjal) and CX40 (Gja5) are downregulated in IBP5 OE mice, indicating an uncoupling of cell-cell contacts [148]. Moreover, downregulation of the potassium channel genes Kcnn2 and Hcn4 indicate a potential decrease in electrical conduction between cells, further supporting the loss of cellular integrity. Furthermore, a downregulation of myosin light chain kinase (Mylk) was observed in IBP5 OE hearts when compared to controls. Mylk is known to be downregulated upon TAC, whereas this downregulation was shown to coincide with the functional transition from compensated to decompensated hypertrophy [149] which is in agreement with the expression pattern of Igfbp5 in the transition to HF. Knockdown of Mylk was reported to be associated with sarcomeric disorganization in vitro [150] as well as in vivo with concomitant cardiomyocyte atrophy [151]. Another gene downregulated in IBP5 OE mice is the chaperone heat shock protein 90 (Hsp90aal). Hsp90aal was found upregulated in mice upon TAC and forms a complex with TGF $\beta$ receptor I (TGF $\beta$ RI) in fibroblasts. Hsp90aal KO mice show drastically reduced collagen protein synthesis as well as inhibition of canonical TGF $\beta$ signalling with improved myocardial fibrosis [152]. Interestingly, cardiac fibroblasts conditioned with HSP90AA1-inhibited hypertrophied myocyte supernatant were reported to express less collagen which highlights the role of cardiomyocytes in the regulation of collagen expression in fibroblasts [153]. Further, these authors showed a novel signalling mechanism where myocyte-derived HSP90AA1 orchestrates interleukin-6 (IL-6) synthesis and its release by exosomes. In turn, exosomal IL-6 activates STAT3 in cardiac fibroblasts which culminates in excess collagen synthesis, leading to severely compromised cardiac function during cardiac hypertrophy. These findings might suggest a potential mechanism by which IGFBP5-induced downregulation of Hsp90aal in cardiomyocytes mediates the decrease in collagen production in cardiac fibroblasts, which needs further investigation. Furthermore, the IL6/STAT3 axis has been shown to be involved in IGFBP5 signalling [129, 154], supporting the hypothesized mechanism. In line with this, Stat5a, which was also shown to be involved in fibrotic processes mediated by Ang II [155], is downregulated upon cardiac IBP5 OE, further corroborating an anti-fibrotic effect of IGFBP5. These results were intriguing, since several publications provide evidence that IGFBP5 has a pro-fibrotic effect [91, 156-161] (discussed in detail in 5.4.4). Moreover, RNAseq data indicates a downregulation of the protein kinase C alpha (PKC $\alpha$, Prkca) in IBP5 OE hearts. PKC $\alpha$ activity was found associated with hypertrophy, dilated cardiomyopathy, ischaemic injury and HF. Inhibition of PKC $\alpha$ was shown to reduce fibrosis and hypertrophy, enhance 
cardiac contractility and attenuates HF [162]. To investigate gene regulation independent of the AAV9 mediated cardiac effect, expression of some IGFBP5-related genes was validated comparing hearts from Luc CT mice with hearts from IBP5 OE mice. qPCR analysis revealed a decreased expression of the developmental genes Mef2c, Nkx2.5 and Myocd. Mef2c loss-offunction mutations were reported to contribute to congenital heart defects due to a reduced transcriptional activity [163], while loss of $M e f 2 c$ in skeletal muscle results in improper sarcomere organization [164]. Moreover, Type I muscle atrophy was shown to be caused by microgravity-induced decrease of Mef2c in rats [165], all associating Mef2c downregulation with a reduced muscle integrity. Expression of $N k x 2.5$ [166] and Myocd [112] is known to be required for adult heart homeostasis, whereas reduced expression has detrimental effects on cardiomyocytes, such as apoptosis. Remarkably, ablation of the Myocd gene in the adult heart leads to a dissolution of sarcomeric organization, disruption of the intercalated disc and to the rapid-onset of HF and death [112]. In line with this, the downregulation of myocardin-related transcription factors were already associated with skeletal muscle atrophy in mice [167]. Additionally, the sarcomeric genes $M y h 7$ and Tnnt2 are downregulated in IBP5 OE mice when compared to Luc controls. Gene ontology analysis clustered the downregulated genes into ECM organization, tissue morphogenesis, cell junction organization and heart contraction, whereas the upregulated genes are clustered in carboxylic acid metabolic process, oxidation-reduction process and lipid metabolic process which will be discussed later. A reduced heart size concomitant with a decreased ECM and sarcomeric gene expression as well as an altered cardiac cell integrity, suggests an atrophic process in the healthy adult heart upon IBP5 OE.

On the one hand IGFBP5 downregulated Mylk, Myocd, Mef2c, Nkx2.5, Myh7 and Tnnt2 which seems to have detrimental effects on cardiomyocyte physiology, while on the other hand IGFBP5 induces the downregulation of key regulators of fibrotic processes like Sox9, Prkca (PKC $\alpha$ ), and Hsp90aal which might have beneficial anti-fibrotic effects. Collectively, this data indicates that IGFBP5 could be both detrimental or beneficial for cardiac function. Investigation of IBP5 OE post-TAC will help to determine its function during HF.

\subsubsection{IGFBP5 increases fatty acid metabolism in the healthy heart}

RNAseq analysis indicated increased fatty acid metabolism in murine hearts upon cardiac IBP5 $O E$. Fatty acid $\beta$-oxidation in the mitochondria is the main ATP source of the adult healthy heart. In the diseased heart, the primary myocardial energy source switches from normal fatty acid $\beta$-oxidation to glycolysis, a reversion to the energy metabolism in the fetal heart, reviewed by Doenst et al. [168]. The shift in substrate preference towards anaerobic glycolysis, also 
called metabolic remodelling [169], might be an oxygen-sparing modulation of the diseased heart. Since fatty acid oxidation provides a greater capacity for energy production compared with glucose, reverting the heart back to using fatty acids might be an effective therapeutic option for treating HF [170]. Recently it has been reported that switching glycolysis back to fatty acid $\beta$-oxidation via PPAR $\alpha$ activation alleviates HF $[171,172]$. PPAR $\alpha$ (peroxisome proliferator-activated receptor $\alpha, \mathrm{NR} 1 \mathrm{C} 1)$ is a member of the nuclear hormone receptor superfamily of ligand-activated transcription factors and is highly expressed in cardiomyocytes. PPAR $\alpha$ regulates the expression of key components of fatty acid metabolism [173] and its expression decreases continuously after TAC induced hypertrophy to HF [174]. IGFBP5 was already shown to interact with other nuclear receptors like the vitamin D receptor (VDR, NR1I1) and the retinoid X receptor- $\alpha$ (RXR $\alpha$, NR2B1) $[175,176]$. IGFBP3, the closest family member to IGFBP5, is known to interact with PPAR $\gamma$ (NR1C3) [177]. Interestingly, several PPAR $\alpha$ target genes like Cyp4a14, Cyp4f15, Cyp8b1, ACADS, Acad10, TXNIP and Ccl2 [178] are found upregulated in murine hearts of IBP5 OE mice when compared to the controls. Moreover, TXNIP and CCL2 were also found regulated in hCFBs upon IBP5 OE in vitro (see chapter 4.4.2), further supporting a direct connection between PPAR $\alpha$ and IGFBP5. Metabolic remodelling is not only characterized by changes in substrate utilization but also by mitochondrial dysfunction, which ultimately can result in ATP deficiency and impaired contractility [168]. Defective mitochondria are targeted for autophagic elimination (mitophagy), a process which controls mitochondrial quality. Reduced autophagy and accumulation of impaired mitochondria have been linked to the progression of HF, whereas increased autophagy in the myocardium in response to stress is initially a protective mechanism (see reviews from Sabbah and Moyzis et al. $[179,180]$ ). RNAseq data from murine hearts with IBP5 OE revealed a downregulation of $B c l 2$ and $B c l 2 l 13$, which participate in mitophagy [181] and an upregulation of Fis1, a protein that promotes mitochondrial fission [180]. Moreover, Pinkl (PTEN-induced putative kinase 1), a mitochondrial serine/threonine-protein kinase was found upregulated. The PINK1/Parkin pathway is involved in marking dysfunctional mitochondria for clearance by autophagy and is indispensable for normal heart function. PINK1 protein levels are markedly reduced in end-stage human HF. In line with this, PINK1 deficient mice develop left ventricular dysfunction, hypertrophy and a higher degree of fibrosis due to oxidative stress and impaired mitochondrial function [182]. Recently it was reported that Fis1mediated upregulation of $P I N K 1$ expression in senescent human umbilical vein endothelial cells (HUVECs) might present a protective mechanism against oxidative damage in mitochondria [183], suggesting that IGFBP5 might have a beneficial effect on mitochondria turnover. 
Collectively, this data indicates that IGFBP5 has a positive effect on fatty acid metabolism, potentially mediated via PPAR $\alpha$, and suggests a role in mitochondrial turnover. Further investigation of IBP5 OE in the diseased heart is necessary to reveal whether it is detrimental or beneficial for cardiac function

\subsection{IGFBP5 is a novel cardiokine with paracrine and endocrine features}

\subsubsection{IGFBP5 is a potential cardiokine which might serve as a biomarker}

To determine which cell population in the diseased murine heart is responsible for the upregulation of $I g f b p 5$, isolated cardiomyocyte and non-myocyte cell populations from TACmice and mice with cardiomyocyte specific $\beta$-Cat GOF were investigated. qPCR analysis revealed that cardiomyocytes exclusively upregulate Igfbp5 in both models when compared to controls. Interestingly neither immunoblot analysis, nor IF staining from isolated $\beta$-Cat GOF cardiomyocytes, could confirm this upregulation. A similar observation was made in total heart lysates from TAC mice and in total heart lysates from patients with dilated cardiomyopathy. There, no differences in intracellular IGFBP5 protein quantity was observed in murine or human HF samples when compared to controls. Since IGFBPs have secretory signal peptides and the mature proteins are mainly found extracellularly [111], this data suggests that increased protein quantities might be directly secreted. ELISA analysis of cell supernatants from $\beta$ Cat GOF cardiomyocytes indicated a high IGFBP5 secretion in comparison to controls which is in line with the mRNA expression data. Since it is known that another IGFBP member, IGFBP3, is detectable in blood serum [184], it was investigated whether increased IGFBP5 secretion can also be detected in blood serum. ELISA analysis from serum samples from TAC mice and from mice with cardiac $\beta$-Cat GOF showed a significant increase of serum IGFBP5 in comparison to control mice. IGFBP5 is already under investigation as a potential biomarker for several diseases, excluding cardiovascular disorders [185-187]. For example, differences in serum IGFBP5 levels could be detected in Crohn's disease [188] or in type 1 and type 2 diabetes mellitus [189] patients when compared to controls. In lung cancer, IGFBP5 is already a well recommended biomarker, since its serum levels correlate with the progression and outcome of the disease [190]. In contrast to IGFBP5, IGFBP3 serum levels were shown to correlate with increased risk of developing ischemic heart disease [108]. To date, no correlation between HF and IGFBP3 serum levels were shown, which is in line with this study, where no difference in Igfbp3 expression could be observed on comparing human or murine failing heart samples to controls. 
Proteins secreted by the heart are termed cardiokines [191]. Cardiokines play a crucial physiological role in maintaining heart homeostasis (e.g. growth factors and endocrine hormones), sending signals of distress and exacerbating pathology (e.g. cytokines) or responding to myocardial damage with remodelling or healing (e.g. extracellular matrix proteins and stem cell-homing factors) [191, 192]. Apart from their paracrine function, cardiokines also exert endocrine regulatory effects on peripheral organs and tissues. Alteration in the repertoire of cardiokines serves as both a determinant of cardiac disease-response and an indicator of cardiac disease state. Therefore, cardiokines could represent potential biomarkers and might serve as promising therapeutic targets. As an example, the most prominent and longest known cardiokine is ANP (atrial natriuretic peptide, encoded by the gene Nppa) [193]. ANP was identified as a heart-secreted hormone that provides a peripheral signal to the rest of the organism to modify blood pressure and volume under conditions of HF [194]. Thus, ANP is a suitable early prognostic marker throughout for cardiac disease and was even recommended as a potential therapeutic target [195]. However, ANP, as a marker, is unable to ascertain a distinct disease state and cannot be used to classify disease progression. The regulatory effects of cardiokines are often complex, as they can exert bidirectional actions to promote repair after cardiac injury and/or aggravate an imbalance of cardiac function [192].

In conclusion, this data provides evidence that IGFBP5 might be a cardiokine, primarily secreted from the cardiomyocytes in the failing heart. Further, IGFBP5 might act in an autocrine/paracrine manner to contribute in intercellular communication within the myocardium. This study showed IGFBP5 upregulation and secretion at the onset of HF, making it a suitable biomarker candidate indicating HF transition.

\subsubsection{IGFBP5 can mediate cardiomyocyte-fibroblast crosstalk}

In the previous section it was shown that IGFBP5 is primarily secreted from cardiomyocytes in the diseased heart. Bidirectional cardiomyocyte-fibroblast crosstalk is a well-known mechanism in both, normal and diseased hearts. To investigate whether secreted IGFBP5 can act in a paracrine manner on possible receiver cells, hCFBs were cultured with IGFBP5-FLAG conditioned medium and showed an uptake of the exogenous IGFBP5. A cellular uptake of IGFBP5 was already described in human breast cancer cells, human osteosarcoma cells and porcine vascular smooth muscle cells $[64,85,120]$ but so far, no IGFBP5 uptake was shown in cardiac cells. Bidirectional cardiomyocyte-fibroblasts crosstalk during cardiac disease can lead to structural and functional changes and finally to cardiomyocyte hypertrophy, fibrosis and arrhythmias [2]. As an example, it was shown that under disease stimuli, cardiomyocytes 
induced paracrine secretion of the cardiokine Ang II and reactive oxygen species (ROS), which mediate the expression of TGF $\beta$ in cardiac fibroblasts. In the fibroblasts, TGF $\beta$ induces the expression of CTGF, COLAIAl (also cardiokines [191, 192]) and led to myofibroblast formation [196]. TGF $\beta$ secreted by fibroblasts in turn can induce cardiomyocyte hypertrophy [197], affects cardiomyocyte electrophysiology [198] and $\mathrm{Ca}^{2+}$ handling [199]. A similar concept was already described for HSP90AA1 [153], which was found regulated in mice with cardiomyocyte specific IBP5 OE in this study, potentially mediating anti-fibrotic effects (see chapter 4.2, 5.2.1). Interestingly, a significant upregulation of the IGFBP5 transcript was detected in IGFBP5-FLAG conditioned medium treated hCFBs, indicating a positive feedback activation. The activation of IGFBP5 expression due to exogenous IGFBP5 could be explained via three possible mechanisms: (i) Exogenous receptor activation with subsequent signalling cascade activation and initiation of transcription by unknown factors. (ii) Reuptake of IGFBP5 and activation of an endogenous receptor. (iii) Direct action as a possible transcription cofactor. Indicative for the first hypothesis is a characterization of a $420 \mathrm{kDa}$ membrane protein which was identified as an IGFBP5-receptor. However this potential IGFBP5-receptor could not be cloned and validated [57]. Flynn et al. provided further evidence that IGFBP5 mediates its actions via binding to an uncharacterized cell surface receptor, since they found IGFBP5dependent activation of Gai3, a heterotrimeric G protein subunit [200]. Several studies show that exogenous addition of IGFBP5 to cells in vitro led to different cellular effects, but none of these authors could describe how the signal was mediated [201-203]. IGFBP5 has the ability to enter cell nuclei via its nuclear localisation sequence [65] and could potentially mediate transcriptional processes via binding to co-factors, nuclear receptors or the histone-DNA complex which supports the third conjecture $[85,86,176,204]$. These findings underline a possible role for IGFBP5 as a transcriptional co-factor, potentially activating its own expression.

Collectively, this data suggests a dynamic paracrine relationship between cardiomyocytes and fibroblasts mediated by IGFBP5. Subsequent to secretion by donor cells (cardiomyocytes), IGFBP5 could be reuptaken by receiver cells (cardiac fibroblasts) and influences its own expression. In the next chapter, it will be demonstrated that cardiac fibroblasts that received an IGFBP5 signal, can respond and even reply via secretion of different cardiokines. 


\subsection{Potential role of IGFBP5 in cardiac fibroblasts and the failing heart}

\subsubsection{Identification of potential IGFBP5 targets in human cardiac fibroblasts}

The previous data regarding IGFBP5 secretion and reuptake indicate a paracrine mediator role for IGFBP5 in cardiomyocyte-fibroblast crosstalk. Furthermore, the effect of IGFBP5 (secreted from the sender cell, the cardiomyocyte) on possible receiver cells (cardiac fibroblasts) was investigated in this study. RNA sequencing of hCFBs with an OE of IGFBP5 (IBP5 OE) revealed twelve differentially expressed genes. Strikingly, among the downregulated genes, there were few genes which could mainly be attributed to cardiomyocytes and there is minimal insight into these genes in the context of cardiac fibroblasts.

$\{1\}$ The most prominent downregulated gene in IBP5 OE hCFBs is MYOCD. MYOCD is a transcriptional coactivator of serum response factor (SRF) which plays an important role in the development of cardiac myocytes and vascular smooth muscle cells [205]. Even when exclusively expressed in cardiac and smooth muscle cells, MYOCD can also be detected in human fibroblasts [206]. MYOCD is essential for adult heart function due to maintenance of cardiomyocyte structure and sarcomeric organization. Conditional cardiomyocyte specific KO leads to severe HF due to cardiomyocyte apoptosis and fibrosis [112]. \{2\} Thioredoxininteracting protein (TXNIP, also known as vitamin D3 upregulated protein 1 or thioredoxin binding protein 2), is an endogenous inhibitor of the antioxidant thioredoxin. Maintained expression of TXNIP post-TAC was reported to have cardioprotective effects due to thioredoxin inhibition [114]. \{3\} Another downregulated gene found upon IBP5 OE in hCFBs was stanniocalcin-1 (STC1). Stanniocalcin-1 is a secreted glycoprotein hormone [207], reported to cause reversible inhibition of transmembrane calcium currents in rat cardiomyocytes through L-channels which might alter calcium homeostasis of the failing heart [113]. \{4\} CCchemokine ligand 2 (CCL2, also monocyte chemoattractant protein 1 (MCP1)) is a potent chemoattractant for monocytes, $\mathrm{T}$ cells, and natural killer cells to the sites of inflammation [208]. Increased CCL2 levels were reported to contribute to fibrotic processes and modulate ECM components in human skin fibroblasts [209]. KO of $\mathrm{Ccl} 2$ attenuated post-infarction remodelling, at the expense of a prolonged inflammatory phase and delayed replacement of injured cardiomyocytes with granulation tissue [210]. \{5\} Hyaluronan synthase 2 (HAS2) is one of three synthases for the acidic carbohydrate hyaluronan, which is one of the major components of the ECM [211]. It was shown that OE of Has2 in mesenchymal cells in mice promotes invasiveness of fibroblasts and causes severe lung fibrosis [212]. \{6\} Among the upregulated genes due to IBP5 OE in hCFBs, the most prominent gene is the growth 
differentiation factor 15 (GDF15), a member of the transforming growth factor $\beta$ superfamily. Recently GDF15 was evaluated as a biomarker of cardiovascular stress but also as a predictor of progression, prognosis and mortality in patients with HF and other established diseases [117, 213]. \{7\} PLEKHA7 (pleckstrin homology domain containing family A member 7) is a cytoplasmic component of the epithelial adherens junction belt [214]. The PLEKHA7 zebrafish homolog HADP1 was shown to interact with the PI4K pathway to regulate normal $\mathrm{Ca}^{2+}$ dynamics, and is thus required for myocardial contractility [215]. \{8\} AHNAK2 (meaning giant in Hebrew) is considered a plasma membrane support protein in muscle and lining epithelium. In cardiomyocytes, AHNAK2 localizes at both the sarcolemma and at Z-band sites suggesting a role in the excitation/contraction coupling mechanism [216]. Haase et al. reviewed that AHNAK has an inhibitory role on the L-type $\mathrm{Ca}^{2+}$ channel (ICaL) predominantly through slowing the channel inactivation [217]. \{9\} Another gene found being upregulated in hCFB upon IBP5 OE is NR3C2 (nuclear receptor subfamily 3 group C member 2, also known as mineralocorticoid receptor). NR3C2 regulates the expression of ionic and water transporters and serves for renal salt-balance maintenance, whereas antagonists are widely used in treating HF [218]. Noteworthy, miR-139-5p, a microRNA found downregulated upon HF [125-127] is predicted to target both, IGFBP5 and NR3C2 [219].

Table 5-1: Comparison of gene expression

\begin{tabular}{|c|c|c|c|}
\hline Sample type & hCFB & whole heart & \\
\hline Gene & hIBP5 OE & HF mouse & HF human \\
\hline AMDHD2 & $\uparrow$ & $\uparrow(\mathrm{TAC}) *$ & $\downarrow(\mathbf{D C M})^{*}$ \\
\hline GDF15 & $\uparrow$ & $\uparrow(\mathbf{T A C})[117]$ & $\uparrow(\mathbf{H F})[220]$ \\
\hline PLEKHA7 & $\uparrow$ & $\uparrow($ TAC)* & $\downarrow(\mathbf{D C M})^{*}$ \\
\hline NR3C2 & $\uparrow$ & $\downarrow$ (MI, TAC) [221] & $\uparrow(\mathbf{C H F})[118]$ \\
\hline SH2D5 & $\uparrow$ & $\uparrow($ TAC) $*$ & $\uparrow(\mathrm{DCM}) *$ \\
\hline AHNAK2 & $\uparrow$ & I & $\downarrow$ (DCM)* \\
\hline STC1 & $\downarrow$ & $\uparrow($ Hypoxia) [222] & $\uparrow(\mathbf{H F})[113]$ \\
\hline CCL2 & $\downarrow$ & $\uparrow(\mathbf{M I})[210]$ & $\uparrow(\mathbf{C H F})[115]$ \\
\hline VEPH1 & $\downarrow$ & $\uparrow(\text { TAC })^{*}$ & $\uparrow(\mathrm{DCM}) *$ \\
\hline HAS2 & $\downarrow$ & $\uparrow(\text { TAC })^{*}$ & $\uparrow(\mathbf{H F}, \mathbf{M I})[116,223]$ \\
\hline MYOCD & $\downarrow$ & $\downarrow(\text { TAC })^{*}$ & $\downarrow(\mathrm{DCM})^{*}$ \\
\hline TXNIP & $\downarrow$ & $\downarrow$ (TAC) [114] & $\uparrow(\mathrm{DCM})^{*}$ \\
\hline
\end{tabular}

Comparison of gene expression in human cardiac fibroblasts (hCFB) upon IBP5 OE with gene expression in ventricles from mice and humans with heart disease. HF: heart failure, DCM: dilated cardiomyopathy, CHF: congestive HF, MI: myocardial infarction, TAC: transverse aortic constriction. Red indicates upregulation, blue indicates downregulation, * indicates sequencing data (Dr. Sara Khadjeh, Department of Cardiology and Pneumology, UMG. Khadjeh et al., unpublished) which is not described/confirmed in literature so far. 


\subsubsection{Potential role of IGFBP5-induced genes in human cardiac fibroblasts}

STC1, AHNAK2 and PLEKHA7, which were found regulated upon IBP5 OE in hCFBs could be associated with calcium handling. Besides the conduction system, calcium plays a role in cell communication between cardiomyocytes and fibroblasts and is mediated via gap junctions [224]. In the diseased heart, cardiomyocyte-fibroblast interactions change and facilitate disease progression [225, 226]. Another reason for the changed expression of these calcium handling related genes might be their involvement in the cellular conduction system. Recent in vitro evidence indicates electrical coupling between cardiomyocytes and fibroblasts which could be a consequence of cardiomyocyte decoupling [227]. A changed expression of calcium handling genes could potentially be due to fibroblast-cardiomyocyte coupling. HAS2, CCL2 and VEPH1 could be associated with fibrotic effects. These genes are downregulated upon IBP5 OE in cardiac fibroblasts, whereas upon hypertrophy and HF in mice and in humans, they are upregulated. Since fibrosis is a process which accompanies and even leads to HF [3], an upregulation of these genes in disease is not surprising. However, the downregulation in cardiac fibroblasts indicates that IGFBP5 might attenuate fibrotic effects, which will be discussed in detail below. Moreover, regulation of the membrane associated proteins PLEKHA7, AHNAK2 and HAS2 might indicate an altered cell integrity. Cardiogenic genes like MYOCD, TXNIP and STC1 are regulated in IBP5 OE cardiac fibroblasts. It was recently shown that cardiac fibroblasts possess potential plasticity and express cardiogenic genes [228]. These authors showed evidence that a subpopulation of cardiac fibroblasts are primed for trans-differentiation by expression of cardiogenic factors. Notably, some studies show that MYOCD, in combination with other cardiac transcription factors, has the capacity to activate the cardiac gene program $[229,230]$. The cardiogenic identity of cardiac fibroblasts is characterised by the presence of transcription factors that are fundamental for cardiogenesis and are found re-activated in the diseased heart [231]. In line with this idea, the appearance of IGFBP5 and its potential target MYOCD in hCFBs is not unexpected. Both genes are developmental transcriptional coactivators (evidence for IGFBP5 see 4.5.1), re-activated in the event of cardiac disease. The potential adaptability of cardiac fibroblasts to a cardiogenic gene program implicates a broader spectrum of functions for cardiac fibroblasts during disease besides myofibroblast formation. It can be speculated as to how these primed cardiogenic fibroblasts contribute to the maintenance of cardiac function during disease.

In summary, IBP5 OE in hCFB leads to downregulation of genes which can be associated with fibrotic processes and upregulation of genes which have a cardiogenic identity. Strikingly, GDF 15 and MYOCD, two genes which are of great importance in the diseased heart, show the 
same regulation upon IBP5 OE in hCFBs as they do in the event of HF in mice and in humans. This indicates a direct and maybe even conserved connection between IGFBP5 and these genes consequent to HF.

\subsubsection{Functional performance of fibroblasts with IGFBP5 overexpression}

The prior data clearly indicates that IGFBP5 induces gene expression in cardiac fibroblasts, but so far it is not known how this might influence hCFB behaviour. Cardiomyocytes-fibroblasts crosstalk is bidirectional. Since IBP5 OE in hCFBs leads to the expression of secretory proteins like GDF15, STC1, HAS2 and CCL2, it needs to be investigated whether these proteins might act in a paracrine manner and influence cardiomyocytes in a feedback reaction. To examine functional performance of these cells, engineered human myocardium (EHM) was generated. Validation of functional performance did not show any difference between EHMs with GFP control hCFBs and EHMs with hCFBs with IBP5 OE regarding force generation, whereas the velocity of tissue relaxation was significantly reduced in EHMs with IBP5 OE hCFBs. Additionally, a faster rate of change in force over the rate of time (isometric contraction and isometric relaxation) could be observed in EHMs with IBP5 OE hCFBs. These results indicate a faster calcium shuttling per contraction, suggesting a more efficient calcium handling in EHMs with IBP5 OE hCFBs. This observation is in agreement with the already mentioned IBP5 OE-induced secretion of proteins which are associated with calcium handling. Further, it cannot be excluded that secreted IGFBP5 itself, alters cardiomyocyte physiology. Such a phenomenon was already described by Cartledge et al., who reported that soluble mediators secreted from either fibroblasts- or myofibroblast have a contrary influence on calcium transient amplitudes in co-cultured rat cardiomyocytes [232]. Furthermore, IGFBP5 mediated change in isometric contraction and isometric relaxation could be due to changed tissue stiffness, while a faster contraction indicates softer tissue which could be due to a change in ECM components. These observations are in line with in vivo data from this study, where gene regulation in hearts with cardiomyocyte specific IBP5 OE is clustered in ECM organization, cell junction organization and heart contraction, indicating that these processes are partially due to the effect of IGFBP5 on cardiac fibroblasts.

Collectively, this data suggests that the IGFBP5 mediated effects on hCFBs alter EHM physiology, which might be due to IGFBP5-induced paracrine actions on cardiomyocytes in the tissue. 


\subsubsection{Potential influence of IGFBP5 on fibrosis and premature fibroblast senescence}

Several publications provide evidence that IGFBP5 has a pro-fibrotic effect. Upregulated expression of IGFBP5 was found in two human fibrotic disorders namely dermal systemic sclerosis [156] and idiopathic pulmonary fibrosis [157]. Both disease phenotypes could also be observed in mouse models, where mice showed increased thickness of the dermis [160] and pulmonary fibrosis [161] upon in vivo IBP5 OE. In liver, IGFBP5 improved the survival of myofibroblasts via enhanced expression of pro-fibrotic genes [158]. Regarding the heart, IGFBP5 was shown to mediate high glucose-induced pro-fibrotic effects in rat neonatal cardiac fibroblasts [91]. All these reports show evidence that IGFBP5-dependent pro-fibrotic effects are accompanied by augmented synthesis of ECM components like collagen and fibronectin. Further, it was shown that IBP5 OE led to increased expression of vimentin and ACTA2, indicating fibroblast-myofibroblast trans-differentiation in vitro and in vivo [160, 161]. Strikingly, in this study IBP5 OE in hCFBs did not lead to an upregulation of ACTA2. Proofof-concept experiments confirmed that cardiac fibroblast had the capacity to transdifferentiate to myofibroblasts upon TGF $\beta$ treatment, while TGF $\beta$ led to the expression ACTA2 but did not influence IGFBP5 expression. Milyavsky et al. reported that TGF $\beta$ treatment activates MYOCD (MYOCD), which is essential for TGF $\beta$-induced myofibroblast differentiation [233]. In this study, MYOCD was found downregulated upon IBP5 OE in hCFBs. Interestingly, a null-mutation of the myocardin-related transcription factor A (MRTF-A) was shown to has anti-fibrotic effects post-MI [234] suggesting a correlation between MYOCD downregulation and anti-fibrotic effects. Among the downregulated genes found in hCFBs upon IBP5 OE, not only MYOCD can be regulated in a TGF $\beta$-dependent manner. The pro-fibrotic genes HAS2, $C C L 2$ and $V E P H 1$ are also known to be associated with TGF $\beta$ as well [235-237]. Additionally, GDF 15 was found upregulated in dermal systemic sclerosis in which TGF $\beta$ plays a central role [238]. It was shown that GDF15 directly activates CCL2 [235], which in turn leads to fibrosis. Interestingly, CCL2 is downregulated in hCFB upon IBP5 OE even when its direct activator GDF15 is upregulated in this condition. This data provides evidence that the pro-fibrotic effect of GDF15, which intrinsically upregulates $C C L 2$, is TGF $\beta$ dependent. Taken together, profibrotic genes which are known to act in a TGF $\beta$-dependent manner are downregulated in hCFB upon IBP5 OE, indicating an anti-fibrotic effect of IGFBP5 in these cells. Significantly, in vivo data from this study indicated that cardiomyocyte specific IBP5 OE downregulates several ECM genes, decreasing the expression of fibrotic key mediators (see chapter 4.2), supporting the recent in vitro data. 
In line with the previous conclusion, Sokolović et al. reported that AAV-mediated liver specific IBP5 OE in mice reduced liver fibrosis in chronic cholangiopathy [159]. The anti-fibrotic effect was shown to be constituted by a reduced cell proliferation due to enhanced cellular senescence. In line with this, IGFBP5 was found to be a paracrine mediator of STAT3-induced premature senescence in TIG3 human fibroblasts [239]. In contrast to replicative senescence, which plays a fundamental role in ageing and which is originally characterized by telomere erosion [240], premature senescence is an irreversible cell-cycle arrest primarily designed to initiate the elimination of damaged cells [241]. In cardiac fibroblasts, premature senescence was found to be associated with cardiac fibrosis subsequent to murine myocardial infarction [242] and in patients with atrial fibrillation [243]. Both studies show that premature fibroblast senescence has beneficial anti-fibrotic effects in vitro. In vivo, premature senescence induced anti-fibrotic effects and cardio-protection in the event of HF in mice as reported by Meyer et al. [244]. There is further evidence for a critical role of IGFBP5 in the process of premature senescence. Both OE and exogenous IGFBP5 induced premature senescence in endothelial cells through a p53dependent signalling pathway [245]. In silico prediction showed that IGFBP5 contains a p53 response elements [246]. Further, It was shown that coagulation factor FXa-induced- [247] as well as irradiation-induced [248] premature senescence in endothelial cells is mediated by IGFBP5. Notably, IGFBP3, -4 , and -6 were also associated with the process of cell senescence [249]. In this study, IBP5 OE in vivo did not disclose any premature senescence markers which is most likely due to the absence of myofibroblast trans-differentiation [244]. Nevertheless, some of the identified IGFBP5 targets can be correlated to this process. The transcriptome data revealed an upregulation of GDF 15 upon IBP5 OE in cardiac fibroblasts. It was shown that GDF 15 is a downstream target of p53 [250], which is activated in premature senescence [221, 251]. Furthermore, IGFBP5 caused the upregulation of AHNAK2 in hCFBs. Ahnak2 was also found upregulated in an in vitro model with overexpressed histone variant H2A.Bbd [252], which was reported to be a senescence marker [253]. Depletion of HAS2 was shown to induced pulmonary fibroblast senescence [254]. In this study, HAS2 was also downregulated in hCFBs upon IBP5 OE. Another characteristic of senescent cells is that they can communicate with their environment through a so-called senescence-associated secretory phenotype (SASP). These paracrine factors can locally propagate the senescence response to the surroundings [255]. This cell characteristic is consonant with features of IGFBP5, which acts in a paracrine manner, mediating cellular crosstalk.

To summarize, this data provides evidence that a divergence from the existing literature, IGFBP5 has an anti-fibrotic- or at least fibrosis extenuating effect on cardiac fibroblasts which 
is confirmed by in vivo data from this study. Results from this study further support a role for IGFBP5 in premature fibroblast senescence, which is described to arrest or even antagonize fibrosis.

\subsection{IGFBP5 acts as a transcriptional co-factor}

In the last chapters it was shown that hCFBs can uptake IGFBP5 and in this way IGFBP5 can influence its own gene expression in these receiver cells. As mentioned before, IGFBP5 has a nuclear localisation sequence which enables it to enter nuclei [64]. Its nuclear import appears to share a common pathway with IGFBP3, both mediated by importin- $\alpha /$ importin- $\beta$ complex $[65,256]$. It has been reported that IGFBP5 interacts with nuclear components $[85,86]$. Since IGFBP5 possesses no DNA binding domain, it might function as a transcriptional co-regulator. Direct evidence for such a transcriptional co-regulator role of IGFBP5 was provided by Schedlich et al. The authors reported that IGFBP5 interacts with the nuclear vitamin D receptor (VDR, NR1I1) and blocks its heterodimerization with the nuclear retinoid X receptor- $\alpha$ (RXR $\alpha$, NR2B1) $[175,176]$. In silico prediction of annotated protein-protein interactions [257] indicate other nuclear receptors (NR2F2, NR2F1, NR4A1) potentially binding IGFBP5. Moreover, an interaction with the nuclear receptors PPAR $\alpha$ is further supported by in vivo data from this study, whereas cardiac IBP5 OE led to the activation of several PPAR $\alpha$ targets (see chapter 5.2.2), indicating that IGFBP5 is a transcriptional co-factor. However, no IGFBP5 association with any DNA loci with subsequent target activation was reported. To determine whether IGFBP5 is associated with genomic DNA regions, ChIP analysis of potentially IGFBP5(co)bound chromatin was done in hCFBs. It revealed two bound gene loci namely IGFBP5 itself and TNNT2. Since the IGFBP5 occupied loci in both, IGFBP5 and TNNT2 mark the 5 'region from the TSS of both genes, both loci represent putative promoter regions. Published data for $\mathrm{H} 3 \mathrm{~K} 4 \mathrm{me}$, from reference hCFBs, mark accessible chromatin in IGFBP5-FLAG bound loci. Whereas there is $\mathrm{H} 3 \mathrm{~K} 4 \mathrm{me}$ occupancy in the IGFBP5 locus, no H3K4me occupancy is visible for TNNT2 in hCFBs indicating no TNNT2 gene activity. TNNT2 is a regulatory protein that plays a crucial role in muscle activity. Since TNNT2 is predominantly expressed in cardiomyocytes and not in fibroblasts, the absence of $\mathrm{H} 3 \mathrm{~K} 4 \mathrm{me}$ occupancy in cardiac fibroblasts confirms the epigenetic silencing of this gene. IGFBP5 was found associated to these loci, which suggests a repressive function of IGFBP5 in this context, which was supported by luciferase reporter assays. Further in silico analysis of the IGFBP5-occupied loci of IGFBP5 and TNNT2 predicts potential NKX2.5 binding motifs. NKX2.5 is a cardiac transcription factor which was shown to regulate both, the TNNT2 [258] and the IGFBP5 promoter [259]. In 
contrast to findings by Nimura et al., luciferase assays revealed that the IGFBP5 promoter is activated upon NKX2.5 expression. In line with these findings, Dorn et. al showed, that OE of NKX2.5 increases IGFBP5 transcription [88]. In line with observations by Kobayashi et al., the TNNT2 promoter showed activation upon NKX2.5 expression. Evaluation of double cotransfection luciferase experiments showed that IGFBP5 led to a significant reduction of NKX2.5-mediated TNNT2 promoter activation, indicating an antagonistic action of IGFBP5 on NKX2.5-mediated actions. NKX2.5 is a cardiac transcription factor and a marker for myocardial progenitor cells. NKX2.5 can activate TNNT2 expression [258], with TNNT2 expression being commonly used as a marker for stem cell or cardiac progenitor cell differentiation $[88,89,103,258,260,261]$. NKX2.5, which commits cells to the cardiac lineage, could promote cardiac cell differentiation by activating TNNT2 expression. Gene regulation is a complex and tightly controlled process. The presence and absence of transcriptional activators and repressors is time and context dependent. Both, IGFBP5 and NKX2.5 are expressed in the early cardiac crescent [87]. It can be hypothesized that the simultaneous occurrence of NKX2.5 and IGFBP5, which keeps cells in a cardiac progenitor like state [87, 89], might be due to, among other things, IGFBP5 which represses the promoter activation of TNNT2 and even antagonizes its NKX2.5-mediated activation. During murine cardiogenesis in vivo, Igfbp5 expression decreases with progressing heart maturation (as described in chapter 2.2.3), which might be in line with its abolished repression of (NKX2.5mediated) TNNT2 activation and subsequent cardiomyocyte differentiation. Of special interest is the revelation that IGFBP5 is primarily a secreted protein that mediates extracellular effects, predominantly in an IGF-dependent manner. There is considerable evidence that secreted factors like hormones and growth factors are capable of modulating cellular responses not only indirectly by activating classical signal transduction pathways, but also directly by nuclear targeting. A duality of function was already been shown for insulin [262], platelet-derived growth factor [263], and fibroblast growth factor [264]. Besides being a binding protein for IGF, IGFBP5s capacity for nuclear uptake and its potential for interactions with nuclear receptors (transcription factors) represents its capacity to act as both, binding protein and ligand.

The collected data provide evidence that IGFBP5 can act as a transcriptional co-factor via indirect association with DNA. Besides binding its own promoter, it can repress the TNNT2 promoter and even antagonize NKX2.5-mediated TNNT2 promoter activation. Furthermore, there is a growing body of evidence that IGFBP5 interacts with nuclear receptors to mediate transcriptional processes. Additional investigations of the nuclear role of IGFBP5 is necessary, 
since a better understanding of IGFBP5 action in the nucleus may open new opportunities for therapeutic intervention in $\mathrm{HF}$ and other diseases like cancer.

\subsection{IGFBP5 plays a central role in the cardiac regulatory hierarchy mediating cardiac progenitor fate}

\subsubsection{IGFBP5 controls stem cell commitment and arrests cardiomyocyte differentiation}

Comparing different cell populations of the adult murine heart, the expression of Igfbp5 is highest in the undifferentiated Sca1-positive progenitor cell pool (unpublished, see preliminary data chapter 2.2.3). In vitro, downregulation of Igfbp5 was correlated with increased stem cell and progenitor differentiation [87-89], while sustained expression was reported to impair cardiomyocyte differentiation. To investigate the impact of IGFBP5 on stem cell commitment and differentiation, a KO hES cell line was generated using a double-paired CRISPR/Cas9D10A nickase (Cas9n) genome editing approach. Application of this technique led to two different hES cell lines where the genomic changes comprised the planned homozygous deletion of the TSS in one cell line (clone (K)22) and an unexpected heterozygous random integration of plasmid material in a second cell line (clone (K)12). Despite deletion of the TSS in in the deletion clone (K22), an expression of the remaining IGFBP5 transcript was detectable, where there was neither a significant difference in transcript quantity nor in protein secretion measurable in comparison to the mock control. Since neither geno-, nor phenotyping of the deletion clone (K22) delivered any conclusive result, the discussion will only focus on the insertion clone (K12). Cell line characterization of clone K12 revealed an increased IGFBP5 transcript abundance and an increased IGFBP5 protein secretion when compared to the control. As indicated in the last chapters, IGFBP5 can activate its own expression. The gain-of-function (GOF) phenotype could potentially be due to a cellular protein accumulation of IGFBP5 with subsequent positive feedback regulation of IGFBP5 transcription. So far, it can only be speculated how the insertion of genetic material leads to a GOF phenotype, but it might be due to a protein stabilization or an aggravated ER release due to the changed protein size and changed biochemical properties. These observations indicate that the insertion of genetic material in this clone led to a GOF-like mutant. The underlying molecular features, leading to this GOF still need further investigation.

Analysing the influence of increased IGFBP5 abundance in stem cells, a decreased expression of pluripotency markers OCT4, TRA1-60 and SOX2 was detected in comparison to control cells indicating reduced stemness of clone K12. Recently it was shown that SOX2 alone is needed 
to preserve self-renewal and pluripotency in hES cells and besides, it regulates OCT4 and TRA1-60 [265]. A direct effect of IGFBP5 on SOX2 and OCT4 was reported by Wang et al. [266]. These authors showed that OE of IGFBP5 in human melanoma cells led to a decrease of SOX2 and $O C T 4$, indicating a direct impact of IGFBP5 on stemness. In the present study, clone K12 possessed the capacity to differentiate in all three germ layers, indicating that IGFBP5 GOF does not fully determine the cell fate at this early stage. Directed differentiation of K12-hES cells led to spontaneously beating cardiomyocytes with a reduced cell size (which was already seen in the hES cells) and a concomitant increased in cyclin D1 expression, all indicating a potential increase in cell proliferation. An IGFBP5-dependent cyclin D1 activation was also shown in human prostate cancer cells [267], underlining a stimulatory effect of IGFBP5 on proliferation in this study. Moreover, AXIN2, a direct Wnt target was found upregulated in the differentiated K12 cells. Wnt-signalling is known to activate proliferation, what is in line with increased cell cycling. Besides, Wnt-signalling plays a multiphasic role during cardiogenesis and cardiomyocyte differentiation [268]. Coherent with increased proliferation of cardiac progenitor cells, active Wnt-signalling is known to inhibit cardiomyocyte differentiation. To investigate stem cell commitment and the potential of the IGFBP5 GOF hES cells to differentiate into cardiomyocytes, the expression of some key markers was investigated after directed differentiation. Analysis of early cardiogenic progenitor markers such as NKX2.5 and TBX5 revealed an increased expression in differentiated K12 cells when compared to control cells. Together with the reduced stemness of K12 hES cells, these observations indicated a stem cell specification towards the cardiac lineage. Further, Myocd, a potential target gene of IGFBP5 as reported earlier in this study, was found upregulated in differentiated K12 cells. Myocd was shown to be important for cardiac cell determination and differentiation [269]. Whereas ectopic OE of Myocd seems to promote cardiac differentiation, repression of Myocd dramatically inhibits cardiomyocyte differentiation and cardiogenesis and in vitro and in vivo [270, 271]. Intriguingly, in over-specified progenitor cells, which highly express IGFBP5, NKX2.5 and TBX5 [87], Myocd was found downregulated [269]. Taken together, the increased NKX2.5 and TBX5 expression with a concomitant MYOCD upregulation indicates that the differentiated K12 cells are determined to the cardiac lineage. In line with this, a very low cTNT protein abundance along with circumferentially expressed CX43 and less organized protein expression was observed in K12 cardiomyocytes in comparison to the control, indicating an impaired cardiomyocyte differentiation. Cardiomyocyte maturation is characterized by CX34 and NCAD polarization at the intercalated disks. This localization enables cardiomyocytes to electrically integrate, to propagate signals more efficient and faster, which corresponds with 
increased cardiomyocyte maturation [272]. Hence, ectopic organization of CX34 and NCAD, as found in K12 cardiomyocytes, is a feature of immaturity [273, 274]. Interestingly, K12 cardiomyocytes showed an increased beating frequency when compared to control cells. These fetal-like electrophysiological properties could also be due to the unorganized CX34 and NCAD protein expression and could be a result of inappropriate electrical coupling and subsequent unsynchronized beating. With subsequent cardiomyocyte maturation, there is a decrease in spontaneous beating frequency due to higher cellular organization $[275,276]$. This corroborates the immature character of the K12-derived cardiomyocytes. Hence, active Wnt signalling, low cTNT expression as well as unorganized CX34 and NCAD protein abundance with subsequent fetal-like electrophysiological properties indicate a limited potential of IGFBP5 GOF hES cells to fully differentiate in cardiomyocytes. A very similar phenotype was observed in murine embryonic stem cells (mESCs) overexpressing Fhl2, which mediates Wnt/ $\beta$-catenin dependent transcriptional activation [89]. These stem cells showed mesodermal cell formation and cell proliferation while arresting cardiac differentiation in an early cardiogenic mesodermal progenitor state. Igfbp5 was found upregulated in these arrested progenitor cells, supporting the findings in the IGFBP5 GOF cell line. A physical interaction between FHL2 and IGFBP5 was reported earlier [85] while an association between IGFBP5 and active $\mathrm{Wnt} / \beta$-catenin signalling was reported in fibroblasts [277] and cardiomyocytes of the adult diseased heart [92, 93] as well as in the developing [278] and diseased intestine [202]. Besides the interaction of FHL2 and IGFBP5, it is not clear how the Wnt/ $\beta$-catenin pathway and IGFBP5 are connected, but requires further investigation.

IGFBP5 causes the expansion of cardiac progenitor cells as indicated by increased expression of cyclin D1, AXIN2, TBX5 and NKX2.5 and seems to assign cells to the cardiac lineage as indicated by an increased MYOCD expression. Taken together, this data shows that IGFBP5 drives stem cell specification but arrests cardiac cell commitment.

\subsubsection{IGFBP5 in the cardiac regulatory hierarchy}

NKX2.5, the pivotal regulator of the cardiac lineage, is high in the cardiac regulatory hierarchy [87] and connects IGFBP5 to this complex network. Igfbp5 expression follows NKX2.5 dependent cardiac progenitor states. Upregulated Igfbp5 levels were found in murine $N k x 2.5$ null embryos in the context of cardiac progenitor over-specification [87], whereas forced OE of $N k x 2.5$ in vitro, led to the inhibition of cardiac specification and negatively regulated Igfbp5 [88]. Interestingly, ChIP revealed that NKX2.5 can regulate IGFBP5 on the promoter level. Whiles this study showed IGFBP5 activation by NKX2.5, Nimura et al. showed the opposite 
[259]. These authors showed a co-occupancy of H3K36me3-specific histone methyltransferase and NKX2.5 on the Igfbp5 promoter, concluding that the methyltransferase enhances the repressive effect of NKX2.5 on Igfbp5 expression in the context of cardiogenesis. These findings show a dual function of NKX2.5 on the Igfbp5 promoter. Furthermore, a dosagesensitive effect of another important cardiogenic transcription factor, TBX5, was found to be mediated in a synergy with Nkx2.5 [279]. This Tbx5 dosage-sensitive genetic program involves a network of cardiac transcription factors including IGFBP5 and further supports the conjecture that IGFBP5 is directly connected to cardiac key regulators. Moreover, it is known that NKX2.5-dependen transcriptional repression inhibits Isll and restricts its expression to the progenitor cell state [88]. Since ChIP analysis showed that Igfbp5 is a direct ISL1 target [88], the restriction of ISL1 to the progenitor state might also restrict Igfbp5 expression to this state. Interestingly, OE of Isl 1 and subsequently sustained Igfbp 5 expression did not prevent cardiac differentiation, which was also observed in the differentiated IGFBP5 GOF cells. Instead, IslI OE led to enhanced specification of cardiac progenitors and an earlier cardiac differentiation. Further, as in the IGFBP5 GOF cells, an increase in beating frequencies was observed in the Isll GOF cell line, where an association with upregulated nodal-specific genes, like pacemaker channel Hcn4, and a downregulation of transcripts of the working myocardium was found to be the reason. In this study, IBP5 OE in the murine adult heart also led to the regulation of Hcn4 (see chapter 4.2), suggesting a connection between Isll and Igfbp5 downstream gene regulation. Since Isll and Igfbp5 regulation seems to be tightly interconnected and there are several phenotypic similarities between the ISL1 GOF cell line [88] and the IGFBP5 GOF cell line, further investigations regarding the regulatory interaction need to be done. ISL as well as NKX2.5 were reported to transcriptionally target TNNT2 and by this, initiate differentiation. In this study it was shown that IGFBP5 can repress the TNNT2 promoter and even antagonize the NKX2.5-mediated TNNT2 promoter activation, further confirming IGFBP5s role in cardiac progenitor cells. Of note, MYOCD, which was found being an IGFBP5 target in this study, and which was also upregulated in differentiated IGFBP5 GOF cells, was found to be directly regulated by ISL1 [269] and NKX2.5 [271]. Several transcription factors in the cardiac regulatory hierarchy have both, activator and repressor functions sometimes even on the same target gene. Negative feedback regulation plays a major role in this context. Regarding this complex network, Prall et al. stated that “(...) the negative feedback pathway of NKX2.5 may be an example of how the number of progenitor cells (...) is controlled by the degree of differentiation - a paradigm that could apply to adult stem cells and organ regeneration. In this paradigm, NKX2.5 acts as both the sensor of differentiation, and as the arbiter of repression." 
[87]. Cardiogenesis is a dynamic process involving multiple phases of pattern formation to drive cell commitment (specification and determination) and finally differentiation of multipotent cardiac cells.

Concluding, IGFBP5 seems to be involved in the tight regulatory network of developmental transcription factors, suggesting an important role during early cardiogenesis.

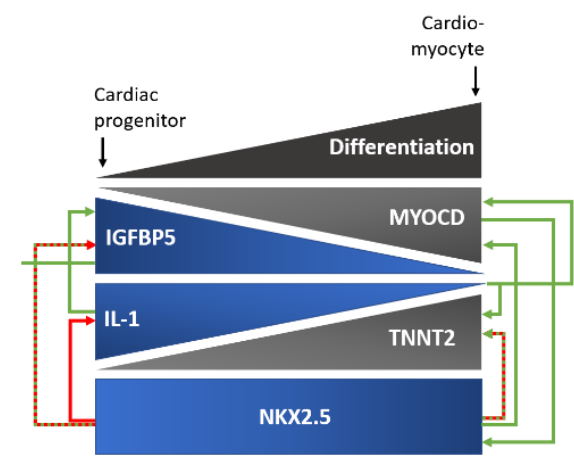

Published interactions

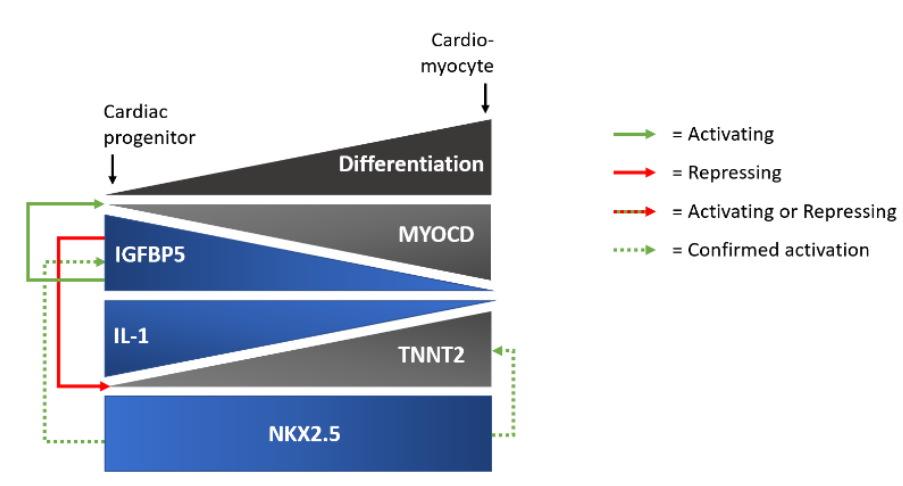

New identified interactions

Figure 5-1: Scheme of gene expression and interactions during cardiogenesis.

Information about reported gene expression and regulatory interactions from published data is referred as "known" [87$89,259,269-271$ ], whereas confirmed and new interactions found in this study are referred as "new identified". Black triangle shows differentiation from progenitor cells to cardiomyocytes, blue triangles show gene expression.

\subsection{Downregulation of Igfbp5 correlates with cardiomyocyte maturation and might be beneficial in the adult diseased heart}

\subsubsection{Neonatal cell maturation is accompanied by Igfbp5 downregulation}

There is evidence that downregulation of Igfbp5 is important for cardiomyocyte differentiation and cardiac maturation as already mentioned above [87-89]. To investigate whether Igfbp5 downregulation correlates with increased cardiomyocyte maturation, murine neonatal cardiomyocytes (MNCMs) served as a suitable model since they are not entirely matured [280]. To induce in vitro maturation, MNCMs were stimulated with Ang II or NE. Ang II, the principal circulating hormone of the renin-angiotensin system and mediator of cardiac hypertrophy in vivo [123], was shown to increase fetal cardiomyocyte maturation in sheep [124]. Also noradrenergic stimulation of neonatal cardiomyocytes is known to drive cardiomyocyte growth and differentiation and increases the amount and organization of myofibrils [281]. Furthermore, NE was reported to enhance sarcomere formation [102], increase the expression of alpha-actin as well as $C x 43$ [122]. Treatment of MNCMs with these 
two hypertrophic mediators led to a downregulation of Igfbp5 with a concomitant decrease of the fetal sarcomere component $M y h 7$, indicating cardiomyocyte maturation. During murine embryonic and fetal stages, expression of $M y h 7$ predominates and decreases after birth, when myosin heavy chain alpha (Myh6) expression gets higher [17]. The switch from $M y h 7$ to a predominant $M y h 6$ expression distinguishes immature- from adult cardiomyocytes.

A decreasing Igfbp5 expression during cardiogenesis is consistent with a downregulated expression upon NE or Ang II treatment in MNCMs in vitro, indicating a correlation between decreased $I g f b p 5$ expression and increased cardiomyocyte maturation.

\subsubsection{Igfbp5 is downregulated during angiotensin II-induced hypertrophy in vivo}

Several studies have shown that Ang II infused mice develop hypertensive heart disease with cardiac hypertrophy and fibrosis, while heart function is often preserved [282]. To confirm previous findings that Igfbp5 is only upregulated consequent to HF, its expression was studied in this mild hypertrophy model. Chronic Ang II infusion for two weeks led to the upregulation of the early hypertrophy marker gene Nppa when compared to saline treated control mice, confirming hypertrophic remodelling. Interestingly, Igfbp5 was found downregulated comparing Ang II infused mice with saline treated control mice. This regulation was the opposite of what was observed in mice with pressure-overload induced HF in this study. A second experimental set up in which mice received a chronic Ang II infusion for two weeks but had two additional weeks after infusion without Ang II stimulation, was studied. In this set up, the progression of Igfbp5 expression was examined to investigate whether its downregulation is a direct Ang II-dependent effect or a consequence of the hypertrophic remodelling process. Interestingly, Igfbp5 was still downregulated in Ang II infused mice compared to control mice, while Nppa was not significantly regulated. Induction of Nppa is a conserved feature of ventricular hypertrophy [283] and it is known that its expression has a local anti-hypertrophic function as reviewed by Song et al. [284]. These findings suggest that the Ang II-induced hypertrophy is not progressive, and a remission might occur. Igfbp5 is not regulated upon TACinduced hypertrophic remodelling which inevitably leads to HF but is downregulated upon Ang II-induced hypertrophy which might be regressive. This observation might suggest a positive effect of downregulated Igfbp5 in the early hypertrophic phase. Trying to find a connection between Ang II and the concomitant downregulation of Igfbp5, another common involvement was observed in cardiac progenitor cells. There are reported effects of Ang II on stem cell and progenitor cell proliferation and differentiation as reviewed by Ahmadian et al. [285]. Ang II was shown to promote differentiation of Sca-1-positive progenitor cells [261] and 
further, promotes differentiation of mouse c-kit-positive cardiac stem cells into pacemaker-like cells in vitro [286]. Regarding Igfbp5, its expression is highest in the undifferentiated Sca1positive progenitor cells of the adult heart (unpublished, see preliminary data chapter 2.2.3), whereas its downregulation could be correlated with increased progenitor differentiation [87, 89].

Collectively the data suggests a potential beneficial effect of Igfbp5 downregulation in Ang IIinduced hypertrophy in vivo, which needs further investigation. 


\section{Conclusion and outlook}

The transition from compensatory hypertrophy to HF is a multi-step process and the mechanisms driving this transition are not well understood. Since HF clinically manifests itself in the form of multiple symptoms, diagnosing its onset and determining an appropriate intervention can be difficult. Hence, it is essential to discover novel biomarkers that define HF transition. IGFBP5 could be such a novel biomarker since this study reveals conserved IGFBP5 upregulation in the transition to HF in humans and mice, in addition to increased IGFBP5 serum levels in mice with HF. However, further investigations of human serum are needed to confirm the observations made in mice. On a cellular level, cardiomyocytes were shown to express and secrete IGFBP5 in the diseased heart, indicating that IGFBP5 might be a novel cardiokine with paracrine and endocrine-like features. In turn, cardiac fibroblasts were shown to uptake exogenous IGFBP5 in vitro, suggesting that IGFBP5 can mediate cardiomyocyte-fibroblast crosstalk. IBP5 OE in hCFBs altered cardiac gene expression including that of MYOCD and cardiovascular disease marker, GDF15. IBP5 OE in cardiomyocytes of the healthy adult murine heart resulted in reduced heart size. Transcriptome analysis revealed a decrease in extra-cellular matrix and sarcomeric gene expression as well as reduced junction and ion channel expression. These observations indicate altered cardiac cell integrity that may have detrimental effects on the healthy heart. On the contrary, key regulators of fibrotic processes like Mylk and Sox 9 were downregulated upon cardiomyocyte specific IBP5 OE concomitant with upregulation of fatty acid metabolism indicating a potential favourable outcome for increased Igfbp5 expression. Further investigation of IBP5 OE and downregulation post-TAC are essential to better understand the effect of IGFBP5 on the diseased heart. In the healthy adult murine heart, Igfbp5 expression was found very low in cardiomyocytes in contrast to a high expression in Sca1positive cardiac progenitor cells. Investigating a human embryonic stem cell line with an IGFBP5 GOF revealed arrested cardiomyocyte differentiation subsequent to progenitor specification. Taken together, the data indicates a role for IGFBP5 on stem cell commitment and progenitor cell homeostasis. Investigation of a knockout (or inducible knock-down) stem cell line would help to further reveal the effect of IGFBP5 expression on cardiomyocyte differentiation and maturation. Previous reports indicated that enhanced cardiomyocyte differentiation correlates with decreasing Igfbp5 expression, which is in agreement with the results of this study. The re-expression of IGFBP5 consequent to HF suggests a role for IGFBP5 in the developmental gene re-activation program of the diseased heart. Mechanistically, IGFBP5 ChIP revealed an IGFBP5 occupancy on its own promoter and on the TNNT2 promoter. Luciferase data showed that IGFBP5 repressed the TNNT2 promoter by antagonizing 
the NKX2.5-mediated TNNT2 promoter activation, indicating that IGFBP5 functions as a transcriptional co-factor. However, other transcriptional co-factors involved in directing IGFBP5 mediated transcriptional regulation need to be identified.

To summarize, IGFBP5 can play multiple roles as (i) an IGF-binding protein, (ii) a paracrine/endocrine-like mediator and (iii) a transcriptional co-factor depending on the cell type, its pattern of distribution and the disease state of the heart. Whether the observed IGFBP5 mediated actions are IGF-dependent or independent has to be clarified. Further studies of IGFBP5 could contribute to our understanding of both cardiac regulatory networks driving cardiogenesis and cellular/molecular mechanisms mediating HF progression. These insights could help define novel pharmacological strategies that enhance the endogenous repair machinery of the adult heart to prevent HF. 

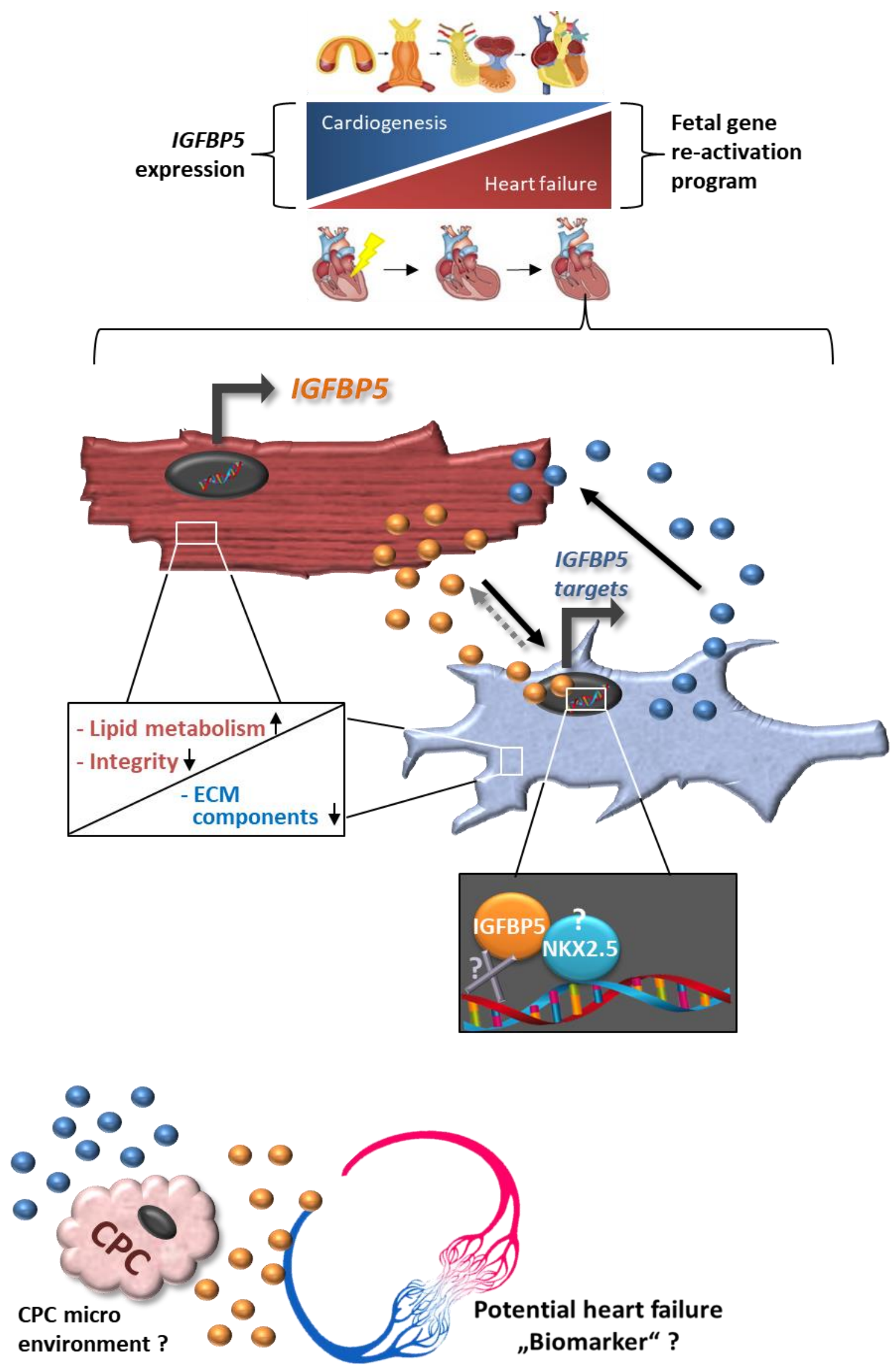

Figure 6-1: Conclusion figure

Top: Igfbp5 regulation during cardiogenesis and heart failure. Bottom: Possible cellular actions mediated by IGFBP5. Red: Cardiomyocyte, blue: fibroblasts, pink: cardiac progenitor cell, orange: secreted IGFBP5, dark blue: secreted IGFBP5 targets, question marks: hypnotized effects and unknown components. 


\section{Bibliography}

1. Wain HM, Bruford EA, Lovering RC, Lush MJ, et al. 2002. Guidelines for human gene nomenclature. Genomics 79: 464-70.

2. Bang Claudia, Antoniades Charalambos, Antonopoulos Alexios S., Eriksson Ulf, et al. 2015. Intercellular communication lessons in heart failure. Eur. J. Heart Fail. 17: 1091-103.

3. Cohn JN, Ferrari R, Sharpe N. 2000. Cardiac remodeling-concepts and clinical implications: a consensus paper from an international forum on cardiac remodeling. $J$. Am. Coll. Cardiol. 35: 569-82.

4. ter Horst P, Smits JFM, Blankesteijn WM. 2012. The Wnt/Frizzled pathway as a therapeutic target for cardiac hypertrophy: where do we stand? Acta Physiol. 204: 110117.

5. Ferrari R, Guardigli G, Mele D, Percoco GF, et al. 2004. Oxidative stress during myocardial ischaemia and heart failure. Curr. Pharm. Des. 10: 1699-711.

6. Cohn JN, Levine TB, Olivari MT, Garberg V, et al. 1984. Plasma Norepinephrine as a Guide to Prognosis in Patients with Chronic Congestive Heart Failure. N. Engl. J. Med. 311: 819-23.

7. Everett AD, Tufro-McReddie A, Fisher A, Gomez RA. 1994. Angiotensin receptor regulates cardiac hypertrophy and transforming growth factor-beta 1 expression. Hypertension 23: 587-92.

8. McMurray JJ, Ray SG, Abdullah I, Dargie HJ, et al. 1992. Plasma endothelin in chronic heart failure. Circulation 85: 1374-9.

9. Frey N, Olson EN. 2003. Cardiac Hypertrophy: The Good, the Bad, and the Ugly. Annu. Rev. Physiol. 65: 45-79.

10. Oka T, Xu J, Molkentin JD. 2007. Re-employment of developmental transcription factors in adult heart disease. Semin. Cell Dev. Biol. 18: 117-31.

11. Mann DL. 2005. Mechanisms and Models in Heart Failure: The Biomechanical Model and Beyond. Circulation 111: 2837-49.

12. Anderson KR, Sutton MG, Lie JT. 1979. Histopathological types of cardiac fibrosis in myocardial disease. J. Pathol. 128: 79-85.

13. Struijker-Boudier HA, Smits JF, De Mey JG. 1995. Pharmacology of cardiac and vascular remodeling. Annu. Rev. Pharmacol. Toxicol. 35: 509-39.

14. Rohini A, Agrawal N, Koyani CN, Singh R. 2010. Molecular targets and regulators of cardiac hypertrophy. Pharmacol. Res. 61: 269-80.

15. Porrello ER, Mahmoud AI, Simpson E, Hill JA, et al. 2011. Transient Regenerative Potential of the Neonatal Mouse Heart. Science 331: 1078-80. 
16. Driesen RB, Verheyen FK, Debie W, Blaauw E, et al. 2009. Re-expression of alpha skeletal actin as a marker for dedifferentiation in cardiac pathologies. J. Cell. Mol. Med. 13: 896-908.

17. Weiss A, Leinwand LA. 1996. The Mammalian Myosin Heavy Chain Gene Family. Annu. Rev. Cell Dev. Biol. 12: 417-39.

18. Allard MF, Schönekess BO, Henning SL, English DR, et al. 1994. Contribution of oxidative metabolism and glycolysis to ATP production in hypertrophied hearts. Am. J. Physiol. 267: H742-750.

19. Ostadal B, Ostadalova I, Dhalla NS. 1999. Development of cardiac sensitivity to oxygen deficiency: comparative and ontogenetic aspects. Physiol. Rev. 79: 635-59.

20. Mercola M, Ruiz-Lozano P, Schneider MD. 2011. Cardiac muscle regeneration: lessons from development. Genes Dev. 25: 299-309.

21. Xin M, Olson EN, Bassel-Duby R. 2013. Mending broken hearts: cardiac development as a basis for adult heart regeneration and repair. Nat. Rev. Mol. Cell Biol. 14: 529-41.

22. Zelarayán LC, Zafiriou MP, Zimmermann W-H. 2013. Emerging Concepts in Myocardial Pharmacoregeneration. In Steinhoff G. ed; Regenerative Medicine. Springer Netherlands. p 637-64.

23. Haubner BJ, Adamowicz-Brice M, Khadayate S, Tiefenthaler V, et al. 2012. Complete cardiac regeneration in a mouse model of myocardial infarction. Aging 4: 96677.

24. Fratz S, Hager A, Schreiber C, Schwaiger M, et al. 2011. Long-term myocardial scarring after operation for anomalous left coronary artery from the pulmonary artery. Ann. Thorac. Surg. 92: 1761-5.

25. Haubner BJ, Schneider J, Schweigmann U, Schuetz T, et al. 2016. Functional Recovery of a Human Neonatal Heart After Severe Myocardial Infarction. Circ. Res. 118: $216-21$.

26. Poss KD, Wilson LG, Keating MT. 2002. Heart regeneration in zebrafish. Science 298: 2188-90.

27. Porrello ER, Mahmoud AI, Simpson E, Johnson BA, et al. 2013. Regulation of neonatal and adult mammalian heart regeneration by the miR-15 family. Proc. Natl. Acad. Sci. U. S. A. 110: 187-92.

28. Bergmann O, Bhardwaj RD, Bernard S, Zdunek S, et al. 2009. Evidence for cardiomyocyte renewal in humans. Science 324: 98-102.

29. Murry CE, Lee RT. 2009. Development biology. Turnover after the fallout. Science 324: $47-8$.

30. Urbanek K, Torella D, Sheikh F, Angelis AD, et al. 2005. Myocardial regeneration by activation of multipotent cardiac stem cells in ischemic heart failure. Proc. Natl. Acad. Sci. 102: 8692-7. 
31. van Berlo JH, Molkentin JD. 2014. An emerging consensus on cardiac regeneration. Nat. Med. 20: 1386-93.

32. Mauretti A, Spaans S, Bax NAM, Sahlgren C, et al. 2017. Cardiac Progenitor Cells and the Interplay with Their Microenvironment. Stem Cells Int. 2017

33. Le T, Chong J. 2016. Cardiac progenitor cells for heart repair. Cell Death Discov. 2: 16052.

34. Oh H, Bradfute SB, Gallardo TD, Nakamura T, et al. 2003. Cardiac progenitor cells from adult myocardium: homing, differentiation, and fusion after infarction. Proc. Natl. Acad. Sci. U.S. A. 100: 12313-8.

35. Pfister O, Mouquet F, Jain M, Summer R, et al. 2005. CD31- but Not CD31+ cardiac side population cells exhibit functional cardiomyogenic differentiation. Circ. Res. 97: 52-61.

36. Bax NAM, van Marion MH, Shah B, Goumans M-J, et al. 2012. Matrix production and remodeling capacity of cardiomyocyte progenitor cells during in vitro differentiation. J. Mol. Cell. Cardiol. 53: 497-508.

37. Mora BN, Huddleston CB. 2011. Heart Transplantation in Biventricular Congenital Heart Disease: Indications, Techniques, and Outcomes. Curr. Cardiol. Rev. 7: 92-101.

38. McMurray JJV, Pfeffer MA. 2005. Heart failure. Lancet Lond. Engl. 365: 1877-89.

39. Doppler SA, Deutsch M-A, Lange R, Krane M. 2013. Cardiac regeneration: current therapies-future concepts. J. Thorac. Dis. 5: 683-97.

40. Pollak MN, Schernhammer ES, Hankinson SE. 2004. Insulin-like growth factors and neoplasia. Nat. Rev. Cancer 4: 505-18.

41. Clemmons DR. 1997. Insulin-like growth factor binding proteins and their role in controlling IGF actions. Cytokine Growth Factor Rev. 8: 45-62.

42. Beattie J, Allan GJ, Lochrie JD, Flint DJ. 2006. Insulin-like growth factor-binding protein-5 (IGFBP-5): a critical member of the IGF axis. Biochem. J. 395: 1-19.

43. Conover CA. 1995. Insulin-like growth factor binding protein proteolysis in bone cell models. Prog. Growth Factor Res. 6: 301-9.

44. Zapf J, Schoenle E, Jagars G, Sand I, et al. 1979. Inhibition of the Action of Nonsuppressible Insulin-Like Activity on Isolated Rat Fat Cells by Binding to its Carrier Protein. J. Clin. Invest. 63: 1077-84.

45. Schneider MR, Lahm H, Wu M, Hoeflich A, et al. 2000. Transgenic mouse models for studying the functions of insulin-like growth factor-binding proteins. FASEB J. Off. Publ. Fed. Am. Soc. Exp. Biol. 14: 629-40.

46. Daza DO, Sundström G, Bergqvist CA, Duan C, et al. 2011. Evolution of the insulinlike growth factor binding protein (IGFBP) family. Endocrinology 152: 2278-89. 
47. Hwa V, Oh Y, Rosenfeld RG. 1999. The insulin-like growth factor-binding protein (IGFBP) superfamily. Endocr. Rev. 20: 761-87.

48. Kelley KM, Oh Y, Gargosky SE, Gucev Z, et al. 1996. Insulin-like growth factorbinding proteins (IGFBPs) and their regulatory dynamics. Int. J. Biochem. Cell Biol. 28: 619-37.

49. Rajaram S, Baylink DJ, Mohan S. 1997. Insulin-like growth factor-binding proteins in serum and other biological fluids: regulation and functions. Endocr. Rev. 18: 801-31.

50. Firth SM, Baxter RC. 2002. Cellular Actions of the Insulin-Like Growth Factor Binding Proteins. Endocr. Rev. 23: 824-54.

51. Beattie J, McIntosh L, van der Walle CF. 2010. Cross-talk between the insulin-like growth factor (IGF) axis and membrane integrins to regulate cell physiology. J. Cell. Physiol. 224: 605-11.

52. Yamada PM, Lee K-W. 2009. Perspectives in mammalian IGFBP-3 biology: local vs. systemic action. Am. J. Physiol.-Cell Physiol. 296: C954-76.

53. Radulescu RT. 1994. Nuclear localization signal in insulin-like growth factor-binding protein type 3. Trends Biochem. Sci. 19: 278.

54. Turner R, Tjian R. 1989. Leucine repeats and an adjacent DNA binding domain mediate the formation of functional cFos-cJun heterodimers. Science 243: 1689-94.

55. Iosef C, Gkourasas T, Jia CYH, Li SS-C, et al. 2008. A functional nuclear localization signal in insulin-like growth factor binding protein-6 mediates its nuclear import. Endocrinology 149: 1214-26.

56. Azar WJ, Zivkovic S, Werther GA, Russo VC. 2014. IGFBP-2 nuclear translocation is mediated by a functional NLS sequence and is essential for its pro-tumorigenic actions in cancer cells. Oncogene 33: 578-88.

57. Andress DL. 1998. Insulin-like growth factor-binding protein-5 (IGFBP-5) stimulates phosphorylation of the IGFBP-5 receptor. Am. J. Physiol.-Endocrinol. Metab. 274: E744-50.

58. James PL, Jones SB, Busby WH, Clemmons DR, et al. 1993. A highly conserved insulin-like growth factor-binding protein (IGFBP-5) is expressed during myoblast differentiation. J. Biol. Chem. 268: 22305-12.

59. Kalus W, Zweckstetter M, Renner C, Sanchez Y, et al. 1998. Structure of the IGFbinding domain of the insulin-like growth factor-binding protein-5 (IGFBP-5): implications for IGF and IGF-I receptor interactions. EMBO J. 17: 6558-6572.

60. Bramani S, Song H, Beattie J, Tonner E, et al. 1999. Amino acids within the extracellular matrix (ECM) binding region (201-218) of rat insulin-like growth factor binding protein (IGFBP)-5 are important determinants in binding IGF-I. J. Mol. Endocrinol. 23: 117-23. 
61. Twigg SM, Baxter RC. 1998. Insulin-like growth factor (IGF)-binding protein 5 forms an alternative ternary complex with IGFs and the acid-labile subunit. J. Biol. Chem. 273: 6074-9.

62. Imai Y, Busby WH, Smith CE, Clarke JB, et al. 1997. Protease-resistant form of insulin-like growth factor-binding protein 5 is an inhibitor of insulin-like growth factorI actions on porcine smooth muscle cells in culture. J. Clin. Invest. 100: 2596-605.

63. Ständker L, Wobst P, Mark S, Forssmann WG. 1998. Isolation and characterization of circulating 13-kDa C-terminal fragments of human insulin-like growth factor binding protein-5. FEBS Lett. 441: 281-6.

64. Schedlich LJ, Young TF, Firth SM, Baxter RC. 1998. Insulin-like Growth Factorbinding Protein (IGFBP)-3 and IGFBP-5 Share a Common Nuclear Transport Pathway in T47D Human Breast Carcinoma Cells. J. Biol. Chem. 273: 18347-52.

65. Schedlich LJ, Page SLL, Firth SM, Briggs LJ, et al. 2000. Nuclear Import of Insulinlike Growth Factor-binding Protein-3 and -5 Is Mediated by the Importin $\beta$ Subunit. $J$. Biol. Chem. 275: 23462-70.

66. Parker A, Clarke JB, Busby WH, Clemmons DR. 1996. Identification of the extracellular matrix binding sites for insulin-like growth factor-binding protein 5. J. Biol. Chem. 271: 13523-9.

67. Booth BA, Boes M, Andress DL, Dake BL, et al. 1995. IGFBP-3 and IGFBP-5 association with endothelial cells: role of C-terminal heparin binding domain. Growth Regul. 5: 1-17.

68. Twigg SM, Kiefer MC, Zapf J, Baxter RC. 1998. Insulin-like growth factor-binding protein 5 complexes with the acid-labile subunit. Role of the carboxyl-terminal domain. J. Biol. Chem. 273: 28791-8.

69. Nam TJ, Busby W, Clemmons DR. 1997. Insulin-like growth factor binding protein-5 binds to plasminogen activator inhibitor-I. Endocrinology 138: 2972-8.

70. Coverley JA, Baxter RC. 1997. Phosphorylation of insulin-like growth factor binding proteins. Mol. Cell. Endocrinol. 128: 1-5.

71. Cheng HL, Shy M, Feldman EL. 1999. Regulation of insulin-like growth factorbinding protein-5 expression during Schwann cell differentiation. Endocrinology 140: 4478-85.

72. Thrailkill KM, Quarles LD, Nagase H, Suzuki K, et al. 1995. Characterization of insulin-like growth factor-binding protein 5-degrading proteases produced throughout murine osteoblast differentiation. Endocrinology 136: 3527-33.

73. Schneider MR, Wolf E, Hoeflich A, Lahm H. 2002. IGF-binding protein-5: flexible player in the IGF system and effector on its own. J. Endocrinol. 172: 423-40.

74. Li X, Cao X, Li X, Zhang W, et al. 2007. Expression level of insulin-like growth factor binding protein 5 mRNA is a prognostic factor for breast cancer. Cancer Sci. 98: 15926. 
75. Güllï G, Karabulut S, Akkiprik M. 2012. Functional roles and clinical values of insulin-like growth factor-binding protein-5 in different types of cancers. Chin. J. Cancer 31: $266-80$.

76. Hwang JR, Cho Y-J, Lee Y, Park Y, et al. 2016. The C-terminus of IGFBP-5 suppresses tumor growth by inhibiting angiogenesis. Sci. Rep. 6

77. Wang J, Ding N, Li Y, Cheng H, et al. 2015. Insulin-like growth factor binding protein 5 (IGFBP5) functions as a tumor suppressor in human melanoma cells. Oncotarget 6: 20636-49.

78. Salih DA, Tripathi G, Holding C, Szestak TA, et al. 2004. Insulin-like growth factorbinding protein 5 (Igfbp5) compromises survival, growth, muscle development, and fertility in mice. Proc. Natl. Acad. Sci. 101: 4314-4319.

79. Ning Y, Hoang B, Schuller AGP, Cominski TP, et al. 2007. Delayed mammary gland involution in mice with mutation of the insulin-like growth factor binding protein 5 gene. Endocrinology 148: 2138-47.

80. Gleason CE, Ning Y, Cominski TP, Gupta R, et al. 2010. Role of Insulin-Like Growth Factor-Binding Protein 5 (IGFBP5) in Organismal and Pancreatic $\beta$-Cell Growth. Mol. Endocrinol. 24: 178-92.

81. Andress DL, Birnbaum RS. 1992. Human osteoblast-derived insulin-like growth factor (IGF) binding protein-5 stimulates osteoblast mitogenesis and potentiates IGF action. $J$. Biol. Chem. 267: 22467-72.

82. Mohan S, Baylink DJ, Pettis JL. 1996. Insulin-like growth factor (IGF)-binding proteins in serum--do they have additional roles besides modulating the endocrine IGF actions? J. Clin. Endocrinol. Metab. 81: 3817-20.

83. Berfield AK, Andress DL, Abrass CK. 2000. IGFBP-5(201-218) stimulates Cdc42GAP aggregation and filopodia formationin migrating mesangial cells. Kidney Int. 57: 1991-2003.

84. Cobb LJ, Salih DAM, Gonzalez I, Tripathi G, et al. 2004. Partitioning of IGFBP-5 actions in myogenesis: IGF-independent anti-apoptotic function. J. Cell Sci. 117: 173746.

85. Amaar YG, Thompson GR, Linkhart TA, Chen S-T, et al. 2002. Insulin-like Growth Factor-binding Protein 5 (IGFBP-5) Interacts with a Four and a Half LIM Protein 2 (FHL2). J. Biol. Chem. 277: 12053-60.

86. Zhao Y, Yin P, Bach LA, Duan C. 2006. Several Acidic Amino Acids in the N-domain of Insulin-like Growth Factor-binding Protein-5 Are Important for Its Transactivation Activity. J. Biol. Chem. 281: 14184-91.

87. Prall OW, Menon MK, Solloway MJ, Watanabe Y, et al. 2007. An Nkx25/Bmp2/Smad1 negative feedback loop controls second heart field progenitor specification and proliferation. Cell 128: 947-59. 
88. Dorn T, Goedel A, Lam JT, Haas J, et al. 2015. Direct Nkx2-5 Transcriptional Repression of Is11 Controls Cardiomyocyte Subtype Identity: Nkx2-5 Represses Is11 in Cardiogenesis. STEM CELLS 33: 1113-29.

89. Renger A, Zafiriou M-P, Noack C, Pavlova E, et al. 2013. The Four and a Half LIMDomain 2 Controls Early Cardiac Cell Commitment and Expansion Via Regulating $\beta$ Catenin-Dependent Transcription. STEM CELLS 31: 928-40.

90. Leung K-P, Qu Y-H, Qiao D-F, Xie W-B, et al. 2014. Critical role of insulin-like growth factor binding protein-5 in methamphetamine-induced apoptosis in cardiomyocytes. Mol. Med. Rep. 10: 2306-12.

91. Song SE, Kim Y-W, Kim J-Y, Lee DH, et al. 2013. IGFBP5 mediates high glucoseinduced cardiac fibroblast activation. J. Mol. Endocrinol. 50: 291-303.

92. Baurand A, Zelarayan L, Betney R, Gehrke C, et al. 2007. $\beta$-Catenin Downregulation Is Required for Adaptive Cardiac Remodeling. Circ. Res.

93. Iyer LM, Nagarajan S, Woelfer M, Schoger E, et al. 2018. A context-specific cardiac $\beta$-catenin and GATA4 interaction influences TCF7L2 occupancy and remodels chromatin driving disease progression in the adult heart. Nucleic Acids Res. 46: 285067.

94. Zelarayán LC, Noack C, Sekkali B, Kmecova J, et al. 2008. Beta-Catenin downregulation attenuates ischemic cardiac remodeling through enhanced resident precursor cell differentiation. Proc. Natl. Acad. Sci. U. S. A. 105: 19762-7.

95. Irion S, Luche H, Gadue P, Fehling HJ, et al. 2007. Identification and targeting of the ROSA26 locus in human embryonic stem cells. Nat. Biotechnol. 25: 1477.

96. Langmead B, Salzberg SL. 2012. Fast gapped-read alignment with Bowtie 2. Nat. Methods 9: 357-9.

97. Anders S, Huber W. 2010. Differential expression analysis for sequence count data. Genome Biol. 11: R106.

98. Bindea G, Mlecnik B, Hackl H, Charoentong P, et al. 2009. ClueGO: a Cytoscape plug-in to decipher functionally grouped gene ontology and pathway annotation networks. Bioinformatics 25: 1091-3.

99. Irion S, Luche H, Gadue P, Fehling HJ, et al. 2007. Identification and targeting of the ROSA26 locus in human embryonic stem cells. Nat. Biotechnol. 25: 1477-82.

100. Tiburcy M, Hudson JE, Balfanz P, Schlick S, et al. 2017. Defined Engineered Human Myocardium With Advanced Maturation for Applications in Heart Failure Modeling and RepairClinical Perspective. Circulation 135: 1832-47.

101. Noack C, Haupt LP, Zimmermann W-H, Streckfuss-Bömeke K, et al. 2017. Generation of a KLF15 homozygous knockout human embryonic stem cell line using paired CRISPR/Cas9n, and human cardiomyocytes derivation. Stem Cell Res. 23: 12731. 
102. Zhang Y, Nuglozeh E, Touré F, Schmidt AM, et al. 2009. Controllable Expansion of Primary Cardiomyocytes by Reversible Immortalization. Hum. Gene Ther. 20: 1687-96.

103. El-Battrawy I, Lan H, Cyganek L, Zhao Z, et al. 2018. Modeling Short QT Syndrome Using Human-Induced Pluripotent Stem Cell-Derived Cardiomyocytes. J. Am. Heart Assoc. 7: e007394.

104. Baker KM, Aceto JF. 1990. Angiotensin II stimulation of protein synthesis and cell growth in chick heart cells. Am. J. Physiol. 259: H610-618.

105. Zincarelli C, Soltys S, Rengo G, Rabinowitz JE. 2008. Analysis of AAV serotypes 19 mediated gene expression and tropism in mice after systemic injection. Mol. Ther. $J$. Am. Soc. Gene Ther. 16: 1073-80.

106. Heckmann MB, Bauer R, Jungmann A, Winter L, et al. 2016. AAV9-mediated gene transfer of desmin ameliorates cardiomyopathy in desmin-deficient mice. Gene Ther. 23: 673-9.

107. Gandhi PU, Chow SL, Rector TS, Krum H, et al. 2017. Prognostic Value of InsulinLike Growth Factor-Binding Protein 7 in Patients with Heart Failure and Preserved Ejection Fraction. J. Card. Fail. 23: 20-8.

108. Juul A, Scheike T, Davidsen M, Gyllenborg J, et al. 2002. Low Serum Insulin-Like Growth Factor I Is Associated With Increased Risk of Ischemic Heart Disease: A Population-Based Case-Control Study. Circulation 106: 939-44.

109. Watanabe S, Tamura T, Ono K, Horiuchi H, et al. 2010. Insulin-like growth factor axis (insulin-like growth factor-I/insulin-like growth factor-binding protein-3) as a prognostic predictor of heart failure: association with adiponectin. Eur. J. Heart Fail. 12: $1214-22$.

110. James PL, Jones SB, Busby WH, Clemmons DR, et al. 1993. A highly conserved insulin-like growth factor-binding protein (IGFBP-5) is expressed during myoblast differentiation. J. Biol. Chem. 268: 22305-12.

111. Hwa V, Oh Y, Rosenfeld RG. 1999. The Insulin-Like Growth Factor-Binding Protein (IGFBP) Superfamily. Endocr. Rev. 20: 761-87.

112. Huang J, Min Lu M, Cheng L, Yuan L-J, et al. 2009. Myocardin is required for cardiomyocyte survival and maintenance of heart function. Proc. Natl. Acad. Sci. U. S. A. 106: 18734-9.

113. Sheikh-Hamad D, Bick R, Wu G-Y, Christensen BM, et al. 2003. Stanniocalcin-1 is a naturally occurring L-channel inhibitor in cardiomyocytes: relevance to human heart failure. Am. J. Physiol.-Heart Circ. Physiol. 285: H442-8.

114. Yoshioka J. 2004. Thioredoxin-Interacting Protein Controls Cardiac Hypertrophy Through Regulation of Thioredoxin Activity. Circulation 109: 2581-6.

115. Aukrust P, Ueland T, Muller F, Andreassen AK, et al. 1998. Elevated Circulating Levels of C-C Chemokines in Patients With Congestive Heart Failure. Circulation 97: $1136-43$. 
116. Sugihara S, Yamada K, Matubara K, Kinugasa Y, et al. 2015. High Hyaluronic Acid Level Predicts Adverse Clinical Outcome in Patients with Acute Decompensated Heart Failure. J. Card. Fail. 21: S173.

117. Wollert KC, Kempf T. 2012. Growth differentiation factor 15 in heart failure: an update. Curr. Heart Fail. Rep. 9: 337-45.

118. Yoshida M, Ma J, Tomita T, Morikawa N, et al. 2005. Mineralocorticoid receptor is overexpressed in cardiomyocytes of patients with congestive heart failure. Congest. Heart Fail. Greenwich Conn 11: 12-6.

119. Akiyama-Uchida Y, Ashizawa N, Ohtsuru A, Seto S, et al. 2002. Norepinephrine Enhances Fibrosis Mediated by TGF- in Cardiac Fibroblasts. Hypertension 40: 148-54.

120. Xu Q. 2004. Evidence That IGF Binding Protein-5 Functions as a Ligand-Independent Transcriptional Regulator in Vascular Smooth Muscle Cells. Circ. Res. 94: e46-54.

121. Marino TA, Walter RA, Cobb E, Palasiuk M, et al. 1990. Effects of norepinephrine on neonatal rat cardiocyte growth and differentiation. Vitro Cell. Dev. Biol. J. Tissue Cult. Assoc. 26: 229-36.

122. Rybkin II, Markham DW, Yan Z, Bassel-Duby R, et al. 2003. Conditional expression of SV40 T-antigen in mouse cardiomyocytes facilitates an inducible switch from proliferation to differentiation. J. Biol. Chem. 278: 15927-34.

123. Williams B. 2001. Angiotensin II and the pathophysiology of cardiovascular remodeling. Am. J. Cardiol. 87: 10C-17C.

124. Sandgren J, Scholz TD, Segar JL. 2015. ANG II modulation of cardiac growth and remodeling in immature fetal sheep. Am. J. Physiol. - Regul. Integr. Comp. Physiol. 308: R965-72.

125. Ali SS, Kala C, Abid M, Ahmad N, et al. 2016. Pathological microRNAs in acute cardiovascular diseases and microRNA therapeutics. J. Acute Dis. 5: 9-15.

126. Empel VPM van, Windt LJD, Martins PA da C. 2012. Circulating miRNAs: Reflecting or Affecting Cardiovascular Disease? Curr. Hypertens. Rep. 14: 498-509.

127. Voellenkle C, van Rooij J, Cappuzzello C, Greco S, et al. 2010. MicroRNA signatures in peripheral blood mononuclear cells of chronic heart failure patients. Physiol. Genomics 42: 420-6.

128. Saddic LA, Chang T-W, Sigurdsson MI, Heydarpour M, et al. 2015. Integrated microRNA and mRNA responses to acute human left ventricular ischemia. Physiol. Genomics 47: 455-62.

129. Xiang M, Birkbak NJ, Vafaizadeh V, Walker SR, et al. 2018. STAT3 Induction of miR-146b Forms a Feedback Loop to Inhibit the NF-kB to IL-6 Signaling Axis and STAT3-Driven Cancer Phenotypes. : 14.

130. Dirkx E, da Costa Martins PA, De Windt LJ. 2013. Regulation of fetal gene expression in heart failure. Biochim. Biophys. Acta BBA - Mol. Basis Dis. 1832: 241424. 
131. Srivastava D, Thomas T, Lin Q, Kirby ML, et al. 1997. Regulation of cardiac mesodermal and neural crest development by the bHLH transcription factor, dHAND. Nat. Genet. 16: 154-60.

132. Dirkx E, Gladka MM, Philippen LE, Armand A-S, et al. 2013. Nfat and miR-25 cooperate to reactivate the transcription factor Hand2 in heart failure. Nat. Cell Biol. 15: 1282-93.

133. Rogers GL, Martino AT, Aslanidi GV, Jayandharan GR, et al. 2011. Innate Immune Responses to AAV Vectors. Front. Microbiol. 2

134. Gordon JW, Shaw JA, Kirshenbaum LA. 2011. Multiple Facets of NF- $\kappa B$ in the Heart: To Be or Not to NF-кB. Circ. Res. 108: 1122-32.

135. Feldman AM, Combes A, Wagner D, Kadakomi T, et al. 2000. The role of tumor necrosis factor in the pathophysiology of heart failure. J. Am. Coll. Cardiol. 35: 537-44.

136. Adela R, Banerjee SK. 2015. GDF-15 as a Target and Biomarker for Diabetes and Cardiovascular Diseases: A Translational Prospective. J. Diabetes Res. 2015: 1-14.

137. Bonaldo P, Sandri M. 2013. Cellular and molecular mechanisms of muscle atrophy. Dis. Model. Mech. 6: 25-39.

138. Awede B, Thissen J, Gailly P, Lebacq J. 1999. Regulation of IGF-I, IGFBP-4 and IGFBP-5 gene expression by loading in mouse skeletal muscle. FEBS Lett. 461: 263-7.

139. Jagoe RT, Lecker SH, Gomes M, Goldberg AL. 2002. Patterns of gene expression in atrophying skeletal muscles: response to food deprivation. FASEB J. 16: 1697-712.

140. Lang CH, Krawiec BJ, Huber D, McCoy JM, et al. 2006. Sepsis and inflammatory insults downregulate IGFBP-5, but not IGFBP-4, in skeletal muscle via a TNF-dependent mechanism. Am. J. Physiol.-Regul. Integr. Comp. Physiol. 290: R963-72.

141. Pellegrinelli V, Rouault C, Rodriguez-Cuenca S, Albert V, et al. 2015. Human Adipocytes Induce Inflammation and Atrophy in Muscle Cells During Obesity. Diabetes 64: $3121-34$.

142. Zhao H, Bian H, Bu X, Zhang S, et al. 2016. Targeting of Discoidin Domain Receptor 2 (DDR2) Prevents Myofibroblast Activation and Neovessel Formation During Pulmonary Fibrosis. Mol. Ther. 24: 1734-44.

143. Valiente-Alandi I, Potter SJ, Salvador AM, Schafer AE, et al. 2018. Inhibiting Fibronectin Attenuates Fibrosis and Improves Cardiac Function in a Model of Heart Failure. Circulation : CIRCULATIONAHA.118.034609.

144. Pontén A, Li X, Thorén P, Aase K, et al. 2003. Transgenic overexpression of plateletderived growth factor- $\mathrm{C}$ in the mouse heart induces cardiac fibrosis, hypertrophy, and dilated cardiomyopathy. Am. J. Pathol. 163: 673-82.

145. Pontén A, Folestad EB, Pietras K, Eriksson U. 2005. Platelet-derived growth factor D induces cardiac fibrosis and proliferation of vascular smooth muscle cells in heartspecific transgenic mice. Circ. Res. 97: 1036-45. 
146. Lacraz GPA, Junker JP, Gladka MM, Molenaar B, et al. 2017. Tomo-Seq Identifies SOX9 as a Key Regulator of Cardiac Fibrosis During Ischemic Injury. Circulation 136: 1396-409.

147. Bruggink AH, Oosterhout MFM van, Jonge N de, Cleutjens JPM, et al. 2007. Type IV collagen degradation in the myocardial basement membrane after unloading of the failing heart by a left ventricular assist device. Lab. Invest. 87: 1125-37.

148. Michela P, Velia V, Aldo P, Ada P. 2015. Role of connexin 43 in cardiovascular diseases. Eur. J. Pharmacol. 768: 71-6.

149. Warren SA, Briggs LE, Zeng H, Chuang J, et al. 2012. Myosin light chain phosphorylation is critical for adaptation to cardiac stress. Circulation 126: 2575-88.

150. Chan JY, Takeda M, Briggs LE, Graham ML, et al. 2008. Identification of cardiacspecific myosin light chain kinase. Circ. Res. 102: 571-80.

151. Massengill MT, Ashraf HM, Chowdhury RR, Chrzanowski SM, et al. 2016. Acute heart failure with cardiomyocyte atrophy induced in adult mice by ablation of cardiac myosin light chain kinase. Cardiovasc. Res. 111: 34-43.

152. García R, Merino D, Gómez JM, Nistal JF, et al. 2016. Extracellular heat shock protein 90 binding to TGF $\beta$ receptor I participates in TGF $\beta$-mediated collagen production in myocardial fibroblasts. Cell. Signal. 28: 1563-79.

153. Datta R, Bansal T, Rana S, Datta K, et al. 2017. Myocyte-Derived Hsp90 Modulates Collagen Upregulation via Biphasic Activation of STAT-3 in Fibroblasts during Cardiac Hypertrophy. Mol. Cell. Biol. 37: e00611-16.

154. Kojima H, Inoue T, Kunimoto H, Nakajima K. 2013. IL-6-STAT3 signaling and premature senescence. JAK-STAT 2

155. Knight RA, Scarabelli TM, Stephanou A. 2012. STAT transcription in the ischemic heart. JAK-STAT 1: 111-7.

156. Feghali CA, Wright TM. 1999. Identification of multiple, differentially expressed messenger RNAs in dermal fibroblasts from patients with systemic sclerosis. Arthritis Rheum. 42: 1451-7.

157. Pilewski JM, Liu L, Henry AC, Knauer AV, et al. 2005. Insulin-Like Growth Factor Binding Proteins 3 and 5 Are Overexpressed in Idiopathic Pulmonary Fibrosis and Contribute to Extracellular Matrix Deposition. Am. J. Pathol. 166: 399-407.

158. Sokolović A, Sokolović M, Boers W, Elferink RPO, et al. 2010. Insulin-like growth factor binding protein 5 enhances survival of LX2 human hepatic stellate cells. Fibrogenesis Tissue Repair 3: 3.

159. Sokolović A, Montenegro-Miranda PS, de Waart DR, Cappai RMN, et al. 2012. Overexpression of insulin like growth factor binding protein 5 reduces liver fibrosis in chronic cholangiopathy. Biochim. Biophys. Acta BBA - Mol. Basis Dis. 1822: 996-1003. 
160. Yasuoka H, Jukic DM, Zhou Z, Choi AMK, et al. 2006. Insulin-like growth factor binding protein 5 induces skin fibrosis: A novel murine model for dermal fibrosis. Arthritis Rheum. 54: 3001-10.

161. Yasuoka H, Zhou Z, Pilewski JM, Oury TD, et al. 2006. Insulin-Like Growth FactorBinding Protein-5 Induces Pulmonary Fibrosis and Triggers Mononuclear Cellular Infiltration. Am. J. Pathol. 169: 1633-42.

162. Singh RM, Cummings E, Pantos C, Singh J. 2017. Protein kinase C and cardiac dysfunction: a review. Heart Fail. Rev. 22: 843-59.

163. Qiao X-H, Wang F, Zhang X-L, Huang R-T, et al. 2017. MEF2C loss-of-function mutation contributes to congenital heart defects. Int. J. Med. Sci. 14: 1143-53.

164. Potthoff MJ, Arnold MA, McAnally J, Richardson JA, et al. 2007. Regulation of Skeletal Muscle Sarcomere Integrity and Postnatal Muscle Function by Mef2c. Mol. Cell. Biol. 27: 8143-51.

165. Yamakuchi M, Higuchi I, Masuda S, Ohira Y, et al. 2000. Type I muscle atrophy caused by microgravity-induced decrease of myocyte enhancer factor 2C (MEF2C) protein expression. FEBS Lett. 477: 135-40.

166. Toko H, Zhu W, Takimoto E, Shiojima I, et al. 2002. Csx/Nkx2-5 Is Required for Homeostasis and Survival of Cardiac Myocytes in the Adult Heart. J. Biol. Chem. 277: 24735-43.

167. Collard L, Herledan G, Pincini A, Guerci A, et al. 2014. Nuclear actin and myocardinrelated transcription factors control disuse muscle atrophy through regulation of Srf activity. J Cell Sci 127: 5157-63.

168. Doenst T, Nguyen TD, Abel ED. 2013. Cardiac Metabolism in Heart Failure Implications beyond ATP production. Circ. Res. 113: 709-24.

169. van Bilsen M, van der Vusse GJ, Reneman RS. 1998. Transcriptional regulation of metabolic processes: implications for cardiac metabolism. Pflugers Arch. 437: 2-14.

170. Arumugam S, Sreedhar R, Thandavarayan RA, Karuppagounder V, et al. 2016. Targeting fatty acid metabolism in heart failure: is it a suitable therapeutic approach? Drug Discov. Today 21: 1003-8.

171. Dong Z, Zhao P, Xu M, Zhang C, et al. 2017. Astragaloside IV alleviates heart failure via activating PPAR $\alpha$ to switch glycolysis to fatty acid $\beta$-oxidation. Sci. Rep. 7: 2691.

172. Kaimoto S, Hoshino A, Ariyoshi M, Okawa Y, et al. 2017. Activation of PPAR- $\alpha$ in the early stage of heart failure maintained myocardial function and energetics in pressureoverload heart failure. Am. J. Physiol.-Heart Circ. Physiol. 312: H305-13.

173. Yang Q, Li Y. 2007. Roles of PPARs on regulating myocardial energy and lipid homeostasis. J. Mol. Med. Berl. Ger. 85: 697-706.

174. Barger PM, Brandt JM, Leone TC, Weinheimer CJ, et al. 2000. Deactivation of peroxisome proliferator-activated receptor-alpha during cardiac hypertrophic growth. $J$. Clin. Invest. 105: 1723-30. 
175. Schedlich LJ, O’Han MK, Leong GM, Baxter RC. 2004. Insulin-like growth factor binding protein-3 prevents retinoid receptor heterodimerization: implications for retinoic acid-sensitivity in human breast cancer cells. Biochem. Biophys. Res. Commun. 314: 838.

176. Schedlich LJ, Muthukaruppan A, O'Han MK, Baxter RC. 2007. Insulin-Like Growth Factor Binding Protein-5 Interacts with the Vitamin D Receptor and Modulates the Vitamin D Response in Osteoblasts. Mol. Endocrinol. 21: 2378-90.

177. Baxter RC. 2015. Nuclear Actions of Insulin-like Growth Factor Binding Protein-3. Gene 569: 7-13.

178. Rakhshandehroo M, Knoch B, Müller M, Kersten S. 2010. Peroxisome ProliferatorActivated Receptor Alpha Target Genes. PPAR Res.

179. Moyzis AG, Sadoshima J, Gustafsson $̊$ B. 2015. Mending a broken heart: the role of mitophagy in cardioprotection. Am. J. Physiol. - Heart Circ. Physiol. 308: H183-92.

180. Sabbah HN. 2016. Targeting mitochondrial dysfunction in the treatment of heart failure. Expert Rev. Cardiovasc. Ther. 14: 1305-13.

181. Murakawa T, Yamaguchi O, Hashimoto A, Hikoso S, et al. 2015. Bcl-2-like protein 13 is a mammalian Atg32 homologue that mediates mitophagy and mitochondrial fragmentation. Nat. Commun. 6: 7527.

182. Billia F, Hauck L, Konecny F, Rao V, et al. 2011. PTEN-inducible kinase 1 (PINK1)/Park6 is indispensable for normal heart function. Proc. Natl. Acad. Sci. U. S. A. 108: $9572-7$.

183. Mai S, Klinkenberg M, Auburger G, Bereiter-Hahn J, et al. 2010. Decreased expression of Drp1 and Fis 1 mediates mitochondrial elongation in senescent cells and enhances resistance to oxidative stress through PINK1. J Cell Sci 123: 917-26.

184. Baxter RC, Martin JL. 1989. Structure of the Mr 140,000 growth hormone-dependent insulin-like growth factor binding protein complex: determination by reconstitution and affinity-labeling. Proc. Natl. Acad. Sci. U. S. A. 86: 6898-902.

185. Jehle PM, Schulten K, Schulz W, Jehle DR, et al. 2003. Serum levels of insulin-like growth factor (IGF)-I and IGF binding protein (IGFBP)-1 to -6 and their relationship to bone metabolism in osteoporosis patients. Eur. J. Intern. Med. 14: 32-8.

186. Nishizawa H, Pryor-Koishi K, Suzuki M, Kato T, et al. 2008. Increased levels of pregnancy-associated plasma protein-A2 in the serum of pre-eclamptic patients. $M H R$ Basic Sci. Reprod. Med. 14: 595-602.

187. Thorén M, Hilding A, Brismar T, Magnusson P, et al. 1998. Serum Levels of Insulinlike Growth Factor Binding Proteins (IGFBP)-4 and -5 Correlate with Bone Mineral Density in Growth Hormone (GH)-Deficient Adults and Increase with GH Replacement Therapy. J. Bone Miner. Res. 13: 891-9.

188. Adali G, Yorulmaz E, Ozkanli S, Ulasoglu C, et al. 2013. Serum concentrations of insulin-like growth factor-binding protein 5 in Crohn's disease. World J. Gastroenterol. WJG 19: 9049-56. 
189. Jehle P. 1998. Serum levels of insulin-like growth factor system components and relationship to bone metabolism in Type 1 and Type 2 diabetes mellitus patients. $J$. Endocrinol. 159: 297-306.

190. Shersher DD, Vercillo MS, Fhied C, Basu S, et al. 2011. Biomarkers of the InsulinLike Growth Factor Pathway Predict Progression and Outcome in Lung Cancer. Ann. Thorac. Surg. 92: 1805-11.

191. Doroudgar S, Glembotski CC. 2011. The cardiokine story unfolds: ischemic stressinduced protein secretion in the heart. Trends Mol. Med. 17: 207-14.

192. Wu Y-S, Zhu B, Luo A-L, Yang L, et al. 2018. The Role of Cardiokines in Heart Diseases: Beneficial or Detrimental? BioMed Res. Int. 2018: 1-14.

193. Koller KJ, Goeddel DV. 1992. Molecular biology of the natriuretic peptides and their receptors. Circulation 86: 1081-8.

194. Planavila A, Fernández-Solà J, Villarroya F. 2017. Cardiokines as Modulators of Stress-Induced Cardiac Disorders. Adv. Protein Chem. Struct. Biol. 108: 227-56.

195. Wright GA, Struthers AD. 2006. Natriuretic peptides as a prognostic marker and therapeutic target in heart failure. Heart 92: 149-51.

196. Tsai C-T, Tseng C-D, Hwang J-J, Wu C-K, et al. 2011. Tachycardia of atrial myocytes induces collagen expression in atrial fibroblasts through transforming growth factor $\beta 1$. Cardiovasc. Res. 89: 805-15.

197. Gray MO, Long CS, Kalinyak JE, Li HT, et al. 1998. Angiotensin II stimulates cardiac myocyte hypertrophy via paracrine release of TGF-beta 1 and endothelin-1 from fibroblasts. Cardiovasc. Res. 40: 352-63.

198. Ramos-Mondragón R, Vega AV, Avila G. 2011. Long-term modulation of Na+ and $\mathrm{K}+$ channels by TGF- $\beta 1$ in neonatal rat cardiac myocytes. Pflugers Arch. 461: 235-47.

199. Avila G, Medina IM, Jiménez E, Elizondo G, et al. 2007. Transforming growth factorbeta1 decreases cardiac muscle L-type $\mathrm{Ca} 2+$ current and charge movement by acting on the Cav1.2 mRNA. Am. J. Physiol. Heart Circ. Physiol. 292: H622-631.

200. Flynn RS, Mahavadi S, Murthy KS, Kellum JM, et al. 2009. Insulin-like growth factor-binding protein-5 stimulates growth of human intestinal muscle cells by activation of Gai3. Am. J. Physiol. - Gastrointest. Liver Physiol. 297: G1232-8.

201. Sureshbabu A, Okajima H, Yamanaka D, Tonner E, et al. 2012. IGFBP5 induces cell adhesion, increases cell survival and inhibits cell migration in MCF-7 human breast cancer cells. J. Cell Sci. 125: 1693-705.

202. Wu K, Zhou M, Wu Q-X, Yuan S-X, et al. 2015. The role of IGFBP-5 in mediating the anti-proliferation effect of tetrandrine in human colon cancer cells. Int. J. Oncol. 46: 1205-13.

203. Yin P, Xu Q, Duan C. 2004. Paradoxical actions of endogenous and exogenous insulinlike growth factor-binding protein-5 revealed by RNA interference analysis. J. Biol. Chem. 279: 32660-6. 
204. Su Y, Nishimoto T, Feghali-Bostwick C. 2015. IGFBP-5 Promotes Fibrosis Independently of Its Translocation to the Nucleus and Its Interaction with Nucleolin and IGF. PLOS ONE 10: e0130546.

205. Wang D, Chang PS, Wang Z, Sutherland L, et al. 2001. Activation of cardiac gene expression by myocardin, a transcriptional cofactor for serum response factor. Cell $\mathbf{1 0 5}$ : $851-62$.

206. van Tuyn J, Knaän-Shanzer S, van de Watering MJM, de Graaf M, et al. 2005. Activation of cardiac and smooth muscle-specific genes in primary human cells after forced expression of human myocardin. Cardiovasc. Res. 67: 245-55.

207. Serlachius M, Zhang K-Z, Andersson LC. 2004. Stanniocalcin in terminally differentiated mammalian cells. Peptides 25: 1657-62.

208. Gu L, Tseng SC, Rollins BJ. 1999. Monocyte chemoattractant protein-1. Chem. Immunol. 72: 7-29.

209. Yamamoto T, Eckes B, Mauch C, Hartmann K, et al. 2000. Monocyte chemoattractant protein-1 enhances gene expression and synthesis of matrix metalloproteinase- 1 in human fibroblasts by an autocrine IL-1 alpha loop. J. Immunol. Baltim. Md 1950 164: 6174-9.

210. Dewald O, Zymek P, Winkelmann K, Koerting A, et al. 2005. CCL2/Monocyte Chemoattractant Protein-1 Regulates Inflammatory Responses Critical to Healing Myocardial Infarcts. Circ. Res. 96: 881-9.

211. Watanabe K, Yamaguchi Y. 1996. Molecular identification of a putative human hyaluronan synthase. J. Biol. Chem. 271: 22945-8.

212. Li Y, Jiang D, Liang J, Meltzer EB, et al. 2011. Severe lung fibrosis requires an invasive fibroblast phenotype regulated by hyaluronan and CD44. J. Exp. Med. 208: 1459-71.

213. Xu X, Li Z, Gao W. 2011. Growth differentiation factor 15 in cardiovascular diseases: from bench to bedside. Biomark. Biochem. Indic. Expo. Response Susceptibility Chem. 16: $466-75$.

214. Pulimeno P, Bauer C, Stutz J, Citi S. 2010. PLEKHA7 Is an Adherens Junction Protein with a Tissue Distribution and Subcellular Localization Distinct from ZO-1 and ECadherin. PLOS ONE 5

215. Wythe JD, Jurynec MJ, Urness LD, Jones CA, et al. 2011. Hadp1, a newly identified pleckstrin homology domain protein, is required for cardiac contractility in zebrafish. Dis. Model. Mech. 4: 607-21.

216. Komuro A, Masuda Y, Kobayashi K, Babbitt R, et al. 2004. The AHNAKs are a class of giant propeller-like proteins that associate with calcium channel proteins of cardiomyocytes and other cells. Proc. Natl. Acad. Sci. U. S. A. 101: 4053-8.

217. Haase H. 2007. Ahnak, a new player in $\beta$-adrenergic regulation of the cardiac L-type $\mathrm{Ca} 2+$ channel. Cardiovasc. Res. 73: 19-25. 
218. Pitt B, Pedro Ferreira J, Zannad F. 2017. Mineralocorticoid receptor antagonists in patients with heart failure: current experience and future perspectives. Eur. Heart J. Cardiovasc. Pharmacother. 3: 48-57.

219. Wong L, Wang J, Liew O, Richards A, et al. 2016. MicroRNA and Heart Failure. Int. J. Mol. Sci. 17: 502.

220. Xu X, Li Z, Gao W. 2011. Growth differentiation factor 15 in cardiovascular diseases: from bench to bedside. Biomarkers 16: 466-75.

221. Martinez-Zubiaurre I, Fenton CG, Taman H, Pettersen I, et al. 2013. Tumorigenic Responses of Cancer-Associated Stromal Fibroblasts after Ablative Radiotherapy: A Transcriptome-Profiling Study. J. Cancer Ther. 04: 208-50.

222. Westberg JA, Serlachius M, Lankila P, Andersson LC. 2007. Hypoxic preconditioning induces elevated expression of stanniocalcin-1 in the heart. Am. J. Physiol.-Heart Circ. Physiol. 293: H1766-71.

223. Tang S-C, Yeh S-J, Tsai L-K, Hu C-J, et al. 2014. Association between plasma levels of hyaluronic acid and functional outcome in acute stroke patients. J. Neuroinflammation 11: 101.

224. Zhang P, Su J, Mende U. 2012. Cross talk between cardiac myocytes and fibroblasts: from multiscale investigative approaches to mechanisms and functional consequences. Am. J. Physiol.-Heart Circ. Physiol. 303: H1385-96.

225. Adam-Vizi V, Starkov AA. 2010. Calcium and mitochondrial reactive oxygen species generation: how to read the facts. J. Alzheimers Dis. JAD 20 Suppl 2: S413-426.

226. Sano R, Hou Y-CC, Hedvat M, Correa RG, et al. 2012. Endoplasmic reticulum protein BI-1 regulates Ca2+-mediated bioenergetics to promote autophagy. Genes Dev. 26: 1041-54.

227. McArthur L, Chilton L, Smith GL, Nicklin SA. 2015. Electrical consequences of cardiac myocyte: fibroblast coupling. Biochem. Soc. Trans. 43: 513-8.

228. Furtado MB, Costa MW, Pranoto EA, Salimova E, et al. 2014. Cardiogenic Genes Expressed in Cardiac Fibroblasts Contribute to Heart Development and Repair. Circ. Res. 114: 1422-34.

229. Nam Y-J, Song K, Luo X, Daniel E, et al. 2013. Reprogramming of human fibroblasts toward a cardiac fate. Proc. Natl. Acad. Sci. 110: 5588-93.

230. Protze S, Khattak S, Poulet C, Lindemann D, et al. 2012. A new approach to transcription factor screening for reprogramming of fibroblasts to cardiomyocyte-like cells. J. Mol. Cell. Cardiol. 53: 323-32.

231. Furtado MB, Nim HT, Boyd SE, Rosenthal NA. 2016. View from the heart: cardiac fibroblasts in development, scarring and regeneration. Development 143: 387-97.

232. Cartledge JE, Kane C, Dias P, Tesfom M, et al. 2015. Functional crosstalk between cardiac fibroblasts and adult cardiomyocytes by soluble mediators. Cardiovasc. Res. 105: 260-70. 
233. Milyavsky M, Shats I, Cholostoy A, Brosh R, et al. 2007. Inactivation of Myocardin and p16 during Malignant Transformation Contributes to a Differentiation Defect. Cancer Cell 11: 133-46.

234. Small EM, Thatcher JE, Sutherland LB, Kinoshita H, et al. 2010. Myocardin-Related Transcription Factor-A Controls Myofibroblast Activation and Fibrosis in Response to Myocardial Infarction. Circ. Res. 107: 294-304.

235. de Jager SCA, Bermúdez B, Bot I, Koenen RR, et al. 2011. Growth differentiation factor 15 deficiency protects against atherosclerosis by attenuating CCR2-mediated macrophage chemotaxis. J. Exp. Med. 208: 217-25.

236. Porsch H, Bernert B, Mehić M, Theocharis AD, et al. 2013. Efficient TGF $\beta$-induced epithelial-mesenchymal transition depends on hyaluronan synthase HAS2. Oncogene 32: 4355-65.

237. Shathasivam P, Kollara A, Ringuette MJ, Virtanen C, et al. 2015. Human ortholog of Drosophila Melted impedes SMAD2 release from TGF- $\beta$ receptor I to inhibit TGF- $\beta$ signaling. Proc. Natl. Acad. Sci. U. S. A. 112: E3000-3009.

238. Lambrecht S, Smith V, De Wilde K, Coudenys J, et al. 2014. Growth Differentiation Factor 15, a Marker of Lung Involvement in Systemic Sclerosis, Is Involved in Fibrosis Development but Is not Indispensable for Fibrosis Development: GDF-15 and Fibrosis Development in SSc. Arthritis Rheumatol. 66: 418-27.

239. Kojima H, Kunimoto H, Inoue T, Nakajima K. 2012. The STAT3-IGFBP5 axis is critical for IL-6/gp130-induced premature senescence in human fibroblasts. Cell Cycle 11: $730-9$.

240. Hayflick L, Moorhead PS. 1961. The serial cultivation of human diploid cell strains. Exp. Cell Res. 25: 585-621.

241. Muñoz-Espín D, Serrano M. 2014. Cellular senescence: from physiology to pathology. Nat. Rev. Mol. Cell Biol. 15: 482-96.

242. Zhu F, Li Y, Zhang J, Piao C, et al. 2013. Senescent Cardiac Fibroblast Is Critical for Cardiac Fibrosis after Myocardial Infarction. PLOS ONE 8

243. Xie J, Chen Y, Hu C, Pan Q, et al. 2017. Premature senescence of cardiac fibroblasts and atrial fibrosis in patients with atrial fibrillation. Oncotarget 8: 57981-90.

244. Meyer K, Hodwin B, Ramanujam D, Engelhardt S, et al. 2016. Essential Role for Premature Senescence of Myofibroblasts in Myocardial Fibrosis. J. Am. Coll. Cardiol. 67: 2018-28.

245. Kim KS, Seu YB, Baek S-H, Kim MJ, et al. 2007. Induction of Cellular Senescence by Insulin-like Growth Factor Binding Protein-5 through a p53-dependent Mechanism. Mol. Biol. Cell 18: 4543-52.

246. Chua MWY, Lin MZ, Martin JL, Baxter RC. 2015. Involvement of the insulin-like growth factor binding proteins in the cancer cell response to DNA damage. J. Cell Commun. Signal. 9: 167-76. 
247. Sanada F, Taniyama Y, Muratsu J, Otsu R, et al. 2016. Activated Factor X Induces Endothelial Cell Senescence Through IGFBP-5. Sci. Rep. 6

248. Rombouts C, Aerts A, Quintens R, Baselet B, et al. 2014. Transcriptomic profiling suggests a role for IGFBP5 in premature senescence of endothelial cells after chronic low dose rate irradiation. Int. J. Radiat. Biol. 90: 560-74.

249. Sanada F, Taniyama Y, Muratsu J, Otsu R, et al. 2018. IGF Binding Protein-5 Induces Cell Senescence. Front. Endocrinol. 9

250. Bootcov MR, Bauskin AR, Valenzuela SM, Moore AG, et al. 1997. MIC-1, a novel macrophage inhibitory cytokine, is a divergent member of the TGF-beta superfamily. Proc. Natl. Acad. Sci. U. S. A. 94: 11514-9.

251. Wu Q, Jiang D, Matsuda JL, Ternyak K, et al. 2016. Cigarette Smoke Induces Human Airway Epithelial Senescence via Growth Differentiation Factor 15 Production. Am. J. Respir. Cell Mol. Biol. 55: 429-38.

252. Sansoni V, Casas-Delucchi CS, Rajan M, Schmidt A, et al. 2014. The histone variant H2A.Bbd is enriched at sites of DNA synthesis. Nucleic Acids Res. 42: 6405-20.

253. Sporn JC, Kustatscher G, Hothorn T, Collado M, et al. 2009. Histone macroH2A isoforms predict the risk of lung cancer recurrence. Oncogene 28: 3423-8.

254. Li Y, Liang J, Yang T, Monterrosa Mena J, et al. 2016. Hyaluronan synthase 2 regulates fibroblast senescence in pulmonary fibrosis. Matrix Biol. 55: 35-48.

255. Acosta JC, Banito A, Wuestefeld T, Georgilis A, et al. 2013. A complex secretory program orchestrated by the inflammasome controls paracrine senescence. Nat. Cell Biol. 15: 978-90.

256. Sun M, Long J, Yi Y, Xia W. 2017. Importin $\alpha$-importin $\beta$ complex mediated nuclear translocation of insulin-like growth factor binding protein-5. Endocr. J. 64: 963-75.

257. Kotlyar M, Pastrello C, Pivetta F, Lo Sardo A, et al. 2015. In silico prediction of physical protein interactions and characterization of interactome orphans. Nat. Methods 12: $79-84$.

258. Kobayashi J, Yoshida M, Tarui S, Hirata M, et al. 2014. Directed Differentiation of Patient-Specific Induced Pluripotent Stem Cells Identifies the Transcriptional Repression and Epigenetic Modification of NKX2-5, HAND1, and NOTCH1 in Hypoplastic Left Heart Syndrome. PLOS ONE 9

259. Nimura K, Ura K, Shiratori H, Ikawa M, et al. 2009. A histone H3 lysine 36 trimethyltransferase links Nkx2-5 to Wolf-Hirschhorn syndrome. Nature 460: 287-91.

260. Oikonomopoulos A, Sereti K-I, Conyers F, Bauer M, et al. 2011. Wnt signaling exerts an anti-proliferative effect on adult cardiac progenitor cells via IGFBP3. Circ. Res. 109: 1363-74.

261. Xue C, ZHANG J, LV Z, LIU H, et al. 2015. Angiotensin II promotes differentiation of mouse c-kit-positive cardiac stem cells into pacemaker-like cells. Mol. Med. Rep. 11: 3249-58. 
262. Miller DS. 1988. Stimulation of RNA and protein synthesis by intracellular insulin. Science 240: 506-9.

263. Collins T, Bonthron DT, Orkin SH. 1987. Alternative RNA splicing affects function of encoded platelet-derived growth factor A chain. Nature 328: 621-4.

264. Imamura T, Engleka K, Zhan X, Tokita Y, et al. 1990. Recovery of mitogenic activity of a growth factor mutant with a nuclear translocation sequence. Science 249: 1567-70.

265. Fong H, Hohenstein KA, Donovan PJ. 2008. Regulation of self-renewal and pluripotency by Sox 2 in human embryonic stem cells. Stem Cells Dayt. Ohio 26: 19318.

266. Wang J, Ding N, Li Y, Cheng H, et al. 2015. Insulin-like growth factor binding protein 5 (IGFBP5) functions as a tumor suppressor in human melanoma cells. Oncotarget 6: 20636-49.

267. Miyake H, Nelson C, Rennie PS, Gleave ME. 2000. Overexpression of insulin-like growth factor binding protein-5 helps accelerate progression to androgen-independence in the human prostate LNCaP tumor model through activation of phosphatidylinositol 3'-kinase pathway. Endocrinology 141: 2257-65.

268. Gessert S, Kuhl M. 2010. The Multiple Phases and Faces of Wnt Signaling During Cardiac Differentiation and Development. Circ. Res. 107: 186-99.

269. Kwon C, Qian L, Cheng P, Nigam V, et al. 2009. A Regulatory Pathway Involving Notch1/ $\beta$-Catenin/Is11 Determines Cardiac Progenitor Cell Fate. Nat. Cell Biol. 11: 9517.

270. Chen J-F, Wang S, Wu Q, Cao D, et al. 2008. Myocardin Marks the Earliest Cardiac Gene Expression and Plays an Important Role in Heart Development. Anat. Rec. Adv. Integr. Anat. Evol. Biol. 291: 1200-11.

271. Ueyama T, Kasahara H, Ishiwata T, Nie Q, et al. 2003. Myocardin Expression Is Regulated by Nkx2.5, and Its Function Is Required for Cardiomyogenesis. Mol. Cell. Biol. 23: 9222-32.

272. Herron TJ, Rocha AMD, Campbell KF, Ponce-Balbuena D, et al. 2016. Extracellular Matrix-Mediated Maturation of Human Pluripotent Stem Cell-Derived Cardiac Monolayer Structure and Electrophysiological Function. Circ. Arrhythm. Electrophysiol. 9: e003638.

273. Matsuda T, Takahashi K, Nariai T, Ito T, et al. 2005. N-cadherin-mediated cell adhesion determines the plasticity for cell alignment in response to mechanical stretch in cultured cardiomyocytes. Biochem. Biophys. Res. Commun. 326: 228-32.

274. Palatinus JA, Rhett JM, Gourdie RG. 2012. The connexin43 carboxyl terminus and cardiac gap junction organization. Biochim. Biophys. Acta 1818: 1831-43.

275. Kamakura T, Makiyama T, Sasaki K, Yoshida Y, et al. 2013. Ultrastructural maturation of human-induced pluripotent stem cell-derived cardiomyocytes in a longterm culture. Circ. J. Off. J. Jpn. Circ. Soc. 77: 1307-14. 
276. Lundy SD, Zhu W-Z, Regnier M, Laflamme MA. 2013. Structural and Functional Maturation of Cardiomyocytes Derived from Human Pluripotent Stem Cells. Stem Cells Dev. 22: 1991-2002.

277. Mohamed TMA, Abou-Leisa R, Stafford N, Maqsood A, et al. 2016. The plasma membrane calcium ATPase 4 signalling in cardiac fibroblasts mediates cardiomyocyte hypertrophy. Nat. Commun. 7: 11074.

278. Garcia MI, Ghiani M, Lefort A, Libert F, et al. 2009. LGR5 deficiency deregulates Wnt signaling and leads to precocious Paneth cell differentiation in the fetal intestine. Dev. Biol. 331: 58-67.

279. Mori AD, Zhu Y, Vahora I, Nieman B, et al. 2006. Tbx5-dependent rheostatic control of cardiac gene expression and morphogenesis. Dev. Biol. 297: 566-86.

280. Peter AK, Bjerke MA, Leinwand LA. 2016. Biology of the cardiac myocyte in heart disease. Mol. Biol. Cell 27: 2149-60.

281. Marino TA, Walter RA, Cobb E, Palasiuk M, et al. 1990. Effects of norepinephrine on neonatal rat cardiocyte growth and differentiation. In Vitro Cell. Dev. Biol. 26: 229236.

282. Tsukamoto Y, Mano T, Sakata Y, Ohtani T, et al. 2013. A novel heart failure mice model of hypertensive heart disease by angiotensin II infusion, nephrectomy, and salt loading. Am. J. Physiol.-Heart Circ. Physiol. 305: H1658-67.

283. Chien KR, Knowlton KU, Zhu H, Chien S. 1991. Regulation of cardiac gene expression during myocardial growth and hypertrophy: molecular studies of an adaptive physiologic response. FASEB J. Off. Publ. Fed. Am. Soc. Exp. Biol. 5: 3037-46.

284. Song W, Wang H, Wu Q. 2015. Atrial Natriuretic Peptide in Cardiovascular Biology and Disease (NPPA). Gene 569: 1-6.

285. Ahmadian E, Jafari S, Khosroushahi AY. 2015. Role of angiotensin II in stem cell therapy of cardiac disease. J. Renin Angiotensin Aldosterone Syst. 16: 702-11.

286. Xiao Q. 2006. Sca-1+ Progenitors Derived From Embryonic Stem Cells Differentiate Into Endothelial Cells Capable of Vascular Repair After Arterial Injury. Arterioscler. Thromb. Vasc. Biol. 26: 2244-51. 


\section{Appendix}

\subsection{Vector maps}
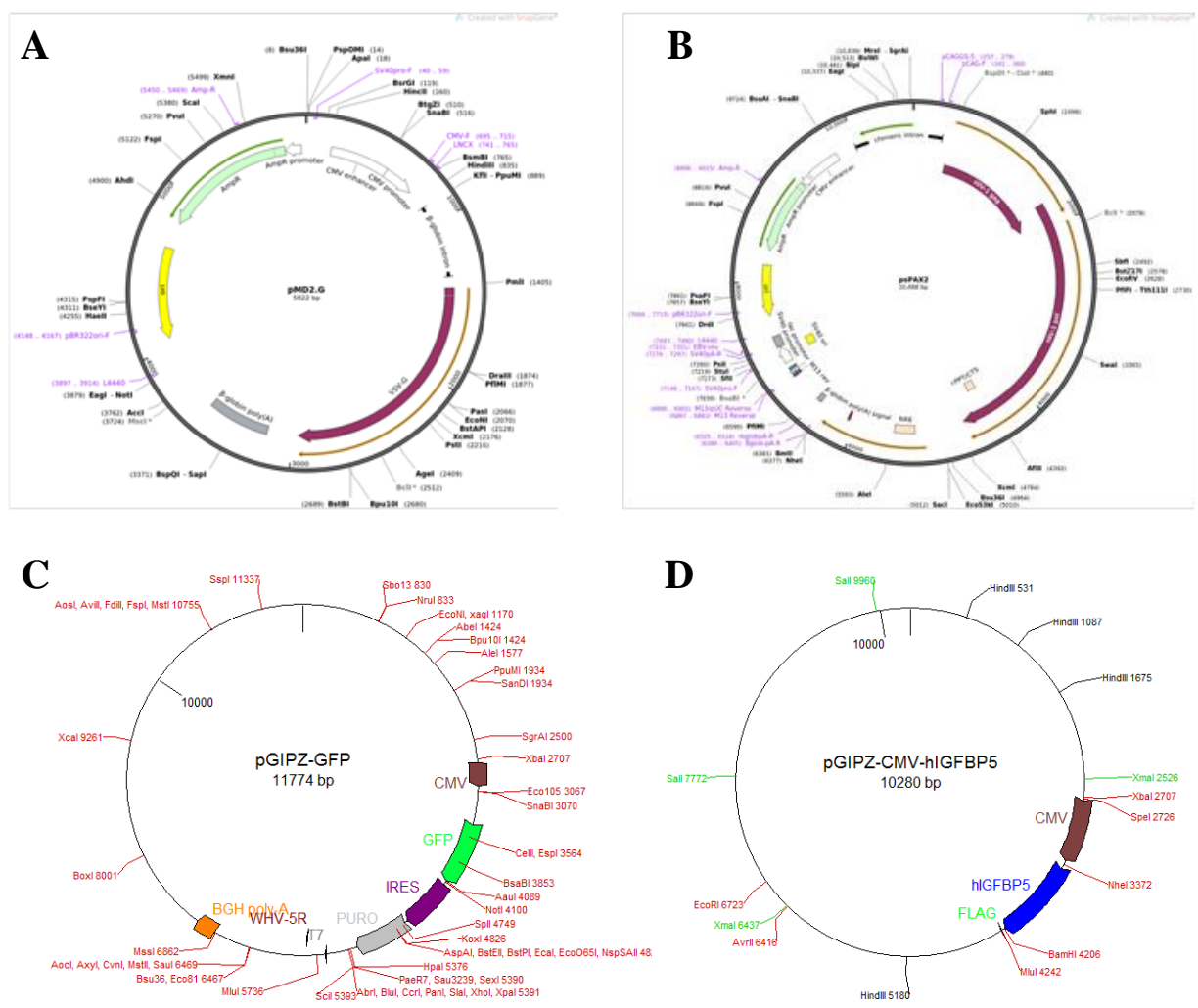

Figure 8-1: Vectors for lentivirus production

(A) Lentiviral envelope plasmid pMD2.G vector by Addgene (Lab of Didié Trono). (B) Lentiviral packaging plasmid psPAX2 vector by Addgene (Lab of Didié Trono). (C) Commercial lentiviral vector pGIPZ with eGFP reporter from Thermo Scientifc Open Biosystems. (D) Modified pGIPZ vector with removed puromycin resistance cassette, IRES and eGFP and inserted CMV hIGFBP5 CDS with FLAG tag. 
A

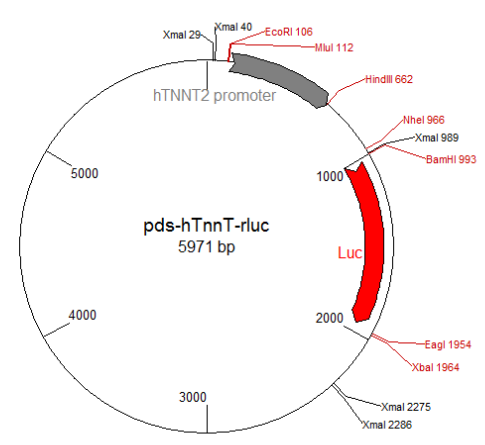

B

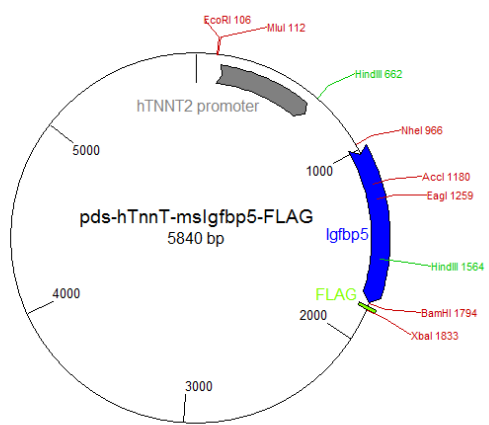

Figure 8-2: Vectors for AAV9 particle production

(A) Self-complementary AAV vector genome plasmid, derived from pdsCMV-MLC0.26-EGFP with luciferase CDS under control of the human troponin T promoter for AAV9 particle production (from Prof O. Müller, Kiel). (B) Modified self-complementary AAV vector genome plasmid with FLAG tagged ms-Igfbp5 CDS.

A

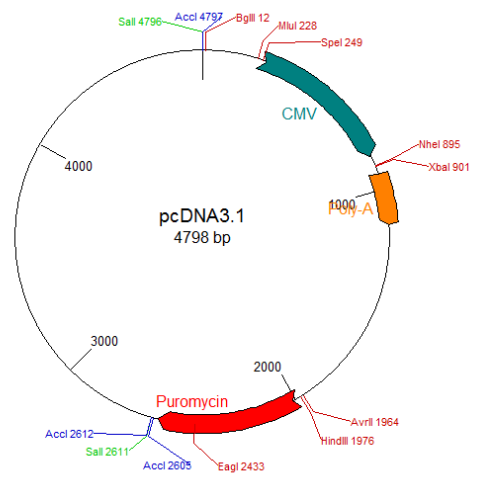

$\mathbf{C}$

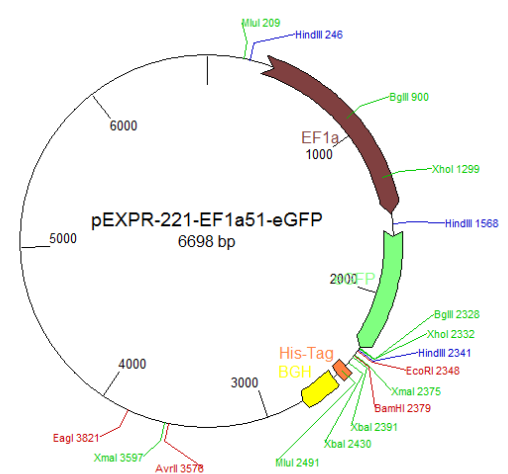

B

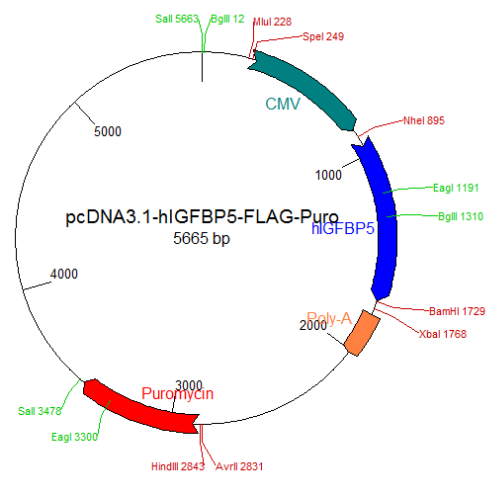

D

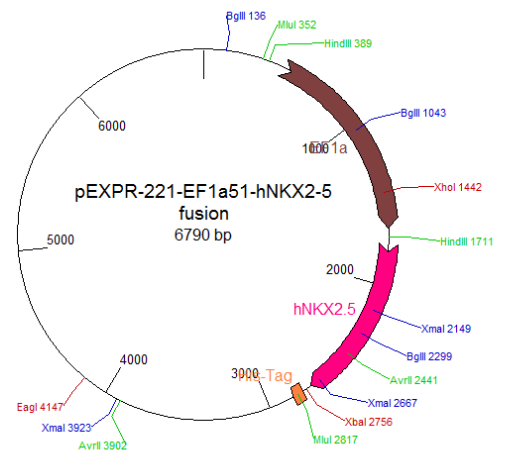

Figure 8-3: Overexpression vectors

(A) Commercial pcDNA3.1 vector with CMV promoter. (B) Modified pcDNA3.1 with FLAG tagged hIGFBP5 CDS. (C) pEXPR-221 vector with EF1 $\alpha$ promoter and eGFP reporter (From a. Roa, Goettingen). (D) pEXPR-221 vector with EF1 $\alpha$ promoter and hNKX2.5 CDS (From a. Roa, Goettingen). 


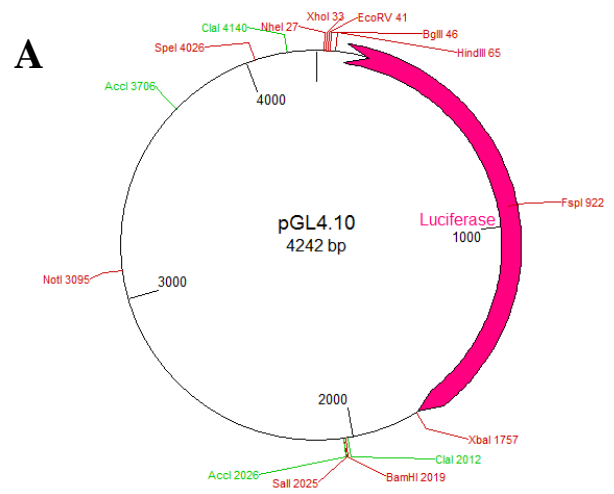

\section{B}
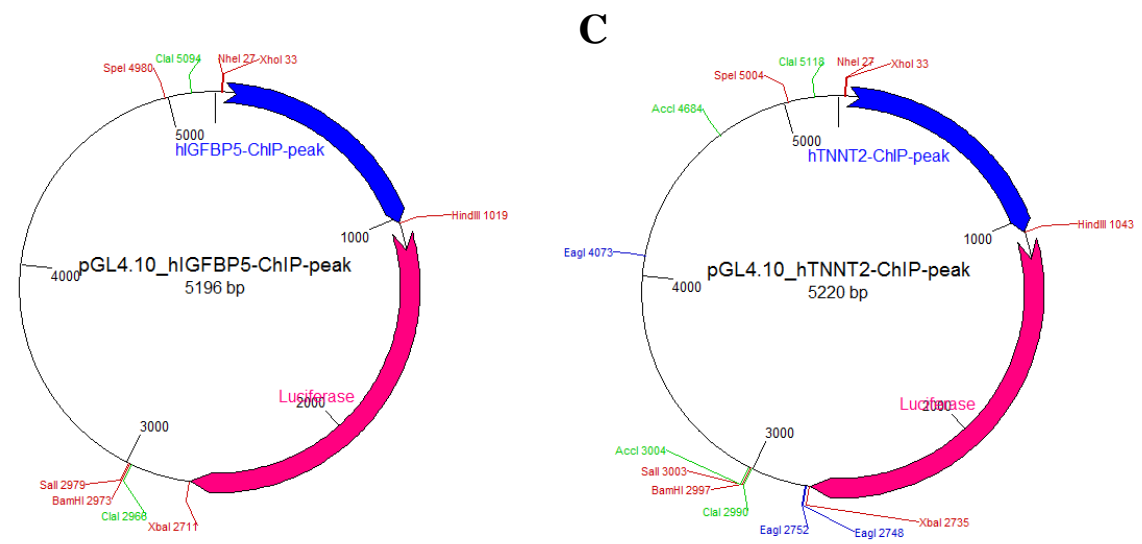

Figure 8-4: Luciferase reporter vectors

(A) Commercial luciferase reporter vector (Promega). (B) Modified luciferase reporter vector with cloned potential hIGFBP5 promoter region and (C) hTNNT2 promoter region, identified by IGFBP5-ChIP.

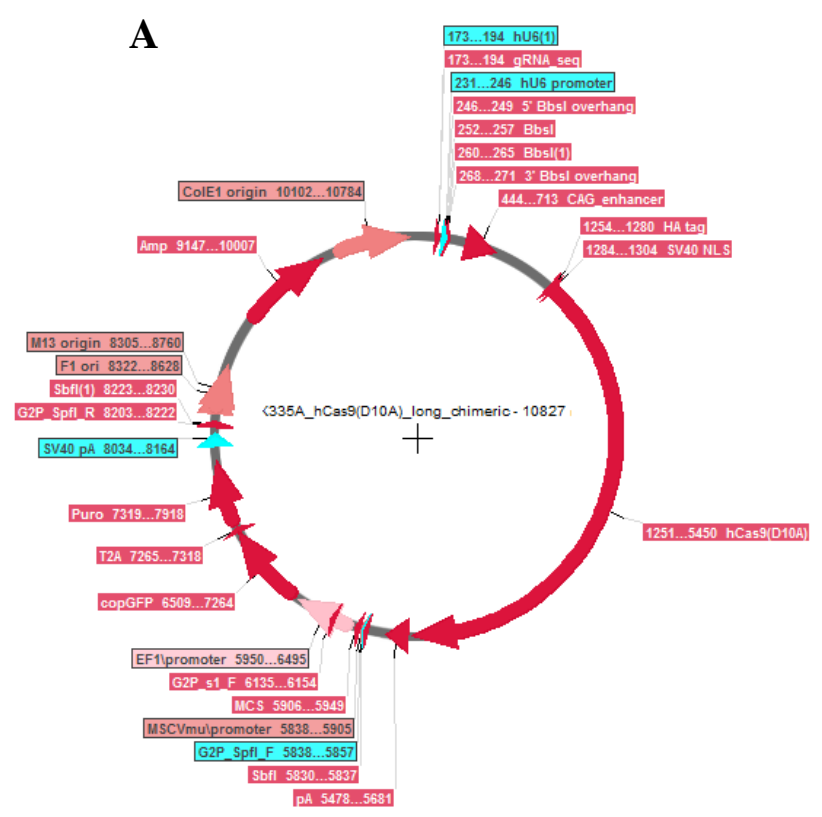

Figure 8-5: Cas9/gRNA vector

Human CAS9 nickase OE vector with insertion side for designed gRNAs (from B. Greber, Münster). 


\subsection{Curriculum vitae}

\section{Monique Wölfer}

Date of birth

15.09.1987

Place of birth

Bautzen, Germany

Nationality

German

\section{Education}

2014-2018

University of Goettingen, Germany

PhD. Studies

Department of Pharmacology and Toxicology, University Medical Center

2011-2014

University of Jena, Germany

Master of Science

Molecular Medicine

2007-2011

University of Goettingen, Germany

Bachelor of Science

Biology (Specialist field: Molecular Biosciences)

2004-2007

Gymnasium am Oelberg, Königswinter, Germany

A-Level

1998-2004

Realschule Oberpleis, Königswinter, Germany

High-school diploma 